\title{
Essays on forced migration and labour market participation in developing countries
}

Citation for published version (APA):

Marchand, K. (2018). Essays on forced migration and labour market participation in developing countries. [Doctoral Thesis, Maastricht University]. Uitgeverij Boekenplan. https://doi.org/10.26481/dis.20181213km

Document status and date:

Published: 01/01/2018

DOI:

10.26481/dis.20181213km

Document Version:

Publisher's PDF, also known as Version of record

\section{Please check the document version of this publication:}

- A submitted manuscript is the version of the article upon submission and before peer-review. There can be important differences between the submitted version and the official published version of record.

People interested in the research are advised to contact the author for the final version of the publication, or visit the DOI to the publisher's website.

- The final author version and the galley proof are versions of the publication after peer review.

- The final published version features the final layout of the paper including the volume, issue and page numbers.

Link to publication

\footnotetext{
General rights rights.

- You may freely distribute the URL identifying the publication in the public portal. please follow below link for the End User Agreement:

www.umlib.nl/taverne-license

Take down policy

If you believe that this document breaches copyright please contact us at:

repository@maastrichtuniversity.nl

providing details and we will investigate your claim.
}

Copyright and moral rights for the publications made accessible in the public portal are retained by the authors and/or other copyright owners and it is a condition of accessing publications that users recognise and abide by the legal requirements associated with these

- Users may download and print one copy of any publication from the public portal for the purpose of private study or research.

- You may not further distribute the material or use it for any profit-making activity or commercial gain

If the publication is distributed under the terms of Article $25 \mathrm{fa}$ of the Dutch Copyright Act, indicated by the "Taverne" license above, 


\section{Essays on Forced Migration and}

Labour Market Participation in

Developing Countries

\section{Katrin Marchand}

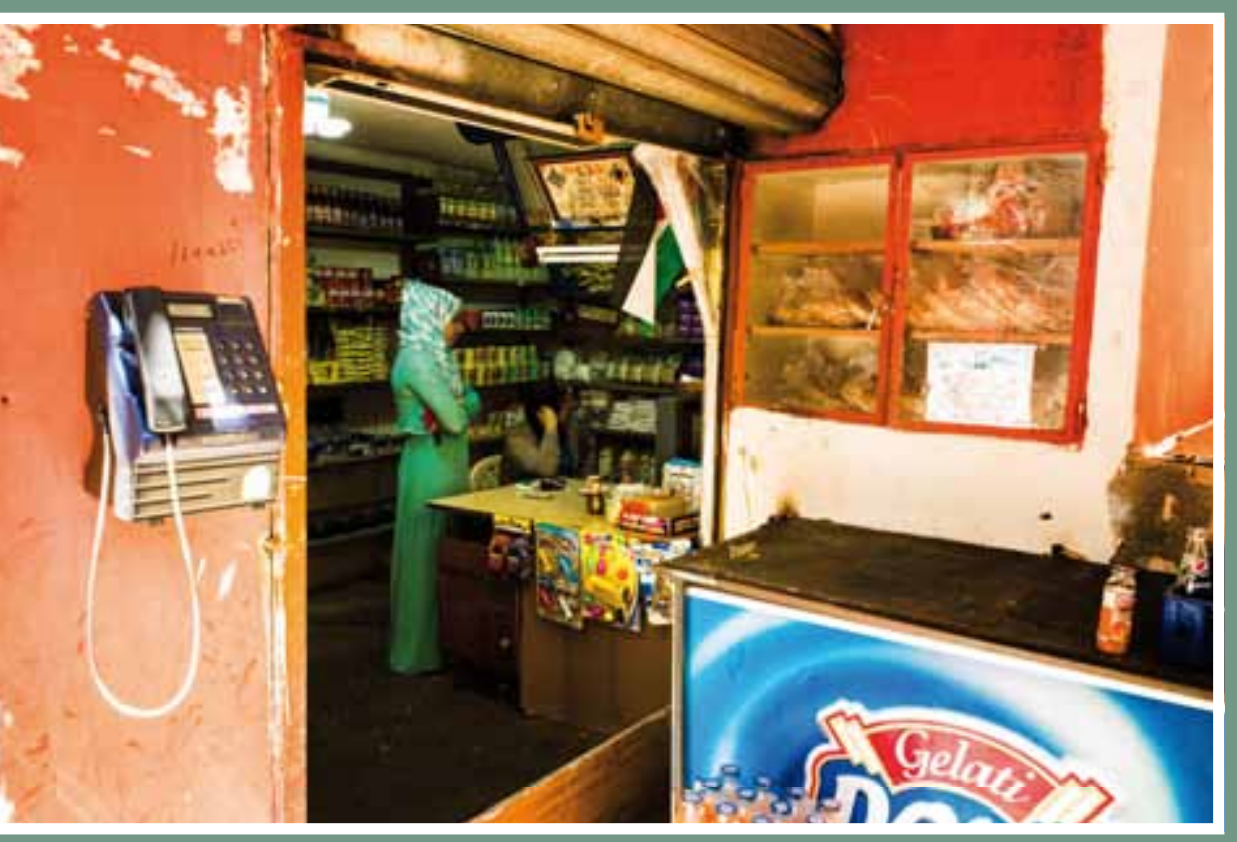



Essays on Forced Migration and

Labour Market Participation in

Developing Countries 
(C) Katrin Marchand, 2018

ISBN 9789086664634

Published by Boekenplan, Maastricht www.boekenplan.nl

Cover pictures by Jeroen Berkhout

All rights reserved. No part of this publication may be reproduced, stored in a retrieval system, or transmitted in any form or by any means, electronic, mechanical, photocopying, recording, or otherwise, without the prior permission in writing from the author. 


\section{Essays on Forced Migration and \\ Labour Market Participation in Developing Countries}

\section{DISSERTATION}

to obtain the degree of Doctor at Maastricht University, on the authority of the Rector Magnificus Prof. Dr. Rianne M. Letschert, in accordance with the decision of the Board of Deans,

to be defended in public on

Thursday 13 December 2018, at 10.00 hours

BY

KATRIN MARCHAND 


\section{PROMOTERS:}

Prof. Dr. Wim Naudé

Prof. Dr. Melissa Siegel

ASSESSMENT COMMITTEE:

Prof. Dr. Khalid Koser (Chair)

Dr. Pascal Beckers, Radboud University

Dr. Isabel Ruiz, Harris Manchester College, University of Oxford Prof. Dr. Klaus Zimmermann 
To my parents 



\section{ACKNOWLEDGEMENTS}

"We keep moving forward, opening new doors, and doing new things, because we're curious and curiosity keeps leading us down new paths."

$\sim$ Walt Disney

When I started this PhD journey, I was eager to explore the linkages between migration and entrepreneurship, specifically focusing on the success determinants of return migrant entrepreneurs. I was interested in economic migrants that saw opportunities and, at the same time, had the skills, resources, and motivation to invest in their countries of origin both for their own economic benefit, but also to contribute to development. While this topic is still one that I want to delve into in the future, my $\mathrm{PhD}$ ended up taking a different path for several reasons. Working on other projects, I became increasingly curious about the economics of forced migration. Recognizing that data is a challenge in this field, I soon realized that I was lucky and had access to datasets on migration in (post-) conflict contexts that would allow me to investigate some of the questions I was interested in. While there were many moments of frustration and doubt, I was finally able to put together this dissertation. And it was with the support of many that I made it to the finish line of my own personal PhD journey.

First and foremost, I am grateful to my supervisors. Wim, I appreciate the encouragement, support, and patience you have shown me at important moments along the way. Thank you for constructive comments and clear suggestions, especially towards the end of this journey, which proved to be invaluable. I'm sure that I will benefit from your feedback far beyond this book in the years to come. Melissa, thank you for giving me the chance to start this journey in the first place and for facilitating the change in topics. More importantly, thank you for always believing and trusting in me, even in the moments I doubted pretty much everything. And, maybe most importantly, thank you for challenging me to get out of my comfort zone again and again. I look forward to seeing what the future holds as we continue to work together! To the members of my assessment committee - Prof. Khalid Koser, Dr. Pascal Beckers, Dr. Isabel Ruiz, and Prof. Klaus Zimmermann - thank you for taking the time to read and comment on my work. Your insightful feedback helped me to further refine the chapters and therefore contributed significantly to the final version of this dissertation. I would also like to thank the members of the corona who will be present during the degree ceremony. 
I can't forget to thank those that worked endlessly to collect the data on which the research contained in this book relies so heavily. I'm extremely grateful to the teams behind the three projects from which I benefitted greatly as well as the institutions that funded the respective projects. Firstly, thank you Özge, Craig, and Melissa, the team behind the project The Economic Impacts of Congolese Refugees in Rwanda: Labour Markets, Social Infrastructure and Aid Effectiveness funded by UNHCR. Secondly, thank you to all of you - especially Lisa, Katie, Melissa, Özge, Silja, and Sonja - who originally worked on the IS Academy Migration and Development: A World in Motion project, which was financed by the Dutch Ministry of Foreign Affairs. Finally, I'm grateful to the team behind the Labour Market Impacts of Forced Migration project, which was funded by the UK Department for International Development and Institute for the Study of Labour. My thanks go to the project team Carlos, Craig, Isabel, Melissa, and Sonja.

Thank you to the directors of the PhD programme, Mindel, Tatiana, and Robin, for giving me the chance to write this dissertation. To all of the staff members at UNUMERIT and its Maastricht Graduate School of Governance, thank you for the support over the years. I'm particularly grateful to Ad, Anouk, Diego, Herman, Howard, Janneke, Kim, Lutz, Marc, Marlies, Mindel, Mourik Jan, Muriel, and Sueli for the cooperation and/ or the help you have offered in various, and in some cases many, instances. I'm especially thankful to Susan for having the patience to deal with all of my questions and expense claims. Eveline, thank you for everything that you do, it means and helps a lot. Ingeborg, Ingrid, and Mieke, thank you for always making us feel welcome and at home when entering the building. It makes all the difference! An extra thank you to Mieke for starting many of my days in recent months with warm words and/ or hugs, when they were much needed. Danny, thank you for always making working with you easy and fun; I hope to continue that soon. Also, thank you for organizing the office football pools, I can't wait to see if/ when I can add a bronze trophy to my collection!

Thank you to Jeroen Berkhout and Josette Dijkhuizen for allowing me to use the pictures from their Selling Strength photo project for the cover of this dissertation. When I learned about the project I immediately connected to the idea and I feel like it matches the message of this dissertation perfectly. Josette, thank you further for the opportunity to work with you on ENPower. It was a very much rewarding experience to get to know you and "your" refugee entrepreneurs! I also truly appreciate the chances I was given to work on many other exciting projects next to, and maybe too often instead of, this $\mathrm{PhD}$. I appreciate all of these opportunities as they have helped 
me to develop further as a researcher. I therefore want to thank our many partners, especially those at GIZ and ICMPD, for the cooperation.

It was a great privilege to start this journey as a member of the first cohort of the joint UNU-MERIT and MGSoG PhD programme. Thank you to Conny, Craig, Eleni, George, Julieta, Ortrun, Rhena, and Yesuf, with whom I got to share the 'Governance' office, as well as to Andrés, Andi, Anthony, Charlotte, Lorena, Simone, Tash, and Satheesh for making the first year memorable. I also appreciate that I had the opportunity to meet many other PhD students, master students, and researchers during the years I have spent in Maastricht. I have had the pleasure to have many fun and inspiring times in- and outside of the UNU-MERIT buildings with many of you! Thank you for that!

I especially want to thank Elaine for, among many other things, one-of-a-kind fieldwork experiences (when are we going back to Berne?), and for introducing me to the, apparently much needed, Positive Songs for Negative People. Dana, thank you for our little (Tuesday evening) time-outs, they have been a true blessing. I look forward to continuing those, more craft evenings, and hopefully Disney trips! Iman, thanks for always being supportive and patient, whether in Maastricht or on the other side of the world. Thank you (and our wonderful travel buddies) for the trip of a lifetime, I will always cherish the time we all spent together Down Under!

Melissa and Flo, thank you for giving me a weekday home in Maastricht for several years! Thank you, Jenny, for being the best housemate for part of that time and for being a constant source of positive energy (even when I just heard you from the other side of the hallway).

Having been a part of the Migration Team for a number of years now, I have seen team members come and, unfortunately, also go. Ayla, Biljana, Carole, Charlotte, Chiara, Clara, Clotilde, Craig, Elaine, Inez, Jenny, Julia, Katharina, Katie, Lika, Lisa, Marieke, Michaella, Nora, Özge, Richa, Sabrina, Sandra, Sarah, Silja, Simona, Sonja, Talitha, Tamara, Veronika F., Veronika G., Vitto, Vivianne, Zach, and all others that were with us for shorter or longer periods of time, it has been and will continue to be a pleasure working with you. It is also always nice to enjoy times outside of the office together at pizza dinners, Christmas parties, etc. An extra big thank you to those that stepped in last year when I had to take a break from my other work to finish this dissertation. It meant a lot that there were wonderful colleagues around that I could trust to take over the online courses and my project work. I have also shared offices in different buildings with several of you (I'm in fact not really sure with how many at Keizer Karelplein). 
Thank you for many inspiring, silly, serious, and, sometimes much-needed, procrastination talks!

Thank you to my paranymphs for agreeing to be there with me on the day of my defence! If there is anyone I trust to calm my nerves on that day, it is the two of you! Michaella, we've come a long way since being part of the first cohort of the MPP Migration Specialization and since my first fieldwork experience under your guidance (I'm glad you stopped apologizing for that finally). Thank you for always having an open ear for my rants and for often telling me exactly what I needed to hear. Ortrun, thank you for being my partner in crime throughout this PhD journey! I could not have asked for a better friend to have by my side and I can't even imagine what it would have been like without you to share the rollercoaster ride that it has been. In addition to sharing many of the challenges, frustrations, and successes of $\mathrm{PhD}$ students, countless coffee breaks and lunches, baking together, planning and going on amazing trips, and so much more will always be some of my fondest memories of my time as a PhD student.

I also want to thank all of my friends from Aachen, Trier, Maastricht, or somewhere in between, who had nothing to do with this $\mathrm{PhD}$, at least not directly. Thank you for constantly reminding me that there are other things in life and for providing me opportunities for much needed breaks, whether for a few hours, days, or weeks. Also, a massive 'I miss you' and thank you for everything to all the friends I made during the years I spent in Indiana and South Carolina, especially Andrea, Caitie, Caitlin, Chris, Mark, Rachael, and Stephanie. I can't wait to see you all real soon!

I am especially grateful to Sonja for being a wonderful friend and a major inspiration! I'm so happy that we developed the friendship that we now have once we graduated from high school. I do not think you realize how much your demonstrated strength and intelligence have impressed me over the many years that we have known each other. Karina, thank you for being by my side for the first years of my academic journey. We might have chosen different paths when we departed Trier, but the moments when we came back together have been my lifeline over the past years. Apologies for the constant company of my laptop and I promise it will not join us (as prominently) on our next adventure in February!

To my American family, thank you for first really opening my eyes to the topic of migration when I was 16. Thank you for giving me a home away from home; no matter how much time passes, coming back really always feels like coming home! And thank you for being a big contributor to the fact that I was able to write this dissertation in 
English without any struggles. Who knew that having four sisters that never stop talking, would one day have such great benefits?!

Last, but most certainly not least, I owe the biggest thanks to my family! Thank you to the Hessen part of our family. We might not see each other quite often enough, but the moments we do are certainly very special to me! My dog Oki might not be trained as a therapy dog but has certainly been acting as one throughout the last years (and yes, he is family). Thank you to my brother Jens, who was the first one of us to study in Maastricht and therefore opened my eyes to the fact that there were amazing opportunities just on the other side of the border. Most importantly, I have to thank my parents to whom I dedicate this book. Mama und Papa, ich glaube es gibt keine Worte um auszudrücken wie dankbar ich euch bin! Ihr habt es mir überhaupt erst ermöglicht diesen Weg zu gehen. Ihr habt meine Entscheidungen nie hinterfragt, sondern immer nur bedingungslos unterstützt. Danke dafür und einfach für alles!

Katrin

Aachen, November 2018 



\section{CONTENTS}

ACKNOWLEDGEMENTS ...............................................................................................

CONTENTS.............................................................................................................. VII

LIST OF FIGURES ..................................................................................................

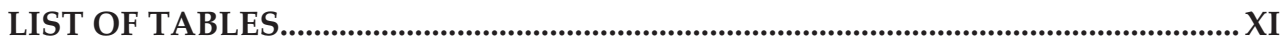

ABBREVIATIONS ....................................................................................................................XV

1. INTRODUCTION ..................................................................................................... 1

1.1 ABOUT THIS DISSERTATION ……………………………………….....

1.2 BACKGROUND AND MOTIVATION ................................................... 4

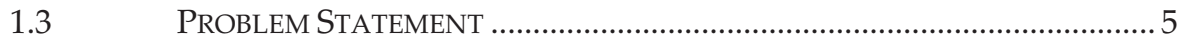

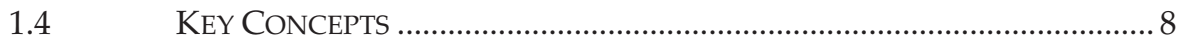

1.5 STRUCTURE OF THIS DISSERTATION ………………………………..... 14

1.6 CONTRIBUTION OF THIS DISSERTATION ……….................................... 17

2. MIGRATION, ENTREPRENEURSHIP, AND DEVELOPMENT: A REVIEW

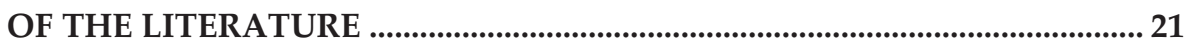

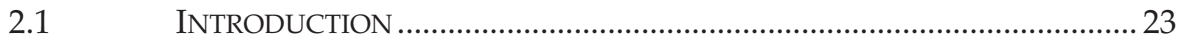

2.2 Re-EVALUATING StYLIZEd Facts: CRITICAL QueSTIONS ....................... 25

2.3 Does Migration MatTER For DeVELOPMENT? ................................... 37

2.4 POLICY IMPLiCATIONS: CAN MigRANT ‘SUPER-ENTREPRENEURS' BE

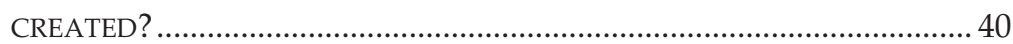



3. LABOUR MARKET ACTIVITIES OF CONGOLESE REFUGEES IN

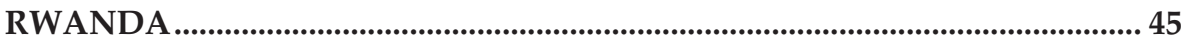

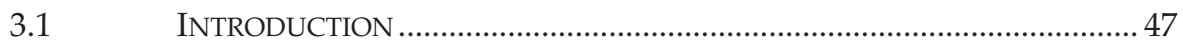

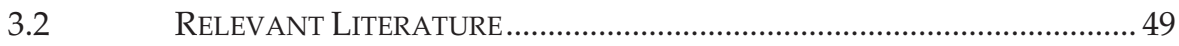

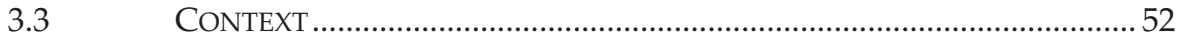

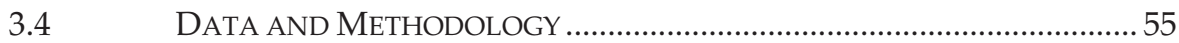

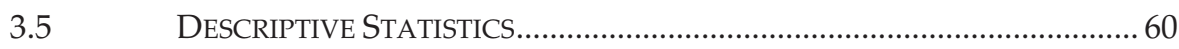

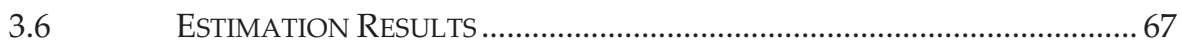




4. INTERNATIONAL MIGRATION OF HOUSEHOLD MEMBERS AND SELF-EMPLOYMENT OF NON-MIGRANTS ................................................ 79

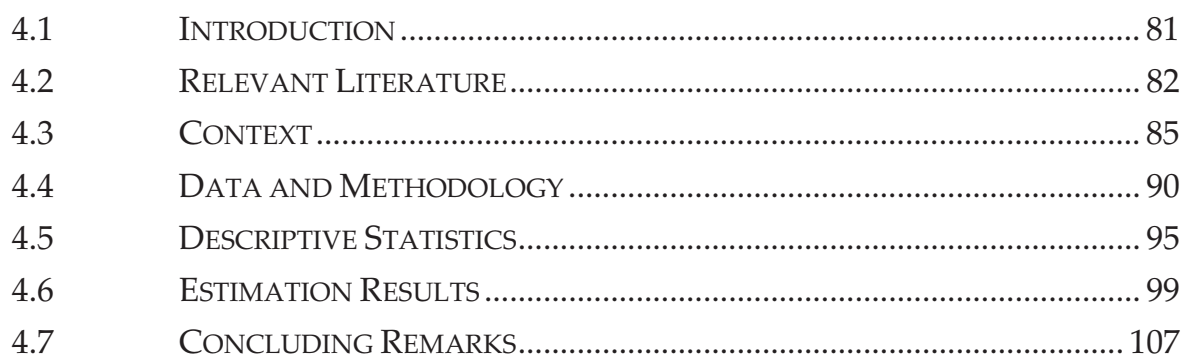

5. LABOUR MARKET REINTEGRATION OF RETURNED REFUGEES IN

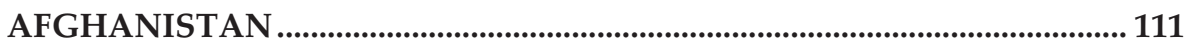

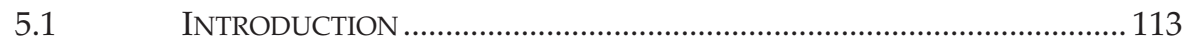

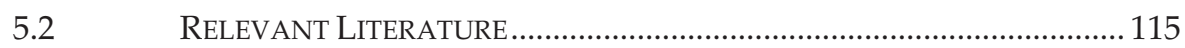

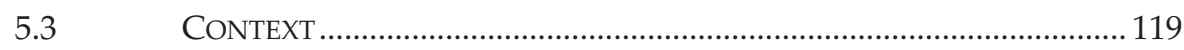

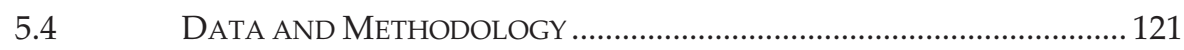

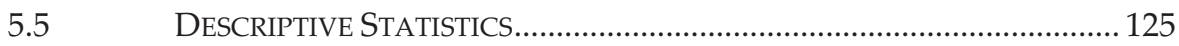

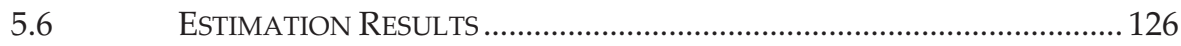

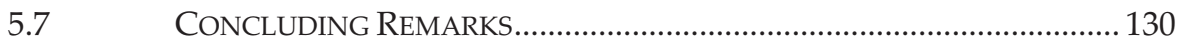

6. DISPLACEMENT AND NON-FARM BUSINESSES - EVIDENCE FROM

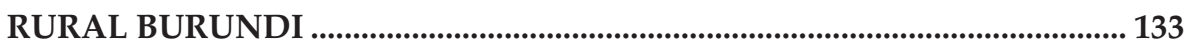



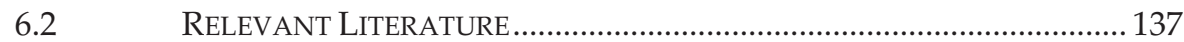

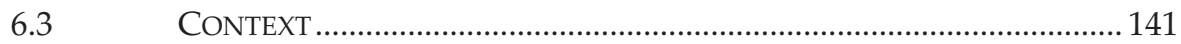

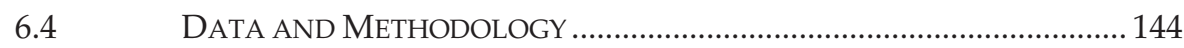
6.5 DESCRIPTIVE STATISTICS................................................................. 148

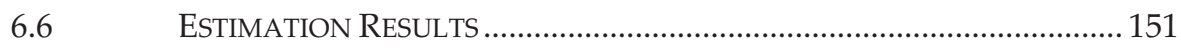

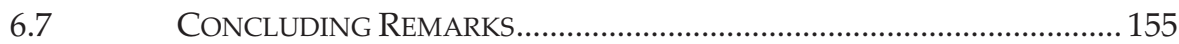

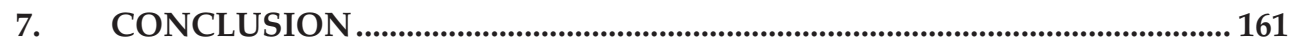

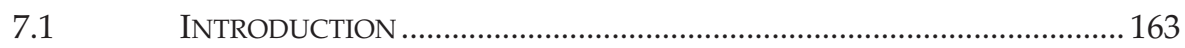

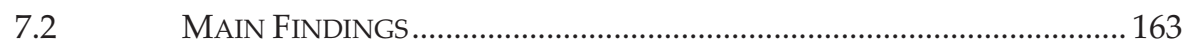

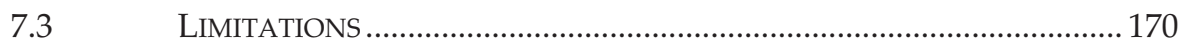

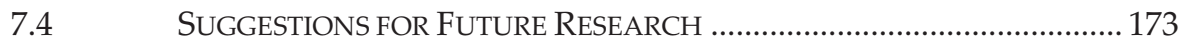

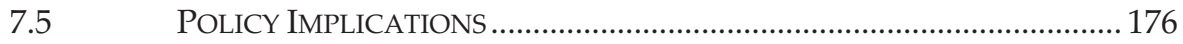


REFERENCES..

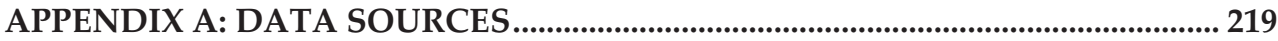

A.1. UNHCR RWANDA DATASET ............................................................ 221

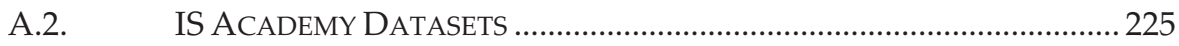

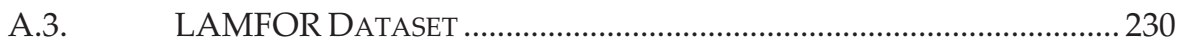

APPENDIX B: LABOUR MARKET ACTIVITIES OF CONGOLESE REFUGEES IN RWANDA

APPENDIX C: INTERNATIONAL MIGRATION OF HOUSEHOLD

MEMBERS AND SELF-EMPLOYMENT OF NON-MIGRANTS

APPENDIX D: LABOUR MARKET REINTEGRATION OF RETURNED

REFUGEES IN AFGHANISTAN. 253

APPENDIX E: DISPLACEMENT AND NON-FARM BUSINESSES EVIDENCE FROM RURAL BURUNDI 261

VALORIZATION 269

ABOUT THE AUTHOR 277 



\section{LIST OF TABLES}

Table 1.1: Empirical Chapters of this Dissertation ......................................................... 16

Table 3.1: Study Sample of Locals and Refugees across Camp Areas ...........................56

Table 3.2: Summary Statistics of Individual and Household Characteristics .............. 59

Table 3.3: Primary Daily Activity in the Past 12 Months................................................ 60

Table 3.4: Employment Status of Locals and Refugees................................................ 61

Table 3.5: Primary Daily Activity of Employed Locals and Refugees...........................62 62

Table 3.6: Multiple Labour Market Activities Carried Out by Refugees and Locals .. 62

Table 3.7: Wage employment by Status and Camp......................................................... 63

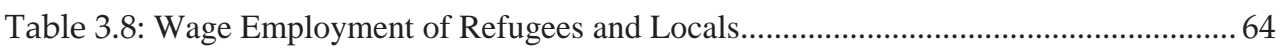

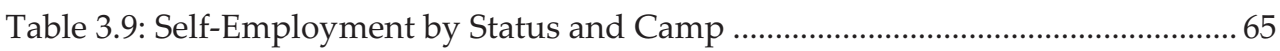

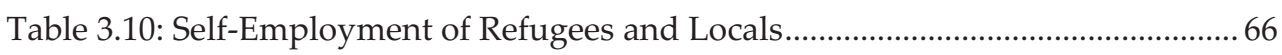

Table 3.11: Labour Market Activities of Refugees and Locals ....................................... 68

Table 3.12: Labour Market Activities of Refugees .......................................................... 72

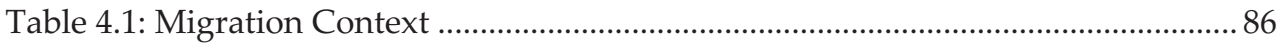

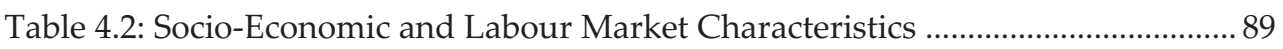

Table 4.3: Sample Size per Country ................................................................................ 91

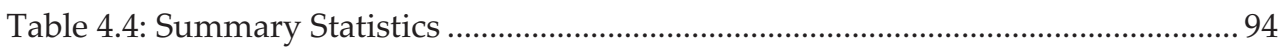

Table 4.5: Primary Daily Activity in the Past 12 Months.............................................. 95

Table 4.6: Type of Primary Daily Activity of Working Population ............................... 96

Table 4.7: Household Member Migration Experiences................................................... 97

Table 4.8: Primary Daily Activity and Current Migrant................................................. 98

Table 4.9: Primary Daily Activity and Return Migrant .............................................. 98

Table 4.10: Binomial Probit with Sample Selection Model Estimations per Country 102

Table 4.11: Binomial Probit with Sample Selection Models by Gender ...................... 105

Table 4.12: Binomial Probit with Sample Selection Models by Location Type .......... 106

Table 5.1: Summary Statistics, Comparing Non-migrants to Returned Refugees..... 124

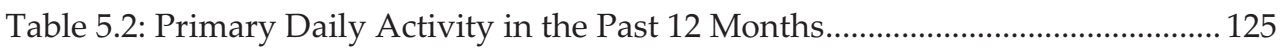

Table 5.3: Labour Market Activity in the Past 12 Months ............................................ 126

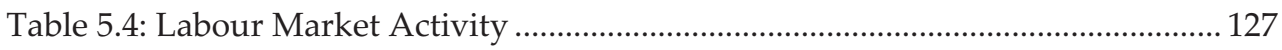

Table 5.5: Labour Market Activity, Non-migrants and Returned Refugees............... 128

Table 5.6: Labour Market Activity of Returnees .......................................................... 129

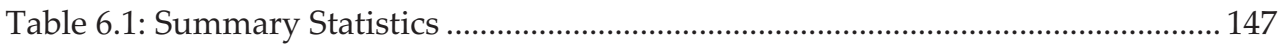

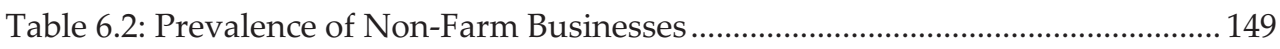

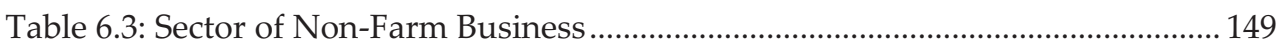


Table 6.4: Determinants of Non-Farm Business Activities 153

Table 6.5: Displacement and Current Non-Farm Business Operations... 155

\section{LIST OF FIGURES}

Figure 3.1: UNHCR Presence in Rwanda, 2016 54

Figure 5.1: Refugees from and Returned Refugees in Afghanistan, 1990-2017.......... 120

Figure 6.1: Importance of Different Income Sources..................................................... 151 




\section{Abbreviations}

DRC Democratic Republic of Congo

FDI Foreign Direct Investment

GEM Global Entrepreneurship Monitor

HDI Human Development Index

ICT Information and communication technology

IDP Internally Displaced Person

ILO International Labour Organization

IOM International Organization for Migration

LAMFOR Labour Market Impacts of Forced Migration

MIDIMAR Ministry of Disaster Management and Refugee Affairs (Rwanda)

NELM New Economics of Labour Migration

NGO Non-Governmental Organization

NRVA National Risk and Vulnerability Assessment

OECD Organisation for Economic Co-operation and Development

UNDP United Nations Development Programme

UNHCR United Nations High Commissioner for Refugees

USD United States Dollar 



\section{CHAPTER 1: INTRODUCTION}





\subsection{About this Dissertation}

This dissertation explores the labour market participation of forced migrants and their households in the context of developing countries. Herein, a specific focus is placed on people displaced by conflict and general insecurity, and their labour market activities both during migration as well as upon return.

Following a review of the literature in Chapter 2, this work consists of four selfcontained chapters covering different angels of analysis on the overall theme in Chapters 3 through 6. Each of these chapters stands on its own and uses a different case study of forced migration to explore one of the following questions respectively:

1) What are the patterns and determinants of refugees' labour market participation and in what ways do their economic activities differ from those of locals?

2) How are self-employment activities of non-migrants shaped by the forced or voluntary migration experiences of household members?

3) To what extent do forced migration experiences shape the labour market reintegration of returned refugees in a (post-) conflict developing country context?

4) What is the relationship between forced migration experiences and engagement in non-farm household business activities in a rural (post-) conflict developing country context?

The background and motivation for these questions are presented in Section 1.2, the problem statement is formulated in Section 1.3 while Section 1.4 introduces the key concepts relevant for this dissertation. The structure of the dissertation is then further explained in Section 1.5 and Section 1.6 summarises the contribution made. 


\subsection{Background and Motivation}

One in every 110 people in the world is currently a conflict-induced forced migrant ${ }^{1}$; or in others words, one in every 110 individuals has been displaced from their home region by conflict, violence, persecution, or human rights violations (United Nations High Commissioner for Refugees, 2018b). The extent of conflict-induced forced migration, also referred to as displacement, has reached a record high of 68.5 million individuals in 2017. That year alone, more than 16.2 million individuals were registered as having been newly displaced, of which slightly more than one quarter crossed an international border to seek safety as asylum seekers, and to receive protection as refugees upon assessment of their asylum claim. The remaining 11.8 million displaced individuals remained within the borders of their own country as internally displaced persons (IDPs). The vast majority of those that cross international borders out of compulsion move to neighbouring countries; in other words, most forced migration takes place between developing countries (United Nations High Commissioner for Refugees, 2018a).

While the main driver of this most recent increase in the number of IDPs, refugees, and asylum seekers is the ongoing conflict in the Syrian Arab Republic, several other countries across the world have also experienced episodes of conflict in recent years that led to the internal and international displacement of individuals and whole households/families. For three decades, for example, Afghanistan was the main country of origin of refugees around the world. It remains in the second place behind Syria. Moreover, at this stage the displacement of more than 2 million Afghans to neighbouring Pakistan and Iran has lasted for more than 38 years (United Nations High Commissioner for Refugees, 2018a).

Such protracted refugee situations have also increased in recent times (United Nations High Commissioner for Refugees, 2018a). A protracted refugee situation is one where a large group of refugees from one specific country of origin is displaced across international borders for a period of five years or more (United Nations High

\footnotetext{
${ }^{1}$ Forced migration is defined as any "migratory movement in which an element of coercion exists, including threats to life and livelihood, whether arising from natural or man-made causes (e.g. movements of refugees and internally displaced persons as well as people displaced by natural or environmental disasters, chemical or nuclear disasters, famine, or development projects)" (International Organization for Migration, 2015). While environmental and other factors as drivers of forced migration are an issue of increasing importance, the migration movements considered in this dissertation are almost exclusively conflict-induced, as are the ones covered by the global trends presented in this section.
} 
Commissioner for Refugees, 2004). By the end of 2017 an estimated 13.4 million individuals were in a protracted refugee situation - a significant increase from the 11.6 million in 2016 (United Nations High Commissioner for Refugees, 2017d, 2018a).

Not all forced migration is fortunately protracted and voluntary return and repatriation to countries or areas of origin are commonly observed when the situation allows it. While returning may not be the desired option for all forced migrants, for many rebuilding their livelihood at 'home' is indeed a preference (Koser \& Black, 1999). In 2016, more than 5 million people did return to their places of origin, 4.2 million IDPs and 667,400 returned refugees (United Nations High Commissioner for Refugees, 2018a).

The process of return of those displaced during violent conflicts is often considered to be an indication of stabilization in the country (Chimni, 2002). To some extent, this legitimises the transition from a conflict to the post-conflict and reconstruction phase (Koser \& Black, 1999) and as such strengthens the confidence of donors in the peacebuilding process (Black \& Gent, 2006). More broadly, return migration is increasingly perceived as an avenue for the development of countries of origin. However, the understanding of the potential of return migration in relation to development remains limited in the context of forced migration and post-conflict situations.

Overall, economic research on forced migration, including both refugees and IDPs, is still in its early stages. While there is a rich literature specifically on the economics of labour migration, many of the same issues addressed in that literature have not been analysed in the same manner in the context of forced displacement. At the same time, there is literature on the consequences of violent conflicts on the welfare and economic development of affected countries and their populations, but this generally does not consider forced displacement in detail (Ruiz \& Vargas-Silva, 2013).

\subsection{Problem Statement}

There is presently a gap in the literature on the economics of forced migration. While in recent years, there has been an increased interest in such issues, also due to the conflict in Syria and its consequences in terms of international displacement, data limitations make many related topics challenging to research. In addition, the main focus of such research has been the impact of forced migration on the local population as well as the economies and labour markets of hosting countries (Ceritoglu, Yunculer, Torun, \& Tumen, 2017; Del Carpio \& Wagner, 2015; Maystadt \& Duranton, 2014; Maystadt \& Verwimp, 2014). Little research has, on the other hand, been conducted 
with a focus on the economic activities of forced migrants and their households themselves and how their participation in the labour market during displacement and upon return relates to displacement experiences.

Due to the wide variety of forced migration situations around the world and the fact that they are often not comparable due to the differences in context of the causes of displacement and the situation in the host country or area, there is therefore a need for more research on this topic. This increased understanding of labour market activities is especially important in the light of the recent shift in approach in the donor community away from seeing refugees as a burden for the hosting country to recognizing the potential links to development, and from dependency on humanitarian assistance to the self-reliance of refugees (Aleinikoff, 2015; United Nations High Commissioner for Refugees, 2017c).

When it comes to post-conflict return migration, much of the discussion in donor and policy circles is about the sustainability of such return movements. Return and reintegration are often challenging processes that take time and, in some cases, may never be achieved resulting in re-migration (Bascom, 2005; Kuschminder, 2017). Among other factors, such as a welcoming community, safety, and basic services and infrastructure, prospects for building a livelihood upon return are crucial for reintegration. The local labour market and the opportunities it presents therefore greatly influences whether or not a returnee chooses to settle permanently again at origin (Black \& Gent, 2006).

At the same time, conflicts have significant impacts on labour markets and change the types of employment opportunities available (Stewart, 2015). A common feature of conflict is an observed reallocation of employment, largely depending on the development of said conflict. Where infrastructure, e.g. power plants or fuel facilities, are destroyed, major providers of employment disappear. Equally, trade and tourism tend to be affected by conflict and impact employment opportunities in related sectors (Cramer, 2015). More generally, labour markets in developing countries often leave individuals to decide between engagement in self-employment activities, agriculture, household work, or migration due to a scarcity of wage employment opportunities, particularly in rural regions (Nagler \& Naudé, 2017).

In the context of labour migration, a number of studies have found evidence that the migration experience greatly influences labour market outcomes of return migrants once back in the country of origin. Still, these experiences are not uniform as some individuals are inherently presented with greater opportunities abroad and therefore greater job prospects upon return (Arif \& Irfan, 1997; Gubert \& Nordman, 2011; Kilic, 
Carletto, Davis, \& Zezza, 2009). In addition, differences in the environment to which the migrants return also play an important role. As such it is important to better understand the labour market activities of returned refugees in particular (post-) conflict settings, in order to promote conditions that facilitate sustainable return and reintegration processes for this type of returnee, which in turn is a pre-condition for their ability to contribute to development.

Overall, the labour market participation of forced migrants themselves and their households, how it relates to prior experiences, and compares to the activities of nonmigrants is in many situations not well understood. This is particularly the case in developing country contexts such as Burundi and Rwanda in Sub-Saharan Africa, as well as Afghanistan in South-Central Asia. These three countries have all been immediately affected by significant forced migration movements in the last decades. Yet, the understanding of the patterns and determinants of the labour market activities of forced migrants and their households during migration (in the case of Rwanda) or upon return to the countries (in the cases of Afghanistan and Burundi) is still in its early stages.

While there is some evidence on the emergence of refugee economies in displacement situations, this is largely based on small scale studies conducted in few contexts. At the same time, the understanding of the impact of forced migration experiences on the ability to reintegrate into the labour market at home is currently limited. Both of these are significant gaps in current research in so far that the ability of forced migrants in different stages of their migration journey to generate an income and live independently has important implications for policy-making and support programmes.

In times when there is a shift in debates on displacement away from a purely humanitarian approach towards acknowledging the potentials of forced migrants in terms of self-reliance, both during displacement as well as upon return, the economic activities of such migrants carry a new meaning in relation to their potential to build a sustainable livelihood for themselves and ultimately contribute to development. The importance of developing a deeper understanding of the labour market activities of forced migrants in different contexts therefore warrants more research in this field.

A key reason for a lack of such research is the limited availability of data on forced migration contexts, specifically where displacement takes place between developing countries. As such, this dissertation takes advantage of three different data sources that do allow to investigate labour market activities of forced migrants and their household members in different developing country contexts. Taking into 
consideration the rising trend of forced migration as of late, which most immediately impacts those countries neighbouring active conflict zones, more research in this area is particularly opportune.

Using the case studies of Afghanistan, Burundi, and Rwanda ${ }^{2}$, this dissertation addresses the four specific research questions introduced in Section 1.1 relating to the labour market participation of forced migrants and their households. The specific research gaps behind the four questions are further elaborated upon in the second chapter of this dissertation, which presents a literature review on the linkages between migration and entrepreneurship more generally.

Each of the research questions will be addressed in one of four empirical chapters that comprise the core of this dissertation. Presented in Chapters 3 through 6, different country contexts are used to provide evidence in answer to these questions using descriptive and econometric methods. ${ }^{3}$ While these studies differ in focus and context, they overall address the research gap that currently exists on the quantitative analysis of the labour market participation of forced migrants and their households in developing countries both during migration as well as upon return to the country of origin.

\subsection{Key Concepts}

At this point, it is timely to discuss the most important concepts relevant for the topic of this dissertation. The following sections will discuss forced migration, labour market activities, as well as entrepreneurship and self-employment in turn and explain how they are used throughout this dissertation. Specific attention is paid to developing country contexts.

\subsubsection{Forced Migration}

As explained in the previous section, this dissertation investigates the labour market activities of conflict-induce forced migrants and their household members (who stay behind). Migration is an integral part of the global development process and in this context migration and its impacts on development are gaining importance in both

\footnotetext{
${ }^{2}$ The relevance of forced migration in each of these countries is presented in detail in the context sections of the respective chapters.

${ }^{3}$ More details on the structure of the dissertation will be presented in Section 1.5 of this introductory chapter.
} 
academic and policy discussions. ${ }^{4}$ Migration is, however, a complex phenomenon that encompasses a lot of different kinds of movements, including both those within a country as well as those that cross an international border, those moving out of compulsion and those moving out of their free will, as well as those moving for shorter periods of time or permanently (Koser, 2007).

As a consequence of its multifacetedness, there is no universally accepted definition for "migration" or a "migrant". The United Nations, for example, defines an international migrant as "an individual who has resided in a foreign country for more than one year irrespective of the causes, voluntary or involuntary, and the means, regular or irregular, used to migrate" (International Organization for Migration, 2011, p. 62). Under such a definition, those moving for shorter periods would not be considered migrants. However, common usage of the term migrant does include certain kinds of shorter-term migrants, such as seasonal farm-workers (International Organization for Migration, 2011). Furthermore, those moving within the borders of a country are excluded in the above definition. The International Organization for Migration (IOM) has therefore adapted a more encompassing definition of a migrant as "any person who is moving or has moved across an international border or within a State away from his/her habitual place of residence, regardless of (1) the person's legal status; (2) whether the movement is voluntary or involuntary; (3) what the causes for the movement are; or (4) what the length of the stay is" (International Organization for Migration, 2015).

The latter, encompassing definition is used to identify the populations that are at the centre of the studies in the present dissertation. ${ }^{5}$ More concretely, throughout this dissertation the focus is largely on migration movements that can be categorized as being forced, at least to some degree. Case studies include, for example, Congolese refugees in Rwanda and returned refugees in Afghanistan (see Section 1.4 for more information on all of the case studies), set in contexts that are principally characterized by political instability and violent conflicts, often resulting in displacement both within countries as well as across international borders. While the categorization of migrants into voluntary versus forced is in many cases not nearly as clear-cut in reality and therefore often not useful in practice (Koser, 2007), those migrants that move out of compulsion, whatever the specific factors behind that may be, do differ in many

\footnotetext{
${ }^{4}$ For a review of the evidence on the linkages between migration and development refer to Section 2.4 of this dissertation.

${ }^{5}$ More specific operationalisations of the respective migrant group(s) will be discussed in each chapter respectively.
} 
ways from those that move mainly for economic and/ or social reasons. The migrants in the case studies presented in Chapters 3 through $6^{6}$ of this dissertation all selfidentified as having moved for reasons that can be classified as motives for forced migration, such as political or security concerns. As such, the terminology applied throughout this dissertation is largely adapted to that of forced migration and displacement for reasons of violence, conflict, persecution, and other human rights violations. Recognizing that it is often a combination of factors that in the end prompt individuals to leave, even in the conflict setting, forced migration is used to describe movements that are mainly caused by persecution, violence, conflict, and human rights violations, though the author understands that there is still an element of choice in these situations.

In terms of legal status forced migrants, and specifically recognized refugees, have the right to protection based on the 1951 Convention Relating to the Status of Refugees and its 1967 Protocol Relating to the Status of Refugees ${ }^{7}$. In the Convention refugees are defined as individuals who "owing to well-founded fear of being persecuted for reasons of race, religion, nationality, membership of a particular social group or political opinion, is outside the country of his nationality and is unable or, owing to such fear, is unwilling to avail himself of the protection of that country; or who, not having a nationality and being outside the country of his former habitual residence as a result of such events, is unable or, owing to such fear, is unwilling to return to it." The definition has been criticized for not fully reflecting the realities of forced migration in the world today as it was written at a time where world politics looked very different. Most notably, it does omit those displaced by environmental factors as well as those persecuted based on their sex or sexuality. It also does not pay particular attention to those displaced within a country. Internally displaced persons are often the most vulnerable populations in the case of a conflict or disaster as they have not been able to leave the country where they are not safe (Koser, 2007).

Nonetheless, the Refugee Convention still does constitute the most important instrument of protection for forced migrants (Koser, 2007). Those individuals that obtain refugee status, in theory are protected by the Refugee Convention and this, in principle, grants them the right to work. Articles 17 through 19 of the Convention confer the right to gainful employment on refugees and states that are signatories

\footnotetext{
${ }^{6}$ An exception are migrants from Ethiopia and Morocco in Chapter 4. These cases serve to act as a comparison to the cases of forced migration from Afghanistan and Burundi.

${ }^{7}$ Subsequently referred to as the Refugee Convention.
} 
therefore agree to "accord to refugees lawfully staying in their territory the most favourable treatment accorded to nationals of a foreign country in the same circumstances, as regards the right to engage in wage-earning employment" (Article 17.1). Furthermore, refugees wanting to be self-employed (Article 18) or work in a liberal profession (Article 19) also should receive at least equal treatment to other migrants.

However, how the access of refugees to labour markets is regulated in practice and how the rights laid out in the Refugee Convention are implemented in practice depends very much on the country context. Firstly, not all countries hosting refugees, including hosting states of large refugee populations, are in fact signatories to the Convention (Zetter \& Ruaudel, 2016). More importantly, the contexts in which refugees live often differ significantly from those of other migrants. The conditions under which they leave their countries of origin often mean that they have to leave resources behind or sell their belongings in order to afford their journey. In addition, they often do not choose where they migrate to, but rather stop their journey either where they find safety or when they run out of resources (Van Hear, 2006). Once in the hosting country, which are often developing countries neighbouring their countries of origin, refugees may face legal restrictions and problems in accessing the labour markets (Zetter \& Ruaudel, 2016).

In order for refugees to become self-reliant and not dependent on humanitarian assistance, access to the labour market of the hosting country is an essential component (Betts, Bloom, Kaplan, \& Omata, 2017). Equally important are opportunities for returning refugees to build livelihoods in the country of origin in the light of sustainable return and reintegration (Black \& Gent, 2006; Kuschminder, 2017). It is therefore important to investigate some of the questions that have been considered more commonly in the context of economic migration and/ or developed countries in the context of forced migrants in less advanced economies. This is the purpose of this dissertation.

\subsubsection{Labour Markets and Labour Market Activities in Developing Countries}

The majority of the world's population lives and works in developing countries. Evidence does exist that labour markets in developing countries look and work significantly different from their counterparts in more developed economies. Understanding the functioning of the heterogeneous labour markets in developing countries is important in the light of facilitating development and poverty reduction (Frölich \& Haile, 2011). 
In this dissertation, the "labour market" is seen as the place where those supplying labour and those demanding labour meet. This can result in wage employment when individuals sell their labour to an employer or self-employment when an individual sells the result of their labour in the form of a product or a service (Fields, 2011). In the context of this dissertation, labour market activities also include agricultural household work, as subsistence farming is an important contributor to many households' livelihood, and, as such, important to consider. The empirical part of this dissertation is based on different case studies investigating the labour market activities of forced migrants and their households in countries of destination and origin, all in developing country contexts. It is therefore important to provide a brief overview of the important characteristics of labour markets in such contexts.

Without going into too much detail, a number of ways in which the labour markets in developing countries differ from those in developed countries can be identified. Firstly, in countries where the economy is weak and growth limited, but the population grows at the same time, demand and supply of labour do likely not match, possibly leading to (youth) unemployment and more importantly underemployment (Stewart, 2015). Secondly, many developing countries are characterized by segmented labour markets, consisting of the formal labour market on the one hand and informal sectors on the other hand (Fields, 2009; Pratap \& Quintin, 2006). In addition, the agricultural sector still plays a much more important role in developing countries than in the developed world. Particularly subsistence farming is the basis for the livelihood of a large share of households in the developing world and especially in Sub-Saharan Africa (Davis, Di Giuseppe, \& Zezza, 2017). At the same time, what is considered wage employment in developed countries is in many cases very different from what can be observed in developing countries. Jobs in regulated companies with a formal agreement in the form of a contract are much less common than work in the informal labour market, including in agriculture as well as other sectors (Stewart, 2015). Instead, casual, informal labour is a common income source for many as is own account work in family businesses.

Another difference in the understanding of labour markets in more advanced and developing countries is the concept of unemployment. In many contexts, only few people are openly unemployed. Many are, however, underemployed, meaning that they carry out an income-generating activity that is less productive than they would be able to and want to. The alternative, unemployment, is often not an option for individuals facing this challenge as many developing countries do not offer their 
citizens social protection schemes, such as unemployment insurance (Mata Greenwood, 1999).

In turn, the lack of wage employment opportunities and absence of assistance mechanisms for the unemployed is also the cause of higher levels of own account work and necessity entrepreneurship (Herrington \& Kelley, 2013; Margolis, 2014; Reardon, Berdegué, Barrett, \& Stamoulis, 2007). This is why this specific income-generating activity is of particular relevance in this dissertation as further explained in the following section.

\subsubsection{Self-Employment and Entrepreneurship in Developing Countries}

Self-employment and entrepreneurship have been found to be of particular importance in the context of developing countries as such activities can potentially be drivers of structural economic transformation and economic development (Ács, 2006; Gries \& Naudé, 2010; Naudé, 2008). In this dissertation, self-employment and entrepreneurship - the two terms are largely used to describe the same kind of activities - generally refer to any activity undertaken by an individual or household that is not wage labour performed for someone else. While agricultural activities themselves are generally not included, many activities in rural developing country contexts may still be associated with the tertiary sector, as long as there is value added to the farm product. An example would be the processing and sale of food items (Nagler \& Naudé, 2017; Rijkers \& Costa, 2012).

As indicated by this wide definition, the self-employed in developing countries is a heterogeneous group. It includes, for example, those working as petty traders or construction workers as well as those running small retail shops or providing personal services (Falco \& Haywood, 2016; Quatraro \& Vivarelli, 2014) and not all these may be beneficial in terms of development of the country. Here, the distinction between opportunity and necessity entrepreneurs is helpful to consider. While opportunity entrepreneurs choose to become self-employed as a result of perceiving a business opportunity, necessity entrepreneurs become self-employed because of a lack of other employment opportunities (Reynolds, Camp, Bygrave, Autio, \& Hay, 2001).

Existing evidence highlights that entrepreneurship in developing countries is much more commonly driven by necessity than in developed countries (Reynolds et al., 2001) and that these ventures are generally not associated with economic growth (Naudé, 2009; Wong, Ho, \& Autio, 2005). This does, however, not mean that such activities are not significant for those engaging in them (Amorós \& Cristi, 2011). This is due to the fact that this necessity is closely related to widespread poverty and the 
need to make an income to survive; in other words, such activities represent a strategy to avoid unemployment (Desai, 2011). They are commonly carried out by one selfemployed person that sets up a small informal business; only few necessity entrepreneurs create jobs for others (Quatraro \& Vivarelli, 2014). Often such non-farm self-employment activities are used as part of a wider household strategy aiming at the diversification of income sources (Davis et al., 2010).

In line with the motivations for engaging in self-employment and entrepreneurship, the majority of these activities in developing countries are informal (Charmes, 2012; Nagler \& Naudé, 2014). While formal entrepreneurship also exists, relatively seen it is the exception, especially in rural areas. Estimates indicate that on average more than half of the working population in developing countries is self-employed, where the relative importance of such activities as income sources starkly varies between countries and depends on a variety of factors. For example, the self-employment rate has been found to be influenced by characteristics such as the infrastructure and business environment, labour market conditions and frictions, as well as social protection schemes (Margolis, 2014).

Recent evidence from several Sub-Saharan African countries confirms that the majority of non-farm businesses in rural areas are small and informal, and that both determinants relating to necessity and to a lesser extent opportunity entrepreneurship can be identified for such endeavours (Nagler \& Naudé, 2017). As such, their contribution to the economic growth of these countries may be limited, as explained above, but they may fulfil an important coping mechanism role - perhaps especially for migrants. Therefore, the role of self-employment and small businesses for the livelihoods of those operating them should not be ignored as they have the potential to decrease poverty and contribute to human development (Amorós \& Cristi, 2011; Ciarli, Parto, \& Savona, 2010; Quatraro \& Vivarelli, 2014).

\subsection{Structure of this Dissertation}

As introduced before, this dissertation explores the labour market participation of forced migrants and their households in the context of developing countries. Herein, a specific focus is placed on people displaced by conflict and general insecurity, and their labour market activities both during migration as well as upon return.

Following this general introduction, Chapter 2 presents a review of the literature on the linkages between migration, labour markets, entrepreneurship, and development. The purpose of this chapter is to identify and highlight the research gaps in this wider 
literature that exist specifically on the labour market participation of forced migrants in developing countries.

Following the literature review, the core of this work consists of four self-contained chapters covering different angels of analysis on the overall theme using different case studies of forced migration contexts in Chapters 3 through 6. Each of these chapters stands on its own and uses a different case study to explore one of the questions presented in Section 1.1, which were derived based on the gaps identified in the literature review in Chapter 2.

The chapters can generally be classified into either looking at labour market activities of forced migrants and their households (1) during migration versus (2) upon return to the home country. Firstly, Chapters 3 and 4 consider labour market participation during forced migration of refugees themselves and household members in the country of origin respectively. Chapter 4 additionally considers return migration. Also focusing on return, Chapters 5 and 6 analyse the labour market participation and household non-farm businesses of those that returned from forced migration.

A further distinction can be made along the lines of the unit of analysis: individual versus household. Chapters 3, 4, and 5 all focus on individuals, while in Chapter 6 the unit of analysis moves to the household level. In terms of the activities of interest, the focus is on labour market activities generally in Chapters 3 and 5 and specifically on self-employment in business in Chapters 4 and 6.

Table 1.1 on the following page provides a comparative overview of the four empirical chapters along those lines and provides an indication of the respective country/ies that they cover, and the data used. More information on the three datasets is provided in the respective chapters as well as in Appendix A of this dissertation, which presents more details on each of the data sources. 


\section{Table 1.1: Empirical Chapters of this Dissertation}

\begin{tabular}{|c|c|c|c|c|}
\hline & Chapter 3 & Chapter 4 & Chapter 5 & Chapter 6 \\
\hline $\begin{array}{l}\text { Main Research } \\
\text { Question }\end{array}$ & $\begin{array}{l}\text { What are the } \\
\text { patterns and } \\
\text { determinants of } \\
\text { refugees' labour } \\
\text { market } \\
\text { participation and } \\
\text { in what ways do } \\
\text { their economic } \\
\text { activities differ } \\
\text { from those of } \\
\text { locals? }\end{array}$ & $\begin{array}{l}\text { How are self- } \\
\text { employment } \\
\text { activities of non- } \\
\text { migrants shaped } \\
\text { by the forced or } \\
\text { voluntary } \\
\text { migration } \\
\text { experiences of } \\
\text { household } \\
\text { members? }\end{array}$ & $\begin{array}{l}\text { To what extent } \\
\text { do forced } \\
\text { migration } \\
\text { experiences shape } \\
\text { the labour market } \\
\text { reintegration of } \\
\text { returned refugees } \\
\text { in a (post-) } \\
\text { conflict } \\
\text { developing } \\
\text { country context? }\end{array}$ & $\begin{array}{l}\text { What is the } \\
\text { relationship } \\
\text { between forced } \\
\text { migration } \\
\text { experiences and } \\
\text { engagement in } \\
\text { non-farm } \\
\text { household } \\
\text { business activities } \\
\text { in a rural (post-) } \\
\text { conflict } \\
\text { developing } \\
\text { country context? }\end{array}$ \\
\hline Migration Phase & During & During \& Return & Return & Return \\
\hline $\begin{array}{l}\text { Group of } \\
\text { Analysis }\end{array}$ & $\begin{array}{l}\text { Individual } \\
\text { (refugees and } \\
\text { locals) }\end{array}$ & $\begin{array}{l}\text { Individual } \\
\text { (non-migrants } \\
\text { with and without } \\
\text { forced migrant in } \\
\text { household) }\end{array}$ & $\begin{array}{l}\text { Individual } \\
\text { (returned } \\
\text { refugees and non- } \\
\text { migrants) }\end{array}$ & $\begin{array}{l}\text { Households } \\
\text { (with and } \\
\text { without } \\
\text { displacement } \\
\text { experience) }\end{array}$ \\
\hline Focus & $\begin{array}{l}\text { All labour market } \\
\text { outcomes }\end{array}$ & Self-employment & $\begin{array}{l}\text { All labour market } \\
\text { outcomes }\end{array}$ & Self-employment \\
\hline Country/ies & Rwanda & $\begin{array}{l}\text { Afghanistan, } \\
\text { Burundi, } \\
\text { Ethiopia, and } \\
\text { Morocco }\end{array}$ & Afghanistan & Burundi \\
\hline Dataset & $\begin{array}{l}\text { The Economic } \\
\text { Impacts of } \\
\text { Congolese } \\
\text { Refugees in } \\
\text { Rwanda }\end{array}$ & $\begin{array}{l}\text { IS Academy: } \\
\text { Migration and } \\
\text { Development }\end{array}$ & $\begin{array}{l}\text { IS Academy: } \\
\text { Migration and } \\
\text { Development }\end{array}$ & $\begin{array}{l}\text { The Labour } \\
\text { Market Impacts } \\
\text { of Forced } \\
\text { Migration }\end{array}$ \\
\hline $\begin{array}{l}\text { Data Collection } \\
\text { Period }\end{array}$ & May 2016 & 2011 and 2012 & First quarter 2011 & First quarter 2015 \\
\hline
\end{tabular}




\subsection{Contribution of this Dissertation}

Overall, this dissertation contributes to a better understanding of the labour market participation of forced migrants and their household members. While the use of unique datasets comes with some limitations for the analysis, the individual case studies by themselves and brought together allow to derive recommendations for both further research in this field of study as well as for the development of policy.

Well-designed policies and programmes have the potential to contribute to the wellbeing of forced migrants and their household members by enabling them to actively participate in the labour market of host countries and/ or upon return to the country of origin; therefore, allowing them to secure their livelihood. At the same time, such policies also consider the realities and potential implications for countries of origin and destination respectively in order to enable all involved parties to benefit.

More evidence is needed on which basis such policies can be developed. In this light, the following paragraphs highlight the specific contribution of each empirical chapter to the respective research question of this dissertation.

1) What are the patterns and determinants of refugees' labour market participation and in what ways do their economic activities differ from those of locals?

The findings of Chapter 3 show that, as one may expect, unemployment is a significant issue for Congolese refugees in Rwanda and that the biggest difference between natives and refugees lies in the access to land in a context where the reliance on agricultural activities is still common. Furthermore, self-employment is an important form of activity for females and especially female refugees, as alternative economic activities for them largely do not exist in the absence of the possibility of engagement in agricultural activities. The local context of refugee camps does matter, and refugees benefit from being closer to urban centres, where they can engage in trade and casual labour arrangements with the local population.

2) How are self-employment activities of non-migrants shaped by the forced or voluntary migration experiences of household members?

The analysis in Chapter 4 shows that in countries where the vast majority of migration is motivated for the most part by the escape from violent conflict and general insecurity no relationship between migration and self-employment of non-migrant 
household members exists. In countries, where the main reasons for migration are economic, such a relationship is more likely. Here it seems that the specific strategy of the respective household may make a difference. While in Ethiopia, where much migration is to the Middle East and remittances are largely used for consumption, a negative relationship regarding self-employment is found, there is a positive relationship in the case of labour migration from Morocco to Europe. This highlights that spill overs of migration on private sector development through migrants' household members should not be expected generally, but that this potential very much depends on the respective context.

Besides the analysis of the potential relationship between a current migrant in the household and self-employment of non-migrants, the relationship between the latter and a return migrant in the household indicates that in the more advanced economy of the four countries - Morocco - migration may overall be used by households as a strategy to overcome liquidity constraints. However, overall there is little evidence for spill overs of return migration on non-migrants in the same household and their selfemployment activities.

3) To what extent do forced migration experiences shape the labour market reintegration of returned refugees in a (post-) conflict developing country context?

The findings in Chapter 5 provide evidence that returned refugees are less likely to be wage employed in comparison to non-migrants, and that those factors related to socioeconomic status including educational attainment and the strength of social networks play an influential role in labour market outcomes in Afghanistan. In addition, there is evidence that even in contexts of forced migration, the migration experience may be influential for the economic reintegration, particularly in contexts where the forcibly displaced do have opportunities to be economically activity during displacement. Overall, the main contribution of this chapter is the analysis of the potential role of migration experiences in labour market outcomes of migrants upon return; an issue that has previously been analysed in the context of voluntary movements for employment purposes, but not those caused by factor such as violent conflict and general insecurity. 
4) What is the relationship between forced migration experiences and engagement in non-farm household business activities in a rural (post-) conflict developing country context?

Chapter 6 contributes to the existing literature by considering that displacement experiences and the consequences upon return in terms of loss of land rights, assets, and deterioration of skills may be an additional reason to engage in entrepreneurial activities in rural contexts that are characterized by land scarcity and limited wage employment opportunities. The analysis does, however, not confirm such an expectation. Instead, it highlights that households with international, internal, or no displacement experiences are more or less likely to operate a non-farm business based on a variety of other factors, including, first and foremost, the necessity to engage in another activity due to the inability to satisfy daily needs based on household agricultural activities. 

CHAPTER 2: MigRATION, ENTREPRENEURSHIP, AND DEVELOPMENT: A REVIEW OF THE LITERATURE 



\subsection{Introduction ${ }^{1}$}

Considering the potential contributions of migrants and entrepreneurs to development ${ }^{2}$ and recognizing that migration and entrepreneurship are interlinked in more than one way, the attention paid to the role of migrant entrepreneurs has been increasing among policy-makers, donors, and other actors. Migrants are often hailed as 'super-entrepreneurs' with consequent high expectations for their role in business start-ups, job creation, and consequentially economic development.

However, discussions around the linkages between migration and entrepreneurship should be more nuanced for several reasons. Firstly, entrepreneurship and selfemployment are not the only possible labour market activity that migrants can engage in to generate an income and to contribute to development in both country of destination and country of origin. Secondly, the possible contributions to development of such activities depend largely on the context in which they are carried out. Finally, the term "migrant" as such is rather ambiguous and groups together a largely heterogeneous group of people. It may include a range of individuals from those moving with the specific purpose of investing in a business in the country of destination to those displaced from their place of origin.

From a policy perspective ignoring such factors may lead to the problem that policies regarding entrepreneurship and migration often do more harm to migrants and to development, than good. Naudé $(2010 b, 2011)$ has dealt with the relationship between entrepreneurship and development and growth, and the difficulties that well-meaning but poorly informed policies may cause. Not all entrepreneurs create sustainable or substantial jobs, most do not innovate much, and substantial numbers of firms fail after only a few years. In such a context of heterogeneity, policies are often ineffective; they may even have unintended and, sometimes, undesired outcomes.

At the same time, the debate on the economic development implications of migration is a long-standing and often emotional one. Within such discussions, the role of migrant entrepreneurs has also been highlighted and expectations for them are high. The problem is that this may mask and even exacerbate bad immigration policies. For instance, in justifying too much of a focus on attracting certain types of migrant

\footnotetext{
1 This chapter has been adapted from: Naudé, W., Siegel, M. \& Marchand, K. (2017). Migration, entrepreneurship and development: critical questions. IZA Journal of Migration, 6(5).

2 The linkages of migration and development as well as of entrepreneurship and development are briefly presented in Sections 2.3 and 1.2.3 of this dissertation respectively.
} 
entrepreneurs, or training return migrants to be entrepreneurs, rather than facilitating migrants' access to wage employment and the formal economy.

Furthermore, the role of entrepreneurship and other labour market activities in the context of forced migration is important in the light of the shift in the paradigm on refugees from relief to development (see Section 1.1). Recognizing the skills, motivations, and activities of refugees and their potential contributions to economies of host and home countries is at the centre of promoting the self-reliance of refugees. Policies limiting the right to move and access to the labour market within the host country may, however, be limiting possibilities for refugees to achieve such selfreliance (Zetter \& Ruaudel, 2016).

As it stands, the debate on the role of (forced) migrants in entrepreneurship and labour markets more broadly may therefore be based on a limited and inadequate understanding of migration and migrant entrepreneurs. Most of the literature to date focuses on cases of voluntary migration, largely in the context of advanced economies. Similar studies in developing countries, where displacement affects a relatively larger number of people, are rare.

The purpose of this chapter is to synthesise the existing evidence on the linkages between migration, entrepreneurship, and development. In addition, it highlights existing research gaps specifically in the context of forced migration.

In order to present the evidence in a structured manner, four questions on the linkages between migration and entrepreneurship are posed and answered using the existing literature:

1) Why are migrants likely to engage in entrepreneurship?

2) Are immigrants more entrepreneurial than natives?

3) Are remittances an important source of funding for entrepreneurship in migrants' home countries?

4) Are return migrants more likely to be entrepreneurial than non-migrants?

The discussion of the posed questions is presented in Section 2.2. In four sub-sections, the above questions are discussed in turn. Each of these sub-sections concludes with the identification of the specific research gaps that the four empirical chapters of this dissertation address. Then, in Section 2.3, given the answers to these questions, the potential impacts of migration on development are analysed in order to position the discussions around entrepreneurship in the wider migration and development literature. In Section2.4 the policy implications regarding the perception of migrants 
as 'super-entrepreneurs' are discussed, given that continued (forced) migration is likely to be a fact in many parts of the world. Section 2.5 concludes.

\subsection{Re-evaluating Stylized Facts: Critical Questions}

\subsubsection{Why Are Migrants Likely to Engage in Entrepreneurship?}

Within debates on migration and development, migrants are often expected to be 'super-entrepreneurs' who will benefit development in home and destination countries through their greater prowess as entrepreneurs, their remittances, their trans-national entrepreneurial activity, and their business acumen in general. Proponents of this view have pointed to the successes of migrant entrepreneurs in China and the United States to argue that migrants may not need formal wage jobs but are much better able to contribute through business activities. For instance it has been pointed out that in successful developing countries, such as China, 25 per cent of migrants are self-employed (Giulietti, Ning, \& Zimmermann, 2012). Saxenian (2002, 2007) and others have praised the role of immigrants in the development of Silicon Valley, where close to one third of the technology businesses were operated by immigrant owners by the end of the 1990s.

But why are migrant entrepreneurs seen as `super-entrepreneurs'? The main argument is based on selection. Migrant entrepreneurs may be less risk averse, as is evident in their decision to migrate, itself a risky activity (Neville, Orser, Riding, \& Jung, 2014). They have also been argued to be better able to spot opportunities for new businesses as they have already spotted opportunities for migration (Hart \& Ács, 2011). In addition, migrants are seen to have access to supplementary sources of support, training, and financing, as they often increase their educational level and/ or gain new skills, save more money, and extend their social network while living abroad (de Haas, 2006; Organisation for Economic Co-operation and Development, 2008).

More generally, an individual's decision to become an entrepreneur or not has been studied by economists as an occupational choice; in other words, the way time is distributed among different economic activities over the life cycle. Self-employment is only one possible occupational choice, next to, for example, wage employment or the allocation of time to activities that are not remunerated. This chapter, or rather this dissertation as a whole, do not aim to establish whether entrepreneurial activities are more viable economically than other possible occupational choices, but rather focuses on them due to their overall relevance in many developing country contexts (as discussed in Section 1.4.3). 
In empirically studying occupational choices, the evidence tends to suggest that the occupational choices of migrants are not significantly different from those of nonmigrants (see Section 2.2.2). Both migrants and non-migrants would be more or less likely to be entrepreneurs as a result of their individual characteristics (schooling, experience), household or community level factors (size of household, cultural background), institutional determinants (access to finance), and the business environment (Organisation for Economic Co-operation and Development, 2010). Based on existing evidence it therefore does not seem like migrant entrepreneurs face significant other challenges than non-migrants - apart from discrimination.

Migrant entrepreneurs, like migrants in general, suffer from various forms of discrimination (Jansen, de Kok, van Spronsen, \& Willemsen, 2003; Zhou, 2004). Bruder and Räthke-Döppner (2008) mention that migrants often face discrimination in formal labour markets, which then drives them into (necessity) self-employment. This can be due to structural discrimination (the need for a visa for example), taste discrimination (when employers prefer not to employ workers of a certain ethnicity due to, amongst others, racial or ethnic stereo-typing, and language barriers), and statistical discrimination (when employers and job seekers have asymmetrical information about their quality) (Bruder \& Räthke-Döppner, 2008).

Rising xenophobia has been found to push disproportionate numbers of migrants with limited English proficiency into self-employment in the United States (Mora \& Dávila, 2005). That discrimination and xenophobia foster self-employment amongst migrants is thus acknowledged. Hence entrepreneurship can be used as a way to circumvent these obstacles (Organisation for Economic Co-operation and Development, 2010) and for migrants to overcome social exclusion and integrate better with their host community (Constant, Shachmurove, \& Zimmermann, 2007), as well as a way to improve their socioeconomic mobility (Zhou, 2004).

A number of studies have attempted to quantify the impact of labour market discrimination on the occupational choices of migrants. In China, where legal discrimination, through for instance the Hukou system ${ }^{3}$, is well known, Frijters, Kong, and Meng (2011) find that if there would be no discrimination against migrants in urban China, the number of self-employed migrants would fall by 16 per cent, a

\footnotetext{
${ }^{3}$ China uses the Hukou system (Household Registration System) to regulate internal migration in the country. Introduced in 1958, Hukou requires every citizen seeking a change in residence to obtain permission from the public security bureau. Public benefits as well as access to schools, health care, and attractive employment opportunities are only available to those who are registered (Bao, Bodvarsson, Hou, \& Zhao, 2011).
} 
significant proportion. Thus, when they have a choice, migrants may often prefer wage employment to being self-employed. This conclusion is supported by the empirical patterns of migrant self-employment in the OECD countries showing mixed results in this regard (Organisation for Economic Co-operation and Development, 2010), as well as studies from e.g. Germany which find that it is more likely for less educated migrants to be self-employed than for higher educated migrants (Constant \& Zimmermann, 2006).

Migrants also face discrimination in consumer markets, which in turn creates a demand for the goods and services migrant entrepreneurs can provide, often in ethnic enclaves (Jansen et al., 2003). Hence, ethnic enclaves often act as a pull factor for migrants to enter into self-employment (Price \& Chacko, 2009).

Finally, migrant entrepreneurs themselves do face discrimination, especially when trying to gain access to finance (Zhang, 2008). Immigrants typically face more difficulties in obtaining credit than their native counterparts, especially forced migrants who have left all their assets and networks behind (European Commission, 2016; Wauters \& Lambrecht, 2008). In addition, immigrants often face language barriers as well as challenges relating to the administrative procedures involved in setting up a business (Fong, Busch, Armour, Heffron, \& Chanmugam, 2007; Lyon, Sepulveda, \& Syrett, 2007; Wauters \& Lambrecht, 2008). As a consequence, it is important to understand the situations in which migrants become entrepreneurs and in how far they do so because it is their desire versus it being one of few or even the only option.

The latter also specifically is an interesting point when looking into the labour market activities of forced migrants. Research suggests that gaining employment is often one of the priorities of those who have been awarded refugee status (Bloch, 2002; Cheung \& Phillimore, 2014; Lundborg, 2013), which in many cases is a requirement to gain the right to work in the country of asylum (Zetter \& Ruaudel, 2016). At the same time, evidence exists that refugees are systematically outperformed by natives, but also by other migrants on the labour market (Bakker, Dagevos, \& Engbersen, 2017; Connor, 2010). Reflecting that as well as the differences in migration motivations and experiences, refugee entrepreneurs may also possess different characteristics and motivations than other migrant entrepreneurs (Lyon et al., 2007; Wauters \& Lambrecht, 2008).

Analysing the motivations of refugee entrepreneurs in Belgium, for example, Wauters and Lambrecht (2006) find evidence that refugees also often enter into entrepreneurship out of necessity when they cannot find wage employment. But, 
refugee entrepreneurs also seek to explore entrepreneurial opportunities, especially when this is what they were doing in the home country before they left to find safety, often leaving a lot behind (Wauters \& Lambrecht, 2006).

The challenges that refugee entrepreneurs face in the process of setting up a business may be quite different than those of other migrants. They often arrive to the country of destination having spent much of their savings on the journey, having left any diplomas and other skill certificates behind, or facing challenges getting them recognized. In addition, social networks, which are crucial for the acquisition of business partners, suppliers and customers, may be lacking (Wauters \& Lambrecht, 2008). Overall, the difference in preparation and conditions of the migration experience may therefore lead to a different position in the labour market and especially self-employment for forced migrants versus those moving for economic purposes.

While existing research is largely applicable for formal labour markets in more advanced economies, entrepreneurship has also been found to be an important activity among refugee populations in developing country contexts (Betts et al., 2017; Werker, 2007). Refugees engage in self-employment activities, whether they reside in camp or urban settings. Many factors drive refugee entrepreneurship in those contexts, but the understanding of the role of businesses as a livelihood strategy of refugees is in its early stages and more research is therefore needed in this field (Betts et al., 2017).

Chapter 3 of this dissertation adds to the literature on this issue by addressing the research question: What are the patterns and determinants of refugees' labour market participation and in what ways do their economic activities differ from those of locals? Answering this research question, the analysis in Chapter 3 investigates the labour market activities of refugees from the Democratic Republic of Congo (DRC) that live in three distinct camps in Rwanda. Within this analysis, self-employment in business receives particular attention as other employment opportunities, especially formal wage labour, are limited in this context. The chapter therefore contributes to the literature on the likelihood of migrants to engage in entrepreneurship by exploring in how far refugees engage in self-employment to secure their livelihoods in such a context.

\subsubsection{Are Immigrants More Entrepreneurial Than Non-Migrants?}

Despite the a priori reasons described in the previous section for seeing migrant entrepreneurs as super-entrepreneurs, the empirical evidence for migrants being more entrepreneurial than natives is not strong. For instance, a recent OECD (2010) review 
finds that migrant entrepreneurship, measured by self-employment rates, is more common than non-migrant entrepreneurship in only 13 out of 25 countries in the OECD. In other words, in about half of these OECD countries, migrants are less likely than natives to be self-employed. Moreover, in the countries with larger immigrant populations, such as Germany, Italy, Spain, Switzerland, and the Netherlands, migrants are much less likely than natives to be self-employed (Organisation for Economic Co-operation and Development, 2010). In the case of migrants in Germany, Brixy, Sternberg, and Vorderwülbecke (2013) even find that migrants believe less often that they have the necessary skills to run a business and that they are not more risk averse than non-migrants. In the Netherlands, Jansen et al. (2003) find the rate of entrepreneurship amongst the native Dutch population as well as of the Turkish immigrant population to be almost twice as high as amongst immigrant populations from Morocco, Suriname, and the Dutch Antilles.

The only study to-date to compare start-up rates (early entrepreneurial activity) amongst migrants and non-migrants across countries is the 2012 Global Entrepreneurship Monitor (GEM). It finds that rates of early entrepreneurial activity are similar between migrants and non-migrants, and that start-up rates of migrants are just as heterogeneous across countries as those of non-migrants. For instance, the GEM finds that only 1.8 per cent of early entrepreneurial activity in Sub-Saharan Africa is undertaken by first generation migrants, while the corresponding shares are 11 per cent and 10 per cent in the USA and Western Europe respectively (Vorderwülbecke, 2013).

Self-employment per se may be a poor measure of entrepreneurship as many argue that what fundamentally characterizes entrepreneurs is their innovativeness, their 'creative destruction' to use Schumpeter's term. So how well do migrant entrepreneurs do in terms of innovation and growth? It has been pointed out that migrant entrepreneurs may be disproportionately represented, at least in the United States, amongst high-growth ${ }^{4}$ and highly innovative enterprises (Organisation for Economic Co-operation and Development, 2011; Saxenian, 2002; Wadhwa, Rissing, Saxenian, \& Gereffi, 2007) and biotech firms (Stephan \& Levin, 2001), as well as public venturebacked US companies (Anderson \& Platzer, 2006) and high-impact companies (Hart \& Ács, 2011). In addition, on average 20 per cent of migrant-owned enterprises in the

\footnotetext{
${ }^{4} \mathrm{~A}$ high-growth enterprise is defined as an enterprise whose sales grows by at least 20 per cent annually for three years and employs at least ten workers (Organisation for Economic Co-operation and Development, 2010).
} 
2012 GEM survey expected to create 10 or more jobs in the next five years, compared to only 14 per cent of non-migrant owned enterprises (Vorderwülbecke, 2013).

As far as innovation is concerned, around 16 per cent of high-tech firms in a recent sample from the United States had a migrant owner, and moreover a migrant owner with skills in science and engineering (Hart \& Ács, 2011). Hunt and Gauthier-Loiselle (2010), using United States patent data, find that "immigrants account for 24 [per cent] of patents, twice their share in the population, and that the skilled immigrant patenting advantage over natives is entirely accounted for by immigrants' disproportionately holding degrees in science and engineering fields" (Hunt \& Gauthier-Loiselle, 2010, p. 33).

Despite the clear contributions that migrant entrepreneurs have made to innovation in the United States, Hart and Ács (2011) cannot find evidence that migrant owned hightech firms are more likely to register patents or spend more on research and development than firms owned by natives. Supporting this point, the survey by Hart and Ács (2011) of high-tech entrepreneurship (the most innovative form of entrepreneurship) in the United States concluded that "most previous studies have overstated the role of immigrants in high-tech entrepreneurship" (Hart \& Ács, 2011, p. 116).

The 2012 GEM survey also attempted to measure the innovations of enterprises across 69 countries using the number of new products or services they introduced, considering whether the enterprises in question were owned by a migrant or nonmigrant. Analyses of the survey results could not find significant differences between the innovativeness of migrant and non-migrant entrepreneurs (Vorderwülbecke, 2013).

As a final measure of the entrepreneurial prowess of migrants, one may compare the average performance of migrant enterprises to that of non-migrants. Using performance measures such as sales growth and profits from new Canadian start-ups, Neville et al. (2014) find that migrant enterprises are not generally better performing than those of non-migrants and that very often immigrant-owned firms underperformed. Only in the case of migrant firms that export do they find superior performance, suggesting that these migrant firms may have better international networks. The usual suspects in firm performance such as experience, skills, gender, access to finance, and growth orientation were found to apply in equal measure to both migrant and non-migrant enterprises. Similarly, Dai and Lui (2009) find that in the case of China's Zhongguancun Science Park (ZSP) return migrants who export more, due to their international networks, performed better than non-migrants. 
Saxenian $(2002,2007)$ and others have argued that the development of high-tech sectors and innovation clusters in countries such as China, India, and Taiwan resulted due to the return migration of entrepreneurs (transnational entrepreneurs) from places like Silicon Valley and elsewhere in the USA. More recently Kenney, Breznitz, and Murphree (2013) challenged this interpretation, concluding from a historical overview of the creation and establishment of ICT industries in these countries that return migrants were not critical in their establishment. They conclude that the roles of native entrepreneurs and governments were more essential for the emergence and establishment of these industries than return migrants and that "[t]he importance of the returnees is more likely in [...] deepening home country industrial development and connections to the U.S. economy" (Kenney et al., 2013, p. 395).

Within the discussions about entrepreneurship among migrants and non-migrants, the distinction between opportunity and necessity entrepreneurship should also not be ignored. As described in the previous section, migrants may face discrimination in the labour market, which drives them into necessity self-employment activities (Bruder \& Räthke-Döppner, 2008). Moreover, in the context of many developing countries, wage employment opportunities may simply be limited, particularly in rural areas (Frese \& de Kruif, 2000). In such contexts, it is likely that natives are preferentially treated, leaving the migrants to be innovative and engaging in necessity self-employment activities.

This is also particularly important in the context of forced migration. While evidence exists that the establishment of refugee camps overall may have positive impacts on the local economy and creates employment opportunities (Ruiz \& Vargas-Silva, 2013), access to the local labour market is often limited for refugees. And even where they theoretically can work, administrative procedures and geographical factors often make it challenging (Zetter \& Ruaudel, 2016). Still, refugees around the world do engage in economic activities, and evidence has shown that it is often in situations were faced with significant constraints that refugees find innovative solutions to help themselves and others through small, usually informal, business operations (Betts, Bloom, \& Weaver, 2015; Bloom \& Betts, 2013).

As mentioned in the previous section, Chapter 3 of this dissertation analyses the labour market outcomes of Congolese refugees in refugee camps in Rwanda. While the focus is on the refugee population, their activities are also seen in comparison to those of locals living around the camps in response to the second part of the first research question of this dissertation: What are the patterns and determinants of refugee's labour 
market participation and in what ways do their economic activities differ from those of locals?

\subsubsection{Are Remittances an Important Source of Funding for Entrepreneurship in Migrants' Home Countries?}

In the new economics of labour migration (NELM) the decision to migrate is not seen as a decision an individual makes, but a decision that is taken at the household level to deal with risks, market imperfections, and other obstacles in their environment. If, for instance, a lack of liquidity and/ or poorly functioning financial markets obstruct households to establish business enterprises, migration of some family members and their remittances may be a way of overcoming these financial constraints, making it possible for them to invest in agricultural innovations, land and housing, as well as small businesses (Lucas \& Stark, 1985).

The literature on the impact of remittances on development, however, contains controversial findings. On the one hand, there exists a somewhat pessimistic view of the role of remittances, recognizing negative effects such as moral hazard (Chami, Fullenkamp, \& Jahjah, 2005) as well as exchange rate appreciation, and reduced export competitiveness (Amuedo-Dorantes \& Pozo, 2004; Bourdet \& Falck, 2006). On the other hand, a more optimistic view emphasizes that remittances can contribute to household expenditure, consumption smoothing, and poverty reduction (Acosta, Fajnzylber, \& Lopez, 2007; Adams, 2006). Remittances can also raise household spending on, for example, education (Acosta et al., 2007; Cox Edwards \& Ureta, 2003), and health services (Hildebrandt \& McKenzie, 2005; Mansuri, 2007).

In addition, part of remittances that are received by households may be used for savings or investments (de Haas, 2005). Related to this, Giuliano and Ruiz-Arranz (2009) show that in some countries with underdeveloped financial systems remittances are used to overcome credit and liquidity constraints and are invested into small business development. They find that in contexts where the development of the financial sector is lower the contribution of remittances to economic growth is stronger (Giuliano \& Ruiz-Arranz, 2009).

The empirical evidence on the effectiveness of remittances to encourage entrepreneurship in migrant sending countries is, however, also mixed. For instance Amuedo-Dorantes and Pozo (2004) show that in the case of the Dominican Republic receiving remittances does not lead to an increased likelihood of owning a business, but rather the opposite. Remittance receipt is associated with a reduced likelihood of 
business operations. It has also been observed that households, who already operate a business, are more likely to receive remittances from abroad in this case (AmuedoDorantes \& Pozo, 2004). Along the same lines, Vasco (2013), studying migration and remittances in the case of rural Ecuador, finds that "neither migration nor remittances have any effect on the odds of a household owning a rural business" (Vasco, 2013, p. 37). Ang, Jha and Sugiyarto (2009) also do not find a significant effect of remittances on productive investments in the Philippines.

In the case of Mexico, on the other hand, remittances have been found to be a significant source of capital for micro-enterprises (López-Córdova \& Olmedo, 2006). Investments in businesses are increasingly seen in Mexican households and communities receiving remittances from the United States (Massey \& Parrado, 1998). Woodruff and Zenteno (2007) also find that small and medium enterprises in Mexico benefit financially from having links to migrant networks in the United States and that in the case of high-tech firms they grow faster as a result, suggesting that migrant networks can alleviate financial constraints. In the case of Nicaragua, Funkhouser (1992) establishes that remittances have a small positive effect on self-employment in receiving households. In El Salvador, in contrast, remittances did not seem to impact self-employment activities in a household survey conducted in 2000. International remittances were, however, significantly and positively associated with business ownership. These effects were particularly strong in rural areas and among females (Acosta, 2007).

Yang (2008) estimates the responses of Filipino households to economic shocks in the destination country of migrated household members. He shows that a positive shock leads to increased levels of investment in entrepreneurship in the origin households. Vaaler (2011) finds evidence that remittances support venture capital funds and firm start-ups in home countries, especially when they come from migrants living in migrant communities abroad. The effects decrease when the remittances are sent by highly educated migrants (Vaaler, 2011).

Besides the direct use of remittances for business investments, remittances might also indirectly contribute to the ability of a recipient household to engage in business activities. A stable remittance income may be considered a positive attribute in the evaluation of creditworthiness of a household when it comes to accessing microloans or small business loans (Ratha, 2007). Especially in contexts where households face high income volatility and shocks otherwise, remittances can also favour income smoothing and as such make households more attractive borrowers (Ratha et al., 2011). 
Overall, however, most of the literature on remittances seems to concur that remittances are largely used to fund consumption (de Haas, 2010), which is not necessarily a bad thing for households in developing countries (Yang, 2011). Whether remittances are used for business investments and self-employment activities is highly dependent on the context as is shown by the mixed evidence on the relationship between the two. It seems that it matters where the remittances come from, where they go, and who is then responsible for the way they are used in the receiving household. As such more research is necessary in order to really understand the interactions between remittances and entrepreneurship and to establish under what conditions migrant remittances are likely to fund entrepreneurship in their home countries, including in (post-) conflict contexts.

Chapter 4 of this dissertation investigates the relationship between migration and the self-employment activities of non-migrant household members, where remittances are one possible channel through which the two may be linked. More broadly, the chapter addresses the research question: How are self-employment activities of non-migrants shaped by the forced or voluntary migration experiences of household members? The case studies of Afghanistan, Burundi, Ethiopia, and Morocco are used in the chapter and present a diversity of different labour market and migration contexts to investigate this question, including (post-) conflict contexts, on which less evidence on the use of remittances for productive investments exists.

\subsubsection{Are Return Migrants More Likely to Be Entrepreneurial Than Non- Migrants?}

While there is a growing literature on the development impacts of the rising flows of remittances to developing countries, it is only fairy recently that attention has been paid to the potential of return migrants to contribute to development by, for example, starting up enterprises in their home countries. The recognition of the potential of return migrants reflects the greater awareness of the fact that most migration is not permanent, but temporary (Mesnard, 2004).

This potential lies in the fact that migrants may learn while away from their home country or region, as well as gather savings and build foreign networks, all of which may alleviate constraints on starting a new enterprise upon return (Marchetta, 2012; Rapoport, 2002). However, while abroad, migrants may also lose contact with their networks at home and hence experience a depreciation of their social capital, which may in turn make it more difficult to establish a new enterprise once back in the country of origin. Accordingly, one may expect return migrants to be more likely to be 
able to start up new firms than non-migrants in situations where credit constraints and a lack of skills and experience are obstacles to entrepreneurship in developing countries, and social capital is not as crucial (Wahba \& Zenou, 2012).

How valid is this expectation? Black and Costaldo (2009) report that the literature does not unambiguously support it and, moreover, that the types of businesses started up by return migrants most often do not have a significant development impact. Gibson and McKenzie (2012) find micro-economic evidence from five developing countries that return migration is common, and that although return migrants share gained knowledge, they are not more productive as entrepreneurs or in wage labour back home than non-migrants.

Looking at further evidence, there are several studies investigating differences in entrepreneurial activities between return migrants and non-migrants. The most common finding of this literature relates to financial capital, and more specifically the role of savings accumulated abroad in the launch of a small business upon return. For instance, both Arif and Irfan (1997) and Piracha and Vadean (2010) find strong indication that return migrants are more likely to be self-employed in business in comparison to non-migrants in Pakistan and Albania respectively. Using data from Ghana and Côte d'Ivoire, Black and Costaldo (2009) find that return migrants are more likely to start a new enterprise if they had accumulated savings and stayed abroad longer. This trend was found to be stronger among poorer migrants.

Black and Castaldo (2009) also find any formal education received by migrants while abroad to be insignificant for the entrepreneurship decision once they have returned. Similar results were obtained for Bosnia-Herzegovina, Bulgaria, Georgia, the Kyrgyz Republic, Romania, and Tajikistan by Lianos and Pseiridis (2009) and by McCormick and Wahba (2001) for Egypt. Ilahi (1999), Dustmann and Kirchkamp (2002), and Mesnard (2004) arrive at similar conclusions showing migrants returning to Pakistan, Turkey and Pakistan as being particularly prone to invest savings from abroad in business ventures back home, suggesting temporary migration may at times be employed as a strategy to overcome credit constraints faced in the country of origin.

In the case of rural to urban migration in China, Démurger and $\mathrm{Xu}$ (2011) find that return migrants were more likely than non-migrants to start up an enterprise and that the likelihood of this was enhanced by the amount of savings accumulated and the experience gained as measured by the frequency of job changes. Also for China, Giulietti, Wahba, and Zimmermann (2013) find that return migrants are not only more likely than non-migrants to start up a business, but that that they also promote entrepreneurship amongst family members who did not migrate, suggesting that 
knowledge and experience may be skills required in China's rural areas to stimulate entrepreneurship.

Wahba and Zenou (2012), using migration data from Egypt, also find that experience, savings, and duration abroad matter, and that the loss of social capital due to being out of the country does not outweigh the benefits of finance and experiences in starting up a business. Their evidence indicates that return migrants could indeed be more likely to become self-employed; however, they do recognize that the decision of a migrant to return could be a decision made simultaneously to that of becoming an entrepreneur, which would upwardly bias the propensity of return migrants to be found in entrepreneurship; they find evidence of such an upward bias in their data (Wahba \& Zenou, 2012). Similar evidence of bias, and of the simultaneity in the decisions to migrate and become entrepreneurial, is found by Batista, McIndoe-Calder, and Vicente (2017) in the case of return migration to Mozambique.

Problems faced by studies into the occupational choice of return migrants and the probability that they enter into entrepreneurship are caused by this endogeneity and simultaneity in the decisions to migrate and to start a new enterprise, and due to the fact that the total population of return migrants is not identifiable. Little has been done in the way of controlled (or natural) experiments and properly matched panel data is still scarce, although a number of studies have used bivariate probit models and instrumental variable methods to deal with endogeneity issues. As a result of these shortcomings and given the relatively few studies on the topic, a recent survey on migration and development concluded that there is still much scope for further research on the determinants and impacts of return migration and entrepreneurship (Gurgand, Lambert, Rapoport, \& Zenou, 2012).

A specific gap in the understanding of the relevance of entrepreneurial activities for return migrants relates to the group of returned refugees. Besides a possible deterioration of skills during displacement due to economic inactivity or underemployment (Hainmueller, Hangartner, \& Lawrence, 2016; Zetter \& Ruaudel, 2016), migrants returning to countries that have been experiencing conflict, often face particularly difficult employment conditions due to the potential effects of conflicts on labour markets and infrastructure (Stewart, 2015). At the same time, incomegenerating activities are the basis of a sustainable livelihood, which in turn is one of the factors contributing to sustainable reintegration in the home country (Black \& Gent, 2006). The understanding of the labour market reintegration of those displaced by violence and persecution is, however, limited at this point. 
Chapter 5 of this dissertation adds to the literature on this issue by addressing the research question: To what extent do forced migration experiences shape the labour market reintegration of returned refugees in a (post-) conflict developing country context? The analysis addressing this question investigates the labour market reintegration of returned refugees in the context of Afghanistan.

Chapter 6 of this dissertation addresses the question: What is the relationship between forced migration experiences and engagement in non-farm household business activities in a rural (post-) conflict developing country context? In a context characterised by a series of violent conflict and resulting displacement, the role of forced migration experiences, both within Burundi as well as across borders, is the focus of the analysis of patterns and determinants of entrepreneurial activities.

\subsection{Does Migration Matter for Development?}

With the focus of this chapter on the linkages between migration, entrepreneurship and development, it is important to take a step back and look at the linkages between migration and development more generally because (migrant) entrepreneurship is but one possible channel. De Haas (2010) provides a critical overview of the literature on migration and development and shows that this body of work has vacillated between pessimism and optimism over time. Based on the neoclassical theory of migration, opinion in the 1950s and 1960s was that migration had a generally positive impact on development reflecting a virtuous circle of labour mobility that would eventually even-off in the long-term (Castles, 2009). The Lewis and Harris-Todaro models, for example, assume emigration from low productivity areas to be essential for rising productivity (Harris \& Todaro, 1970; Lewis, 1954).

This view changed in the 1970s and 1980s, when migration became more widely seen as being part of a vicious circle of under-development, which widened the gap between core and periphery countries. Migration was blamed for maintaining economic dependencies between developed and developing countries by causing a brain drain from poor to rich economies. However, before the recent rise in immigration to Europe (mainly as a result of conflict in the Middle East and Eastern Africa) the pendulum had started to swing back towards a more positive assessment of the development impact of migration, with notions of a brain gain being modified to account for brain circulation (Docquier \& Rapoport, 2012; Mountford, 1997; Saxenian, 2007). 
Recent theorizing on migration and development is based on the New Economics of Labour Migration (NELM) and livelihood approaches more generally (de Haas, 2010), which take a more holistic view of migration and development. Different aspects of migration, such as the role of diasporas ${ }^{5}$, have surfaced and migrants are seen as potential agents of development, leading to more nuanced research. For instance, migration has been established to have brain drain effects only for some of the poorest countries (Beine, Docquier, \& Rapoport, 2008; Di Maria \& Stryszowski, 2009). In addition, new evidence suggests that emigration of highly skilled individuals has substantial benefits, mainly for "the migrants themselves, who benefit through massive gains in income and through greater human capital" (Gibson \& McKenzie, 2012, p. 371).

Migration has also been found to contribute to raising living standards of those left behind (Acosta, 2007; Adams, 1991, 2004, 2006; Adams \& Page, 2003, 2005; Itzigsohn, 1995; Taylor, Mora, Adams, \& Lopez-Feldman, 2005) as well as increased human capital, brain gain, and better return to human capital investments (Mountford, 1997; Stark \& Wang, 2002).

The role of remittances has been the subject of special scrutiny given their sheer volume. ${ }^{6}$ Remittances have significant welfare impacts on countries with high volumes of emigration, for example Jamaica and El Salvador (di Giovanni, Levchenko, \& Ortega, 2015); although this is more the case when low-skilled individuals migrate than in the case of higher-skilled migrants, who tend to remit less in per capita terms than low-skilled migrants (Adams, 2009). ${ }^{7}$ Remittances can also facilitate increases in household spending on education (Acosta et al., 2007; Cox Edwards \& Ureta, 2003), health services (Hildebrandt \& McKenzie, 2005; Mansuri, 2007) and savings or investments (de Haas, 2005). There is, however, no conclusive evidence that remittances unambiguously promote macro-economic growth (Yang, 2011).

Others have argued that emigration does not only lead to higher levels of trade (Egger, von Ehrlich, \& Nelson, 2012; Fairlie \& Lofstrom, 2013; Rauch \& Trindade, 2002) and

\footnotetext{
${ }^{5}$ Diasporas are "groups of emigrants who leave their countries of origin for a prolonged period of time but still demonstrate a strong link with their migration history and a sense of co-ethnicity with others of a similar background" (Kotabe, Riddle, Sonderegger, \& Täube, 2013).

${ }^{6}$ Migrant remittances are estimated to have a volume of more than US dollar 400 billion annually (more than four times the volume of official development assistance) (World Bank, 2017b).

7 It is also the case that middle-income countries receive more remittances per capita than low-income countries (Adams, 2009), and the countries with the most sizable amount of remittances are the most populous emerging economies namely India, China, Mexico, the Philippines, and Nigeria (Yang, 2011).
} 
foreign direct investment (FDI) (Kugler \& Rapoport, 2011) to developing countries, but also contributes to potential changes and development in the home country through 'social remittances'. "Social remittances are the ideas, behaviours, identities, and social capital that flow from receiving- to sending-country communities" (Levitt, 1998, p. 927). They can be transferred to the origin country through modern communication methods such as telephone, internet and mail, through migrants' temporary return visits to their origin country, or through permanent return. Migrants transfer their knowledge and skills to family members or friends living in the origin country and this knowledge can then be utilized by individuals or households in the home country.

In this context, Docquier et al. (2016) and Spilimbergo (2009) show that in some contexts a relationship exists between the level of emigration and political developments in the home country. Migrants can contribute to the diffusion of democratic values and norms either directly upon return or through contacts with relatives, or indirectly through social networks connecting the diasporas with groups in the origin country (Docquier et al., 2016). Some have even argued that return migrants can increase the demand for political accountability and so improve governance in their home countries (Batista \& Vicente, 2011). However, the opposite can also hold; Stel (2013) for instance finds in the case of the Lebanese diaspora, migrants often play an active role in entrenching political power in their home country.

It is important to note that research on the impacts of migration on development conducted so far, seems to focus mostly on labour migration and that for the most part in the context of migration movements from the Global South to the Global North. As such, one may say that the current understanding of migration and development is biased towards such movements and lacks the same level of understanding on dynamics in the context of south-south movements as well as forced migration movements. However, the emerging academic and policy literature on migration and development in conflict- contexts does highlights the potential of migration to contribute to economic development, reconstruction, and even peace building (Fransen, 2015). Both the role of remittances (see, e.g., (Feeley et al., 2013) and return migration (Nyberg-Sørensen, Van Hear, \& Engberg-Pedersen, 2002) in such contexts have attracted increased attention in this regard in the past years, but the role of entrepreneurship specifically and labour market participation more generally is not yet well understood.

To conclude this section, it can be stated that even though migrant entrepreneurs are not super-entrepreneurs, migration as a process can positively impact on development in both sending and receiving countries through many other channels. The 
entrepreneurial behaviour of migrants and migrant households is only one of the channels through which migration may affect economic growth. Because economic growth and development in themselves affect entrepreneurship (entrepreneurship is endogenous to development) this has to be considered in policies that aim to maximize the potential of migrant entrepreneurs. In the following section we discuss how policies for migration and migrant entrepreneurship may be improved.

\subsection{Policy Implications: Can Migrant 'Super-Entrepreneurs' be created?}

Migration has the potential to contribute to development, but not all individuals and all countries benefit automatically from migration: there is much country and individual heterogeneity in migration-development outcomes. In this respect, de Haas (2010) has cautioned against simplified assumptions about the relationship between migration and development. He points out that there "is no automatic mechanism by which international migration leads to development" (de Haas, 2010, p. 240). This means that policies may matter very much in migration and, moreover, that migration policies may do much harm to development by distorting outcomes. Because of the nature of the public and policy debates on migration (characterized very often by a high degree of subjectivity), the need for an automatic mechanism of development through migration has concentrated attention in recent years on the role on migrants as entrepreneurs and facilitators of entrepreneurship.

As discussed in Section2.2.1, not all migrant entrepreneurs choose this path and as such may be very vulnerable to external shocks when they are in entrepreneurship due to a lack of access to wage employment (Brixy et al., 2013). In other words, they are necessity entrepreneurs (Constant \& Zimmermann, 2006). Moreover, they often have access only to types of businesses, e.g. in trade and services, which are more exposed to external economic shocks (OECD, 2010). The GEM study could not find evidence across 69 countries that migrants are more likely to be necessity entrepreneurs than non-migrants (Vorderwülbecke, 2013). This does, however, not mean that it is not the case; certainly the finding that migrant entrepreneurs often perform worse than nonmigrants may suggest they indeed face more difficulties (Neville et al., 2014).

It should also be stressed that a selection of migrant entrepreneurs occurs before migrants even enter the host country. As the link between migration and entrepreneurship receives more attention by policy-makers, a growing number of countries are introducing specific policy measures for this group. As immigrant 
entrepreneurs are a heterogeneous group running different types of businesses, policies should ideally be equally diverse in order not to exclude potential future entrepreneurs (Collins, 2003). However, considering policies currently implemented, it is evident that the diversity of this population is not addressed. While overall the share of immigrants entering a country on an entrepreneur visa is relatively small, the bulk of immigrant entrepreneurs does not qualify for this type of visa, likely due to a lack of capital and experience, and usually enters the country through another channel. Some of these migrants might still come with the intention of starting their own business.

Particularly among highly skilled immigrants there may also be people with high entrepreneurial ability. In some cases, however, policy hinders the implementation of entrepreneurial activities. Migrants entering on a work visa, for example, may not be allowed to start a business while on this specific visa. This may be a waste of their potential contribution to the local economy. An example from the Netherlands is that of 'knowledge migrants' who were only allowed to work for their current employer. They were, on the other hand, not allowed to start their own business next to this employment while on a knowledge migrant visa; They would have to switch to a different type of visa to start their own company. At the same time, it is, for example, common for academics to start their own (consultancy) business next to their University work; this type of entrepreneurship was then restricted in the case of the Netherlands (Marchand \& Siegel, 2014).

When looking at return migrants and entrepreneurship it can be observed that policies and programmes are also sometimes developed based on overly positive assumptions. An example of this is the fact that increasingly voluntary return programmes, designed for migrants unwilling or unable to stay in the country of destination, contain entrepreneurship components of different format. Some simply provide in-kind or financial support, while others also offer training. The fact that this support is often given to people with no prior experience in running a business and maybe even no interest in doing so, can in this context be seen as a form of positive discrimination. It is, however, the case that evaluations of such programmes are largely lacking. In order to increase the efficiency and effectiveness of such programmes, more evidence is therefore needed.

Overall it can be seen that there are several factors that on the one hand drive migrants into entrepreneurship, such as the discrimination on the labour market, while on the other hand, access to finance and policies often hinder potential entrepreneurs to put their plans into action and play the role that many expect of them. Other policies and 
programmes drive migrants into entrepreneurship that are not necessarily suited for this. Seen altogether, this highlights the need for more sensitive policy development, which requires a wider evidence base on the linkages between (forced) migration, entrepreneurship, and development.

\subsection{Concluding Remarks}

Migration can be an important mechanism for raising the welfare of individuals and households in both sending and receiving countries. One way is through the entrepreneurial activities of migrants and their families. Based on the theoretical notion that migrants, like entrepreneurs, tend to be less risk averse they are often seen as 'super-entrepreneurs'. In this chapter it is argued that the discussion on the linkages between migration and entrepreneurship need to be more nuanced. Doubt is casted on four stylized facts or beliefs on migration and entrepreneurship namely that (1) migrants are particularly prone to engage in entrepreneurship; (2) migrants are more entrepreneurial than natives; (3) migrant remittances can fund start-ups in the countries of origin; (4) return migration can bring valuable entrepreneurial skills to developing home countries. None of these assumptions are substantiated fully by evidence.

In fact, the evidence is mixed on the question whether immigrants are more likely to be self-employed than natives as well as whether immigrant entrepreneurs outperform their native counterparts. For policies to indeed support the promotion of migrant 'super-entrepreneurs', policy-makers and scholars need to first better understand the broader relationship between migration and development, and entrepreneurship and development, as this indicates that migrants often make a more substantial contribution to development not as entrepreneurs, but as employees, and that the success of those who do select into entrepreneurship do depend critically on the state of the economy (-ies) in which they are embedded.

In this respect it needs to be reiterated that immigrants may face discrimination in their destination country. This may either prevent potential entrepreneurs from actively pursuing business activities or drive immigrants into necessity entrepreneurship that may otherwise prefer wage employment. Non-discrimination policies, addressing stereotyping and prejudging of immigrants, would be beneficial in order to ensure maximization of productivity and the contributions of migrants to the local economy. It is also important to note that not all discrimination stems from active resistance against foreigners. Often immigrants face language barriers, challenges relating to the administrative procedures involved in setting up a business, as well as difficulties in 
obtaining credit. This type of bias against migrant entrepreneurship is more difficult, although not impossible, to address with policy. It should for instance consider that if migrants need to re-build their collateral and assets, and invest in the local economy, that a long-term vision and commitment to the host country is needed. Without longerterm residence permits and integration measures this is unlikely to happen though, highlighting an incoherence of policies.

Furthermore, given that migrant entrepreneurs have not been proven to be superentrepreneurs in this chapter and given that there is a significant demand for lowskilled workers in most advanced economies, particularly in Europe (de Haas, 2008) (including a structural demand for more workers in general, given declines in population growth ${ }^{8}$ ), imposing policies based on the view of migrants as 'superentrepreneurs' is likely to be sub-optimal. The costs of misunderstanding the potential of migrant entrepreneurs, or raising immigration barriers, and of not doing more to allow their integration into wage employment, is thus likely to be costly.

In conclusion, the message of this chapter is that not all migrants are entrepreneurs and that different kinds of migrants are much more likely to end up in entrepreneurship, with different success rates. More research along these lines is therefore necessary, so that the dialogue is not so much on migration and entrepreneurship, but rather on, for example, highly skilled migrants and entrepreneurship, forced return migrants and entrepreneurship, or immigrants and necessity versus opportunity entrepreneurship. Different kinds of migration as well as different kinds of entrepreneurship ultimately also have different implications for development in diverse contexts.

Further research along these lines is therefore needed in order to fully understand the dynamics guiding the interactions between migration, entrepreneurship, and development. This dissertation contributes to this by focusing specifically on forced migration, labour market participation, and entrepreneurship in the context of developing countries by addressing the four research questions posed in the introductory chapter of this dissertation in the four following empirical chapters as well as the concluding one.

\footnotetext{
8 Some regions, such as Europe, will have to enter into a "global race for talent" (Münz, 2014). Chamie (2013) has mentioned that in 76 countries populations will go into decline without immigration. They face the choice of "more immigrants or fewer citizens", and include countries such as Germany, Japan and Russia who need respectively 200,000, 230,000 and 350,000 immigrants every year to maintain their population sizes, much more than the current inflows.
} 



\section{Chapter 3: LABOUR MARKeT ACTIVITIES OF CONGOLESE REFUGEES IN RWANDA}





\subsection{Introduction}

Settling and earning a livelihood in the destination country is an extremely challenging process for many forced migrants (Yakushko, Backhaus, Watson, Ngaruiya, \& Gonzalez, 2008). Hurdles they face include overcoming legal, social, and economic challenges, traumata, as well as seeking employment and navigating careers after leaving their home country, often rushed and leaving most belongings behind (ColicPeisker \& Tilbury, 2006).

While social scientists have long considered the way in which migration from one country to another may influence an individual's job prospects and eventual choice of employment (Castles, de Haas, \& Miller, 2014), the scope of such a research agenda has been limited for the most part to voluntary, economic migration towards Western Europe and North America. These studies generally find that migrants often have worse outcomes than natives in terms of unemployment (Fleischmann \& Dronkers, 2010; Jean, Causa, Jiménez, \& Wanner, 2010) due to discrimination and other challenges related to finding suitable employment (for a more elaborate discussion of this please refer to Chapter 2 of this dissertation).

Herein, refugees, in contrast to labour migrants, present a group with particular challenges, often facing legal restrictions and/ or administrative hurdles, when trying to gain access to the labour markets of destination countries (Zetter \& Ruaudel, 2016). Nonetheless, only a few scholarly works, in comparison, have focused on how forced migration relates to labour market outcomes, particularly in low income countries. Only recently has literature emerged on refugees and their labour market activities and impacts in countries such as Jordan, Lebanon, and Turkey in the light of the refugee movements resulting from the crisis in Syria (Del Carpio \& Wagner, 2015; Fakih \& Ibrahim, 2016; Kattaa, 2016; Turner, 2015).

Taking into consideration the rising trend of forced migration as of late which most immediately impacts those countries neighbouring active conflict zones, especially also in Sub-Saharan Africa, more research in this area is particularly opportune. Refugee camps are an important protection mechanism for forced migrants and the conditions in and around such camps unavoidably shape the lives of their residents. It is important for policy-makers and practitioners to understand the opportunities found and challenges faced by refugees that reside in camps in terms of accessing the local labour market. Only if this understanding is provided can it be ensured that support is provided where necessary and in appropriate ways to enable refugees to sustain their livelihoods and to ultimately achieve self-reliance. 
With this in mind, this chapter contributes to the literature by investigating conflictinduced forced migration and labour market activities using the case study of Congolese refugees residing in Rwanda. This is in line with the first research question posed in the introduction of this dissertation: What are the patterns and determinants of refugees' labour market participation and in what ways do their economic activities differ from those of locals?

Rwanda has hosted refugees, among others, from the neighbouring Democratic Republic of Congo (DRC) for decades; and Congolese refugees continue to arrive due to the on-going conflicts in the DRC. Using data from a newly collected household survey and focus group discussions, differences in employment status between the refugees living in three distinct refugee camps (Gihembe, Kigeme, and Kiziba) and local Rwandans in communities surrounding these camps are analysed. In regard to the latter, it is important to mention that the purpose of this chapter is not to analyse the effects of hosting the refugees on the local population or the interactions between both groups. Refugees may compliment or substitute the local population; however, these dynamics are not at the focus in this analysis, which aims to provide insights into the determinants of the labour market activities of the refugees.

The results show that unemployment is indeed a significant problem for the Congolese refugees. Considering that the majority of locals work in agriculture, which requires access to land that refugees do not have, this is not surprising. Wage employment opportunities outside the camps are limited, specifically for refugees, for which a limited number of jobs within the camps is provided by international or nongovernmental organizations next to some opportunities with private employers.

The analysis further shows that females a have higher likelihood to be engaged in selfemployment than their male counterparts for both groups, but even more for refugee women. This is likely due to the fact that the majority of opportunities that are available are in manual labour such as casual agricultural work or construction. Furthermore, the household composition and the position of an individual within the household seems to matter for occupational choices of its members. This reflects the responsibility refugees often have not only for themselves but for other household members, specifically in the case of household heads and those caring for more dependants. In addition, a higher level of education seems to increase the likelihood of unemployment for both locals and refugees.

Regarding location, the analysis shows that there are differences in the labour market activities across the three camps and surrounding areas. Agriculture, which is the most significant activity type for locals overall by far, is less common around Gihembe 
compared to the other two locations. This is likely due to the fact that Gihembe camp is the one camp that is close to an urban centre. However, unemployment remains the main concern for refugees in all three camps and as such the economic independence and self-reliance of refugees in this context remains a challenge.

The remainder of the chapter proceeds as follows. In Section 3.2, a review of the literature is provided on the economic lives of refugees and factors impacting this. Next, the background on Congolese refugees in Rwanda and their rights to move and work is presented in Section 3.3, before introducing the data and methodology of this chapter in Section 3.4. Sections 3.5 and 3.6 present descriptive and analytical results respectively. Finally, Section 3.7 concludes with a summary of the main results.

\subsection{Relevant Literature}

In recent years increased attention has been paid to the livelihoods and self-reliance of refugees especially by practitioners in the field of refugee protection. This is a result of the fact that protracted refugee situations are becoming more common and most often affect host countries that have limited resources to support refugees in the first place (Martin, 2016; Milner \& Loescher, 2011). Consequently, there has been a renewed interest in refugees' economic lives. Still, a review of the literature shows that the understanding of these issues is still limited (Betts et al., 2017; Zetter \& Ruaudel, 2016).

Recognizing that refugees are subject to different infrastructure-related factors than locals or other migrants, Betts et al. (2017) recently developed a framework grouping refugee economies into three categories: urban, protracted camp, and emergency camp. This classification makes clear that the economic lives of refugees are diverse and that they are largely affected by the context in which they live. Urban refugees, for example, have an extremely different set of opportunities and constraints than do those living in camps. In addition, the conditions in camps usually change over time.

Aside from infrastructure, regulations and authorities also help shape the labour market activities of refugees and differ significantly depending on the particular situation. In their research, the authors find that urban refugees are most similar to locals with respect to conditions and activities, in contrast to those refugees in emergency camp situations where the institutional context is the furthest from that of locals living in the same area. Protracted camp situations are between these two extremes (Betts et al., 2017) and are most relevant in the context of this chapter.

In terms of self-reliance, the major challenge that many refugees in protracted camp situations face is the fact that in most cases the level of humanitarian assistance 
provided decreases significantly after some years and the assistance provided is much smaller than it was in the first years after originally settling in the camp (Crisp, 2003). It is in such situations that refugees are often left with few income-generating opportunities and are driven into necessity entrepreneurial activities in the context of the camps and surrounding communities, which enable them to satisfy their daily needs (Betts et al., 2017).

Research into the conditions that shape the economic lives of refugees has shown that there are a variety of factors influencing their labour market participation. One recurring theme is that of social networks, both for self-settled and camp refugees. The networks in which refugees are embedded influence their economic lives in many ways with respect to consumption, trade, and access to the labour market (Betts et al., 2017; Buscher, 2013). These networks are specific to the individual and the context in which they are living and often consist of local, national, as well as transnational linkages (Monsutti, 2005; Porter et al., 2008).

In the immediate local environment, networks with refugees from the same country have been found to increase employment chances as well as access to credit (Amisi, 2006; Grabska, 2005). For example, refugees from Sudan in Cairo often find jobs with Egyptian-Sudanese business owners that have a preference for hiring this particular population (Grabska, 2006). In situations where refugees from different origin countries live in the same place, Betts et al. (2017) find that refugees also engage economically across nationalities.

While social networks of refugees from the same or different countries of origin are shown to be influential, networks that include locals are also of importance for the economic engagement of refugees. Indeed, most refugees do not live isolated from their surroundings. Particularly in the case of refugee camps that exist for decades, interactions between refugees and locals are common. People as well as goods move between the camps and surrounding areas (Ranalli, 2014; Werker, 2007) and generally relationships between camp residents and surrounding communities develop over time. Refugees search for employment in local communities and locals go into the camps to look for employment opportunities. In addition, goods are sold and/ or traded between the groups and, in some instances, refugees and locals even link up and engage in business together (Betts et al., 2017; Phillips, 2003). Furthermore, evidence exists that some refugees manage to establish and strengthen trade and business links that go beyond the immediate camp surroundings, such as Somalis in Kenya who have built trade links between camps and the capital Nairobi (Pavanello, Elhawary, \& Pantuliano, 2010). 
As may further be expected, the location of refugee camps is equally important to consider in terms of the impact that the respective local context and infrastructure has on the economic lives of refugees. Camps are often far from cities in relatively unpopulated areas of the host country. This offers very different opportunities to the refugees living there in contrast to urban refugees, who are more likely to have access to already existing economic structures. In contrast, refugees in camps may be more likely to have access to land for agricultural activities in cases where such land is available in the camp environment (Bakewell, 2014). At the same time, a lack of opportunities and services in the camp surroundings can also be an incentive for refugees to set up their own businesses, addressing the needs of the camp community (Dick, 2002; Omata, 2013; Porter et al., 2008). Therefore, while the local context does matter for the labour market outcomes of refugees, the potential effects are varied.

As mentioned previously, policies also influence the economic lives of refugees by enabling or restricting their economic activities. Besides the impacts on the refugees, it should be mentioned that such policies also have the potential to impact the economy of the host country in various ways (Zetter \& Ruaudel, 2016). Like all workers, refugees can engage in the formal or informal job market, the latter meaning work without legal permission as well as protection. And unsurprisingly the likelihood of engaging in the informal sector increases significantly in the presence of restrictions on the right to work for refugees (Jacobsen, 2002).

Nonetheless, prior literature has found that refugees have the potential to contribute to the economy of their country of asylum if they are allowed to work. In the cases of Kampala, Uganda and Kakuma, Kenya, for example, refugees that had the right to work have established businesses that over time were able to create new jobs, also providing employment for locals in some cases (Omata \& Kaplan, 2013). Besides actively creating jobs, the presence of refugees also brings other job opportunities for locals such as positions in international or non-governmental organizations, in managing camps, or in providing goods and services (de Montclos \& Kagwanja, 2000). ${ }^{1}$

Refugees living in camps also often receive humanitarian assistance, and the impact of this on their livelihoods has been the focus of a number of studies. These come to mixed conclusions in so far that some individuals may be enabled through assistance to engage in economic activities, while for others it leads to either the conscious or

\footnotetext{
${ }^{1}$ The impact of hosting refugees on local communities and the economy more generally is the topic of a separate, related field of study. For a review of existing economic literature on the topic see Ruiz \& Vargas-Silva (2013).
} 
unconscious decision of unemployment or inactivity (De Vriese, 2006; Jacobsen, 2005). At the same time, in protracted refugee situations funds spent on assistance of individual refugees are often significantly reduced. In such situations, refugees have to become innovative and find ways to sustain their livelihoods without receiving assistance (Betts et al., 2017).

Overall, the review of the literature shows that it is important to consider the context that refugees live in - their opportunities and constraints - when studying the labour market activities of specific refugee populations (Betts et al., 2017). The next section will therefore provide an overview of the situation of the case of Congolese refugees in Rwanda.

\subsection{Context}

Rwanda is a small, landlocked country in the Great Lakes sub-region in Eastern Africa. While the country has recovered remarkably after the civil war in the early 1990s, remaining politically stable and showing strong economic growth (World Bank, 2017c), Rwanda still faces significant development challenges and currently ranks as the $159^{\text {th }}$ country out of 188 in the Human Development Index (HDI) (United Nations Development Programme, 2016). The labour market in Rwanda is currently experiencing some structural changes and the government is aiming to move away from an economy based on the agricultural sector towards being more knowledgebased and service-oriented by 2020 (Republic of Rwanda, 2012). While declining, at this stage the Rwandan workforce is still largely engaged in agricultural activities, with three quarters working in this sector. The remaining workforce is engaged in the service (17.8 per cent) and industry sectors (7.2 per cent) respectively. Females represent a slightly larger share of the workforce in agriculture, while males dominate the service and industry sectors (International Labour Organization, 2018).

In terms of segmented labour markets characterized by a formal and informal sector (see Section 1.2.2), the majority of employment in Rwanda exists in the informal sector. The results from the latest, fourth round of the Rwandan Integrated Household Living Conditions Survey in 2013/14 showed that close to 90 per cent of the employment captured in the data was informal (National Institute of Statistics of Rwanda, 2016). At the same time, in a context where there is no formal social security system to protect families in case of unemployment, few Rwandans are officially unemployed, simply because people have to find a way to generate an income somehow; including through entrepreneurial activities driven by necessity when other opportunities are not available to them. As a consequence, like in most developing countries, 
underemployment is much more common than unemployment. While unemployment rates are estimated to have stayed below 4 per cent in the past decade, it was estimated that in 2013 one third of the workforce was underemployed. This is closely related to issues such as casual labour, including involuntary part-time work, and the strong informal labour market (Ulandssekretariatet, 2016).

Despite facing its own challenges in terms of economic and human development, and due to its location in a region where many countries have been affected by political instability, ethnic tensions, and conflicts, Rwanda has been hosting refugees from neighbouring countries, particularly Burundi and the DRC, for many years. As of 31 July 2017, UNHCR's operation in Rwanda was supporting 74,302 Congolese refugees (United Nations High Commissioner for Refugees, 2017f).

Figure 3.1 provides an overview of the locations in which UNHCR works in Rwanda. Overall, the agency currently maintains six refugee camps, three reception/ transit centres, and also supports refugees living in urban areas. Five of the refugee camps across the country (marked by the red tent symbol) are dedicated to hosting refugees from the DRC specifically: Gihembe in the Northern Province, Nyabiheke in the Eastern Province, Kigeme and Mugombwa in the Southern Province, and Kiziba in the Western Province. These camps were opened between 1996 and 2014, assisting those that fled the First (1996-1997) and Second (1998-2003) Congo War and those that left due to much more recent events of violent conflict, particularly in the Eastern parts of the DRC, respectively (United Nations High Commissioner for Refugees, 2016).

The Ministry of Disaster Management and Refugee Affairs (MIDIMAR), the responsible Rwandan governmental institution, works together with UNHCR aiming to support refugees to become self-reliant. The regulatory basis for this is given in so far that once awarded status, refugees in Rwanda have the right to free movement within the country as well as access to the labour market (United Nations High Commissioner for Refugees, 2017e).

These rights may theoretically affect the refugees' level of integration into their host communities and may subsequently affect their choice of livelihood activities. A small number of Congolese refugees has, however, settled in urban areas of Rwanda as well as in smaller communities along the border between the two countries. Evidence does indicate that the vast majority of Congolese refugees in Rwanda live in one of the five camps, where living conditions are not easy, and that their local integration has been challenging. Administrative procedures limit the actual possibilities for free movement and working outside of camps (Easton-Calabria \& Lindsay, 2013). 
Figure 3.1: UNHCR Presence in Rwanda, 2016

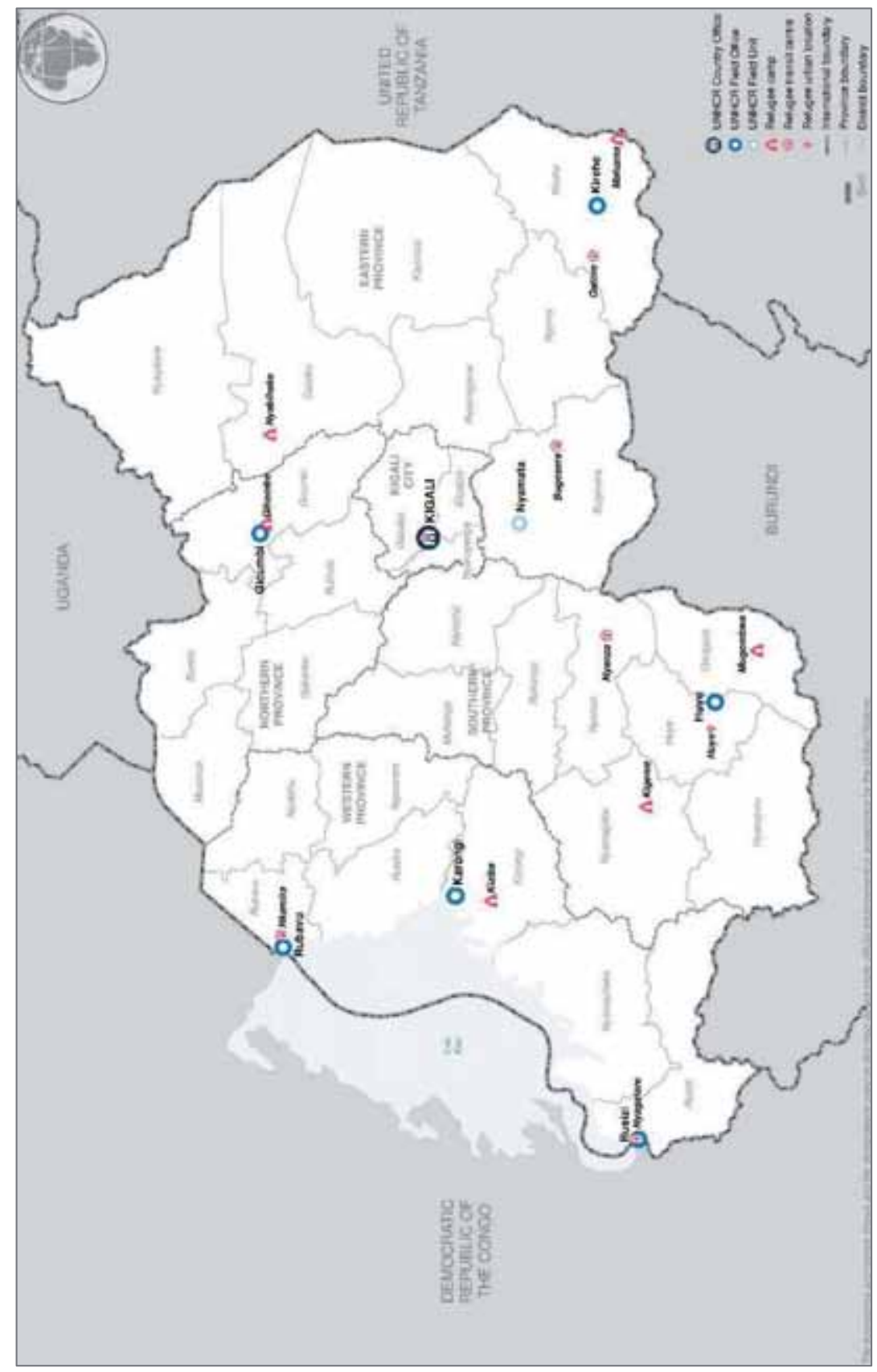

Source: United Nations High Commissioner for Refugees (2016). 
Moreover, a majority of Congolese refugees was active in agricultural activities in their home country and have no access to land in Rwanda. At the same time, opportunities for wage employment in and around the camps are rather scarce, overall limiting the options for building sustainable livelihoods. As a consequence, many Congolese refugees do still depend on humanitarian assistance (Hovil, 2011).

The World Food Programme provides both in-kind food as well as cash assistance to Congolese refugees in Rwandan camps. In 2016, at the time the data used in this chapter was collected, refugees in Kiziba and Mugombwa received food assistance, while residents of Gihembe, Kigeme, and Nyabiheke received Cash-Based Transfers (CBTs), enabling refugees to purchase food of their choice at the local markets and to therefore engage with the local economy (Hedley, Dunn, \& Izabiriza, 2016). However, little is known about refugees' economic activities and the labour market activities that they do engage in to generate income in order not to depend on assistance and how such activities compare to those of local Rwandans living in the same areas of the country surrounding the refugee camps.

\subsection{Data and Methodology}

\subsubsection{Data Collection and Sample}

The data used in this chapter was collected within the framework of a project funded by UNHCR aiming to assess the economic impact of Congolese refugees on host communities in Rwanda. For this purpose, an original household survey was conducted in May 2016 in three locations across Rwanda. These were chosen based on the sites of three of the largest of five refugee camps designated explicitly for the Congolese refugee population: Gihembe, Kigeme, and Kiziba (United Nations High Commissioner for Refugees, 2016). Both, Congolese refugees living within the camps as well as native Rwandans living in areas surrounding the camps, were surveyed, which allows the investigation of differences in their labour market activities as well as differences in labour market activities across different camp sites.

The choice of refugee camps was also based on the fact that the camps and their surroundings have distinct characteristics that may shape the labour market activities of refugees and may therefore allow for interesting comparisons. For example, the residents in Gihembe and Kiziba have largely been living in these camps since the late 1990s, while Kigeme was only opened for Congolese refugees in 2012, having hosted refugees from Burundi prior. At the same time, Kiziba is located on the top a mountain, with the nearest town, Kibuye, a few hours' drive away. In contrast, 
Gihembe and Kigeme are located along main national roads not far from important cities (Byumba and Gikongor respectively). As a consequence, the opportunities and constraints for labour market activities of refugees in these camps as well as the potential for interaction between the refugee population and host communities are expected to differ depending on local conditions, which in turn is likely to impact the labour market engagement of refugees as discussed in the literature review in Section 3.2. A hypothesis to be tested further in this chapter.

A description of the sampling strategy that was utilized to collect the data used in this chapter is provided in Appendix A.1 of this dissertation. In total, information was collected on 7,046 individuals residing in 1,380 households in Rwanda, with one main respondent providing the answers for all household members. However, the population of interest for this chapter is comprised of working age individuals (16-65) ${ }^{1}$ only. Once screening for this elimination criterion and valid, non-missing responses for all variables of interest, a sample of 3,416 individuals within 1,328 household remained. Table 3.1 shows the composition of this sub-sample in terms of location and refugees versus locals.

Table 3.1: Study Sample of Locals and Refugees across Camp Areas

\begin{tabular}{lcccccccc}
\hline \hline & \multicolumn{2}{c}{ Gihembe } & \multicolumn{2}{c}{ Kigeme } & \multicolumn{2}{c}{ Kiziba } & \multicolumn{2}{c}{ Total } \\
\cline { 2 - 10 } & $N$ & $\%$ & $N$ & $\%$ & $N$ & $\%$ & $N$ & $\%$ \\
\hline Locals & 734 & 33.50 & 746 & 34.05 & 711 & 32.45 & 2,191 & 100.00 \\
Refugees & 459 & 37.47 & 371 & 30.29 & 395 & 32.24 & 1,225 & 100.00 \\
\hline Total & 1,193 & 34.92 & 1,117 & 32.70 & 1,106 & 32.38 & 3,416 & 100.00 \\
\hline \hline
\end{tabular}

In addition to the household survey, focus group discussions were conducted in order to gain a deeper understanding of the economic opportunities and constraints of locals and refugees as well as the local impacts of hosting the refugees. A total of twelve focus groups was organized and these sessions were split equally between refugees and locals. In each of the three camps the team conducted two focus groups as well as another two in randomly chosen communities close to each camp.

The discussions in each community were split by gender in order to ensure that women also felt that their opinions and concerns would be heard, a point that was highlighted as being problematic by local stakeholders prior to the fieldwork. Local moderators led the discussions based on an interview guide provided by the project

\footnotetext{
${ }^{1}$ The legal working age in Rwanda is 16 and hence it was decided that no one below this limit should be included in the analysis of this study.
} 
leaders. This guide covered a variety of topics addressing the different topics of interest to the bigger research project and also included questions about labour market activities and interactions between refugees and locals. While a certain structure was therefore given, the discussions remained rather open and participants were therefore able to highlight those topics most important in their respective case. In order to facilitate the engagement of all participants, the discussions were conducted in the local language Kinyarwanda. Each discussion was recorded and also attended by a note taker. Full transcriptions and translations were provided by the note taker and team leader following each discussion.

\subsubsection{Empirical Approach}

In order to analyse the labour market activities of Congolese refugees in Rwanda, the empirical approach of this chapter is two-fold: on the one hand, a comparison of refugees and locals living in areas surrounding the camps and, on the other hand, an analysis of the refugees in the three camps. Logistic regression analyses on binary dependent variables describing the labour market activities are used in order to understand the associations between the economic activities of the sample and a set of covariates. Based on the review of the literature and context, this set of covariates was developed, which covers individual, household, as well as community characteristics that may play a role as determinants of labour market activities in this context. Robust standard errors clustered at the community level are reported for all models.

Formally, the logit models used can be expressed as

$$
\operatorname{Pr}\left(L_{i}=1 \mid r_{i}, x_{i} y_{i} z_{i}\right)=F\left(\alpha+r_{i}^{\prime} \beta+x_{i}^{\prime} \gamma+y_{i}^{\prime} \delta+z_{i}^{\prime} \theta\right)
$$

where $L_{i}$ is a binary dependent variable indicating whether the individual $i$ is engaged in any or a specific labour market activity (value one) or not (value zero). $L_{i}$ takes three different forms alternatively used to analyse the labour market participation of refugees. The binary variable represents employment (value one) versus unemployment (value zero), wage or self-employment (value one) versus unemployment (value zero), or self-employment (value one) versus wage employment (value zero) in turn. These alternatives are employed in three different models estimated to investigate the differences between refugees and locals, while in the case of two models estimated to analyse the differences between refugees in different camps only the latter two options are used as agricultural activities are very minimal among the refugee population. 
$r_{i}^{\prime}$ is the variable indicating whether the individual is a refugee (value one) or not (value zero) in the comparison of both groups. In the case of the analysis of refugees across camps, it stands for the specific refugee camp in which the refugees live and as such captures the differences in terms of location and infrastructure described in Section 3.3.

$x_{i}^{\prime}$ is a vector of individual characteristics, including age, gender, marital status, as well as education and the time spent in the current community. $y_{i}^{\prime}$ represents a vector of household characteristics, including the household composition, social networks, and the receipt of remittances. Finally, $z_{i}^{\prime}$ denotes the distance to the nearest market as a characteristic of the community in which the individual lives. Concrete operationalisations of each of the included possible determinants of labour market activity can be found in Table B.1 in Appendix B of this dissertation.

Prior to estimating the models, it is important to consider the possibility of endogeneity present in the analysis. There are clear reasons to believe that there may be intrinsic differences between the refugees and the local population based on unobservable characteristics that are correlated with labour market activities. Most of the evidence in this regard has been discussed in the context of labour migration and relates to the fact that migrants often self-select to where they settle and take into account labour market opportunities and other factors when doing so (Borjas, 1987, 1995). Due to the cross-sectional nature of the data, the relatively small sample size, and the fact that the focus of the data was not on the labour market activities of refugees, the options of controlling for such endogeneity are limited. ${ }^{2}$ The context does, however, allow to limit the likelihood of self-selection being present in the data in such a way that it would significantly alter the results.

As discussed in the context section (Section 3.3), the vast majority of Congolese refugees in Rwanda lives in the refugee camps and while the allocation of refugees is not fully random, as it depends on the time of displacement and factors related to that, refugees do not actively make a choice about the location in which they live now. Those few refugees that made the choice to leave the camp situation are not captured in the data and therefore are not a concern in terms of selection issues in this analysis.

There is also reason to believe that the establishment of the camps had adverse effects on the local population in the respective areas. Specifically, the development of the camps could have attracted Rwandans to move closer to the camps when they

\footnotetext{
${ }^{2} \mathrm{~A}$ more detailed discussion of these issues is provided in Chapter 7 as they are common to the different studies conducted as part of this dissertation.
} 
perceived or had reason to believe that this could benefit them. It may also be the case that individuals moved away once the camps were being established, however, these would not be captured in the present data. In order to address the issue of potential moves after camps were already opened, robustness checks are conducted as part of the multivariate analysis; in these any individuals that moved to the communities after the respective camp was opened are excluded.

Table 3.2 presents the summary statistics of the variables included in the analysis, differentiated for locals and refugees across the three camp locations. In comparing both groups, some differences can be observed. For example, the locals are on average older ( 33 years) than the refugees ( 31 years), are more often married, and the household head than the refugees. At the same time, it seems that the refugees are on average better educated as they generally have completed more years of formal education. Refugee households are also on average slightly larger than those of locals, but the share of children per adult does not differ between the groups.

Table 3.2: Summary Statistics of Individual and Household Characteristics (means)

\begin{tabular}{|c|c|c|c|c|c|c|c|c|}
\hline & \multicolumn{2}{|c|}{ Gihembe } & \multicolumn{2}{|c|}{ Kigeme } & \multicolumn{2}{|c|}{ Kiziba } & \multicolumn{2}{|c|}{$\mathrm{Chi}^{2}$} \\
\hline & Refugees & Locals & Refugees & Locals & Refugees & Locals & $\begin{array}{l}\text { Refugees } \\
\text { / Locals }\end{array}$ & $\begin{array}{c}\text { Refugees } \\
\text { across } \\
\text { camps }\end{array}$ \\
\hline$N$ & 459 & 734 & 371 & 746 & 395 & 711 & & \\
\hline Female & 0.56 & 0.54 & 0.55 & 0.57 & 0.54 & 0.52 & - & - \\
\hline Age & 31.12 & 33.72 & 30.05 & 33.79 & 31.18 & 33.74 & $* * *$ & - \\
\hline Married & 0.31 & 0.49 & 0.42 & 0.54 & 0.38 & 0.55 & $* * *$ & $* * *$ \\
\hline Household head & 0.26 & 0.33 & 0.30 & 0.34 & 0.24 & 0.36 & $* * *$ & - \\
\hline Education (years) & 7.20 & 6.09 & 6.05 & 5.62 & 7.40 & 4.90 & $* * *$ & $* * *$ \\
\hline Size of household & 7.01 & 5.44 & 7.19 & 5.51 & 7.19 & 5.74 & $* * *$ & $* * *$ \\
\hline Share of children & 0.70 & 0.69 & 0.99 & 0.75 & 0.73 & 0.97 & $* * *$ & $* * *$ \\
\hline Market distance & 40.00 & 33.77 & 120.00 & 97.41 & 0.00 & 83.16 & $* * *$ & $* * *$ \\
\hline $\begin{array}{l}\text { Time in com- } \\
\text { munity }\end{array}$ & 18.35 & 28.18 & 3.80 & 24.82 & 17.24 & 29.27 & $* * *$ & $* * *$ \\
\hline Remittances & 0.06 & 0.00 & 0.11 & 0.02 & 0.08 & 0.03 & $* * *$ & $* *$ \\
\hline Informal network & 0.47 & 0.41 & 0.55 & 0.40 & 0.42 & 0.46 & $* * *$ & $* * *$ \\
\hline \multicolumn{9}{|l|}{ Refugees only } \\
\hline Food assistance & 0.04 &.. & 0.11 & .. & 1.00 & .. & .. & $* * *$ \\
\hline Cash assistance & 0.98 & .. & 0.88 & .. & 0.08 & .. & .. & $* * *$ \\
\hline \multicolumn{9}{|c|}{ Work prior to migration } \\
\hline $\begin{array}{l}\text { Wage- } \\
\text { employment }\end{array}$ & 0.01 &.. & 0.04 & .. & 0.01 &.. & .. & $* * *$ \\
\hline Self-employment & 0.00 & .. & 0.15 & .. & 0.03 & .. & .. & $* * *$ \\
\hline Agriculture & 0.42 &.. & 0.71 & .. & 0.62 & .. & .. & $* * *$ \\
\hline
\end{tabular}

Note: The last two columns present results of chi-square tests of independence for refugees versus locals and refugees across the three camps respectively. ${ }^{* * *} \mathrm{p}<0.01,{ }^{* *} \mathrm{p}<0.05,{ }^{*} \mathrm{p}<0.1$. 
Comparing refugees living in the three camps, the descriptive statistics also show significant differences among the total refugee population captured in the data. The most obvious difference is that refugees in Kigeme have been residing in the camp for a much shorter than in the other two camps, naturally a consequence of the former opening much more recently. In line with this, refugees in Kigeme have significantly more labour market experiences in the home country than the residents in Gihembe and Kiziba. Considering there is no significant age gape, the refugees in the older camps were therefore much younger and had much less time to engage economically in the home country. In turn, the refugees in the older camps are on average slightly more educated than those in Kigeme.

\subsection{Descriptive Statistics}

Before analysing the specific economic activities of refugees and locals, a first look should be taken at the participation in the labour market of both groups. Table 3.3 provides an overview of the primary daily activity that the respondents indicated for the period of the 12 months prior to the survey.

Table 3.3: Primary Daily Activity in the Past 12 Months

\begin{tabular}{lrr}
\hline \hline & Locals & Refugees \\
\hline Working & 1,521 & 233 \\
$\%$ & 69.42 & 19.02 \\
Unemployed & 56 & 244 \\
$\%$ & 2.56 & 19.92 \\
Student & 339 & 316 \\
$\%$ & 15.47 & 25.80 \\
Family business (unpaid) & 90 & 252 \\
$\%$ & 4.11 & 20.57 \\
Doing housework & 99 & 133 \\
$\%$ & 4.52 & 10.86 \\
Sick/ disabled & 75 & 31 \\
$\%$ & 3.42 & 2.53 \\
Community work & 8 & 13 \\
$\%$ & 0.37 & 1.06 \\
Retired & 3 & 3 \\
$\%$ & 0.14 & 0.24 \\
\hline Total & 2,191 & 1,225 \\
$\%$ & 100.00 & 100.00 \\
\hline \hline
\end{tabular}

Note: Differences between locals and refugees are significant at the 1 per cent level. 
As can be seen, the sample contains a significant share of people that were inactive during that time. This includes those that indicated having been a student, working unpaid in a family business, doing housework, being sick or disabled, doing community work, or already being retired. The share of the inactive is much larger among the refugees (61.1 per cent) than the locals (28.0 per cent). The main reason for inactivity is education with overall close to 20 per cent of the sample being a student for the majority of the past year, with a much higher share of refugees than locals.

In a next step, the incidence of unemployment among both groups is investigated. As Table 3.4 shows there are significant differences between locals and refugees, where refugees are much more likely to be unemployed than locals. This is the case across all three camp areas. Differences between the refugees in the different camps are on the other hand not significant and unemployment remains around 50 per cent in each one of them.

Table 3.4: Employment Status of Locals and Refugees

\begin{tabular}{lrrrrrrrr}
\hline & \multicolumn{2}{c}{ Gihembe } & \multicolumn{2}{c}{ Kigeme } & \multicolumn{2}{c}{ Kiziba } & \multicolumn{2}{c}{ Total } \\
\cline { 2 - 9 } Status & Refugees & \multicolumn{1}{c}{ Locals } & Refugees & Locals & Refugees & Locals & Refugees & \multicolumn{1}{c}{ Locals } \\
\hline Employed & 73 & 511 & 76 & 520 & 84 & 490 & 233 & 1,521 \\
$\%$ & 51.77 & 95.16 & 48.41 & 97.38 & 46.93 & 96.84 & 48.85 & 96.45 \\
Unemployed & 68 & 26 & 81 & 14 & 95 & 16 & 244 & 56 \\
$\%$ & 48.23 & 4.84 & 51.59 & 2.62 & 53.07 & 3.16 & 51.15 & 3.55 \\
\hline \hline
\end{tabular}

Note: Differences between locals and refugees are significant at the 1 per cent level.

Finally, turning to only those that are employed, Table 3.5 shows the primary daily activity of locals and refugees in all three camp areas. According to the data, locals are largely working in farming/ livestock, while this is the case for a very small share of refugees only. This is observed across all three refugee camps, though overall activities in agriculture are relatively less common in the area around Gihembe. This may be an indication of more other job opportunities being available as it is located in an urban area. In Kiziba camp, which is located on top of a mountain, on the other hand, selfemployment in business is especially common among refugees. 
Table 3.5: Primary Daily Activity of Employed Locals and Refugees

\begin{tabular}{lrrrrrrrr}
\hline \hline & \multicolumn{2}{c}{ Gihembe } & \multicolumn{2}{c}{ Kigeme } & \multicolumn{2}{c}{ Kiziba } & \multicolumn{2}{c}{ Total } \\
\cline { 2 - 9 } Activity & Locals & Refugees & Locals & Refugees & Locals & Refugees & Locals & Refugees \\
\hline Employee & 143 & 51 & 71 & 50 & 87 & 43 & 301 & 144 \\
$\%$ & 27.98 & 69.86 & 13.65 & 65.79 & 17.76 & 51.19 & 19.79 & 61.80 \\
Self-employment & 52 & 21 & 30 & 23 & 22 & 40 & 104 & 84 \\
$\%$ & 10.18 & 28.77 & 5.77 & 30.26 & 4.49 & 47.62 & 6.84 & 36.05 \\
Agriculture & 316 & 1 & 419 & 3 & 381 & 1 & 1,116 & 5 \\
$\%$ & 61.84 & 1.37 & 80.58 & 3.95 & 77.76 & 1.19 & 73.37 & 2.15 \\
\hline Total & 511 & 73 & 520 & 76 & 490 & 84 & 1,521 & 233 \\
$\%$ & 100.00 & 100.00 & 100.00 & 100.00 & 100.00 & 100.00 & 100.00 & 100.00 \\
\hline \hline
\end{tabular}

Note: Differences between locals and refugees are significant at the 1 per cent level.

The following sections will look at the kind of activities in which the respondents engage in these different categories in turn. At this point, it is important to note that close to one quarter of the sample carried out more than one of these activities during the past year, mostly in the case of locals (see Table 3.6); this further highlights the challenging conditions for refugees in terms of access to income-generating activities. Most commonly individuals combine agricultural work with either wage- or selfemployment activities. To provide a full picture of the labour market activities of refugees and locals, it was decided to include all recorded activities in the following descriptive statistics and not only focus on the identified primary activities. In the analysis following in Section 3.6, on the other hand, the focus will be on the respective individual's primary activity.

Table 3.6: Multiple Labour Market Activities Carried Out by Refugees and Locals

\begin{tabular}{lrrrrrrrr}
\hline \hline & \multicolumn{2}{c}{ Gihembe } & \multicolumn{2}{c}{ Kigeme } & \multicolumn{2}{c}{ Kiziba } & \multicolumn{2}{c}{ Total } \\
\cline { 2 - 8 } Activities & Refugees & Locals & Refugees & Locals & Refugees & Locals & Refugees & Locals \\
\hline Single & 70 & 275 & 63 & 198 & 73 & 277 & 206 & 750 \\
$\%$ & 4.11 & 53.82 & 82.89 & 38.08 & 86.90 & 56.53 & 88.41 & 49.31 \\
Multiple & 3 & 236 & 13 & 322 & 11 & 213 & 27 & 771 \\
$\%$ & 4.11 & 46.18 & 17.11 & 61.92 & 13.10 & 43.47 & 11.59 & 50.69 \\
\hline \hline
\end{tabular}

Note: Differences between locals and refugees are significant at the 1 per cent level.

\subsubsection{Wage Employment}

Engagement in wage employment activities for locals and refugees differ significantly from each other in so far that overall as well as in and around the three distinct camps, locals are more often engaged in such activities than refugees. As Table 3.7 shows, 39.0 per cent of locals and 16.1 per cent of refugees worked for someone that is not a 
member of their household in the past 12 months. It is also interesting to see that wage employment is overall the least common in and around Kiziba, followed by Gihembe and Kigeme, a fact that can likely be explained by the geographic conditions and infrastructure available as described in Section 3.3.

Table 3.7: Wage employment by Status and Camp

\begin{tabular}{lrrrrr}
\hline \hline & Gihembe & \multicolumn{1}{c}{ Kigeme } & \multicolumn{1}{c}{ Kiziba } & \multicolumn{1}{c}{ Total } & Chi $^{2}$ \\
\hline Refugees & 64 & 78 & 55 & 197 & $* * * *$ \\
$\%$ & 13.94 & 21.02 & 13.92 & 16.08 & \\
Locals & 287 & 329 & 239 & 855 & $* * *$ \\
$\%$ & 39.10 & 44.10 & 33.61 & 39.02 & \\
\hline Total & 351 & 407 & 294 & 1,052 & $* * *$ \\
$\%$ & 29.42 & 36.44 & 26.58 & 30.80 & \\
\hline \hline
\end{tabular}

Note: Percentages indicate the share of the total respective population that engages in a wage employment activity. The last column presents results of chi-square tests of independence for refugees, locals, and both combined across the three camp locations respectively. ${ }^{* *} \mathrm{p}<0.01,{ }^{* *} \mathrm{p}<0.05,{ }^{*} \mathrm{p}<0.1$.

The majority (63.9 per cent) of work that locals do is in farming/ livestock, while 16.2 per cent of employed refugees have a job work in that same sector. The share among refugees is, however, about twice as high among those residing in Kigeme (22.2 per cent) compared to those in Kiziba (10.9 per cent) and Gihembe (13.1 per cent). For locals the difference is not quite as big between Kigeme (70.6 per cent) and Kiziba (72.7 per cent), but wage employment in the agricultural sector is a lot less common in Gihembe also for this group (48.9 per cent).

Construction is overall the second most common industry and 19.0 per cent of refugees as well as 12.2 per cent of locals work in this sector. Again, there are differences across the different locations in this industry. In Gihembe the difference between locals (21.8 per cent) and refugees (19.7 per cent) is not very big, while in Kigeme (locals: 9.1 per cent; refugees: 20.8 per cent) and Kiziba (locals: 4.8 per cent; refugees: 15.2 per cent) larger shares of refugees are working in construction relative to the locals. Only a small share of individuals work as professionals in education (6.7 per cent of refugees; 1.8 per cent of locals), health (4.5 per cent of refugees; 0.6 per cent of locals) or other fields (6.2 per cent of refugees; 3.6 per cent of locals), while the remainder of individuals work in a variety of sectors such as transport, trade, security, or cooking and maid services.

Differentiating the jobs by the type of employer shows some interesting trends which can be seen in Table 3.8. Overall, the majority of people is employed by a private employer, but this is even more common (85.3 per cent) for locals than for refugees 
(62.1 per cent). In contrast, a larger share of refugees works for non-governmental organizations (15.5 per cent) and international organizations (13.8 per cent) than do locals ( 0.7 and 0.2 per cent respectively). This may be an indication of the kind of jobs that are available to refugees in contrast to natives. Differences between refugees across the different camps, on the other hand, are not significant regarding the type of employer.

In terms of working conditions, Table 3.8 also shows that the majority of work in and around the camps is informal. Formal work is even less common among locals (6.8 per cent) than among refugees (12.1 per cent). At the same time, locals (68.6 per cent) are more likely to be working in their own community than refugees (45.3 per cent). Differences across the three refugee camps are also not significant regarding these aspects.

Table 3.8: Wage Employment of Refugees and Locals

\begin{tabular}{|c|c|c|c|c|c|c|c|c|}
\hline & \multicolumn{2}{|c|}{ Gihembe } & \multicolumn{2}{|c|}{ Kigeme } & \multicolumn{2}{|c|}{ Kiziba } & \multicolumn{2}{|c|}{$\mathrm{Chi}^{2}$} \\
\hline & Refugees & Locals & Refugees & Locals & Refugees & Locals & $\begin{array}{l}\text { Refugees } \\
\text { E Locals }\end{array}$ & $\begin{array}{c}\text { Refugees } \\
\text { across } \\
\text { camps }\end{array}$ \\
\hline Type of Employer & & & & & & & $* * *$ & - \\
\hline Private employer & 31 & 240 & 43 & 285 & 34 & 184 & & \\
\hline$\%$ & 53.45 & 85.71 & 59.72 & 89.06 & 77.27 & 79.65 & & \\
\hline State owned & 1 & 18 & 2 & 20 & 2 & 14 & & \\
\hline$\%$ & 1.72 & 6.43 & 2.78 & 6.25 & 4.55 & 6.06 & & \\
\hline NGO & 13 & 3 & 12 & 2 & 2 & 1 & & \\
\hline$\%$ & 22.41 & 1.07 & 16.67 & 0.63 & 4.55 & 0.43 & & \\
\hline International org. & 9 & 0 & 11 & 2 & 4 & 0 & & \\
\hline$\%$ & 15.52 & 0.00 & 15.28 & 0.63 & 9.09 & 0.00 & & \\
\hline Other & 4 & 19 & 4 & 11 & 2 & 32 & & \\
\hline$\%$ & 6.90 & 6.78 & 5.56 & 3.44 & 4.55 & 13.85 & & \\
\hline Formal work & 8 & 25 & 5 & 13 & 8 & 18 & $* *$ & - \\
\hline$\%$ & 13.33 & 8.96 & 7.14 & 4.11 & 18.60 & 7.79 & & \\
\hline In community & 31 & 183 & 36 & 214 & 15 & 175 & $* * *$ & - \\
\hline$\%$ & 49.21 & 65.36 & 50.00 & 66.67 & 32.61 & 75.11 & & \\
\hline Days/ week (avg) & 4.90 & 4.26 & 5.63 & 3.67 & 5.63 & 3.76 & $* * *$ & * \\
\hline Standard deviation & 1.65 & 1.69 & 1.36 & 1.79 & 1.22 & 1.72 & & \\
\hline Time in job (avg yrs) & 4.51 & 8.49 & 1.46 & 9.50 & 5.00 & 7.79 & $* * *$ & ** \\
\hline Standard deviation & 5.50 & 8.83 & 1.35 & 9.96 & 6.16 & 8.41 & & \\
\hline $\begin{array}{l}\text { Months worked in } \\
\text { past year }(a v g)\end{array}$ & 7.05 & 7.41 & 5.68 & 7.58 & 9.35 & 7.51 & * & * \\
\hline Standard deviation & 4.33 & 3.96 & 4.07 & 4.11 & 3.60 & 4.11 & & \\
\hline
\end{tabular}

Note: The last two columns present results of chi-square tests of independence for refugees versus locals and refugees across the three camps respectively. ${ }^{* * *} \mathrm{p}<0.01,{ }^{* *} \mathrm{p}<0.05,{ }^{*} \mathrm{p}<0.1$. 
Refugees work an average of 5.4 days per week compared to the locals who work 3.9 days. The data also shows that the locals have on average held their jobs longer (8.7 years) than refugees (3.4 years). Recognizing that Kigeme camp was only opened for Congolese refugees in 2012, they have had their jobs shortest, but the time is still shorter for refugees in Gihembe and Kiziba, which have existed much longer, compared to the locals.

Both, locals and refugees, worked an average of seven months in their respective main wage employment job in the past year, which shows that these are largely not full-time jobs and, in many cases, may be seasonal. The number of people that have a second wage employment job, on the other hand, is low among both groups with 3.4 per cent of locals and 1.7 per cent of refugees. The data does, however, show that individuals sometimes hold different combinations of jobs of wage employment, self-employment, and agriculture as mentioned above.

\subsubsection{Self-employment}

Table 3.9 below shows the incidence of self-employment among locals and refugees in and around the three camps. As can be seen, differences between the two groups are specifically significant in and around Gihembe camp, where locals are significantly more often active in a household owned business than refugees. Overall, a little less than 10 per cent of the working refugee population is active in self-employment, in contrast to 12 per cent of locals.

Table 3.9: Self-Employment by Status and Camp

\begin{tabular}{lrrrr}
\hline \hline & \multicolumn{1}{c}{ Locals } & \multicolumn{1}{c}{ Refugees } & Total & Chi $^{2}$ \\
\hline Gihembe & 100 & 32 & 132 & $* * *$ \\
$\%$ & 13.87 & 7.06 & 11.24 & \\
Kigeme & 91 & 36 & 127 & \\
$\%$ & 12.55 & 10.00 & 11.71 & \\
Kiziba & 65 & 49 & 114 & $*$ \\
$\%$ & 9.63 & 12.93 & 10.82 & \\
\hline Total & 256 & 117 & 373 & $* *$ \\
$\%$ & 12.07 & 9.82 & 11.26 & \\
\hline \hline
\end{tabular}

Note: Percentages indicate the share of the total respective population that engages in a self-employment activity. The last column presents results of chi-square tests of independence for refugees, locals, and both combined across the three camp locations respectively. ${ }^{* *} \mathrm{p}<0.01,{ }^{* *} \mathrm{p}<0.05,{ }^{*} \mathrm{p}<0.1$.

Table 3.10 presents further details on the self-employment activities of locals and refugees respectively. The first point of interest here is whether the respondent is the 
owner of the business or if it is another member of the household. Interestingly, refugees are the owner of the business in close to 95 per cent of the cases, with no significant differences across camps, while around three-quarters are the owner of the household business among the locals. Related to that, businesses of locals have on average one employee compared to 0.26 employees in refugee businesses, which translates to about one in four refugees hiring one other person.

Table 3.10: Self-Employment of Refugees and Locals

\begin{tabular}{|c|c|c|c|c|c|c|c|c|}
\hline & \multicolumn{2}{|c|}{ Gihembe } & \multicolumn{2}{|c|}{ Kigeme } & \multicolumn{2}{|c|}{ Kiziba } & \multicolumn{2}{|c|}{$\mathrm{Chi}^{2}$} \\
\hline & Refugees & Locals & Refugees & Locals & Refugees & Locals & $\begin{array}{l}\text { Refugees } \\
\mathcal{E} \text { Locals }\end{array}$ & $\begin{array}{c}\text { Refugees } \\
\text { across } \\
\text { camps }\end{array}$ \\
\hline Business owner & 30 & 57 & 34 & 82 & 40 & 47 & $* * *$ & - \\
\hline$\%$ & 96.77 & 60.64 & 94.44 & 94.25 & 93.02 & 75.81 & & \\
\hline No employees (avg) & 0.13 & 0.64 & 0.67 & 0.56 & 0.12 & 2.16 & $* * *$ & - \\
\hline Standard deviation & 0.56 & 2.15 & 1.89 & 2.22 & 0.76 & 4.36 & & \\
\hline In community & 27 & 65 & 27 & 66 & 38 & 49 & $* * *$ & - \\
\hline$\%$ & 87.10 & 69.15 & 75.00 & 75.86 & 88.37 & 79.03 & & \\
\hline Days per week ( $a v g$ ) & 4.80 & 4.29 & 4.53 & 3.52 & 5.26 & 4.56 & $* * *$ & * \\
\hline Standard deviation & 1.69 & 2.07 & 2.02 & 2.22 & 1.48 & 2.17 & & \\
\hline Time in job (avg yrs) & 1.00 & 8.92 & 2.50 & 6.75 & 2.00 & 5.73 & - & - \\
\hline Standard deviation & 1.26 & 8.56 & 2.12 & 12.84 & 1.00 & 7.78 & & \\
\hline $\begin{array}{l}\text { Months worked in } \\
\text { past year (avg) }\end{array}$ & 8.03 & 8.02 & 7.36 & 8.00 & 9.95 & 8.39 & * & * \\
\hline Standard deviation & 3.95 & 3.98 & 3.86 & 4.43 & 2.84 & 4.26 & & \\
\hline
\end{tabular}

Note: The last two columns present results of chi-square tests of independence for refugees versus locals and refugees across the three camps respectively. ${ }^{* * *} \mathrm{p}<0.01,{ }^{* *} \mathrm{p}<0.05,{ }^{*} \mathrm{p}<0.1$.

Locals are more often operating their business in the community in which they live and on average their businesses have been in existence three years longer than those of refugees. Refugees do, however, spent more time during the week on the business and were also active in it for more time during the past year than the locals. The number of individuals that have a second business is negligible with a total of three.

\subsubsection{Agriculture}

Considering activities in the agricultural sector, the data shows that there are clear differences between locals and refugees, which can likely be explained by a lack of access to land. To be exact, locals are much more often active in an agricultural activity than refugees. Overall, 68.0 per cent of local respondents engage in such activities compared to only 2.6 per cent of the refugees. This big difference is stable across all three refugee camps (Gihembe: 62.9 vs. 2.0 per cent; Kigeme: 73.4 vs. 3.2 per cent; Kiziba: 67.0 vs. 2.8 per cent), but significant differences between refugees in different locations cannot be observed. 
Agricultural work as such largely depends on seasonal factors and is therefore seldom a full-time job all year around. The data shows that locals on average worked eight months out of the last year in this sector, while the few refugees that worked in the sector at all only spent an average of five months doing so. Overall, it is clear that agricultural work, apart from that as casual farm labour, is much less important as a contributor to the livelihoods of refugees and, at the same time, the main economic activity of the local population, a fact that influenced the analysis for which the results are presented in the following section.

\subsection{Estimation Results}

\subsubsection{Labour Market Activities of Refugees and Locals}

This section aims to further examine the differences in the labour market activities of refugees and locals, before analysing the activities of refugees and the relevance of the local camp context for their activities in more detail in the next section. As described previously, the primary daily activities of both groups differ significantly from each other and therefore exploring the determinants of the employment outcomes is important in order to understand why this may be the case. As described in Section 3.4.2, several logistic regressions on different possible labour market outcomes are estimated to investigate the differences between refugees and locals.

Table 3.11 presents the results of the regression estimates of the labour market activities of refugees and locals. Herein, models 1 and 2 analyse the likelihood of working in either of the categories (wage employment, self-employment, or agricultural work) against being unemployed. Consistent with the descriptive results, the analysis finds that being a refugee is associated with lower odds of being employed. There is no strong location-based effect when comparing Gihembe and Kigeme to Kiziba respectively.

Including interaction terms of the camp area and being a refugee in model 2 confirms that the lower odds of employment are consistent for refugees in all three camps. In the focus group discussions, refugee respondents confirmed that wage employment opportunities within the camps are mostly provided by UNHCR, Non-governmental organizations (NGOs), and International Organizations. This may also help explain differences across the camps as such opportunities are more present in Gihembe and Kigeme camps than in Kiziba. The focus group discussions further highlighted that these opportunities are limited and only available for a small number of refugees: 
"Some also worked as mason aids with ARC, when they were building the houses we currently live in. - But not everyone in the camp had the opportunity to be engaged in those activities. - Only the lucky ones (Respondents 1 and 3, Kigeme Camp).

Table 3.11: Labour Market Activities of Refugees and Locals (Logit estimates)

\begin{tabular}{|c|c|c|c|c|c|c|}
\hline \multirow[b]{2}{*}{ Model: Logit (odds ratio/ se) } & \multicolumn{2}{|c|}{$\begin{array}{l}\text { Employment versus } \\
\text { Unemployment }\end{array}$} & \multicolumn{2}{|c|}{$\begin{array}{l}\text { Wage or self- } \\
\text { employment versus } \\
\text { Unemployment }\end{array}$} & \multicolumn{2}{|c|}{$\begin{array}{c}\text { Self-employment } \\
\text { versus Wage } \\
\text { employment }\end{array}$} \\
\hline & $(1)$ & $(2)$ & (3) & $(4)$ & (5) & (6) \\
\hline \multirow[t]{2}{*}{ Refugee } & $0.08^{* * *}$ & $0.05^{* * *}$ & $0.19^{* * *}$ & $0.16^{* * *}$ & 1.44 & $2.26^{*}$ \\
\hline & $(0.02)$ & $(0.02)$ & $(0.03)$ & $(0.06)$ & $(0.40)$ & $(1.01)$ \\
\hline \multirow[t]{2}{*}{ Gihembe } & 1.18 & 0.74 & $1.40^{* * *}$ & 1.23 & 0.78 & 1.07 \\
\hline & $(0.23)$ & $(0.33)$ & $(0.18)$ & $(0.48)$ & $(0.19)$ & $(0.46)$ \\
\hline \multirow[t]{2}{*}{ Kigeme } & 1.41 & 1.46 & 1.27 & 1.17 & 1.23 & 1.50 \\
\hline & $(0.52)$ & $(0.65)$ & $(0.29)$ & $(0.33)$ & $(0.41)$ & $(0.71)$ \\
\hline \multirow[t]{2}{*}{ Female } & 1.17 & 1.18 & 0.88 & 0.88 & $2.91^{* * *}$ & $2.94^{* * *}$ \\
\hline & $(0.37)$ & $(0.38)$ & $(0.23)$ & $(0.24)$ & $(1.15)$ & $(1.16)$ \\
\hline \multirow[t]{2}{*}{ Age } & 1.01 & 1.02 & 1.02 & 1.02 & 1.00 & 1.00 \\
\hline & $(0.02)$ & $(0.02)$ & $(0.02)$ & $(0.02)$ & $(0.01)$ & $(0.01)$ \\
\hline \multirow[t]{2}{*}{ Married } & $2.84^{* * *}$ & $2.83^{* * *}$ & $2.55^{* * *}$ & $2.55^{* * *}$ & $1.47^{*}$ & $1.49^{*}$ \\
\hline & $(0.83)$ & $(0.82)$ & $(0.67)$ & $(0.67)$ & $(0.31)$ & $(0.31)$ \\
\hline \multirow[t]{2}{*}{ HH head } & 1.01 & 1.03 & 1.02 & 1.02 & 1.17 & 1.20 \\
\hline & $(0.13)$ & $(0.13)$ & $(0.10)$ & $(0.10)$ & $(0.22)$ & $(0.23)$ \\
\hline \multirow[t]{2}{*}{ Education (years) } & $0.91 * * *$ & $0.91^{* * *}$ & $0.92 * * *$ & $0.92 * * *$ & 1.00 & 1.00 \\
\hline & $(0.03)$ & $(0.03)$ & $(0.02)$ & $(0.02)$ & $(0.03)$ & $(0.03)$ \\
\hline \multirow[t]{2}{*}{ Size of household } & $0.85^{* * *}$ & $0.85^{* * *}$ & $0.84^{* * *}$ & $0.84^{* * *}$ & $0.95^{*}$ & $0.95^{*}$ \\
\hline & $(0.03)$ & $(0.03)$ & $(0.04)$ & $(0.04)$ & $(0.03)$ & $(0.03)$ \\
\hline \multirow[t]{2}{*}{ Share of children } & $1.26^{* *}$ & $1.28^{* *}$ & $1.24^{* *}$ & $1.24^{* *}$ & 0.89 & 0.88 \\
\hline & $(0.13)$ & $(0.14)$ & $(0.13)$ & $(0.13)$ & $(0.08)$ & $(0.08)$ \\
\hline \multirow[t]{2}{*}{ Market distance } & 1.00 & 1.00 & 1.00 & 1.00 & $0.99 * * *$ & $0.99^{*}$ \\
\hline & $(0.00)$ & $(0.00)$ & $(0.00)$ & $(0.00)$ & $(0.00)$ & $(0.00)$ \\
\hline \multirow[t]{2}{*}{ Time in community } & $1.04^{* * *}$ & $1.04^{* * *}$ & $1.03^{* *}$ & $1.03^{* *}$ & 0.99 & 0.99 \\
\hline & $(0.01)$ & $(0.02)$ & $(0.01)$ & $(0.01)$ & $(0.01)$ & $(0.01)$ \\
\hline \multirow[t]{2}{*}{ Remittances } & 0.97 & 0.94 & 1.08 & 1.07 & $2.29^{*}$ & $2.38^{* *}$ \\
\hline & $(0.33)$ & $(0.32)$ & $(0.41)$ & $(0.41)$ & $(0.97)$ & $(1.05)$ \\
\hline \multirow[t]{2}{*}{ Informal network } & 0.85 & 0.84 & 0.90 & 0.90 & 1.39 & 1.41 \\
\hline & $(0.18)$ & $(0.19)$ & $(0.19)$ & $(0.19)$ & $(0.33)$ & $(0.34)$ \\
\hline \multirow[t]{2}{*}{ Gihembe X Refugee } & & 2.23 & & 1.22 & & 0.51 \\
\hline & & $(1.34)$ & & $(0.62)$ & & $(0.23)$ \\
\hline \multirow[t]{2}{*}{ Kigeme X Refugee } & & 1.09 & & 1.23 & & 0.57 \\
\hline & & $(0.52)$ & & $(0.59)$ & & $(0.34)$ \\
\hline Adjusted R-squared & 0.45 & 0.45 & 0.29 & 0.29 & 0.09 & 0.09 \\
\hline Observations & 2054 & 2054 & 933 & 933 & 633 & 633 \\
\hline
\end{tabular}

Note: $* * * \mathrm{p}<0.01, * * \mathrm{p}<.05,{ }^{*} \mathrm{p}<0.10$. Kiziba is the reference refugee camp. Standard errors in parentheses are robust and clustered at the community level. 
Opportunities for wage employment outside of the camp are on the other hand hardly possible to find according to the focus group participants. This is largely due to the fact that they do not have ID papers which they would need to find local employment though theoretically this should not be an issue as they do have the right to work. Unemployment of refugees is therefore a consequence of these challenges relating to accessing job opportunities in and around the camps. While there may be opportunities further away, such opportunities would have no added benefit for the refugees as the cost of getting to the workplace would be too high. As one focus group participant put it:

"Let us take an example of the person who lives here and her job is too far away for instance in Nyamagabe. It requires the transport for both getting there and coming back, yet the payment is very small for instance 700, which means that I am going to spent all of it on the transport expenses. So that is why we decide to stay unemployed because we don't gain anything since all the payment covers the transport expenses only" (Participant 1, Kigeme Camp).

Other factors negatively associated with employment are having a higher number of years of education, potentially indicating that it is harder for better educated people to find work that matches their qualifications, and living in a bigger household, where there are more people that can pool together income. Factors that increase the odds of employment on the other hand are being married and the share of children in the household, which can be seen as indicators for having to provide for others.

A final significant factor with larger odds of being employed is the time spent in the respective community, which may be beneficial for knowing how things function, where employment opportunities exist, but also for owning land for agricultural activities. Against the theoretical notion that social networks are important for finding employment, the model does not confirm this as the indicator for having an informal network does not show significance in these models.

Models 3 and 4 in Table 3.11 present results for the logistic regression analysis of working versus being unemployed, excluding agricultural activities. As the descriptive statistics showed, self-employment in agriculture is largely dominated by locals and options for refugees are limited due to a lack of land. Looking at the two other employment categories shows that it is largely the same factors that lead to larger or smaller odds of wage- or self-employment versus being unemployed as when considering all possible activities. Being a refugee is still significantly related with lower odds, but logically the effect is smaller than when agriculture is also considered. 
Finally, models 5 and 6 investigate the differences between being self-employed and being wage employed. Here, being a refugee does not significantly affect the odds of being active in either of these categories. While the odds for refugees to be in selfemployment are larger than those of locals, this effect is not significant in model 5 and only significant at the 10 per cent level in model 6, overall not indicating a strong difference between refugees and locals regarding this aspect.

Location based effects are also not found in this case. Instead, the results show that females have significantly larger odds than males to be in self-employment instead of wage employment, if they are working (not in agriculture). This may be an indication that job opportunities for females are even more limited than they are for males across both groups. Considering the nature of the work available in the major sectors of employment identified in the descriptive analysis, namely agriculture and construction, this may be less surprising. Those married also have slightly larger odds of being self-employed. The significant minimal negative effect of market distance may be counter-intuitive at first as markets offer opportunities for trade which would more likely be related to self-employment. However, it is likely that there are more economic opportunities in general around those locations and therefore wage employment is also more readily available.

Finally, those individuals that indicated receiving remittances do have larger odds of being in self-employment rather than wage employment. While no causal relationship can be established here, this finding possibly shows that the additional financial capital enables those receiving remittances to overcome liquidity constraints that exist in the poorly functioning financial market.

Robustness checks are conducted at this stage in order to ensure that the differences in labour market activities are not influenced by the fact that locals moved to the areas around the camps after the camps were established (see Section 3.4.2). This is done by excluding any individual that moved to the area anytime from one year before the opening of the camp until the time of data collection. The results of this analysis show that the majority of the results reported above are stable when conducting this robustness check, but there are a few small changes to the results (see Table B.2 in Appendix B).

Most interestingly, excluding newly arrived locals leads to a significant positive relationship between being a refugee and being self-employed versus wage employed in contrast to the locals. This shows that those Rwandans that moved to the camp areas after establishment of the respective camp did so to engage in business activities, showing potential self-selection based on spotting opportunities for such activities. 
The positive odds ratio for refugees in this regard, on the other hand, confirms that due to limited other opportunities they do show entrepreneurial behaviour by engaging in self-employment.

\subsubsection{Labour Market Activities of Refugees across Camps}

The analysis in this section now zooms in to investigate the labour market activities of only refugees more specifically across the three camps. Table 3.12 presents the results of the analysis of the unemployment of refugees as well as their primary daily activities in wage or self-employment. ${ }^{3}$ The basic models in columns (1) and (3) are complimented by information on the individual's occupation prior to migration (models 2 and 4 ) to control for prior working experiences as a proxy for human capital.

As the descriptive statistics above have shown, close to half of all economically active refugees are unemployed. The challenge of unemployment is also evident in the estimations in this section. In addition, many of the findings of the quantitative analysis on the labour market activities of refugees were also reflected in the focus group discussions. Regarding unemployment, the focus group participants also confirmed that labour market opportunities for refugees are limited in all the camps. In a first step, this unemployment is therefore further investigated.

The analysis indicates that it may make a difference in what camp refugees live for their labour market activities. Kiziba, the most isolated of the three camps, is used as the reference camp and the results show that the odds of being employed are significantly larger for the refugees residing in Gihembe (six times) and Kigeme (two times) respectively.

In line with the findings of the analysis of locals and refugees in the prior section, the analysis of refugees further shows that living in a larger household is negatively associated with employment, a finding which indicates that there may be other household members that are able to provide for the household.

Being married as well as the share of children in the household increase the odds of being employed, indicating that those responsible for providing for others do find employment opportunities, as was the case in the previous section for the total sample of locals and refugees. In terms of education, models 1 and 2 show that a higher education level is linked to lower odds of employment. In addition, those with

\footnotetext{
${ }^{3}$ As shown in the descriptive analysis, only 2 per cent of refugees are active in agriculture and as such this small sub-group is excluded in the further analyses.
} 
experience in wage employment in the home country also have lower odds of being employed in the camp context, while other prior experiences do not show significant effects. Overall, this may indicate that higher levels of human capital make it more challenging to find suitable work opportunities in the camps and local environments surrounding the camps.

Networks, which are often associated with positive labour market outcomes, do not seem to be significant for refugees in finding employment. The analysis does, however, show that receiving cash assistance does have a negative relationship with being employed. Those receiving food assistance have higher odds of being employed than those not receiving it.

The discussions during the focus groups revealed that, to some extent, assistance enables refugees to engage in small business and trade activities. The participants indicated that they are able to purchase some goods with the money they receive in the form of cash assistance or use the in-kind assistance received to then resell them to make some profit. These are most often food products which they are able to buy in the surrounding communities for resale to other refugees as well as the locals. In these cases, the receipt of this assistance is indeed enabling them to engage economically, despite this not being the specific aim. The multivariate analysis does not unambiguously confirm this, however, as the effect of cash assistance is not positive, indicating that assistance also may have a disincentive effect regarding finding employment.

Turning to the primary daily activity of those that are working, models 3 and 4 in table 3.12 provide the odds ratios of being self-employed in contrast to being wage employed. Here it does not seem to matter in which camp refugees reside. While the odds of being self-employed in contrast to being wage employed are lower in Gihembe and Kigeme compared to Kiziba respectively, these effects are not significant.

Interestingly, the finding that stands out the most, is the fact that female refugees have significantly larger odds of being self-employed rather than wage employed compared to their male counterparts. The effect is much larger than it was in the case of refugees and locals combined. It is likely that wage employment opportunities for female refugees are even more limited and the option of agricultural activities is not available to them; therefore, the women need to be even more creative and set-up selfemployment activities if they still want or need to generate an income. 
Table 3.12: Labour Market Activities of Refugees (Logit estimates)

\begin{tabular}{|c|c|c|c|c|}
\hline \multirow[b]{2}{*}{ Model: Logit (odds ratio/ se) } & \multicolumn{2}{|c|}{$\begin{array}{c}\text { Wage or self-employment } \\
\text { versus Unemployment }\end{array}$} & \multicolumn{2}{|c|}{$\begin{array}{c}\text { Self-employment versus } \\
\text { Wage employment }\end{array}$} \\
\hline & $(1)$ & $(2)$ & (3) & $(4)$ \\
\hline \multirow[t]{2}{*}{ Gihembe } & $6.14^{* * *}$ & $6.90 * * *$ & 0.38 & 0.54 \\
\hline & $(2.33)$ & $(2.00)$ & $(0.77)$ & $(1.19)$ \\
\hline \multirow[t]{2}{*}{ Kigeme } & $2.13^{* * *}$ & $2.47^{* *}$ & 0.34 & 0.42 \\
\hline & $(0.38)$ & $(0.98)$ & $(0.76)$ & $(0.92)$ \\
\hline \multirow[t]{2}{*}{ Female } & 0.76 & 0.78 & $12.04^{* * *}$ & $13.14^{* * *}$ \\
\hline & $(0.28)$ & $(0.29)$ & $(5.12)$ & $(5.18)$ \\
\hline \multirow[t]{2}{*}{ Age } & 1.02 & 1.02 & $0.97^{* * *}$ & $0.97^{* * *}$ \\
\hline & $(0.02)$ & $(0.02)$ & $(0.01)$ & $(0.01)$ \\
\hline \multirow[t]{2}{*}{ Married } & $1.62 * * *$ & $1.59 * * *$ & 1.65 & 1.46 \\
\hline & $(0.24)$ & $(0.27)$ & $(0.70)$ & $(0.53)$ \\
\hline \multirow[t]{2}{*}{ HH head } & 0.88 & $0.89 * *$ & 0.76 & 0.80 \\
\hline & $(0.07)$ & $(0.05)$ & $(0.47)$ & $(0.43)$ \\
\hline \multirow[t]{2}{*}{ Education (years) } & $0.93^{* * *}$ & $0.94^{* *}$ & 0.94 & 0.94 \\
\hline & $(0.02)$ & $(0.02)$ & $(0.04)$ & $(0.04)$ \\
\hline \multirow[t]{2}{*}{ Size of household } & $0.86^{* *}$ & $0.86^{* *}$ & 0.94 & 0.95 \\
\hline & $(0.06)$ & $(0.06)$ & $(0.05)$ & $(0.06)$ \\
\hline \multirow[t]{2}{*}{ Share of children } & $1.27^{* * *}$ & $1.26^{* *}$ & 0.90 & 0.87 \\
\hline & $(0.11)$ & $(0.14)$ & $(0.15)$ & $(0.13)$ \\
\hline \multirow[t]{2}{*}{ Time in community } & $0.97^{*}$ & 0.97 & 0.99 & 0.99 \\
\hline & $(0.02)$ & $(0.02)$ & $(0.03)$ & $(0.02)$ \\
\hline \multirow[t]{2}{*}{ Remittances } & 0.87 & 0.94 & $6.83^{*}$ & $10.82^{* *}$ \\
\hline & $(0.46)$ & $(0.43)$ & $(6.80)$ & $(10.49)$ \\
\hline \multirow[t]{2}{*}{ Informal network } & 1.06 & 1.06 & 1.09 & 1.08 \\
\hline & $(0.33)$ & $(0.31)$ & $(0.22)$ & $(0.23)$ \\
\hline \multirow[t]{2}{*}{ Food assistance } & $3.16^{* * *}$ & $3.64^{* * *}$ & 0.44 & 0.53 \\
\hline & $(0.20)$ & $(0.74)$ & $(0.50)$ & $(0.66)$ \\
\hline \multirow[t]{2}{*}{ Cash assistance } & $0.63^{*}$ & $0.64^{* *}$ & 0.36 & 0.29 \\
\hline & $(0.15)$ & $(0.15)$ & $(0.42)$ & $(0.35)$ \\
\hline \multicolumn{5}{|l|}{ Work prior to migration } \\
\hline \multirow[t]{2}{*}{ Wage employment } & & $0.20^{* *}$ & & 1.00 \\
\hline & & $(0.14)$ & & $()$. \\
\hline \multirow[t]{2}{*}{ Business } & & 0.88 & & $3.73^{* * *}$ \\
\hline & & $(0.70)$ & & $(1.61)$ \\
\hline \multirow[t]{2}{*}{ Agriculture } & & 1.01 & & 1.11 \\
\hline & & $(0.38)$ & & $(0.54)$ \\
\hline Observations & 0.12 & 0.12 & 0.29 & 0.30 \\
\hline Adjusted R-squared & 472 & 472 & 228 & 227 \\
\hline
\end{tabular}

Note: ${ }^{* * *} \mathrm{p}<0.01,{ }^{* *} \mathrm{p}<.05,{ }^{*} \mathrm{p}<0.10$. Kiziba is the reference refugee camp. Standard errors in parentheses are robust and clustered at the community level.

Another interesting finding is that refugees that receive remittances have significantly higher odds of being self-employed and not wage employed. While a causal link cannot be established here, this may highlight that if refugees do have access to some financial capital they are able to set up entrepreneurial activities to support their 
livelihoods reflecting liquidity constraints that can be overcome through the use of remittances.

In addition, the odds of those refugees that were self-employed in business in the DRC prior to displacement are four times larger to be in self-employment and not wage employment than of those that were active in another occupation or inactive. In other words, refugees that were active in business in the home country are more likely to be entrepreneurs in the host nation. This may indicate that prior experience in such activities may help with setting them up during displacement, potentially highlighting the entrepreneurial inclination of some of these refugees.

\subsection{Concluding Remarks}

This chapter investigated conflict-induced forced migration and labour market activities in the context of Congolese refugees residing in Rwanda. Using data from a newly collected household survey, it addressed the research question What are the patterns and determinants of refugees' labour market participation and in what ways do their economic activities differ from those of locals? In order to answer this question, the analysis examined the differences in employment status between refugees living in three distinct camps and local Rwandans in communities surrounding these camps. Given the recent trends in forced migration and the gap in the literature on the understanding of labour market dynamics within the context of forced migration, this chapter investigated the labour market activities of refugees and locals to identify differences and similarities and to gain insights into the factors that drive them.

In line with the literature, the findings indicate that refugees face significantly more challenges regarding their active engagement in the labour market and unemployment is therefore much more common among refugees than among locals, which is an indication of limited labour market opportunities for refugees despite them officially having the right to work in Rwanda. In terms of the primary daily activity, it is clear that the majority of locals works in the agricultural sector. Access to that is, on the other hand, limited for refugees as they do not own land on which they could farm and/ or keep livestock. At the same time, agriculture also does not seem to provide enough income throughout the year for local households as they often seem to complement these activities with casual labour and self-employment activities. Looking at wage employment, it is interesting that the kind of jobs that refugees engage in significantly differ from those of locals as they more often work for nongovernmental or international organizations. This is an indication of the nature of the jobs that are available to refugees in contrast to natives, showing that while these 
refugees are able to make an income, they still depend on the international and local humanitarian and/ or development community indirectly. Furthermore, the lack of access to agriculture and limited wage employment, does incentivize entrepreneurial activities of refugees.

One specific contribution of this chapter is the analysis of the economic activities of Congolese refugees in three different camps which are located in different parts of Rwanda and characterized by different geographical characteristics. The analysis shows that there are indeed differences across the three camps and surrounding areas. Specifically, the analysis shows that refugees in Gihembe and Kigeme camps have significantly higher odds of being working in either wage or self-employment than those refugees settled in Kiziba. Considering that Kiziba is the most isolated of the three camps, located on top of a mountain far from the closest urban centre, this is not necessarily surprising. The finding does, however, highlight the need for specific support in such a surrounding if the self-reliance of refugees is the aim of policymakers.

Agriculture, which is so important overall as the main activity type for locals, is less common around Gihembe compared to the other two locations likely due to the fact that Gihembe camp is the one camp that is close to an urban centre. It also seems that wage employment opportunities for refugees do exist in Gihembe and Kigeme, while their main type of activity in Kiziba is in self-employment based on the descriptive statistics. While this may be driven by other characteristics than the simple fact of being a refugee, as there is no significance of that variable in the results of the multivariate analysis, it is indicative of the fact that when facing constraints such as a lack of access to a local economy, some refugees do show entrepreneurial behaviour and engage in trade and other self-employment activities. The fact that experience in similar activities prior to the displacement from the DRC positively influences the odds of being in such an activity now, does speak for this entrepreneurial spirit.

The analysis further shows that females have higher chances to be engaged in selfemployment than their male counterparts. This is the case for both refugees and locals, but the odds of refugee women are especially large, highlighting limited labour market opportunities for them in particular due to the sectors (mainly agricultural work and construction) in which such opportunities are available at all. Furthermore, the household composition seems to matter for occupational choices of its members. There is evidence that working age adults in households with a higher share of children are more likely to be working, irrespective of the specific occupation. The same is found 
for married individuals, overall showing that responsibility for others is a main driver to find some type of income-generating activity.

Overall, it is important to acknowledge that wage employment opportunities are also limited for locals and largely dependent on the seasons in sectors such as construction, which is similar for those refugees not able to access one of the jobs mentioned above. This highlights that many of issues in accessing the labour market are not limited to refugees but affect locals as well. However, the lack of access to land presents a major additional barrier for refugees. The main constraint to self-employment, on the other hand, appears to be start-up capital that allows the initial engagement in such activities. In this regard, the discussions during the focus groups highlighted that humanitarian assistance received is in some cases used by recipients to start engaging economically with other refugees and locals, an indication of the entrepreneurial spirit of some refugees, which if fostered could contribute significantly to their self-reliance and ultimately to development.

Considering the record levels of displacement around the world, it is important to understand the type of economic activities refugees engage in and how this relates to the activities of those native to hosting countries. As this understanding is currently still limited, the present chapter contributes to the literature by investigating this issue using the case study of Congolese refugees in Rwanda. It is clear that, overall, wage employment opportunities are limited for both refugees and locals. Considering the overall important role of agricultural activities, the fact that refugees do not have access to land, poses a big challenge to their economic independence. Nonetheless, the data also shows that there are many refugees that find ways to support their own livelihood and this innovativeness is an issue that needs and deserves further investigation. 


CHAPTER 4: INTERNATIONAL MigRATION AND SELF-EMPLOYMENT OF NON-MIGRANT HOUSEHOLD MEMBERS 



\subsection{Introduction}

Within the overall discussion concerning migration and development, the role of household members remaining in the home country is often looked at through the lens of remittance usage (Adams \& Page, 2003; Yang, 2011). And indeed, remittances are one of the possible channels of impact of migration on households. As such, they are also be a possible driver of self-employment activities among remaining household members. However, there are also other channels through which migration impacts those staying behind, such as the reallocation of time and labour within the household as a consequence of a household member leaving as well as when a household member returns from abroad (Karymshakov \& Sulaimanova, 2017; Mu \& van de Walle, 2011). In addition, return migrants may bring back accumulated savings and new skills that can enable themselves or other household members to start a self-employment activity (Giulietti et al., 2013).

Considering these different possible channels through which migration experiences of household members may affect the labour market engagement of non-migrants, the role of self-employment activities of non-migrant household members remains one that is not well understood. While there is commonly a focus in the literature on migration leading to economic inactivity of household members left behind (Azam \& Gubert, 2006; Karymshakov \& Sulaimanova, 2017), the engagement in small businesses and self-employment activities specifically has been researched less.

To address this gap, this chapter analyses the potential relationship between household member migration and the self-employment of non-migrants. Specifically, it answers the second research question posed in the introduction of this dissertation: How are self-employment activities of non-migrants shaped by the forced or voluntary migration experiences of household members?

Using unique datasets from Afghanistan, Burundi, Ethiopia, and Morocco ${ }^{20}$, this chapter analyses the labour market activities of non-migrants in these four countries. The specific focus here lies on self-employment activities in business in contrast to those in agriculture and wage employment activities as well as unemployment and inactivity. Each of the focus countries shows distinctly different migration determinants and patterns, as well as varied general socio-economic characteristics. Each country by itself presents an interesting case study for the question at hand and in comparing them, considering the differences in context, even more can be

\footnotetext{
${ }^{20}$ The cases of Ethiopia and Morocco, where migration is mostly motivated by economic reasons, serve to act as a comparison to the cases of forced migration from Afghanistan and Burundi.
} 
understood about the linkages between migration and self-employment of household members in the country of origin.

Overall, the results of this chapter highlight that the respective context in which the household member migration and the employment of the non-migrant is set, matters. In cases were migration is dominated by movements that are for reasons such as escaping from violent conflict or general insecurity, in this case Afghanistan and Burundi, no relationship between either a current or a return migrant and selfemployment activities could be identified. In the case of Ethiopia, on the other hand, there is evidence that the presence of a current migrant in the household is negatively associated with self-employment, specifically when contrasted with inactivity. Considering that most of the migration captured from this country is migration to the Middle East with the main purpose of sending remittances and contributing to consumption smoothing of the household left behind, such a finding may not be surprising. Migration from Morocco, on the other hand, is much more likely to be for reasons such as overcoming credit constraints and gathering of savings. In this case, the estimates suggest that there is indeed a positive relationship between the migration experiences and self-employment activities of non-migrant household members.

The remainder of this chapter is structured as follows. The next section provides a brief literature review of the linkages between household member migration and the effects on household members remaining in the home country, with a focus on migration and self-employment choices of these household members. This is followed by providing some information on the respective context of each of the four countries studied in this chapter in Section 4.3 and a description of the methodology and data used in the empirical analysis in Section 4.4. Sections 4.5 and 4.6 present the results of the descriptive and multivariate analysis respectively, before the chapter concludes with a summary and discussion of the findings in Section 4.7.

\subsection{Relevant Literature}

The impacts of migration on the country of origin as a whole and the households and communities from which migrants leave have been the focus of much existing research. Remittances as well as return migration are two of the major channels through which migration and development are related at both the micro- and macrolevel (Adams \& Page, 2003; de Haas, 2010; Plaza \& Ratha, 2011; Skeldon, 2014). At the household level, migration also impacts the allocation of time and labour of the household members that stay in the country of origin (Airola, 2008; Amuedo-Dorantes \& Pozo, 2006; Chang, Dong, \& MacPhail, 2011; Lokshin \& Glinskaya, 2009). The 
following paragraphs will present a short discussion of the existing evidence on each of these channels in turn in an effort to underline why more research is needed on the relationship between migration of a household member and self-employment of nonmigrants.

Overall, the literature on migration and occupational choice or labour market activities is largely concerned with the labour market decisions of migrants themselves (see Chapter 2 for a review of this literature). There is, however, also evidence on the effects of migration of a household member on the allocation of time and labour of those household members that stay in the country of origin. In this context, some studies have found negative effects of migration, associated with the loss of one or more household members and their labour, on the labour market participation of those left behind (Funkhouser, 1992; Lokshin \& Glinskaya, 2009; Mu \& van de Walle, 2011; Rodriguez \& Tiongson, 2001).

Negative effects are specifically often found for women, who in many cases shift activities to unpaid farm or family work in response to the migration of the household member (Acosta, 2006; Binzel \& Assaad, 2011; Cabegin, 2006; Karymshakov \& Sulaimanova, 2017; Mendola \& Carletto, 2009). Looking specifically at the relationship between migration of a household member and self-employment of those staying, Mansuri (2007) shows that in the case of Pakistan members of households with current rural-to-urban migrants are less likely to be self-employed than those in non-migrant households. In the case of India, it is found that while women reallocate their time to household work when a household member migrates, men are likely to engage in entrepreneurial activities in the same situation (Khan \& Valatheeswaran, 2016).

Negative or insignificant relationships between current migration and selfemployment of those staying behind may be observed because of the loss of labour and skills, which financial remittances from the migrant household member cannot compensate. In other cases, migrants may not (be able to) send remittances or only start doing so after some time in the host country. In either case, when remittances are absent or the received sum is too little to compensate the migrants' contribution to the household prior to migration, this can then result in an inability of the remaining household members to run a self-employment activity. On the other hand, negative relationships between remittance income and self-employment may indeed be a result of remittances providing sufficient income and there not being a need for such an activity (Giulietti et al., 2013). Existing studies on the linkages between remittance receipt and entrepreneurial activities come to different conclusion on the relationship between the two (also see Section 2.2.3). 
Generally, it has been found that in developing countries where financial markets are difficult to access for large parts of the population, remittances have the potential to alleviate the credit constraints faced by households. This may enable them to invest in agricultural innovations, small businesses, or large assets such as land and housing, among many other uses of this type of income (Lucas \& Stark, 1985). In line with this, Giuliano and Ruiz-Arranz (2009) find that remittances help households to overcome credit and liquidity constraints particularly in countries with underdeveloped financial systems. In such cases, remittances are invested into small business development and the contribution of remittances to economic growth is more significant than in countries with more developed financial systems (Giuliano \& RuizArranz 2009).

Looking at more specific case studies, much research on the use of remittances has been conducted in the case of Mexico. Several studies highlight a positive impact of remittances sent by migrants from the United States to Mexico on the establishment of small businesses. A study by Massey and Parrado (1998) is among the earliest studies that find a positive relationship between international migration, remittances, and economic development through the creation of businesses in the case of Mexico. Overall, though depending on the situation and composition of the household and their surroundings, remittances from the United States are found to contribute to the establishment of new businesses (Massey \& Parrado, 1998). Along the same lines, Woodruff and Zenteno (2007) find that migrant networks benefit small businesses in Mexico generally, and especially in high-capital sectors. This leads the authors to conclude that linkages with migration networks help business owners to overcome liquidity constraints in such sectors (Woodruff \& Zenteno, 2007).

Different case studies in other countries have also found that remittances are used by receivers for investments into small businesses and self-employment activities. Funkhouser (1992), for example, finds remittances to have a small positive effect on self-employment in Nicaragua. Findings from El Salvador are a bit more mixed in so far that no direct relationship between remittances and self-employment could be identified, but the remittance income is positively related with the ownership of a small business. Overall, remittances do seem to alleviate credit constraints for households in rural areas of the country (Acosta, 2007). Another set of literature does, however, not find such evidence. Different studies cannot identify a relationship between the receipt of remittances and self-employment in, for example, Ecuador (Vasco, 2013), the Dominican Republic (Amuedo-Dorantes \& Pozo, 2006), the Philippines (Ang et al., 2009), or Tonga (Gibson, McKenzie, \& Stillman, 2011). 
Existing evidence on the usage of remittances points to the finding that generally speaking remittances are mainly used for consumption or investments in education or health of household members, but less so in productive investments (Agunias, 2006; de Haas, 2010; Page \& Plaza, 2006). It therefore appears that the use of monetary remittances for productive investments, including small businesses, very much depends on the respective context (see also Section 2.2.3 of this dissertation).

The evidence on the effects of return migration on the self-employment choices of other household members has attracted far less attention in the existing literature than the potential impacts of current migration and remittances. In the case of rural China, Giulietti et al. (2013) find that return migrants do promote entrepreneurship amongst non-migrant household members, potentially indicating the importance of human capital such as knowledge and experience for the stimulation of entrepreneurship in rural China. However, no other case studies looking specifically at this linkage are known to the author at this point in time.

The existing evidence on the relationship between migration and self-employment of non-migrant household members is thus scattered across different strands of literature and much remains unclear in this context. The existing evidence points to the fact that indeed there may be a positive relationship in some cases. However, based on the empirical evidence and the theoretical background of the NELM, it can be posited that this positive effect mainly exists in cases where individuals migrate with the intention of overcoming market constraints. It is therefore less likely that positive relationships will be observed in contexts of forced migration or in cases where migration is simply a strategy of households to smooth consumption.

In addition, the conditions of the labour market in the country of origin, in terms of the incidence of self-employment more generally and the availability of other labour market opportunities, are likely to largely impact this relationship. Therefore, a comparative approach to the question of linkages between migration of household members and self-employment activities of non-migrants may be beneficial in order to identify commonalities and differences in the light of the four different country contexts of Afghanistan, Burundi, Ethiopia, and Morocco considered in this chapter.

\subsection{Context}

This chapter analyses the self-employment activities of non-migrants and the potential relationship with having a current and/ or return migrant in their household in Afghanistan, Burundi, Ethiopia, and Morocco. It is important to acknowledge that the 
context in these four countries, in terms of the socio-economic characteristics of the population, the labour market situation, as well as common migration patterns and experiences, differs significantly. These differences may impact and, at the same time, help to explain the results of the present analysis. It is therefore important to gain an understanding of some of the most relevant differences before moving on to present the data and methodology of the empirical part of this chapter in the next section. For this purpose, Tables 4.1 and 4.2 provide some key indicators regarding the migration, socio-economic, and labour market contexts of each of the four countries.

\section{Table 4.1: Migration Context}

\begin{tabular}{|c|c|c|c|c|}
\hline & Afghanistan & Burundi & Ethiopia & Morocco \\
\hline $\begin{array}{l}\text { Stock of emigrants (2013), } \\
\text { thousands a }\end{array}$ & $5,632.2$ & 378.8 & 749.1 & $3,040.3$ \\
\hline $\begin{array}{l}\text { Emigrants (2013), \% of total } \\
\text { population a }\end{array}$ & 18.4 & 3.6 & 0.8 & 9.1 \\
\hline $\begin{array}{l}\text { Main five countries of } \\
\text { destination }(2015)^{b}\end{array}$ & $\begin{array}{l}\text { Iran, Pakistan, } \\
\text { Saudi Arabia, } \\
\text { Germany, UK }\end{array}$ & $\begin{array}{r}\text { Tanzania, } \\
\text { Rwanda, } \\
\text { Uganda, DRC } \\
\text { South Africa }\end{array}$ & $\begin{array}{r}\text { USA, Saudi } \\
\text { Arabia, Israel, } \\
\text { Sudan, Kenya }\end{array}$ & $\begin{array}{r}\text { France, Spain, } \\
\text { Italy, the } \\
\text { Netherlands, } \\
\text { Israel }\end{array}$ \\
\hline Main reasons for migration * & $\begin{array}{r}\text { Conflict, } \\
\text { general } \\
\text { insecurity, } \\
\text { economic, } \\
\text { education }\end{array}$ & $\begin{array}{r}\text { Conflict, } \\
\text { general } \\
\text { insecurity }\end{array}$ & $\begin{array}{r}\text { Economic, } \\
\text { general } \\
\text { insecurity }\end{array}$ & Economic \\
\hline $\begin{array}{l}\text { Migrant remittance inflows } \\
(2017), \text { US\$ million }{ }^{c}\end{array}$ & 479 & 58 & 806 & 7,088 \\
\hline $\begin{array}{l}\text { Personal remittances } \\
\text { received (2016), \% of GDP d }\end{array}$ & 2.21 & 1.04 & 1.01 & 6.84 \\
\hline
\end{tabular}

Sources: a World Bank (2016); b United Nations, Department of Economic and Social Affairs, Population Division

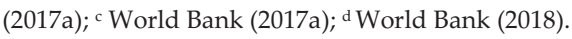

Note: ${ }^{*}$ The sources used to identify the main reasons for migration for each country are identified in the text below.

Firstly, the four countries are characterized by vastly different migration contexts, an indication of which is given by the data on absolute and relative levels of emigration, top destination countries, and the absolute and relative volume of remittances in Table 4.1. As can be seen, emigration is much more significant both in absolute terms and as a share of the total population in Afghanistan and to a lesser extent in Morocco than it is in the Sub-Saharan countries. At the same time, remittances are the most significant as a financial flow at the macro-level in Morocco both in absolute terms and seen 
relative to GDP. Particularly in relative terms, they are much less significant in the other three countries, though it is important to point out that this data only accounts for remittances sent through official channels and it is not clear what the volume transferred through informal channels is.

Based on the discussions in Chapters 1 and 2 of this dissertation on the differences regarding voluntary and forced migration, it is also especially important to provide an overview of the respective main drivers of migration across the four countries. These different main reasons for migration in turn have consequences for the geographical dimension of emigration.

In the case of Afghanistan, an array of reasons can be identified for driving emigration to other countries. Decades of violent conflict and tensions have been and continue to displace individuals both within the country as well as internationally. In addition, poverty and a lack of economic opportunities are main reasons for migration, along with emigration for study purposes (Marchand et al., 2014).

In Burundi, conflict-induced emigration is the main form of migration. Due to various historical conflicts in 1965, 1972, 1988, 1991, and 1993 as well as more recent violent outbreaks, significant numbers of Burundians sought refuge in other nation states, with the majority of refugees having fled to neighbouring countries (see top migration destinations in Table 4.1) (Fransen \& Otieno Ongáyo, 2010).

In the Ethiopian context, a large proportion of emigration that occurred historically was a result of "escaping political conflict, famine, and persecution" (Fransen \& Kuschminder, 2009, p. 10). However, these patterns have altered and more recently Ethiopian emigration has been dictated predominantly by economic reasons with high rates of female migration, particularly to Middle Eastern countries (Fransen \& Kuschminder, 2009; Marchand, Reinold, \& Dias e Silva, 2017).

Morocco's patterns of emigration are, on the other hand, largely influenced by its colonial past. Traditionally, emigration of Moroccans was primarily characterized by migration for employment purposes to France. In the 1960s and 70s, the demand for low-skilled workers in other European countries grew and labour migration from Morocco, and Northern African countries more generally, increased and diversified to countries such as Belgium, Germany, and the Netherlands. Nowadays, migration from Morocco is even more diverse, with France still remaining the top destination of Moroccan migrants (Berriane \& Aderghal, 2009).

Considering the overall focus of this dissertation on forced migration movements, this chapter therefore provides the opportunity to analyse the question of interest 
regarding the self-employment activities of non-migrants in the context of two countries, Afghanistan and Burundi, which are largely characterized by forced migration. In addition, two countries where socio-economic factors, and specifically employment, are the most common reason for migration are included with Ethiopia and Morocco. Migration from these countries shows geographical diversity in so far that in the case of Morocco most migration is to European countries and in the case of Ethiopia large shares migrate to the Middle East and other African countries, besides the main destination of the United States. In Afghanistan and Burundi, on the other hand, most of the migration, or rather forced displacement, is to neighbouring countries.

Closely related to the main drivers and patterns of migration, the four countries are also characterized by differences in their geographic and socio-economic features (see Table 4.2). With a size of 27,830 square kilometres, Burundi is by far the smallest of the four countries, while Ethiopia is the largest. The same is true in terms of the population size, which ranges from 11.5 million in Burundi to 105 million in Ethiopia, making the latter the $12^{\text {th }}$ most populated country in the world (Central Intelligence Agency, 2017).

In terms of human development, Morocco is the only one of the four countries that is classified as having medium levels, while the remaining three countries are considered to have low levels of human development. With a score of 0.479 Afghanistan only achieves rank 169 out of 188, and with this still fares better than both Burundi and Ethiopia. In terms of economic performance, the data shows that GDP per capita is much higher in Morocco than the other countries and by far the lowest in Burundi.

Looking specifically at the labour market, the reported unemployment rates in the four countries are all relatively low, staying below 10 per cent for all of them. Yet, the rates are significantly higher in Morocco and Afghanistan and are lowest in Burundi. However, as explained in Chapter 1, this likely does not reflect actual unemployment, and particularly underemployment, due to the relatively low number of people that are openly unemployed. The labour force participation rate provides an indication of the share of the working-age population in each country that is actively engaged in the labour market, either by working or by actively looking for work. As the data shows these shares are much higher in Burundi and Ethiopia than they are in Afghanistan and Morocco respectively.

When looking at the participation rates for women and men separately, the difference across countries is clearly explained by the difference in the rates for females. While the share of economically active women is rather low in Afghanistan and Morocco, the 
differences between the gender groups are much smaller in the Sub-Saharan African countries.

Table 4.2: Socio-Economic and Labour Market Characteristics

\begin{tabular}{|c|c|c|c|c|}
\hline & Afghanistan & Burundi & Ethiopia & Morocco \\
\hline Size, sq km a & 652,230 & 27,830 & $1,104,300$ & 446,550 \\
\hline $\begin{array}{l}\text { Population est. (2017), } \\
\text { millions }{ }^{b}\end{array}$ & 35.74 & 10.86 & 104.96 & 35.74 \\
\hline Human Development Index & 0.479 & 0.404 & 0.448 & 0.647 \\
\hline (Rank out of 188 countries) $^{c}$ & 169 & 184 & 174 & 123 \\
\hline $\begin{array}{l}\text { GDP per capita (2016), } \\
\text { current USD }^{d}\end{array}$ & 561.78 & 285.73 & 706.76 & $2,829.78$ \\
\hline Unemployment rate, in \% d & 8.8 & 1.6 & 5.2 & 9.3 \\
\hline $\begin{array}{l}\text { Labour Force Participation } \\
\text { Rate (2017), \% of total } \\
\text { population ages } 15+\mathrm{e}\end{array}$ & 52.53 & 78.87 & 82.46 & 49.00 \\
\hline $\begin{array}{l}\text { Female Labour Force } \\
\text { Participation Rate (2017), \% } \\
\text { of female population ages 15+ }\end{array}$ & 19.47 & 80.21 & 77.22 & 24.96 \\
\hline $\begin{array}{l}\text { Male Labour Force } \\
\text { Participation Rate (2016), \% } \\
\text { of male population ages 15+ }\end{array}$ & 86.71 & 77.45 & 87.82 & 74.14 \\
\hline
\end{tabular}

Sources: a Central Intelligence Agency (2017); b United Nations, Department of Economic and Social Affairs, Population Division (2017b); c United Nations Development Programme (2016); ${ }^{\mathrm{d}}$ International Labour Organization (2018); e World Bank (2018).

It is likely that these differences in socio-economic, labour market, and migration contexts will shape the findings on the linkages between migration of household members and self-employment activities of non-migrants. For one, the differences in reasons for migration lead to the hypothesis that having a migrant in the household only relates to self-employment activities of non-migrants in the cases where the migration of the household member is motivated by economic factors, so in Ethiopia and Morocco. Secondly, the differences in labour force participation rates, specifically of females, indicates that the relationship between a household migrant and selfemployment differs by gender in so far that especially in Afghanistan and Morocco a positive relationship is not expected. 


\subsection{Data and Methodology}

\subsubsection{Data and Sample}

The data used in this chapter was collected in 2011 and 2012 through household surveys conducted in each of the four focus countries of the IS Academy Migration and Development: A World in Motion project. As mentioned previously, these countries are Afghanistan, Burundi, Ethiopia, and Morocco, representing a variety of migration contexts, including two that are largely characterized by forced migration movements. The surveys conducted as part of the project contain extensive information on characteristics of the households and its members with a focus on their migration experiences. Random sampling, ideally applied in order achieve representativeness of results, was not possible and desired in all cases. With the exception of Burundi, each country used a purposive sampling frame in order to be able to capture enough households with both current and return migrants. The sampling frameworks and data collection process applied in each of the four countries are described in more detail in Appendix A.2.

In total, information was gathered from 2,000 Afghan, 2,310 Burundian, 1,286 Ethiopian, and 1,600 Moroccan households. In addition to the household surveys, information was also collected at the community level through a survey with respective community leaders in each of the communities where households were sampled. More information on this is also provided in Appendix A.2.

Considering the different contexts of the four countries, the surveys and resulting data do not come without some challenges that should be addressed in the context of this analysis. Specifically, in the case of Burundi capturing household members that are currently living abroad is difficult. This is due to the fact that when individuals leave a household, they are not considered to be a part of the household anymore by those household members staying behind. Therefore asking whether a household member is currently abroad, which is how the current migrant variable is constructed in the other three countries, vastly underestimated the rates of current emigration in the case of Burundi (Fransen, 2015). It is therefore not possible to use this variable in the same manner in the case of Burundi as in the other three cases.

As there is an undeniable connection between receiving remittances and current migration, generally of someone close to the household, the information collected through the survey on remittances received by each respective household is used to proxy for a current migrant in the household in this case. Specifically, the data captures 
the relationship of the household with the sender of the remittances. In cases where the answer to this question was a family member, it is assumed that this is a prior member of the household.

For the other three countries remittance data appears to be much less reliable than that on current migrants in the household, so that this remains the chosen key explanatory variable as further explained below, instead of remittances directly. In addition, the sole use of remittances may omit other potential effects of the migration of a household member, which overall may underestimate the relationship between migration and self-employment activities of non-migrant household members (McKenzie, 2006).

Secondly, in the case of Afghanistan, the matching of the information from the community survey to the respective households living in that community was not straightforward due to differences in coding of the communities in both datasets. The matching was therefore conducted manually and in some cases some degree of uncertainty remains that the correct households were matched. In order to ensure that this does not skew any results, robustness tests where these communities have been excluded were conducted. The exclusion of these communities did not change the results reported in the upcoming section and as such this does not present a major reason for concern. This issue did not arise in any of the other countries.

Being aware of these challenges and the characteristics of the data more generally, a sub-sample of the overall collected data is used to analyse the engagement in selfemployment activities of non-migrants in the present chapter. The sub-sample for each country includes only individuals of working age, aged between 15 and 65, that have no own migration experience and for which all relevant information was obtained in the surveys.

Table 4.3 provides an overview of the total number of individuals within the surveyed households that information was collected for as well as the sub-sample used in this chapter. As can be seen, the sample sizes for each country range from 3,079 individuals in Afghanistan to 5,808 in Burundi, resulting in a total of 16,737 individuals in the four countries.

Table 4.3: Sample Size per Country

\begin{tabular}{lcccc}
\hline \hline & Afghanistan & Burundi & Ethiopia & Morocco \\
\hline Total Sample & 14,777 & 12,146 & 6,878 & 5,618 \\
Sub-Sample & 3,079 & 5,808 & 3,742 & 4,108 \\
\hline \hline
\end{tabular}




\subsubsection{Empirical Approach}

The aim of this chapter is to analyse the relationship between self-employment activities of non-migrants and the migration experience of other household members. In order to do so, it needs to be considered that making the decision to engage in selfemployment is essentially a two-step process. First, the respective individual needs to decide to work, and only among those that are working can self-employment be observed. Ignoring those not working in the analysis of self-employment determinants may lead to biased results. Therefore, it is important to account for both choices: the decision to work or not and the decision to work in self-employment or another economic activity (wage employment or agricultural activities).

In order to explain the choice of self-employment, a binominal probit with sample selection model is applied in this chapter, following the approach of Van de Ven and Van Praag (1981). This model consists of a sequence of two probit models, which are linked by potential correlation between the models' errors.

The model can formally be expressed as a latent equation:

$$
y_{i}^{*}=x_{i} \beta+u_{1 i}
$$

where only the binary outcome is observed in form of the following outcome equation:

$$
y_{i}^{\text {outcome }}=\left(y_{i}^{*}>0\right) \text {. }
$$

This outcome, in this case the dependent variable indicating self-employment, is only observed, however, if:

$$
y_{i}^{\text {selection }}=\left(z_{i} \gamma+u_{2 j}>0\right)
$$

where

$$
\begin{gathered}
u_{1} \sim N(0,1) \\
u_{2} \sim N(0,1) \\
\operatorname{corr}\left(u_{1}, u_{2}\right)=\rho .
\end{gathered}
$$

In other terms, the model considers that there is a possible correlation between the errors of the two equations. Only if that correlation is zero, can it be assumed that there is no bias in the estimation of self-employment. If the correlation is nonzero, focusing on only those that are working and considering only the factors that impact their likelihood to engage in self-employment is not appropriate as the selection into working is not fully random. 
In order to estimate the model, the independent variables in the selection and outcome equations must differ. $x_{i}$ in the outcome equation is a vector consisting of household member migration experiences (current and return migrant), individual (gender, age, age squared, household head, and years of education), household (household size, land and house ownership, and access to a bank account), and community level (urban versus rural, availability of employment, economic situation, and migration incidence) characteristics. Concrete operationalisations of each of the included possible determinants can be found in Appendix $C$ of this dissertation.

The vector $z_{i}$ in the selection equation contains the same independent variables and in addition controls for a set of three different exclusion restrictions: marital status, the number of children in the household, and an interaction term of gender and the number of children. All three of these can be assumed to impact whether an individual is working or not, but to not directly impact whether this is in self-employment or another activity. Married individuals may be more likely to be working as they have increased economic responsibilities. The number of children, on the other hand, may influence how an individual spends their time, and as this is expected to much more influential among women, the interaction term is also included.

The following Table 4.4 presents the summary statistics of the included independent variables, differentiated by country. 


\section{Table 4.4: Summary Statistics}

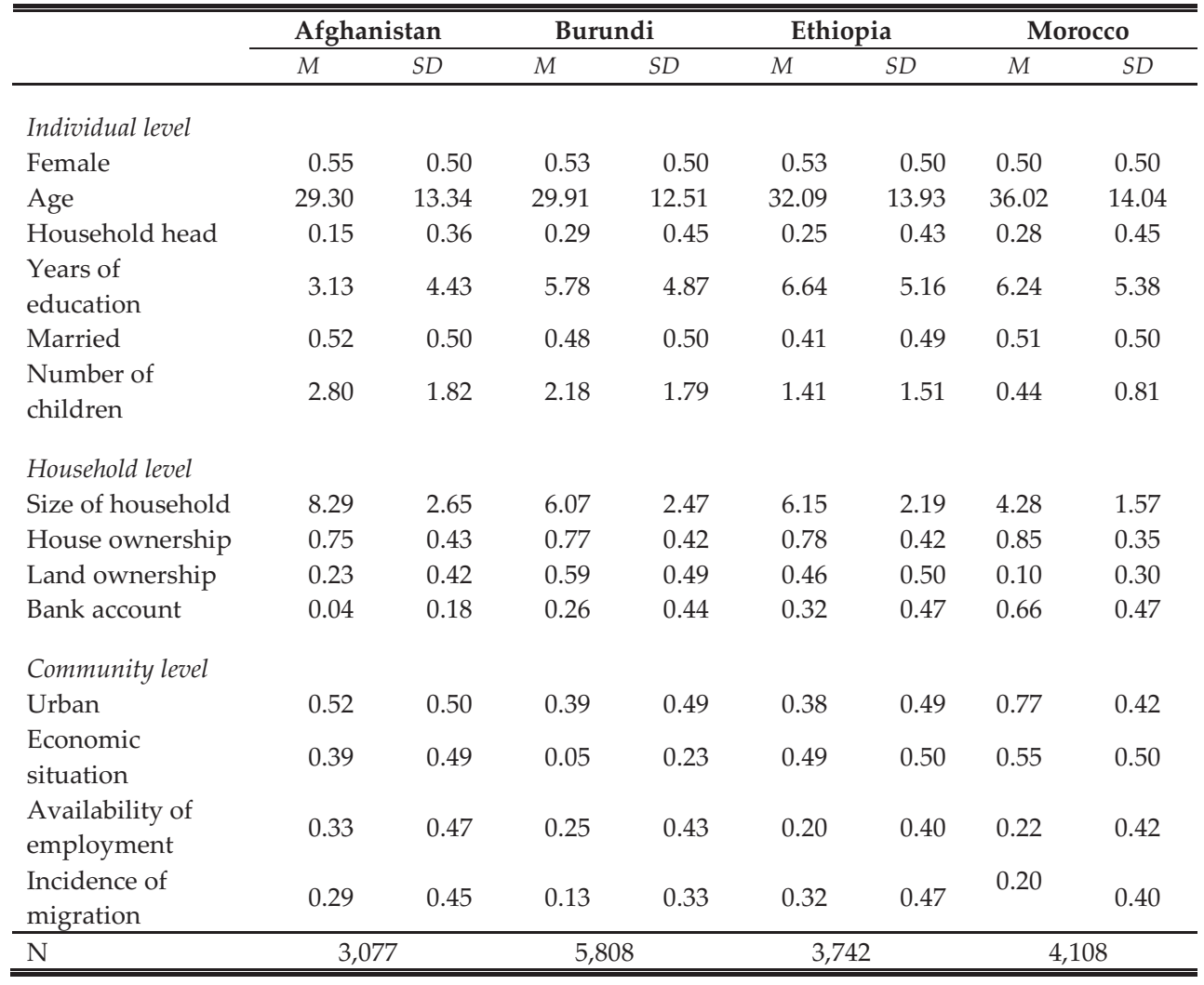

Prior to estimating the models, it is important to consider the possibility of selfselection that is inherently a concern when researching migration and return migration. There is reason to believe that the self-selection into the initial migration movement as well as the self-selection into return migration affect the results in this chapter, as such presenting a significant limitation of the analysis. The main argumentation in this regard is that migrant households differ significantly in observable and unobservable ways from non-migrant households. Therefore, it can also be assumed that those individuals living in these different types of households may have different characteristics that cannot be controlled for in the analysis due to a lack of information on these individuals prior to the migration experience of their household member and the specific motivations for this migration. Therefore, the estimates presented in Section 4.6 are likely to be affected by self-selection and should be taken with caution. If the assumption is that there is a positive selection effect, the bias caused by this would lead to the inflation of the estimates, which means that the results reported should be seen as upper boundaries. 


\subsection{Descriptive Statistics}

Before analysing the relationship between having a migrant in the household and selfemployment activities of non-migrants as well as other determinants of such activities, this section provides an overview of the employment status of the respondents in each country as well as of the migration experiences of household members.

As a first step, it is interesting to look at the participation in the labour market of the overall population of interest in this chapter, which are those of working age (15 to 65). There are interesting differences in this regard across the four countries as can be seen in Table 4.5. Specifically looking at the share of those inactive on the labour market at the time of the survey, the rate in Afghanistan is significantly higher at more than 70 per cent than that in the other countries, with Burundi and Morocco both below 40 per cent. At the same time, unemployment among the sample is much higher in Morocco, with more than one fifth of the sample, than in the other three countries.

Table 4.5: Primary Daily Activity in the Past 12 Months

\begin{tabular}{lcccc}
\hline \hline & Afghanistan & Burundi & Ethiopia & Morocco \\
\hline Working & 784 & 3,394 & 1,526 & 1,598 \\
$\%$ & 25.48 & 41.37 & 40.78 & 38.90 \\
Unemployed & 101 & 75 & 287 & 873 \\
$\%$ & 3.28 & 1.29 & 7.67 & 21.25 \\
Inactive & 2,192 & 2,399 & 1,929 & 1,637 \\
$\%$ & 71.24 & 40.27 & 51.55 & 39.58 \\
\hline \hline
\end{tabular}

The shares of those working also differ significantly across the four countries. In Afghanistan only one quarter of the sample is engaged in one of the three types of economic activities considered (self-employment, wage employment, and agricultural work), while close to 60 per cent are in Burundi. The shares of Ethiopia and Morocco are around 40 per cent respectively.

When breaking this down by gender, the data shows that in all countries but Burundi females are significantly more likely to be inactive than men (see Table C.2 in Appendix C). This is especially the case in Afghanistan, where more than 97 per cent of females are not active on the labour market. In Ethiopia and Morocco, the rates are 68 and 59 per cent respectively. In contrast, the incidence of inactivity for males in these three countries varies between 21 per cent in Morocco and 40 per cent in 
Afghanistan. In Burundi, on the other hand, around 40 per cent of both females and males are inactive.

Descriptive statistics of the employment status of the sub-sample per country show interesting differences. Table 4.6 shows the share of those engaged in self-employment relative to wage employment and self-employment in agriculture across the four countries. The starkest difference is the engagement in agriculture, which ranges from only 6 per cent of the Moroccan sample to more than 70 per cent for Burundi. Wage employment, on the other hand, is the most common in Morocco and least present in Burundi, with Ethiopia and Afghanistan ranging between the two in both cases.

Table 4.6: Type of Primary Daily Activity of Working Population

\begin{tabular}{lcccc}
\hline \hline & Afghanistan & Burundi & Ethiopia & Morocco \\
\hline Self-employment & 362 & 408 & 359 & 549 \\
$\%$ & 46.17 & 12.02 & 23.53 & 34.36 \\
Wage employment & 305 & 583 & 639 & 953 \\
$\%$ & 38.90 & 17.18 & 41.87 & 59.64 \\
Agriculture & 117 & 2,403 & 528 & 96 \\
$\%$ & 14.92 & 70.80 & 34.60 & 6.01 \\
\hline \hline
\end{tabular}

Considering self-employment, the data shows that it is most common as an activity in the case of Afghanistan and least common in Burundi. The differentiation of activities by gender shows interesting differences across the countries also (see Table C.3 in Appendix C). In Burundi, females are in the vast majority of cases active in agricultural work; and more so than their male counterparts. In contrast, males in Ethiopia are relatively more commonly engaged in agriculture than females, who in turn are more often wage or self-employed. In Morocco, three quarters of the females, and more than the males, are active in wage employment. Differences in self-employment between females and males are also apparent in all countries but Afghanistan, though this difference may be less telling due to the overall small share of active women. In Burundi and Morocco, however, relatively less females than males are engaged in selfemployment activities, while the opposite is the case in Ethiopia.

Overall, these basic descriptive statistics show that the composition of the labour force and specifically the working population specifically differs quite significantly between the four countries. This is consistent with what was presented in the context section, which highlighted the difference in labour market contexts in the four countries. In that section, the other point of interest was the difference in migration patterns from 
the four countries. It is therefore of interest to provide an overview of the migration experiences captured in the present data before moving on to analysing the relationship of these with the self-employment activities of non-migrants.

The main interest in this chapter is to investigate whether a migration experience of a household member is related to the self-employment activities of non-migrants. As Table 4.7 shows, the incidence of current and return migrants in the households differs significantly across the four countries. While close to one third of the individuals in the case of Ethiopia indicate that one of their household members is currently living abroad, only slightly more than 1 per cent indicate the same in the case of Burundi.

Table 4.7: Household Member Migration Experiences

\begin{tabular}{lcccc}
\hline \hline & Afghanistan & Burundi & Ethiopia & Morocco \\
\hline \multirow{2}{*}{ Current Migrant } & 241 & 68 & 1,231 & 645 \\
& 7.83 & 1.17 & 32.90 & 15.70 \\
Return Migrant & 594 & 434 & 285 & 87 \\
Current and Return & 19.30 & 7.47 & 7.62 & 2.12 \\
Migrant & 79 & 34 & 86 & 62 \\
& 2.57 & 0.59 & 2.30 & 1.51 \\
No Migrant & 2,163 & 5,272 & 2,140 & 3,314 \\
& 70.30 & 90.77 & 57.19 & 80.67 \\
\hline \hline
\end{tabular}

The incidence of return migrants in the households is significantly higher in Afghanistan than the other three countries, with it being lowest in the case of Morocco. Across the four countries, the individuals that have both a current and a return migrant in the household is relatively low with a maximum of 2.6 per cent in Afghanistan. The vast majority of individuals captured in the data in all four countries, on the other hand, does not live in a household that has a member with a migration experience. This ranges from 57.2 per cent of the respondents in Ethiopia to 90.8 per cent in the case of Burundi.

When looking at cross-tabulations of the primary daily activities of non-migrants and whether their household has a current migrant (Table 4.8) or return migrant (Table 4.9) does not generally indicate that there is a clear relationship between these migration experiences and self-employment activities.

In the case of current migrants there is only a relatively clear difference in selfemployment in Ethiopia, where relatively less individuals with a current migrant are engaged in self-employment than those without a migrant. In the other three countries, 
the relative shares are relatively equal between both types of individuals. Looking at return migrants, there is a bigger difference in the case of Afghanistan than in the other countries. Here, those with a return migrant are relatively less likely to be selfemployed than those without. Similar, even if smaller, differences are observed in Burundi and Ethiopia. In Morocco, on the other hand, there is a relatively larger share of those with a return migrant engaged in self-employment.

Table 4.8: Primary Daily Activity and Current Migrant

\begin{tabular}{lrrrrrrrr}
\hline \hline & \multicolumn{2}{c}{ Afghanistan } & \multicolumn{2}{c}{ Burundi } & \multicolumn{2}{c}{ Ethiopia } & \multicolumn{2}{c}{ Morocco } \\
\cline { 2 - 9 } & \multicolumn{1}{c}{ No } & \multicolumn{1}{c}{ Yes } & \multicolumn{1}{c}{ No } & \multicolumn{1}{c}{ Yes } & \multicolumn{1}{c}{ No } & \multicolumn{1}{c}{ Yes } & \multicolumn{1}{c}{ No } & \multicolumn{1}{c}{ Yes } \\
\hline Self-empl. & 326 & 36 & 402 & 6 & 269 & 90 & 455 & 94 \\
$\%$ & 11.82 & 11.25 & 7.05 & 5.88 & 11.09 & 6.83 & 13.38 & 13.30 \\
Wage empl. & 282 & 23 & 572 & 11 & 436 & 203 & 865 & 88 \\
$\%$ & 10.23 & 7.19 & 10.02 & 10.78 & 17.98 & 15.41 & 25.43 & 12.45 \\
Agriculture & 105 & 12 & 2,377 & 26 & 335 & 193 & 79 & 17 \\
$\%$ & 30.81 & 3.75 & 41.66 & 25.49 & 13.81 & 14.65 & 2.32 & 2.40 \\
Unemployed & 91 & 10 & 74 & 1 & 184 & 103 & 672 & 201 \\
$\%$ & 3.30 & 3.13 & 1.30 & 0.98 & 7.59 & 7.82 & 19.76 & 28.43 \\
Inactive & 1,953 & 239 & 2,281 & 58 & 1,201 & 728 & 1,330 & 307 \\
$\%$ & 70.84 & 74.69 & 39.98 & 56.86 & 49.53 & 55.28 & 39.11 & 43.42 \\
\hline \hline
\end{tabular}

Table 4.9: Primary Daily Activity and Return Migrant

\begin{tabular}{lrrrrrrrr}
\hline \hline & \multicolumn{2}{c}{ Afghanistan } & \multicolumn{2}{c}{ Burundi } & \multicolumn{2}{c}{ Ethiopia } & \multicolumn{2}{c}{ Morocco } \\
\cline { 2 - 9 } & \multicolumn{1}{c}{ No } & \multicolumn{1}{c}{ Yes } & \multicolumn{1}{c}{ No } & \multicolumn{1}{c}{ Yes } & \multicolumn{1}{c}{ No } & \multicolumn{1}{c}{ Yes } & \multicolumn{1}{c}{ No } & Yes \\
\hline Self-empl. & 320 & 42 & 382 & 26 & 329 & 30 & 526 & 23 \\
$\%$ & 13.31 & 6.24 & 7.15 & 5.56 & 9.76 & 8.09 & 13.29 & 15.44 \\
Wage empl. & 273 & 32 & 539 & 44 & 576 & 63 & 931 & 22 \\
$\%$ & 11.36 & 4.75 & 10.09 & 9.40 & 17.09 & 16.98 & 23.52 & 14.77 \\
Agriculture & 103 & 14 & 2,253 & 150 & 503 & 25 & 95 & 1 \\
$\%$ & 4.28 & 2.08 & 42.19 & 32.05 & 14.92 & 6.74 & 2.40 & 0.67 \\
Unemployed & 87 & 14 & 69 & 6 & 256 & 31 & 852 & 21 \\
$\%$ & 3.62 & 2.08 & 1.29 & 1.28 & 7.59 & 8.36 & 21.52 & 14.09 \\
Inactive & 1,621 & 571 & 2,097 & 242 & 1,707 & 222 & 1,555 & 82 \\
$\%$ & 67.43 & 84.84 & 39.27 & 51.71 & 50.64 & 59.84 & 39.28 & 55.03 \\
\hline \hline
\end{tabular}




\subsection{Estimation Results}

To understand the potential relationship between migration and self-employment activities of non-migrants, a binominal probit with sample selection model. as specified in Section 4.2.2, is estimated with the data from Afghanistan, Burundi, Ethiopia, and Morocco respectively. Table 4.10 reports the estimation results for each country in the form of average marginal effects with standard errors in parenthesis.

The upper part of the table presents the outcome stage; in this case self-employment, which takes the value one if the individual engages in this activity and zero otherwise (wage employment or agricultural self-employment). The bottom half contains the selection stage, where it is estimated whether an individual is working or not. Both dependent variables, working and self-employment, are estimated based on a series of independent variables at the personal, household, and community level. As the statistics at the bottom of the table show, both equations should not be estimated separately as the likelihood-ratio test of independent equations rejects the null hypothesis in each of the estimated models.

In the first stage, the selection equation estimates the likelihood of individuals to be working. The results in the lower part of Table 4.10 show that household members that are either current or return migrants differently impact non-migrant individuals' likelihood to work in the four countries. In the case of Afghanistan and Burundi there is no significant relationship. In the case of Ethiopia, on the other hand, there is a negative relationship of a current migrant and no effect of a return migrant. Finally, in the case of Morocco, the estimation also reveals a negative relationship between a current migrant and the likelihood of non-migrants to be working. There is also a positive relationship estimated for a return migrant, significant at the 10 per cent level.

Besides these main variables of interest, there are several other factors that significantly impact the likelihood of a non-migrant to be working at the individual level. Age and being the household head show consistent results across the four countries. The age variable shows that the likelihood of working increases as a person gets older, an effect that is not linear as evidenced by the significance of the squared age term. Being the household head equally is associated with a higher likelihood of working in all four countries.

The effect of gender is consistent across Afghanistan, Ethiopia, and Morocco and shows that females are significantly less likely to be working than their male counterparts. In the case of Burundi this is not significant. The years of education completed, on the other hand, appears to have opposing effects on the likelihood of 
working in Afghanistan and Burundi, where it is negative, in contrast to Ethiopia and Morocco where it is positive.

As explained in Section 4.4.2, being married, the number of children, as well as an interaction term of being female and the number of children were included in the selection equations as exclusion restrictions. The marital status of individuals is not significant in the case of Afghanistan, but positively relates to the likelihood of working in Burundi and Ethiopia and negatively in Morocco. The number of children as such, on the other hand, only increases the likelihood of working in the case of Afghanistan. Furthermore, the interaction term of females and the number of children in their household has the expected negative relationship with the likelihood of working in all countries but Burundi.

At the household level, the effect of the size of the household is significant and negative in Afghanistan and Burundi, but positive in Morocco. More consistently, individuals living in households that own land are more likely to be working in three of the countries, with Afghanistan not showing a significant relationship. House ownership, on the other hand, is only significant and positive in Burundi as well as significant and negative in Ethiopia. Access to a bank account is also only positively related to the likelihood of working in the case of Burundi.

At the community level, factors show even less consistent patterns across the four countries. In Afghanistan, a better economic situation in the community increases the likelihood of working for individuals. In Burundi, on the other hand, only the type of location matters in so far that those living in urban Burundi are significantly less likely to be working than those in rural parts of the country. In Ethiopia, both the overall economic situation as well as the availability of employment increase the likelihood of working. A higher incidence of migration in the community, in contrast, shows a significant negative effect. Finally, in the case of Morocco the availability of employment, counter-intuitively, decreases the likelihood of working.

In the second stage, the outcome equation estimates the binary variable for selfemployment conditional on working. The results show interesting trends that differ across the four countries. In the case of Afghanistan and Burundi, the two cases included as examples of forced migration contexts, neither a current migrant nor a return migrant in the household show any relationship with self-employment activities of non-migrant household members. This is in line with the assumption that in the case of forced migration this movement is less motivated by factors such as the sending of remittances or transmission of skills as the main priority is safety of the household members. 
In the cases of Ethiopia and Morocco, on the other hand, some significant relationships can be observed. In the case of Ethiopia, the return migrant variable is not significant, but the presence of a current migrant in the household does appear to be negatively related to self-employment activities of non-migrants. This means that those individuals that have a current migrant household member have a significantly lower probability of being engaged in self-employment in contrast to working in another activity. Considering that most of the migration captured in the data is labour migration to the Middle East, this result may be in line with the finding in existing literature that migration is used by many Ethiopian households as a livelihood strategy and that the receipt of remittances is a major contribution to their livelihood, but not used for productive investments (Andersson, 2014).

In the case of Morocco, both having a current migrant and a return migrant household member increase the likelihood of non-migrants to be engaged in self-employment. Considering the type of migration from Morocco, this finding may indicate that in the case of the most advanced of the economies included in this chapter with the highest rates of migration to European countries, migration may indeed be used by households as a strategy to overcome credit constraints or to gather additional knowledge and skills to bring people into self-employment in contrast to other labour market activities.

There are also a number of other factors that are related to engaging in selfemployment rather than wage employment or agricultural activities. Looking firstly at individual level factors, as expected, gender is a significant determinant of selfemployment versus other labour market activities in the majority of countries. Females are significantly less likely to engage in such activities than their male counterparts in Afghanistan, Burundi, and Morocco. Age only shows a significant positive sign in Afghanistan. A higher number of years of education generally decreases the likelihood of individuals to be self-employed in all four countries.

At the household level, the household size is positively related with self-employment in Burundi, indicating that individuals in larger households have a higher likelihood of engaging in this activity. The finding in all countries that land ownership decreases the likelihood of self-employment is not surprising as individuals that own land are more likely to engage in self-employment in agriculture than in business. The effect of house ownership, on the other hand, is much less clear. In Afghanistan and Ethiopia no significant effect can be observed. In the case of Burundi, the results show that those individuals in households that own the house in which they reside are less likely to engage in self-employment than other activities. In Morocco, on the other hand, house 
ownership increases the likelihood of self-employment, a finding more in line with expectations as it is often households that are a bit more well off that are able to support self-employment activities in the first place. Access to a bank account by the household, a proxy for access to financial markets, increases the likelihood of selfemployment in Ethiopia and Morocco, an expected finding in so far that this may indicate that the household has access to financial capital to start a self-employment activity in the first place.

Table 4.10: Binomial Probit with Sample Selection Model Estimations per Country

\begin{tabular}{|c|c|c|c|c|}
\hline & $(1)$ & $(2)$ & (3) & $(4)$ \\
\hline & Afghanistan & Burundi & Ethiopia & Morocco \\
\hline \multicolumn{5}{|l|}{ Self-Employment } \\
\hline Current migrant & $\begin{array}{c}0.048 \\
(0.040)\end{array}$ & $\begin{array}{c}0.033 \\
(0.050)\end{array}$ & $\begin{array}{c}-0.045 * \\
(0.025)\end{array}$ & $\begin{array}{c}\mathbf{0 . 1 4 0} * * * \\
(0.049)\end{array}$ \\
\hline Return migrant & $\begin{array}{l}-0.016 \\
(0.033)\end{array}$ & $\begin{array}{l}-0.010 \\
(0.024)\end{array}$ & $\begin{array}{c}0.011 \\
(0.039)\end{array}$ & $\begin{array}{c}\mathbf{0 . 1 5 1} * * \\
(0.066)\end{array}$ \\
\hline \multicolumn{5}{|l|}{ Individual level } \\
\hline Female & $\begin{array}{c}-0.205 * * * \\
(0.044)\end{array}$ & $\begin{array}{c}-\mathbf{0 . 0 7 5} * * * \\
(0.017)\end{array}$ & $\begin{array}{c}0.069 \\
(0.054)\end{array}$ & $\begin{array}{c}-\mathbf{0 . 1 2 7} * \\
(0.069)\end{array}$ \\
\hline Age & $\begin{array}{c}\mathbf{0 . 0 1 2} * * \\
(0.005)\end{array}$ & $\begin{array}{c}0.006 \\
(0.004)\end{array}$ & $\begin{array}{c}-0.002 \\
(0.011)\end{array}$ & $\begin{array}{c}0.011 \\
(0.011)\end{array}$ \\
\hline Age squared & $\begin{array}{c}-\mathbf{0 . 0 0 0 * *} \\
(0.000)\end{array}$ & $\begin{array}{c}-0.000 * \\
(0.000)\end{array}$ & $\begin{array}{l}-0.001 \\
(0.013)\end{array}$ & $\begin{array}{l}-0.015 \\
(0.014)\end{array}$ \\
\hline Household head & $\begin{array}{c}0.051 \\
(0.032)\end{array}$ & $\begin{array}{l}-0.017 \\
(0.019)\end{array}$ & $\begin{array}{c}0.055 \\
(0.036)\end{array}$ & $\begin{array}{c}0.052 \\
(0.048)\end{array}$ \\
\hline Years of education & $\begin{array}{c}-\mathbf{0 . 0 0 7} * * \\
(0.003)\end{array}$ & $\begin{array}{c}-\mathbf{0 . 0 0 4} * * \\
(0.002)\end{array}$ & $\begin{array}{c}-\mathbf{0 . 0 1 3} * * * \\
(0.004)\end{array}$ & $\begin{array}{c}-\mathbf{0 . 0 1 7} * * * \\
(0.005)\end{array}$ \\
\hline \multicolumn{5}{|l|}{ Household level } \\
\hline Size of household & $\begin{array}{c}0.003 \\
(0.005)\end{array}$ & $\begin{array}{l}\mathbf{0 . 0 0 5} \text { * } \\
(0.003)\end{array}$ & $\begin{array}{c}0.001 \\
(0.005)\end{array}$ & $\begin{array}{l}-0.004 \\
(0.007)\end{array}$ \\
\hline Land ownership & $\begin{array}{c}\mathbf{- 0 . 1 0 0 *} \\
(0.059)\end{array}$ & $\begin{array}{c}-\mathbf{0 . 0 4 0} * * * \\
(0.015)\end{array}$ & $\begin{array}{c}-\mathbf{0 . 1 8 6} * * * \\
(0.043)\end{array}$ & $\begin{array}{c}-\mathbf{0 . 1 3 8} * * * \\
(0.052)\end{array}$ \\
\hline House ownership & $\begin{array}{c}0.014 \\
(0.025)\end{array}$ & $\begin{array}{c}-0.055 * * * \\
(0.015)\end{array}$ & $\begin{array}{c}0.016 \\
(0.027)\end{array}$ & $\begin{array}{c}\mathbf{0 . 0 6 7} \\
(0.034)\end{array}$ \\
\hline Bank account & $\begin{array}{l}-0.085 \\
(0.070)\end{array}$ & $\begin{array}{c}0.018 \\
(0.017)\end{array}$ & $\begin{array}{c}\mathbf{0 . 1 1 5} \text { *** } \\
(0.029)\end{array}$ & $\begin{array}{c}\mathbf{0 . 0 5 6} \mathbf{6}^{* *} \\
(0.028)\end{array}$ \\
\hline \multicolumn{5}{|l|}{ Community level } \\
\hline Urban & $\begin{array}{c}0.055 \\
(0.039)\end{array}$ & $\begin{array}{c}\mathbf{0 . 2 0 4} * * * \\
(0.025)\end{array}$ & $\begin{array}{c}0.037 \\
(0.033)\end{array}$ & $\begin{array}{c}\mathbf{0 . 0 6 9} * * \\
(0.033)\end{array}$ \\
\hline Employment availability & $\begin{array}{c}0.015 \\
(0.031)\end{array}$ & $\begin{array}{c}-\mathbf{0 . 0 2 7} * \\
(0.014)\end{array}$ & $\begin{array}{c}0.027 \\
(0.064)\end{array}$ & $\begin{array}{l}-0.011 \\
(0.033)\end{array}$ \\
\hline Economic situation & $\begin{array}{c}0.030 \\
(0.027)\end{array}$ & $\begin{array}{c}-0.021 \\
(0.017)\end{array}$ & $\begin{array}{c}-\mathbf{0 . 1 0 3} * * * \\
(0.033)\end{array}$ & $\begin{array}{c}\mathbf{0 . 0 8 7} * * * \\
(0.031)\end{array}$ \\
\hline Migration incidence & $\begin{array}{l}-0.058 \\
(0.038)\end{array}$ & $\begin{array}{c}-0.032 * \\
(0.020)\end{array}$ & $\begin{array}{c}-\mathbf{0 . 1 7 0} * * * \\
(0.058)\end{array}$ & $\begin{array}{c}0.025 \\
(0.031)\end{array}$ \\
\hline
\end{tabular}




\begin{tabular}{|c|c|c|c|c|}
\hline \multicolumn{5}{|l|}{ Working } \\
\hline Current migrant & $\begin{array}{c}0.020 \\
(0.019)\end{array}$ & $\begin{array}{c}0.018 \\
(0.034)\end{array}$ & $\begin{array}{c}-\mathbf{0 . 0 3 2} * * \\
(0.015)\end{array}$ & $\begin{array}{c}-0.054^{* * *} \\
(0.016)\end{array}$ \\
\hline Return migrant & $\begin{array}{l}-0.022 \\
(0.015)\end{array}$ & $\begin{array}{c}0.019 \\
(0.016)\end{array}$ & $\begin{array}{l}-0.029 \\
(0.023)\end{array}$ & $\begin{array}{l}0.050 \text { * } \\
(0.030)\end{array}$ \\
\hline \multicolumn{5}{|l|}{ Individual level } \\
\hline Female & $\begin{array}{c}-\mathbf{0 . 2 8 2} * * * \\
(0.022)\end{array}$ & $\begin{array}{c}0.020 \\
(0.014)\end{array}$ & $\begin{array}{c}-\mathbf{0 . 1 9 0 * * *} \\
(0.017)\end{array}$ & $\begin{array}{c}-0.292 * * * \\
(0.012)\end{array}$ \\
\hline Age & $\begin{array}{c}\mathbf{0 . 0 3 0} * * * \\
(0.003)\end{array}$ & $\begin{array}{c}\mathbf{0 . 0 4 8} * * * \\
(0.002)\end{array}$ & $\begin{array}{c}\mathbf{0 . 0 6 0} * * * \\
(0.003)\end{array}$ & $\begin{array}{c}\mathbf{0 . 0 5 2} * * * \\
(0.003)\end{array}$ \\
\hline Age squared & $\begin{array}{c}-\mathbf{0 . 0 0 0 * * *} \\
(0.000)\end{array}$ & $\begin{array}{c}-0.001 * * * \\
(0.000)\end{array}$ & $\begin{array}{c}-\mathbf{0 . 0 7 5} * * * \\
(0.003)\end{array}$ & $\begin{array}{c}-0.069 * * * \\
(0.003)\end{array}$ \\
\hline Household head & $\begin{array}{c}\mathbf{0 . 1 5 5} * * * \\
(0.019)\end{array}$ & $\begin{array}{c}\mathbf{0 . 1 5 2} * * * \\
(0.015)\end{array}$ & $\begin{array}{c}0.256 * * * \\
(0.020)\end{array}$ & $\begin{array}{c}\mathbf{0 . 2 7 2} * * * \\
(0.017)\end{array}$ \\
\hline Years of education & $\begin{array}{c}-\mathbf{0 . 0 0 5} * * * \\
(0.001)\end{array}$ & $\begin{array}{c}-0.015 * * * \\
(0.001)\end{array}$ & $\begin{array}{c}\mathbf{0 . 0 0 9} * * * \\
(0.002)\end{array}$ & $\begin{array}{c}\mathbf{0 . 0 0 5} * * * \\
(0.001)\end{array}$ \\
\hline Married & $\begin{array}{c}0.010 \\
(0.016)\end{array}$ & $\begin{array}{c}\mathbf{0 . 1 6 3} * * * \\
(0.011)\end{array}$ & $\begin{array}{c}\mathbf{0 . 0 4 3} * * \\
(0.017)\end{array}$ & $\begin{array}{c}-0.052 * * * \\
(0.015)\end{array}$ \\
\hline Number of children & $\begin{array}{c}\mathbf{0 . 0 1 1} * * \\
(0.005)\end{array}$ & $\begin{array}{c}0.008 \\
(0.005)\end{array}$ & $\begin{array}{c}0.009 \\
(0.008)\end{array}$ & $\begin{array}{l}-0.007 \\
(0.011)\end{array}$ \\
\hline Female * children & $\begin{array}{c}-0.032 * * * \\
(0.007)\end{array}$ & $\begin{array}{l}-0.004 \\
(0.005)\end{array}$ & $\begin{array}{c}-\mathbf{0 . 0 4 8} * * * \\
(0.009)\end{array}$ & $\begin{array}{c}-0.037^{* *} \\
(0.016)\end{array}$ \\
\hline \multicolumn{5}{|l|}{ Household level } \\
\hline Size of household & $\begin{array}{c}-0.006 * * \\
(0.003)\end{array}$ & $\begin{array}{c}-0.015 * * * \\
(0.003)\end{array}$ & $\begin{array}{l}-0.002 \\
(0.004)\end{array}$ & $\begin{array}{l}\mathbf{0 . 0 0 7} * \\
(0.004)\end{array}$ \\
\hline Land ownership & $\begin{array}{c}0.015 \\
(0.014)\end{array}$ & $\begin{array}{c}\mathbf{0 . 0 8 3} * * * \\
(0.011)\end{array}$ & $\begin{array}{l}\mathbf{0 . 0 3 3} \text { * } \\
(0.019)\end{array}$ & $\begin{array}{c}\mathbf{0 . 0 4 4} * * \\
(0.019)\end{array}$ \\
\hline House ownership & $\begin{array}{c}0.013 \\
(0.014)\end{array}$ & $\begin{array}{c}\mathbf{0 . 0 6 9} * * * \\
(0.012)\end{array}$ & $\begin{array}{c}-0.049 * * * \\
(0.018)\end{array}$ & $\begin{array}{l}-0.003 \\
(0.017)\end{array}$ \\
\hline Bank account & $\begin{array}{c}0.002 \\
(0.032)\end{array}$ & $\begin{array}{c}\mathbf{0 . 0 2 5} * * \\
(0.012)\end{array}$ & $\begin{array}{l}-0.009 \\
(0.016)\end{array}$ & $\begin{array}{l}-0.007 \\
(0.014)\end{array}$ \\
\hline \multicolumn{5}{|l|}{ Community level } \\
\hline Urban & $\begin{array}{l}-0.014 \\
(0.012)\end{array}$ & $\begin{array}{c}-\mathbf{0 . 1 3 3} * * * \\
(0.012)\end{array}$ & $\begin{array}{l}-0.028 \\
(0.020)\end{array}$ & $\begin{array}{l}-0.013 \\
(0.016)\end{array}$ \\
\hline Employment availability & $\begin{array}{l}-0.022 \\
(0.015)\end{array}$ & $\begin{array}{c}0.016 \\
(0.011)\end{array}$ & $\begin{array}{c}\mathbf{0 . 1 2 6} * * * \\
(0.029)\end{array}$ & $\begin{array}{c}-\mathbf{0 . 0 3 6} * * \\
(0.017)\end{array}$ \\
\hline Economic situation & $\begin{array}{l}\mathbf{0 . 0 2 7} * \\
(0.015)\end{array}$ & $\begin{array}{l}-0.000 \\
(0.013)\end{array}$ & $\begin{array}{c}\mathbf{0 . 0 4 1} * * * \\
(0.016)\end{array}$ & $\begin{array}{l}-0.016 \\
(0.013)\end{array}$ \\
\hline Migration incidence & $\begin{array}{l}-0.010 \\
(0.013)\end{array}$ & $\begin{array}{l}-0.010 \\
(0.014)\end{array}$ & $\begin{array}{c}-0.091 * * * \\
(0.026)\end{array}$ & $\begin{array}{l}-0.023 \\
(0.015)\end{array}$ \\
\hline $\mathrm{N}$ & 3,077 & 5,808 & 3,742 & 4,108 \\
\hline Uncensored N & 784 & 3,394 & 1,526 & 1,598 \\
\hline rho & 0.59 & 0.11 & 0.38 & 0.03 \\
\hline $\begin{array}{l}\text { LR test of indep. eqns } \\
(\mathrm{rho}=0) \text { : chi2(1) }\end{array}$ & 1.79 & 0.73 & 0.02 & 0.01 \\
\hline
\end{tabular}

Note: Average marginal effects are reported with standard errors in parentheses. ${ }^{* * *} \mathrm{p}<0.01,{ }^{* *} \mathrm{p}<0.05,{ }^{*} \mathrm{p}<0.1$. 
At the household level, the household size is positively related with self-employment in Burundi, indicating that individuals in larger households have a higher likelihood of engaging in this activity. The finding in all countries that land ownership decreases the likelihood of self-employment is not surprising as individuals that own land are more likely to engage in self-employment in agriculture than in business. The effect of house ownership, on the other hand, is much less clear. In Afghanistan and Ethiopia no significant effect can be observed. In the case of Burundi, the results show that those individuals in households that own the house in which they reside are less likely to engage in self-employment than other activities. In Morocco, on the other hand, house ownership increases the likelihood of self-employment, a finding more in line with expectations as it is often households that are a bit more well off that are able to support self-employment activities in the first place. Access to a bank account by the household, a proxy for access to financial markets, increases the likelihood of selfemployment in Ethiopia and Morocco, an expected finding in so far that this may indicate that the household has access to financial capital to start a self-employment activity in the first place.

At the community level, the type of location in terms of urban and rural does impact the likelihood of being in self-employment in Burundi and Morocco, where those in urban areas are significantly more likely to engage in such activities than those in rural areas. This is likely due to the fact that markets and opportunity structures overall are more prominent in such settings and as such drive self-employment. The availability of employment shows a negative effect in Burundi, though this is only significant at the 10 per cent level and is likely driven by a heavy reliance on agricultural activities in the rural parts of the country. The overall economic situation in the community is significant in Ethiopia and Morocco and shows opposing signs for the two countries, with a decreasing likelihood of self-employment in the former and an increasing one in the latter country. Furthermore, a higher incidence of migration at the community level decreases the likelihood of self-employment versus other labour market activities in Burundi and Ethiopia. This may be due to the fact that when others leave, more opportunities exist in wage employment and agriculture for those staying behind.

Following this overall analysis of the role of migration experiences of household members on the likelihood of self-employment of non-migrants, it is important to separately estimate the models by gender as well as location type to check the robustness of the results reported above. The separate analysis by gender is important considering the differences in labour market participation rates identified in Section 4.3 and the evidence in the literature that migration of a household member may have 
different impacts on females and males (see Section 4.2). The second distinction is necessary based on the fact that labour markets and opportunities for self-employment tend to be quite different in rural areas of developing countries than they are in urban areas (McElwee, 2008).

Table 4.11 reports the results for the main variables of interest capturing the migration experiences of models estimated separately for females and males for each country respectively. The model for females in Afghanistan was not estimated separately as the number of working females is so low. Table 4.12 does the same separating urban and rural areas in each country. The same control variables as previously were used, and the full tables are included in Appendix D of this dissertation for reference, but not discussed further here. Corresponding to the above analysis, the top half of the tables reports the outcome stage of the estimation, while the selection stage is presented in the bottom half.

With regards to the potential relationship of migration experiences of household members and the labour market engagement of non-migrants, the results show that the effects identified above do not hold. When differentiating the estimation by gender only the positive effect of a current migrant in the context of Morocco remains significant for males. This is the case in both the selection and the outcome estimation. In the case of females, no relationship can be found.

Table 4.11: Binomial Probit with Sample Selection Models by Gender

\begin{tabular}{|c|c|c|c|c|c|c|c|c|}
\hline & \multicolumn{2}{|c|}{ Afghanistan } & \multicolumn{2}{|c|}{ Burundi } & \multicolumn{2}{|c|}{ Ethiopia } & \multicolumn{2}{|c|}{ Morocco } \\
\hline & Female & Male & Female & Male & Female & Male & Female & Male \\
\hline \multicolumn{9}{|l|}{ Self-employment } \\
\hline \multirow{2}{*}{ Current Migrant } & & 0.057 & 0.012 & 0.065 & -0.009 & -0.039 & 0.044 & $0.116^{* *}$ \\
\hline & & $(0.059)$ & $(0.071)$ & $(0.100)$ & $(0.024)$ & $(0.033)$ & $(0.073)$ & $(0.047)$ \\
\hline \multirow[t]{2}{*}{ Return Migrant } & & -0.010 & -0.045 & 0.017 & 0.040 & -0.010 & 0.203 & 0.079 \\
\hline & & $(0.052)$ & $(0.036)$ & $(0.048)$ & $(0.035)$ & $(0.054)$ & $(0.137)$ & $(0.073)$ \\
\hline Controls & & $X$ & $X$ & $X$ & $X$ & $X$ & $X$ & $X$ \\
\hline \multicolumn{9}{|l|}{ Working } \\
\hline \multirow[t]{2}{*}{ Current Migrant } & & -0.004 & 0.036 & 0.007 & -0.033 & -0.020 & -0.027 & $-0.072 * * *$ \\
\hline & & $(0.039)$ & $(0.048)$ & $(0.045)$ & $(0.020)$ & $(0.020)$ & $(0.017)$ & $(0.024)$ \\
\hline \multirow[t]{2}{*}{ Return Migrant } & & -0.027 & 0.029 & 0.011 & -0.033 & 0.003 & 0.029 & 0.030 \\
\hline & & $(0.031)$ & $(0.022)$ & $(0.023)$ & $(0.030)$ & $(0.032)$ & $(0.028)$ & $(0.054)$ \\
\hline Controls & & $X$ & $X$ & $X$ & $X$ & $X$ & $X$ & $X$ \\
\hline Observations & & 1,394 & 3,099 & 2,709 & 1,980 & 1,762 & 2,044 & 2,064 \\
\hline
\end{tabular}


Looking at the potential role of household members' migration experiences in selfemployment engagement of non-migrants separately for urban and rural areas also reveals some interesting findings. While the effects are only significant at the 10 per cent level, the presence of a current migrant in the household increases the likelihood of non-migrants to be working in rural parts of both Afghanistan and Burundi, while the opposite is the case in Ethiopia (significant at the 5 per cent level). In the case of rural Afghanistan, a negative relationship can be observed for a return migrant, while this effect is positive in the case of rural Morocco. In urban areas, on the other hand, the negative effect of a current migrant, which was observed in the full model above, holds in the case of Morocco. In addition, a positive effect of a return migrants is observed in Burundi.

Turning to the outcome stage, it is found that there is no relationship between migration experiences of household members and self-employment activities of nonmigrants in rural areas. In urban areas, on the other hand, the presence of a current and return migrant both increase the likelihood of those working in Morocco to be engaged in self-employment. The fact that this is not observed in rural areas of the country, is likely due to the differences in opportunity structure that exist in the different types of location. No significant effects can be observed in the other three countries.

Table 4.12: Binomial Probit with Sample Selection Models by Location Type

\begin{tabular}{lcccccccc}
\hline \hline & \multicolumn{2}{c}{ Afghanistan } & \multicolumn{2}{c}{ Burundi } & \multicolumn{2}{c}{ Ethiopia } & \multicolumn{2}{c}{ Morocco } \\
\cline { 2 - 8 } & Urban & Rural & Urban & Rural & Urban & Rural & Urban & Rural \\
\hline Self-employment & & & & & & & & \\
Current Migrant & 0.058 & 0.038 & 0.103 & -0.014 & -0.013 & -0.051 & $\mathbf{0 . 1 4 9 * * *}$ & 0.080 \\
& $(0.084)$ & $(0.076)$ & $(0.126)$ & $(0.039)$ & $(0.041)$ & $(0.032)$ & $(0.057)$ & $(0.087)$ \\
Return Migrant & 0.003 & 0.013 & -0.018 & -0.005 & 0.030 & 0.012 & $\mathbf{0 . 1 8 7} * *$ & 0.043 \\
& $(0.045)$ & $(0.078)$ & $(0.058)$ & $(0.018)$ & $(0.055)$ & $(0.058)$ & $(0.077)$ & $(0.121)$ \\
Controls & $\mathrm{X}$ & $\mathrm{X}$ & $\mathrm{X}$ & $\mathrm{X}$ & $\mathrm{X}$ & $\mathrm{X}$ & $\mathrm{X}$ & $\mathrm{X}$ \\
\hline \multirow{2}{*}{ Working } & & & & & & & & \\
Current Migrant & -0.007 & $\mathbf{0 . 0 3 9 *}$ & -0.041 & $\mathbf{0 . 0 7 4} *$ & -0.021 & $-\mathbf{0 . 0 4 4} * *$ & $\mathbf{- 0 . 0 5 6 * *}$ & -0.045 \\
& $(0.036)$ & $(0.022)$ & $(0.059)$ & $(0.040)$ & $(0.025)$ & $(0.018)$ & $(0.019)$ & $(0.028)$ \\
Return Migrant & 0.002 & $-\mathbf{0 . 0 4 6 * *}$ & $\mathbf{0 . 0 5 0 *}$ & 0.004 & 0.001 & -0.039 & 0.037 & $\mathbf{0 . 1 1 2}$ \\
& $(0.024)$ & $(0.019)$ & $(0.029)$ & $(0.018)$ & $(0.035)$ & $(0.031)$ & $(0.034)$ & $(0.062)$ \\
Controls & $\mathrm{X}$ & $\mathrm{X}$ & $\mathrm{X}$ & $\mathrm{X}$ & $\mathrm{X}$ & $\mathrm{X}$ & $\mathrm{X}$ & $\mathrm{X}$ \\
\hline Observations & 1,591 & 1,486 & 2,237 & 3,571 & 1,420 & 2,322 & 3,169 & 939 \\
\hline \hline
\end{tabular}




\subsection{Concluding Remarks}

This chapter investigated the linkages between self-employment of non-migrants and migration experiences of their household members to address the research question How are self-employment activities of non-migrants shaped by the forced or voluntary migration experiences of household members?

Using unique data from Afghanistan, Burundi, Ethiopia, and Morocco the determinants of self-employment were analysed with a specific focus on current and return migration of household members. Due to differences in country context in terms of migration and socio-economic characteristics, the analysis across these four countries allowed to develop an understanding of situations in which spill overs of migration on other household members are more likely to influence self-employment of individuals and in which this is less likely to be the case. In addition, the results provided evidence on the determinants of self-employment activities in the four countries more generally.

Considering that most often the relationship between migration and occupational outcomes focuses on the migrants themselves, research on the effects on the economic activities of non-migrant household members is less common. Existing studies on this relationship mainly focus on two aspects, namely the reallocation of time within households as a result of the migration or the return of a household member or the use of remittances, one of which could be productive investments in small businesses. Research on self-employment activities in relation to household member migration specifically is, however, limited at this stage (Giulietti et al., 2013). The present chapter therefore contributes to this literature by analysing the topic in four different country contexts. Each of these countries is characterized by different socio-economic and labour market contexts as well as distinctly different migration determinants and patterns. Due to these differences, each country by itself represents an interesting and valid case study for the question at hand. The chance to compare them, while considering such differences in context, provides an opportunity to learn more about the linkages between migration and self-employment of household members in the country of origin.

While the results should be interpreted with caution due to the possibility of present bias, some interesting results did come out of the estimations. Considering the results across the four countries highlights that indeed the respective country context matters. As expected in cases were migration is dominated by movements that are for reasons such as escaping from violent conflict or general insecurity, in this case Afghanistan 
and Burundi, no relationship between either a current or a return migrant and selfemployment activities could be identified.

In the case of Ethiopia, there is evidence that the presence of a current migrant in the household is negatively associated with working in the first place and then also negatively associated with self-employment conditional on working. Considering that most of the migration captured from this country is migration to the Middle East with the main purpose of sending remittances and contributing to consumption smoothing of the household left behind, such a finding may not be surprising.

Migration from Morocco, on the other hand, is much more likely to be for reasons such as overcoming credit constraints and gathering of savings. In this case the estimates suggest that there is indeed a positive relationship between household members' migration experiences and self-employment activities of working non-migrant household members. This may show that in such an environment, there is potential of migration to contribute to development through positive spill overs of migration on small business development, of not only (return) migrants themselves (Hamdouch \& Wahba, 2015), but also their household members.

While the relationship between migration of household members and the selfemployment of non-migrants is the main focus of the analysis in this chapter, the analysis also provides evidence on determinants of these type of economic activity more generally. Based on the examination of the labour market contexts in each of the four countries and significant differences in terms of the labour market participation rates of women, it was expected that females would be significantly less likely to engage in self-employment generally and specifically in Afghanistan and Morocco. The estimations verify this expectation overall, with the exception of Ethiopia.

Much like in the other chapters of this dissertation, other characteristics that relate to the engagement in self-employment versus other labour market activities are education and land ownership with a negative effect, as well as access to financial capital, proxied through access to a bank account, which is positively correlated with self-employment in Ethiopia and Morocco. In addition, it seems that specifically in the cases of Burundi and Morocco, opportunity structures for self-employment are specifically available in urban areas.

Overall, this chapter contributes to the literature on the impacts of migration on those that stay behind when one or more household members migrate. Considering both current and return migration highlights that there is a potential relationship between the two, but that this largely depends on the country context. Moreover, there are also 
differences in the propensities to engage in self-employment based on the location within a country; an issue that needs further investigation in relation to migration and its potential to support the engagement of non-migrant household members in entrepreneurship. As the present data limits the ability to control for selection effects that may inflate the reported results, more research in this area is particularly opportune in order to gain a deeper understanding of the factors under which such positive spill overs of migration can be expected. This understanding would then enable the development of efficient and effective support mechanisms to maximize the potential that lies in such a relationship for the migrant households, but also the wider communities in the light of local development. 



\section{CHAPTER 5: LABOUR MARKET REINTEGRATION OF RETURNED REFUgEeS IN AFGHANISTAN}





\subsection{Introduction $^{21}$}

The consideration of the labour market participation of forced migrants and their households during migration, as done in the previous two chapters, is important in the light of self-reliance and potential impacts on the hosting and origin country. However, the labour market opportunities in destination countries are also important in terms of perspectives for return to the country of origin. While it is difficult to estimate just how many of today's refugees will be integrated into their host societies, an important consideration over the medium- and long-term is their potential return back to their countries of origin. Just as the influx of refugees from elsewhere may have important development-related consequences for a local community, so too can the sudden arrival of returnees who may have spent years, if not lifetimes, abroad.

Only relatively recently has return migration begun to gain interest among academic scholars and policy-makers as evidence mounts that the knowledge, skills, and savings acquired abroad and, subsequently, transferred upon return have the potential to contribute to positive development outcomes. For the potential of return migration to be realized, the manner in which returnees reintegrate into their communities, including into the labour market, is fundamental. As discussed in Section 2.2.4 of this dissertation, certain case studies on record have found that return migrants are more likely than non-migrants to be self-employed rather than employed as wage labour (Piracha \& Vadean, 2010; Wahba \& Zenou, 2012). Yet, such an observation is ultimately ambiguous without a qualified understanding of the greater context under study, including the underlying causes of migration in the first place. The majority of studies looking at labour market outcomes of returnees focus on contexts characterized by voluntary labour migration. Very few offer insights into the livelihood activities of returned refugees in (post-) conflict environments.

With this in mind, this chapter addresses the following research question: To what extent do forced migration experiences shape the labour market reintegration of returned refugees in a (post-) conflict developing country context? Specifically, it investigates the labour market outcomes of returned refugees in Afghanistan. Even though Afghans today still make up one of the largest refugee populations outside their country, Afghanistan has also experienced significant return migration at various intervals over

\footnotetext{
${ }^{21}$ This chapter is based on: Loschmann, C. \& Marchand, K. (forthcoming). The Labour Market Reintegration of Returned Refugees in Afghanistan (currently under review at Small Business Economics).
} 
the last three decades. This study is motivated by the fact that the reintegration of returned refugees in a (post-) conflict setting like Afghanistan greatly depends on the ability to access sustainable income-generating activities as a basis of their livelihood.

The analysis relies on cross-sectional data from an original household survey collected in five provinces of Afghanistan in 2011. The analytical approach is twofold: first, to compare returned refugees to non-migrants in regard to what influences their respective labour market outcomes; and second, to investigate the influence of the returnees' migration and return experience on those outcomes. Because we are interested in the labour market reintegration of returned refugees, we only take into consideration those returnees who originally migrated because of political or security concerns, or because of an environmental disaster. ${ }^{22}$ While recent reports highlight the increasingly involuntary nature of return for many Afghan refugees and asylum seekers (Bjelica \& Ruttig, 2017; Human Rights Watch, 2017), our sample is made up of returnees from Iran and Pakistan who chose to return because of perceived improvements to the political and security situation in the country, or due to a variety of personal reasons (e.g., missed country, culture or family). None returned because of work-related opportunities, helping to isolate our estimates from selection bias. Based on these criteria, the sample ultimately covers 1,841 working-age individuals, of which 461 are returned refugees.

The results indicate that returned refugees in Afghanistan are less likely to be wage employed in comparison to non-migrants. Differences in labour market outcomes arise from dissimilarities in socio-economic status, including educational attainment, and the strength of social networks. As for the influence of the migration and return experience on employment status, a few key factors are found to be of consequence. First and somewhat expected, being employed prior to migrating helps raise the likelihood of being wage employed upon return. Less expected, however, given the context of forced migration, the more years spent abroad the greater the odds of being wage employed, indicating possible skill acquisition while abroad. Moreover, the amount of savings brought back upon return is positively associated with becoming

\footnotetext{
${ }^{22}$ While the overall focus in this dissertation is on displacement due to conflict and other political factors, environmental factors are also increasingly driving forced migration movements. The drivers of these movements are different, however, the focus in this chapter is on the motivations to return. There are no significant differences between those displaced by conflict and by environmental factors when considering their migration experiences and, particularly, their reasons for return, which is why it was decided to include both reasons for forced migration in this chapter.
} 
self-employed in agriculture or herding (i.e. subsistence farming), while the opposite is true if the individual received assistance upon return or has intentions to re-migrate.

From a scholarly perspective, this study contributes to the academic discussion in a variety of ways. For one, the empirical evidence on refugee return and reintegration into the labour market is relatively limited. Even though descriptive accounts of certain contexts provide insight (International Labour Organization, 2013; Mesić \& Bagić, 2011), none, to the best of our knowledge, take a quantitative methodological approach. One clear reason for this is the fact that large-scale datasets covering conflict-affected environments, such as Afghanistan, are generally rare. That we are able to rely on relatively uncommon primary data in this context provides us with a unique opportunity to investigate the labour market reintegration of returned refugees using this case study. Furthermore, by investigating labour market outcomes, including self-employment in business, of both returned refugees and non-migrants, the study contributes more generally to the literature on labour markets in (post-) conflict settings. Such analysis is important considering the linkages that have been drawn in the literature between employment creation, economic growth, and stabilization after conflict (Collier, 2009; Cramer, 2015).

The remainder of this chapter is structured as follows. The next section provides a review of the relevant literature concerning return migration and the dynamics related to labour market outcomes upon return. This is followed by a more detailed account of the methodology, including the empirical approach and sample. We finally present the results and conclude with a brief summary and policy discussion concerning ways to support returned refugees in Afghanistan in their labour market reintegration.

\subsection{Relevant Literature}

In a (post-) conflict setting still fraught with lingering uncertainty about the future, the sustainability of return and reintegration is often a challenging process (Bascom, 2005). Reintegration takes time and for some returnees is never achieved, often resulting in re-migration (Kuschminder, 2013). Many factors contribute to a successful return and reintegration, including a welcoming community, security, access to basic infrastructure and services, and the chance to make a decent living. A robust local labour market providing job opportunities and livelihood possibilities therefore greatly influences whether or not a returnee chooses to settle permanently again at origin (Black \& Gent, 2006). 
At the same time, conflicts have significant impacts on labour markets and change the types of employment opportunities available (Stewart, 2015). A common feature of conflict is an observed reallocation of employment, largely depending on the development of said conflict. Where infrastructure, for example power plants or fuel facilities, are destroyed, major providers of employment disappear. Equally, trade and tourism tend to be affected by conflict and impact employment opportunities in related sectors (Cramer, 2015). More generally, labour markets in developing countries often leave individuals to decide between engagement in self-employment activities, agriculture, household work, or migration due to a scarcity of wage employment opportunities, particularly in rural regions (Nagler, 2015).

The role of small businesses and self-employment, especially in the informal sector, therefore has received specific attention within these discussions, highlighting the importance of such activities in the context of developing countries in terms of employment and income generation (Zenou, 2008). While self-employment in such contexts may intrinsically be subsistence-based, it is helpful to consider such an activity in relation to entrepreneurship, which more often than not is associated with positive changes such as job and wealth creation, innovation, and related welfare effects (Ács, 2006; Desai, 2011; Naudé, 2010b).

Desai (2011), for example, argues that entrepreneurship creates bottom-up activities addressing immediate and short-term problems. Naudé (2010a), on the other hand, believes that entrepreneurs drive the structural transformation of an economy away from agriculture and towards manufacturing and services. Beyond these macro-level effects, small businesses may also simply be a viable survival strategy when institutional support and social protection mechanisms are lacking (Ciarli et al., 2010). In this respect, it is necessary to make the distinction between opportunity and necessity entrepreneurship.

Whereas opportunity entrepreneurs are thought to seize unique opportunities in the market, necessity entrepreneurs engage in entrepreneurial activities because it is the best or only option available (Reynolds et al., 2001). According to Margolis (2014), roughly two thirds of self-employment in developing countries is due to a lack of other alternatives for income-generation. Even though entrepreneurship based on opportunity may be preferred, the activities of necessity entrepreneurs are still important to consider in a context like that of Afghanistan; such enterprises generally provide at least one livelihood and, furthermore, do have the potential to contribute to local development (Ciarli et al., 2010). 
In order to start such a self-employment activity, or when it comes to finding a suitable activity in the labour market more generally, three primary types of capital are essential: human, financial, and social. Human capital describes natural characteristics like intelligence and health, but also skills and abilities acquired mainly through education and work experience (Bosma, Van Praag, Thurik, \& De Wit, 2004). Financial capital principally consists of personal savings as well as private and public loans either from friends and family, a financial institution, or the government. Social capital embodies an individual's relationships to others and the network on which one can rely (Westlund \& Bolton, 2003).

Return migrants are often believed to have a distinct advantage in comparison to their non-migrant counterparts (Black, King, \& Tiemoko, 2003). Beyond the potentially innate differences regarding risk aversion and the like, returnees often had sent or come back with substantial savings accumulated while abroad to be consumed and/ or invested once back (Organisation for Economic Co-operation and Development, 2008). Moreover, returnees might arrive with additionally acquired education or skills useful to local markets (Cassarino, 2004). Lastly, in many cases spending time abroad exposes one to a diverse set of social networks potentially providing a returnee with a greater number of links and therefore opportunities beyond the community once back. On the other hand, migrating in the first place may lead to a loss in contact with local networks which may put returnees at a disadvantage with respect to local opportunities (Klagge et al., 2007).

With this conceptual framework at hand, a number of empirical studies focusing on voluntary migration have tried to identify the labour market activities of returnees, and more specifically the factors leading to self-employment and small business establishment. With regards to human capital, there is ample evidence that points to its importance in finding employment and for the small business creation by returnees. Looking at Turkish returnees from Germany, Dustmann and Kirchkamp (2002) find evidence of education as a driving factor of self-employment. In this case those returnees with a higher education level have a greater probability of opening a business compared to non-participation, likely due to expected positive returns of education increasing the likelihood of choosing such an activity. Borodak and Piracha (2011) confirm such a finding when it comes to returning Moldovans, yet explain that those at a lower skill level are unable to afford being without a formal source of income leading to the greater likelihood of wage employment.

Conversely however, Ilahi (1999) and McCormick and Wahba (2001) show that returnees with higher levels of education are more likely to be wage employed rather 
than self-employed in the case of Pakistan and Egypt, respectively. Still, additional evidence in the latter case suggests that the length of employment while abroad also positively influences the odds of becoming self-employed upon return, an outcome corroborated elsewhere (Black \& Castaldo, 2009; McCormick \& Wahba, 2001; Wahba \& Zenou, 2012).

Therefore it appears, as Tani and Mahuteau (2008) show in their study of returnees to North Africa, that the practical experiences and skills gained abroad play a crucial role in determining self-employment, while formal education is more likely to lead to wage employment, even if it also decreases the chance of unemployment more generally.

The most common finding concerning self-employment in particular relates to financial capital, and more specifically the role of savings accumulated abroad, in the launch of a small business upon return. For instance, both Arif and Irfan (1997) and Piracha and Vadean (2010) find strong indications that return migrants are more likely to be self-employed in business in comparison to non-migrants precisely because they had the opportunity to gather start-up capital abroad. Focusing exclusively on return migrants, Ilahi (1999), Dustmann and Kirchkamp (2002), and Mesnard (2004) arrive at a similar conclusion showing that return migrants are prone to invest savings from abroad in business ventures back home; suggesting that temporary migration may at times be employed as a strategy to overcome credit constraints faced in the country of origin. While in the context of forced migration this strategy is less applicable, it may still be the case that migrants are able to accumulate savings abroad that they can indeed utilize upon return to the home country.

Finally, when it comes to social capital, personal networks play a significant role in the reintegration of return migrants in the home country (Omata, 2012). The role networks play in the labour market reintegration of returnees is on the other hand empirically unclear. Black and Castaldo (2009), for instance, find that the strength of personal linkages, measured by membership in an association in the host country and visits to the home country, does have a positive effect on business start-ups of return migrants in both Ghana and Côte d'Ivoire.

Conversely, Piracha and Vadean (2010) find no evidence of social capital, proxied by the number of friends one has, having any impact on the occupational choice of return migrants in the case of Albania, despite there being a significant effect for nonmigrants. Going one step further, Wahba and Zenou (2012) model the potential tradeoff between the financial and human capital accumulated while abroad against the social capital lost due to moving in the first place. In the context of Egypt, they provide evidence that gains in both financial and human capital play a significant role in the 
choice of self-employment upon return, whereas a loss in social capital has no impact on returnees to become entrepreneurs, even if it does for non-migrants. Ultimately, the role of social capital largely depends on the specific local context as well as the type of employment activity. Return migrants may have comparative advantages in sectors where foreign networks are specifically beneficial, while non-migrants may benefit from having stronger local networks where those are most important.

Although at times differing, overall the existing studies indicate that the migration experience greatly influences labour market outcomes of return migrants once back in the country of origin. Still, these experiences are not uniform as some individuals are inherently presented with greater opportunities abroad and therefore greater job prospects upon return (Arif \& Irfan, 1997; Gubert \& Nordman, 2011; Kilic et al., 2009). In a study of returnees in seven capital cities in Western Africa for example, de Vreyer et al. (2010) show that there are significant differences in the uptake of an entrepreneurial activity upon return depending on the country of migration. In particular, they find those who returned from OECD countries in comparison to nonOECD countries are more likely to be entrepreneurs due to the better chances to accumulate financial and human capital at those destinations. Additionally, differences in the environment to which the migrant returns also play an important role. As such, it is important to better understand the labour market activities of returned refugees in particular (post-) conflict settings, in order to promote conditions that facilitate sustainable return and reintegration processes for this type of returnee.

\subsection{Context}

After decades of conflict, Afghanistan was for a long time the country with the largest refugee population worldwide and has only recently been surpassed by the Syrian Arab Republic. As of 2017, there were still around 2.6 million Afghans located both within the immediate region and further abroad (United Nations High Commissioner for Refugees, 2018a). At the same time however, the country has witnessed massive return migration at various intervals over the last three decades. The fall of the Najibullah-led government in 1992, for instance, led to nearly 3 million refugees officially repatriating within two years. Likewise, the Taliban's ouster in 2001 resulted in the sudden return of 2 million refugees in the following year alone, and another 3.6 million in the immediate years following (see Figure 5.1). While return flows tapered off around 2006, the most recent yearly figure of officially returned refugees in 2016 was back up to levels not seen since then. In fact, the estimated 385,000 individuals repatriated throughout 2016 is a more than five-fold increase relative to the year prior. 
The International Organization for Migration (2017) believes there may have been an additional 690,000 returnees who remained undocumented in the same year.

Figure 5.1: Refugees from and Returned Refugees in Afghanistan, 1990-2017

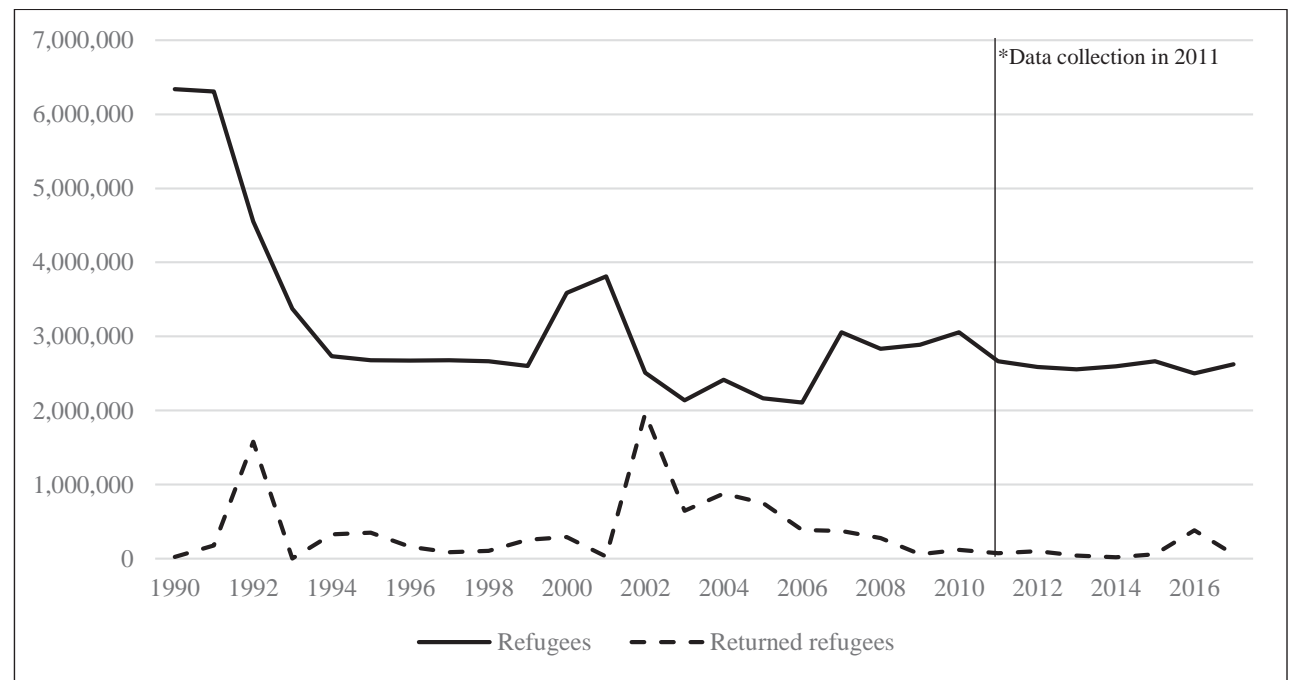

Source: UNHCR (2018d).

Note: The number of 'Refugees' indicates the stock of the population from Afghanistan, while the number of 'Returned refugees' indicates flows within the calendar year (i.e. January-December).

Whereas more recent return movements to Afghanistan have been reported to increasingly include involuntary returnees (Bjelica \& Ruttig, 2017; Human Rights Watch, 2017), earlier return movements, like the ones captured in the present data, were largely voluntary. And while the voluntary repatriation of such a large number of individuals may be seen as an overall encouraging trend, it is not without complications when these movements are to a (post-) conflict setting; also in terms of labour market integration.

As discussed in the literature review in the previous section as well as in Section 2.2.4, earlier empirical studies indicate that migration and return experiences may influence the propensity of returnees to become self-employed back in the country of origin. Still, clearly the environment to which the migrant returns also greatly influences their employment opportunities. In the case of Afghanistan, the many years of conflicts have had a severe impact on individual well-being and more general development of the country. The latest round of the National Risk and Vulnerability Assessment (NRVA) from 2011/12 showed that fixed, formal jobs are broadly insufficient especially in rural areas of high return and a quarter of the population is not gainfully employed at all (Central Statistics Office, 2014). This number, however, might be underestimating 
the challenges present in the Afghan labour market as ILO reports an underemployment rate of 48.2 per cent (International Labour Organization, 2012). Given the general situation present in Afghanistan for not only returnees but the population at large, the labour market integration of returnees poses a challenge in the framework of sustainable reintegration and as such a deeper understanding of this issue is necessary.

\subsection{Data and Methodology}

\subsubsection{Empirical Approach}

As indicated prior, our objective is twofold: firstly, to compare returned refugees to non-migrants in regard to what influences their respective labour market outcomes; and secondly, to investigate the influence of the returnees' migration and return experience on those outcomes.

In both cases we employ a multinomial logit model to estimate the propensity that an individual is engaged in one of three labour market activities compared to the base alternative of not working. These three activities include self-employment in business, agriculture which incorporates subsistence farming and/ or animal herding, and wage employment.

Formally, the model can be expressed as:

$$
\operatorname{Pr}\left(y_{i}=j\right)=\frac{e^{\beta_{j} x_{i}}}{\sum_{k=1}^{K} e^{\beta_{k} x_{i}}}
$$

where $y_{i}$ represents activity $j$ of individual $i$. On the right-hand side of the equation, the $x_{i}$ vector incorporates a range of individual, household, and community characteristics $^{23}$, as well as migration- and return-related characteristics when looking exclusively at returnees, and $\beta_{j}$ represents the vector of activity-specific coefficients.

Prior to estimating the models, it is important to consider the possibility of selfselection. As has been established in the literature, there is reason to believe that both migrants and returnees may be intrinsically different from non-migrants based on unobservable characteristics that are correlated with employment status. Most of the evidence in this regard pertains to labour migration and the prospect that migrants are inherently more intrepid, and thus less risk averse, than the non-migrant population,

\footnotetext{
${ }^{23}$ A description of the included variables can be found in Table D.1 in Appendix D.
} 
and that return migrants may have picked up informal skills and expertise during their time abroad (Organisation for Economic Co-operation and Development, 2008). Similarly, migrants may return only when they believe that the prospects for employment have improved to their advantage (Hautaniemi, Juntunen, \& Satō, 2013; Novak, 2007).

As discussed prior, our sample is limited to only those returnees who originally migrated because of political or security concerns, or because of an environmental disaster, and who stated their return was motivated by improvements to the political and security situation of the country, or a variety of personal reasons (e.g. missed country, culture or family). ${ }^{24}$ We believe that by excluding voluntary migrants, and the few returnees motivated by employment opportunities, our estimates are less afflicted by selection bias than would otherwise be the case. Nonetheless, even in a context of systematic insecurity there may be inherent differences between those able to migrate as well as those deciding to return. The estimates, therefore, may still potentially suffer from positive self-selection and should be interpreted with caution. However, under such conditions, one can assume such bias would lead to inflated estimates and as a result the reported findings can be considered upper bounds.

\subsubsection{Data and Sample}

The data used for the analysis comes from an original household survey implemented across Afghanistan in 2011 for the IS Academy “Migration \& Development: A World in Motion" project. ${ }^{25}$ Although not nationally representative due to difficulties surveying in high risk locations throughout the country, the sampling incorporated households of differing fundamental characteristics in order to increase overall representativeness.

More specifically, the five provinces of Kabul, Herat, Balkh, Nangarhar, and Kandahar were selected because of their highly populated urban centres, geographical dispersion, and varied profiles of migration. Within each province, a stratification of districts was applied based on whether they were considered urban, semi-rural, or

\footnotetext{
${ }^{24}$ The percentage of all returnees who indicated their original migration episode was voluntary is around a quarter of the original sample, while the percentage of all returned refugees who indicated they returned for employment opportunities is less than 1 per cent.

${ }^{25}$ More information on the project more generally as well as the sampling and data collection process is provided in Appendix A.2 of this dissertation.
} 
rural. ${ }^{26}$ This stratification allowed for greater representation of different socioeconomic groups, and districts were chosen based on their representativeness of the province at large.

The primary sampling units were then selected at random taking into consideration a detailed list of specific sites for enumeration provided by the Afghan Central Statistics Office. In all, ten communities within an urban area and five from each of the semirural and rural areas were selected for enumeration. Within the communities, the absence of any official household listing made it necessary for the team leader to discuss the rough makeup of the community with a local leader or elder prior to enumeration. This led to a general distributional profile of the community based on current migrant, return migrant, and non-migrant households which was then respected throughout enumeration in order to be as representative as possible. Finally, the selection of households followed a random starting point and fixed interval sampling strategy in order to meet the pre-specified quota in each community. Ultimately, the survey covered a total 14,777 individuals within 2,005 households across 100 distinct communities.

Once excluding individuals outside the working age range of 15 to 65 , inactive on the labour market, females and returnees who migrated voluntarily as well as those that returned before 1992, we are left with a sample of 1,841 respondents of which 461 are returned refugees. ${ }^{27}$ Table 5.1 provides the summary statistics of the sample, differentiated by migration status. We report a mean difference test in the final column, which only applies to those variables applicable to both non-migrants and returnees. This shows that returned refugees and non-migrants differ significantly in terms of many of the socio-economic characteristics, such as age, marital status, household head status, and the number of children. In addition, returned refugees are interestingly more likely to engage in community organizations, the proxy for social networks, than non-migrants.

\footnotetext{
${ }^{26}$ Urban refers to those communities which are the district capital; semi-rural refers to those communities which share a common border with the district capital; and rural refers to those communities with no common border with the district capital.

${ }^{27}$ We look at male respondents only given women's labour force participation in Afghanistan is systematically lower than that of men (Central Statistics Office, 2014). We exclude inactive individuals, for example retired or permanently sick/disabled. We do not consider individuals who returned prior to 1992 because of differences to the political climate prior to the fall of the Najibullah regime in that year. These individuals account for only 8 per cent of all returnees in the original sample.
} 
Table 5.1: Summary Statistics, Comparing Non-migrants to Returned Refugees

\begin{tabular}{|c|c|c|c|c|c|}
\hline & \multicolumn{2}{|c|}{ Returned Refugees } & \multicolumn{2}{|c|}{ Non-migrant } & \multirow[b]{2}{*}{$t$-tes } \\
\hline & mean & $s d$ & mean & $s d$ & \\
\hline \multicolumn{6}{|l|}{ Socio-demographic covariates } \\
\hline Head of $\mathrm{HH}$ & 0.9306 & 0.2544 & 0.5043 & 0.5002 & $* * *$ \\
\hline Age & 41.30 & 12.09 & 32.57 & 14.17 & $* * *$ \\
\hline Married & 0.9393 & 0.2391 & 0.5920 & 0.4916 & $* * *$ \\
\hline Number of Children & 3.28 & 1.88 & 2.90 & 1.95 & $* * *$ \\
\hline \multicolumn{6}{|l|}{ Education Attainment: } \\
\hline Lower than secondary & 0.8482 & 0.3593 & 0.8884 & 0.3150 & * \\
\hline Secondary or higher & 0.1518 & 0.3593 & 0.1116 & 0.3150 & * \\
\hline HH Owns Land & 0.2234 & 0.4170 & 0.2290 & 0.4203 & \\
\hline Social Network & 0.7983 & 0.4017 & 0.6812 & 0.4662 & $* * *$ \\
\hline \multicolumn{6}{|l|}{ Migration and return covariates } \\
\hline Employed Pre-Migration & 0.2581 & 0.4381 & & & \\
\hline \multicolumn{6}{|l|}{ Migration Destination: } \\
\hline Pakistan & 0.7115 & 0.4536 & & & \\
\hline Iran & 0.2885 & 0.4536 & & & \\
\hline Migration Duration (years) & 12.32 & 7.58 & & & \\
\hline Remittances Sent & 0.0564 & 0.2309 & & & \\
\hline \multicolumn{6}{|l|}{ Return Period: } \\
\hline 1992-2001 & 0.5141 & 0.5003 & & & \\
\hline $2002-2011$ & 0.4859 & 0.5003 & & & \\
\hline Time Since Returned (years) & 10.26 & 5.03 & & & \\
\hline Return Reason: Political/Security & 0.7223 & 0.4483 & & & \\
\hline Return Savings (USD) & 246.19 & 889.54 & & & \\
\hline Return Assistance & 0.2842 & 0.4515 & & & \\
\hline Re-migration Intentions & 0.1887 & 0.3917 & & & \\
\hline
\end{tabular}

Note: Significance Levels reported are ${ }^{*} \mathrm{p}<0.10,{ }^{* *} \mathrm{p}<0.05,{ }^{* * *} \mathrm{p}<0.01$.

In looking at some of the migration-related characteristics for returned refugees only, a quarter of returnees were employed prior to migrating and over two thirds of all returnees migrated to Pakistan while the rest went to Iran. ${ }^{28}$ The average time abroad is around 12 years and only 6 per cent of the respondents sent remittances during the period they were abroad. In terms of the return experience, around half repatriated between the fall of the Najibullah regime in 1992 and the ouster of the Taliban regime in 2001, corresponding to the average of ten years since return. Nearly three-fourths of

\footnotetext{
${ }^{28}$ Just four returnees in the original sample indicated having migrated to and returned from a country besides Pakistan or Iran (i.e. England, UAE, Saudi Arabia and Tajikistan). However, none of those observations are included in the final sample used for analysis following the aforementioned exclusion criteria.
} 
returnees cited improvements in the political and/ or security situation as the main reason for return, while the rest reported personal reasons (i.e. wanting to be closer to my family and friends). Looking at financial capital of returned refugees, the average amount of savings brought back upon return is 246 USD, and 28 per cent received support upon return in the form of financial assistance by either an international organization or the government. Lastly, only 19 per cent of returnees have concrete intentions to re-migrate in the future.

\subsection{Descriptive Statistics}

Before analysing the labour market reintegration of returned refugees relative to the activities of non-migrants in the next section, we first analyse the participation in the labour market of both groups more generally.

Table 5.2 provides an overview of the primary daily activity of returned refugees and non-migrants for the period 12 months prior to the survey. As can be seen, the sample contains a significant share of people that were not working during that time. This includes those that indicated having been unemployed, working unpaid in a family business, or doing household work. The share of those not working is slightly larger among the non-migrants (16.5 per cent) than the returned refugees (14.8 per cent).

\section{Table 5.2: Primary Daily Activity in the Past 12 Months}

\begin{tabular}{lrr}
\hline \hline & $\begin{array}{c}\text { Returned } \\
\text { refugees }\end{array}$ & $\begin{array}{c}\text { Non- } \\
\text { migrants }\end{array}$ \\
\hline Working & 393 & 1,154 \\
$\%$ & 85.25 & 83.62 \\
Unemployed & 35 & 116 \\
$\%$ & 7.59 & 8.40 \\
Family business (unpaid) & 32 & 77 \\
$\%$ & 6.94 & 5.58 \\
Doing housework & 1 & 33 \\
$\%$ & 0.22 & 2.39 \\
\hline Total & 461 & 1,380 \\
$\%$ & 100.00 & 100.00 \\
\hline \hline
\end{tabular}

Note: Differences between returned refugees and non-migrants are significant at the 1 per cent level.

When looking at the kinds of economic activities that those that are working engage in, Table 5.3 shows the primary daily activity split up into the three possible types of activities. When comparing non-migrants to returned refugees based on this main variable of interest, we find that the difference regarding the likelihood of not working 
is mostly due to the fact that returnees are more likely to be self-employed in business. Close to 59 per cent of the returned refugees indicated that their main activity was in this category, while this is the case for 52.2 per cent of the non-migrants. The share of both groups working in wage employment also differs significantly (31.5 per cent of non-migrants versus 24.9 per cent of returnees), while the shares of returned refugees and non-migrants in agriculture are relatively seen more similar at 16 per cent.

Table 5.3: Labour Market Activity in the Past 12 Months

\begin{tabular}{lrr}
\hline \hline & $\begin{array}{c}\text { Returned } \\
\text { refugees }\end{array}$ & $\begin{array}{c}\text { Non- } \\
\text { migrants }\end{array}$ \\
\hline Self-employed & 230 & 602 \\
$\%$ & 58.52 & 52.17 \\
Wage employed & 98 & 364 \\
$\%$ & 24.94 & 31.54 \\
Agriculture & 65 & 188 \\
$\%$ & 16.54 & 16.29 \\
\hline Total & 393 & 1,154 \\
$\%$ & 100.00 & 100.00 \\
\hline \hline
\end{tabular}

Note: Differences between returned refugees and non-migrants are significant at the 1 per cent level.

\subsection{Estimation Results}

In presenting our empirical results, we begin with a simple examination of whether being identified as a returned refugee makes an individual more likely to be involved in one of the three labour market activities in comparison to not working. In all models hereafter, we report the relative risk ratios along with robust standard errors in parentheses estimated using multinomial logit models as described in Section 5.4.1. Aside from the socio-demographic covariates presented in the tables, all models control for the ethnicity (i.e. Pashtun, Tajik, other ${ }^{29}$ ) of the returnee as well as the district type (i.e. urban, semi-rural or rural), and province of return. ${ }^{30}$

Table 5.4 shows that when controlling for basic socio-demographic characteristics, a returned refugee is on average less likely to be involved in agricultural activity as well as wage employment holding all else constant. More specifically, for returned refugees

\footnotetext{
${ }^{29}$ The original questionnaire included more ethnic groups including Uzbek, Hazara, Turkmen, and Baloch, however the limited number of each in the sample led us to group these into one 'other' category.

${ }^{30}$ For reference Table D. 2, Table D. 3, and Table D. 4 in Appendix B contain the results including these variables for each of the models presented here in Table 5.4, Table 5.5, and Table 5.6 respectively.
} 
relative to non-migrants, the relative risk of being wage employed is less by a factor of 0.42 . While the same relationship holds for self-employment in business, the result is significant at the ten percent level. Taking into consideration the potential for positive self-selection as previously discussed, these estimates can be considered upper bounds meaning the negative effect may be even greater than is found here.

Table 5.4: Labour Market Activity (Multinomial logit estimates)

\begin{tabular}{|c|c|c|c|}
\hline & Self-employment & Agriculture & Wage Employment \\
\hline \multirow[t]{2}{*}{ Returned Refugee } & $0.7093 *$ & $0.5800 * *$ & $0.4169 * * *$ \\
\hline & $(-0.1417)$ & -0.1515 & -0.0913 \\
\hline \multirow[t]{2}{*}{ Head of HH } & $4.6679 * * *$ & $5.1664 * * *$ & $4.8012 * * *$ \\
\hline & -1.1397 & -1.6244 & -1.2508 \\
\hline \multirow[t]{2}{*}{ Age } & $0.9438 * * *$ & $0.9634 * * *$ & $0.9484 * * *$ \\
\hline & -0.0073 & -0.0092 & -0.0079 \\
\hline \multirow[t]{2}{*}{ Married } & $3.1273 * * *$ & $3.0185 * * *$ & $2.3338 * * *$ \\
\hline & -0.7458 & -0.9691 & -0.5853 \\
\hline \multirow[t]{2}{*}{ Number of Children } & 0.9571 & 0.9949 & 0.9839 \\
\hline & -0.0385 & -0.051 & -0.0421 \\
\hline \multirow[t]{2}{*}{$\begin{array}{l}\text { Educational Attainment: } \\
\text { Secondary or higher }\end{array}$} & $0.6412 * *$ & $0.2429 * * *$ & $2.4956 * * *$ \\
\hline & -0.1449 & -0.1071 & -0.5743 \\
\hline \multirow[t]{2}{*}{ HH Owns Land } & 1.053 & $5.0329 * * *$ & 0.9316 \\
\hline & -0.2051 & -1.1382 & -0.1926 \\
\hline \multirow[t]{2}{*}{ Social Network } & $2.2726 * * *$ & $2.6145 * * *$ & $2.1635 * * *$ \\
\hline & -0.3962 & -0.6345 & -0.3945 \\
\hline Pseudo-R2 & 0.2080 & & \\
\hline $\mathrm{N}$ & 1,841 & & \\
\hline
\end{tabular}

Note: Significance Levels: ${ }^{*} \mathrm{p}<0.10,{ }^{* *} \mathrm{p}<0.05,{ }^{* * *} \mathrm{p}<0.01$. Relative risk ratios are reported, with robust standard errors in parentheses. The base category for the labour market activity is 'Not Working'. The reference group for Educational Attainment is 'Lower than secondary'. Other controls not reported here include 'Ethnicity', 'District Type' and 'Province'.

Expecting differences between non-migrants and returned refugees, we conduct a Chow test to rule out the null hypothesis of similar coefficients across the two groups. The results of the test show a statistically significant chi-square value for both selfemployment in business and wage employment. This indicates that the estimated coefficients between groups are statistically different and individual covariates in our model influence non-migrants and returnees differently for both labour market categories. The estimated coefficients for agriculture, on the other hand, are not statistically different between both groups, suggesting return migration may not be influential for this activity.

Table 5.5 compares non-migrants and returned refugees in regard to what influences their respective labour market activity by estimating separate models. First, we notice 
statistically significant similarities in terms of basic demographic characteristics. For instance, being the head of the household as well as being married makes an individual more likely to be employed in nearly all three categories compared to not working for both non-migrants and returnees. Alternatively, the older an individual the slightly less prone they are to be self-employed in business or wage employed, regardless of migration status. Only in the case of returnees are these characteristics not relevant for being involved in agriculture.

Table 5.5: Labour Market Activity, Comparing Non-migrants to Returned Refugees (Multinomial logit estimates)

\begin{tabular}{|c|c|c|c|c|c|c|}
\hline \multirow[b]{2}{*}{ Base: Not working } & \multicolumn{3}{|c|}{ Non-migrant } & \multicolumn{3}{|c|}{ Returned refugee } \\
\hline & $\begin{array}{l}\text { Self- } \\
\text { employ. }\end{array}$ & Agric. & $\begin{array}{l}\text { Wage } \\
\text { employ. }\end{array}$ & $\begin{array}{l}\text { Self- } \\
\text { employ. }\end{array}$ & Agric. & $\begin{array}{l}\text { Wage } \\
\text { employ. }\end{array}$ \\
\hline \multirow[t]{2}{*}{ Head of HH } & $4.4075^{* * *}$ & $5.3701 * * *$ & $4.7482 * * *$ & $4.8621 * *$ & 3.6079 & $5.7055^{* *}$ \\
\hline & -1.0821 & -1.7967 & -1.2748 & -3.0015 & -2.8974 & -4.8777 \\
\hline \multirow[t]{2}{*}{ Age } & $0.9464 * * *$ & $0.9617 * * *$ & $0.9478 * * *$ & $0.9381 * * *$ & 0.9634 * & $0.9501 * * *$ \\
\hline & -0.0087 & -0.0111 & -0.0094 & -0.015 & -0.0188 & -0.0167 \\
\hline \multirow[t]{2}{*}{ Married } & $3.3443 * * *$ & $3.1959 * * *$ & $2.5051 * * *$ & 2.7105 & 2.7101 & 1.9905 \\
\hline & -0.8405 & -1.1225 & -0.657 & -1.9118 & -2.535 & -1.7207 \\
\hline \multirow[t]{2}{*}{ Number of children } & $0.9130 * *$ & 0.9906 & 0.9446 & 1.0858 & 1.0204 & 1.1387 \\
\hline & -0.0418 & -0.0604 & -0.0471 & -0.0908 & -0.1072 & -0.1041 \\
\hline \multirow{2}{*}{$\begin{array}{l}\text { Education: secondary or } \\
\text { higher }\end{array}$} & 0.6148 * & $0.2753 * *$ & $2.8348^{* * *}$ & 0.8992 & $0.1652 * *$ & 2.2920 \\
\hline & -0.1721 & -0.1707 & -0.8252 & -0.3872 & -0.1254 & -1.0599 \\
\hline \multirow[t]{2}{*}{ HH owns land } & 0.9018 & $3.9817 * * *$ & 0.9534 & 1.7468 & $11.3484^{* * *}$ & 0.855 \\
\hline & -0.2044 & -1.03 & -0.2276 & -0.7893 & -5.8669 & -0.4509 \\
\hline \multirow[t]{2}{*}{ Social Network } & $2.3039 * * *$ & $2.6049 * * *$ & $2.0563 * * *$ & $2.9124 * * *$ & $3.3171 * *$ & $2.8980 * * *$ \\
\hline & -0.4655 & -0.7477 & -0.433 & -1.112 & -1.9121 & -1.1689 \\
\hline Pseudo-R ${ }^{2}$ & 0.2177 & & & 0.2118 & & \\
\hline $\mathrm{N}$ & 1,380 & & & 461 & & \\
\hline
\end{tabular}

Note: Significance levels: ${ }^{*} \mathrm{p}<0.10,{ }^{* *} \mathrm{p}<0.05,{ }^{* * *} \mathrm{p}<0.01$. Relative risk ratios are reported, with robust standard errors in parentheses. The reference group for educational attainment is 'lower than secondary'. Other controls not reported include 'Ethnicity', 'District type' and 'Province'.

As for educational attainment, the results paint a mixed picture. Non-migrants with a higher level of educational attainment (i.e. at least secondary schooling) are less likely to be engaged in agricultural work, and more likely to be involved in wage labour. For returned refugees, however, statistical significance drops out for wage employment. This suggests that non-migrants with low levels of education have few options other than subsistence agricultural labour, whereas relatively higher levels of education open up opportunities for wage labour. Conversely, the prospect of wage employment for returned refugees has less to do with their level of education. 
With respect to household socio-economic characteristics, as to be expected both nonmigrants and returned refugees within households owning land have a higher likelihood of being engaged in an agricultural activity relative to not working. More interestingly, the strength of social networks, proxied for by involvement in a community organization, appears to be similarly relevant for both returned refugees and non-migrants across all labour market outcomes.

Table 5.6 reports the differences across labour market activities based on the migration and return experience of returned refugees only. Nearly all of those same individual and household characteristics influential in the previous models are once again statistically significant, so as a matter of parsimony only the migration- and returnrelated characteristics of interest are presented here, but the full table (Table D.4) can be found in Appendix D.

\section{Table 5.6: Labour Market Activity of Returnees (Multinomial logit estimates)}

\begin{tabular}{|c|c|c|c|}
\hline Base: Not working & Self-employment & Agriculture & Wage employment \\
\hline \multirow[t]{2}{*}{ Employed pre-migration } & 1.0656 & 0.3563 & $2.1744 * *$ \\
\hline & -0.4277 & -0.2324 & -0.9228 \\
\hline \multirow[t]{2}{*}{ Migration duration (years) } & 1.0342 & 1.0031 & $1.0479 *$ \\
\hline & -0.0264 & -0.0389 & -0.0298 \\
\hline \multicolumn{4}{|l|}{ Migration destination } \\
\hline \multirow[t]{2}{*}{ Iran } & 0.831 & $10.2048 * *$ & 1.7203 \\
\hline & -0.4893 & -10.4416 & -1.019 \\
\hline \multirow[t]{2}{*}{ Remittances sent } & 0.9843 & 1.3304 & 0.1693 \\
\hline & -0.851 & -1.4124 & -0.2071 \\
\hline \multicolumn{4}{|l|}{ Return period } \\
\hline \multirow[t]{2}{*}{$2002-2011$} & 0.5023 & 1.0911 & 0.9115 \\
\hline & -0.275 & -0.7591 & -0.5451 \\
\hline \multirow[t]{2}{*}{ Time since returned (years) } & 1.0092 & $1.1223 *$ & 1.0449 \\
\hline & -0.056 & -0.0822 & -0.0646 \\
\hline \multirow[t]{2}{*}{ Return reason: political/security } & 0.6685 & 0.979 & 0.9114 \\
\hline & -0.2608 & -0.4874 & -0.3816 \\
\hline \multirow[t]{2}{*}{ Return savings (log of USD) } & 1.1102 & $1.1884 *$ & 0.9854 \\
\hline & -0.0789 & -0.1143 & -0.0778 \\
\hline \multirow[t]{2}{*}{ Return assistance } & 0.6446 & $0.3509 * *$ & $0.5031 *$ \\
\hline & -0.2323 & -0.18 & -0.2069 \\
\hline \multirow[t]{2}{*}{ Re-migration intentions } & 1.803 & $0.2808 * *$ & 1.2658 \\
\hline & -0.9119 & -0.2015 & -0.6818 \\
\hline Pseudo-R ${ }^{2}$ & 0.2680 & & \\
\hline $\mathrm{N}$ & 461 & & \\
\hline
\end{tabular}

Note: Significance levels: ${ }^{*} \mathrm{p}<0.10,{ }^{* *} \mathrm{p}<0.05,{ }^{* * *} \mathrm{p}<0.01$. Relative risk ratios are reported, with robust standard errors in parentheses. The reference group for Migration destination is 'Pakistan'; and for Return period is '1992$2001^{\prime}$. Results for the full model can be supplied upon request. 
First, and somewhat expectedly, we find that those individuals who were employed prior to migrating have a higher likelihood of being wage employed in comparison to not working upon return. Less expected, however, given the context of forced migration, the more years spent abroad the slightly greater the likelihood of being wage employed, indicating a degree of skill acquisition during displacement. Conversely, returnees who migrated to Iran compared to Pakistan are more likely to be involved in farming or herding upon return. The same is true regarding the number of years since return and the amount of savings brought back, although all are only marginally statistically significant at the 10 per cent level. Lastly, individuals having received assistance upon return and with concrete intentions to re-migrate are less likely to be occupied with agriculture. We believe this indicates labour-intensive activities such as farming or herding animals may necessitate high upfront investment in productive assets like land and livestock not covered by the support received, but which makes future movement less desirable.

\subsection{Concluding Remarks}

Using a unique dataset, this chapter investigated the labour market outcomes of returned refugees in Afghanistan; a country that has been characterized by conflict and general insecurity for decades. The reintegration into the local labour market is a key element of the sustainable return of refugees in (post-) conflict settings. Yet, the income-generating activities of such populations upon return, and particularly the role of self-employment, are not well understood to date. Literature on the return of labour migrants has shown that return migrants have a higher likelihood of being selfemployed in contrast to wage employment than their non-migrant counterparts. Similar studies looking at the return of forced migrants, on the other hand, are lacking.

The results of the analysis show that returned refugees are less likely to be wage employed in comparison to non-migrants, and that differences in labour market outcomes seem to arise primarily from dissimilarities in socio-economic status. For example, non-migrants with higher levels of schooling are more likely to be in waged labour, whereas labour market activities have less to do with educational attainment for returnees. As such we can deduce that those individuals of a higher socio-economic status are generally able to take advantage of the insufficient employment opportunities available, yet having left the country and since returned limits such ability. On the other hand, having social capital within the local community, proxied for by community organization involvement, helps both a non-migrants' and returnees' chances of being engaged in all labour market activities similarly. 
As for the influence of the migration and return experience on labour market outcomes, a few key factors are found to be of consequence. First, and somewhat expectedly, being employed prior to migrating helps raise the likelihood of being wage employed upon return. Less expected, however, given the context of forced migration, the more years spent abroad the greater the odds of being wage employed, pointing to skill acquisition. Moreover, and likely corresponding to the prior notion related to socio-economic status, those who received financial assistance to return from either an international organization or government programme are less likely to be wage employed. On the other hand, the amount of savings brought back upon return is beneficial when it comes to becoming self-employed in both business and agriculture or herding, highlighting the importance of financial capital for engaging in such activities. Finally, individuals with concrete intentions to re-migrate are less likely to be occupied with agriculture or herding, indicating labour-intensive activities such as farming necessitate greater investment in land and assets including livestock, making future movement less desirable.

Taking a step back from our findings, it is important to consider the evolving context related to migration from and return to Afghanistan since the data was collected in 2011. As Figure 1 shows, return has in fact increased over the last few years in great part due to a changing policy environment towards Afghans in Pakistan as well as a rise in forced returns from Europe. Therefore, even though our dataset may be relatively dated, the fundamental issues addressed are arguably more relevant today than they were just a few years ago.

Above all, reintegration into the labour market is an important step in the process of sustainable return to a (post-) conflict environment like that of Afghanistan. In a context where wage employment is systematically limited, however, self-employment may simply be the only if not best viable income-generating activity. Providing support then to returned refugees for this specific purpose, whether for a business venture or agricultural endeavour, has the potential to not only facilitate reintegration and improve individual welfare, but also contribute to local development. 



\section{CHAPTER 6: DISPLACEMENT AND NON-FARM}

\section{BUSINESSES - EVIDENCE FROM RURAL BURUNDI}





\subsection{Introduction}

Non-farm businesses play an important role in the livelihood of a significant and increasing number of households in rural parts of developing countries. ${ }^{31}$ Evidence exists that households living in poverty in such contexts show behaviour such as the diversification of crops and income sources as well as the processing of agricultural products for selling them, indicating "untapped entrepreneurial potential at the bottom-of-the-pyramid" (Cieslik \& D'Aoust, 2017, p. 19). As such, it can be expected that, as evidenced for other Sub-Saharan African countries (Nagler \& Naudé, 2017), non-farm business activities are an important activity for a growing number of households in rural Burundi. However, the context of Burundi has special characteristics, which have not been the focus of many studies on the patterns and determinants of non-farm businesses in rural parts of developing countries.

Burundi is characterised by the fact that a large share of its population has experienced forced displacement during one or more of the violent conflicts that have occurred in the country. More than one million Burundians alone were uprooted from their home during the civil war which started in 1993 and lasted for the following thirteen years (Uvin, 2007). In addition, episodes of violent conflict continue to arise until today and lead to displacement both within the country as well as across international borders (United Nations Department of Political Affairs, 2018).

At the same time, large numbers of Burundian refugees and IDPs have returned to the country and their regions of origin. This has had adverse effects on the country and its population. Specifically, land access, which is crucial for the livelihoods of the rural population, has been the cause of social conflicts, especially in areas with high return rates where not enough land is available for all households (Fransen \& Kuschminder, 2012).

The scarcity of land may, on the other hand, be a significant driver of necessity entrepreneurship leaving households without or with insufficient land few other options in terms of economic activities in a context where wage employment opportunities are largely not available. The importance of land in the context of subsistence economies, which still characterize large parts of rural Sub-Saharan Africa, was already highlighted in Chapter 3 of this dissertation, where a lack of access to land led to a significant incidence of unemployment among Congolese refugees. In contrast,

\footnotetext{
${ }^{31}$ A discussion of the relevance of entrepreneurial non-farm activities is provided in Section 1.4.3 of this dissertation.
} 
agricultural activities were identified as the main activity through which the local Rwandan population satisfy its daily needs. Therefore, in cases where displacement leads to a loss of or lack of access to land, there are reasons to believe that displacement may impact the establishment of non-farm businesses by driving those affected into necessity entrepreneurship.

Based on this hypothesis, this chapter examines the patterns and determinants of nonfarm business operations by households in rural Burundi. In a country where the majority of households has, to different extents, been affected by violent conflict over the last decades, the role of non-farm business activities has received less attention in research so far. Within this context, the potential impact of displacement experiences, both within Burundi as well as across borders to neighbouring countries, is of specific interest, considering the current gap in the literature on the linkages between forced migration and entrepreneurship (see Chapter 2 for a discussion on this). This chapter answers the following research question: What is the relationship between forced migration experiences and engagement in non-farm household business activities in a rural (post-) conflict developing country context?

To answer this question, this chapter uses data gathered in a country-wide household survey in 2015 in the framework of the "The Labour Market Impacts of Forced Migration (LAMFOR)" project, which was funded by the UK Department for International Development (DFID) and the Institute for the Study of Labor (IZA). A quarter of the households in the sub-sample used in this study operate a non-farm business. Using descriptive and multivariate analysis, it is found that displacement as such does not appear to be a determinant of non-farm business operation in the context of rural Burundi. Instead, factors relating to the capital present within households appear to be driving such operations.

Specifically, social capital as well as access to financial capital are important determinants of non-farm businesses in this context. In contrast, higher education levels are negatively correlated with business operation. Furthermore, there is some evidence on non-farm businesses being employed by households out of necessity. Households reporting that they cannot satisfy their food needs based on produce from land they own, are more inclined to run a non-farm business, indicating that they have to look for other alternative income sources in a context that can largely be described as a subsistence economy, characterized at the same time by land scarcity.

The remainder of this chapter proceeds as follows. In Section 6.2, a review of the literature is provided on the role of non-farm businesses in developing countries as well as of the determinants of such businesses. Next, the context of Burundi, in terms 
of both labour market characteristics and forced migration patterns, is described in Section 6.3, before introducing the data and methodology of this chapter in Section 6.4. Sections 6.5 and 6.6 present descriptive statistics and analytical results on the patterns and determinants of non-farm businesses in rural Burundi respectively. Finally, Section 6.7 concludes with a summary of the main results.

\subsection{Relevant Literature}

The economies of most Sub-Saharan countries are largely characterized by a heavy reliance on the primary sector of the economy, where the largest share of the labour force works in the agricultural sector. These activities remain the most significant income source for the majority of rural households (Davis et al., 2010; Zezza, Carletto, Davis, Stamoulis, \& Winters, 2009). At the same time, the same countries are among the least developed in the world with high shares of the population living below or close to the poverty line (United Nations Development Programme, 2016).

Based on studies in the context of rural Africa that have identified a positive correlation between entrepreneurial activities and the welfare of households, income from nonfarm business activities has been highlighted as an alternative way out of poverty under such conditions (Naudé, 2010a). This applies specifically to households that have relatively good pre-conditions in terms of asset possession and/ or human capital as these households are the ones that have commonly been identified as being better able to exploit non-farm opportunities which offer higher returns (Barrett, Reardon, \& Webb, 2001). In turn, as elaborated in Section 1.2.3, the existing literature acknowledges that a relationship exists between entrepreneurship and economic development (Ács, 2006; Naudé, 2010b), but that entrepreneurship among poor households in Africa has little potential to contribute to economic growth and poverty reduction (Haggblade, Hazell, \& Reardon, 2010).

In the entrepreneurship literature, the decision to open a business is most commonly described as the occupational choice of an individual (Blau, Gustad, Jessor, Parnes, \& Wilcock, 1956). However, the entrepreneur as such does often not act in solitude, which is why it is important to consider the role of the family or household in the business. Family or household members can be influential in the decision-making process directly or indirectly by, for example, making joint decisions about individual household members' income-generating activities or in situations where the composition of the household requires one member to provide for the others. This is especially the case where the business is a part of an overall household income strategy (Alsos, Carter, \& Ljunggren, 2014). However, "[w]hile there is now a broader 
recognition of the importance of the entrepreneurial household, this context remains under-researched"(Alsos et al., 2014, p. 166).

In contrast to urban contexts, the rural environment often constitutes a constraint to entrepreneurship and adds challenges to the process instead of facilitating it. Mostly this is due to the given infrastructure or lack thereof, which plays a critical role in business development (Audretsch, Heger, \& Veith, 2015). In rural Sub-Saharan Africa important infrastructure components, such as roads, electricity, or telecommunications systems, are often poorly developed or lacking completely (Calderón \& Servén, 2010). As such the context may in many cases not provide immediate opportunities for individuals to start non-farm businesses, but the need to generate or increase an income may still drive households into necessity-motivated entrepreneurial activities.

This directly relates to the discussion presented in the introduction of this dissertation about the common characterisation of self-employed individuals and entrepreneurs in the literature in terms of whether they open their business because they identify an opportunity or because they are driven by necessity (Reynolds et al., 2005). While in reality this typology is not as forthright, it may be helpful in understanding non-farm businesses in developing country contexts as these different kinds of motivations have implications for the significance and the potential impacts of such businesses.

The common assumption in developing country contexts, like that of rural Burundi, is that the majority of self-employment activities and businesses are started out of necessity (Margolis, 2014). Such an assumption is based on the fact that in the light of a lack of government provided protection mechanisms and imperfect, if not fully missing, insurance markets, in combination with the high incidence of (extreme) poverty and a lack of wage employment opportunities, many households have the necessity to find alternative ways of making an income when agricultural activities are not an option, for example due to a lack of land, or not sufficient to secure their livelihood. In such cases individuals and households may indeed be driven into selfemployment by necessity (Reardon et al., 2007).

But even in contexts where labour market opportunities are not available in sufficient quantities and land scarcity is a problem in terms of the self-subsistence of households, not all households start a non-farm business. Certain factors have been found in previous studies in different contexts to be determinants of such activities. These can largely be classified as encompassing household as well as individual characteristics. These include demographic characteristics such as gender, marital status, and age, the latter of which may also capture life experience (Ardagna \& Lusardi, 2010; Benzing, Chu, \& Kara, 2009; Parker, 2004). Human capital in the form of prior labour market 
experiences as well as education and training, especially where these are relevant to the respective business, are other important determinants of business establishment that have been identified in the literature (Bosma et al., 2004; Gimeno, Folta, Cooper, \& Woo, 1997). It is, however, important to point out that in developing country contexts, higher levels of education are more often found to be helpful for finding wage labour opportunities and as such are associated with a lower likelihood of operating a non-farm business (Reardon et al., 2007).

Furthermore, the size and composition of the household may impact the operation of a business in several ways. A larger number of household members allow the diversification of income sources, especially as larger households may not be able to satisfy their food needs based solely on cultivating their own land and as such have been found to diversify rather than specialize concerning their income sources (Barrett et al., 2001; Davis et al., 2010). At the same time, they may have more individuals contributing to the household's overall income, which may mean that individual household members engage solely in household activities and do not contribute to the household income as such.

Larger households also have potentially larger networks, which are an indicator of social capital - another factor that has been identified as being a driver of entrepreneurship (Elfring \& Hulsink, 2003). One of the most commonly cited obstacles to entrepreneurship in any context, but especially that of developing countries, is the access to financial capital. Access to credit is often crucial for business start-ups and in the light of capital market imperfections this access may be a deciding factor in nonfarm business operation (Beck \& Demirguc-Kunt, 2006; Evans \& Jovanovic, 1989; Hurst \& Lusardi, 2004).

Besides characteristics of the household and its members, the context in which they live also may impact the likelihood of non-farm business operations. This includes factors such as the accessibility of the community, which is an important factor in rural areas where market potential within one's own community is limited (Fafchamps \& Shilpi, 2003). Directly related, the presence of a market, where products and services can be offered to potential buyers and clients, is often positively related to business establishment (Renkow, 2007; World Bank, 2007).

Furthermore, adverse shocks, including environmental and economic shocks, which have been experienced by households and the wider communities in which they live may be additional determinants of non-farm businesses. Businesses have been found to act as both an informal insurance anticipating such shocks as well as a coping strategy once they happened (Barrett et al., 2001). Conflict and associated disruptions 
are an additional sort of shock, one consequence of which is the displacement of populations away from their place of residence.

In the context of Burundi, forced displacement is a significant feature that has shaped and continues to shape a lot of the social and economic dynamics of the country. As discussed previously in this dissertation (see, e.g., Section 2.2.4), there is both a theoretical argument as well as empirical evidence that in some contexts return migrants and their households are more likely to operate a business due to a comparative advantage in relation to these different types of capital (Naudé, Siegel, \& Marchand, 2017). However, this does depend on the given context and the context of Burundi and Burundian migration and displacement presents quite a unique context. In general, forced migrants often leave behind their assets such as their house, land, and livestock, which are the basis of their pre-conflict livelihood and they may not be able to retrieve them upon return.

Especially in contexts where refugees and IDPs are not able to work in their prior or related fields, particularly in camp settings, the deterioration or loss of skills is likely to be an issue (Hainmueller et al., 2016). Considering these factors and the fact that reasons for migration of forced migrants are by nature often quite different than those of economic migrants, the accumulation of capital argument may therefore not hold in contexts such as that of previously displaced households in rural Burundi. Conflictinduced forced migration may diversely impact household members' financial, human, and social capital, which all have been shown to influence self-employment and non-farm business establishment in developing country contexts (Barrett et al., 2001; Gindling \& Newhouse, 2014).

The nature of forced displacement may lead to the loss of savings and/ or assets that have to be left behind or sold to afford the journey. Furthermore, while in displacement individuals may be limited in their abilities to work, which may lead to a deterioration of skills and consequential loss of human capital (Ruiz \& Vargas-Silva, 2013). Finally, in terms of social capital the forced displacement and conflict disrupts existing social networks (Navarra, Niehof, \& van der Vaart, 2013). At the same time, the theoretical discussion on the potential positive impacts of migration on different types of capital (see Chapter 2 for an elaborate discussion) may still be relevant in cases of forced displacement. All in all, these diverse potential impacts of forced displacement on different types of capital highlight the importance of the analysis of their role in nonfarm businesses in a context like that of rural Burundi.

In conclusion, forced displacement is often associated with short-distance movements to neighbouring countries, where economic possibilities, including the accumulation 
of capital, may be limited (Ruiz \& Vargas-Silva, 2013). An earlier study, using the same dataset as this present chapter, investigates the economic outcomes of returned refugees in Burundi. In terms of the occupational choices of individuals, this analysis shows that having been displaced across international borders has a negative impact on an individual's likelihood of being self-employed as their main economic activity (Fransen, Ruiz, \& Vargas-Silva, 2017).

Considering the discussed importance of household entrepreneurship in contrast to individual occupational choices, this chapter does propose that displacement experiences could act as additional determinant of household non-farm enterprises in a (post-) conflict context like that of rural Burundi. It is therefore important to present this context in more detail before moving onto the empirical part of this chapter.

\subsection{Context}

Burundi is a small, landlocked country in the Great Lakes Region of East Africa. The country borders Rwanda in the north, Tanzania in the south-east, and the Democratic Republic of the Congo (DRC) in the west. With around 11.5 million, the population of Burundi is relatively small, but the country is one of the most densely populated ones in Africa (Central Intelligence Agency, 2017). At the same time, Burundi is one of the poorest countries in the world. Estimates indicate that 77.7 per cent of the population lived below the international USD 1.90 (in purchasing power parity terms) poverty line in the period between 2005 and 2014. Moreover, 81.8 per cent of the population has been identified by the United Nations Development Programme (UNDP) as being multi-dimensionally poor. Closely related, the country has low levels of human development with a Human Development Index of 0.404, which placed it in the fifth lowest position globally in 2015 (United Nations Development Programme, 2016).

In line with the high incidence of poverty and the extremely low levels of development, the Burundian labour market is characterized by low labour productivity, high levels of informality, and vulnerable working conditions (Ulandssekretariatet, 2015). The country as such is lacking natural resources and the manufacturing and services sectors remain underdeveloped (Niragira et al., 2015). The unemployment rate has been estimated to be around 7 per cent overall and about 11 per cent for youth, which is below the average of Sub-Saharan countries. However, due to a lack of formal work opportunities, the large majority of the workforce is working in the informal economy without any sort of formal protection and underemployment is likely to be a significant issue (Ulandssekretariatet, 2015). In rural Burundi in particular, economic activities are largely limited to farming and livestock. Estimates indicate that about 90 per cent of 
the country's population live in the rural parts of the country where subsistence farming is one of the few, if not the only, source of income and food for many (Niragira et al., 2015; Vinck, Bizuneh, Rubavu, \& Tahirou, 2008).

In line with this, recent estimates from the International Labour Organization (ILO) (2018) show that 91.4 per cent of the employed population in Burundi are working in the agricultural sector. On the other hand, only 2.5 per cent and 6.1 per cent work in the industry and services sectors respectively. In terms of employment status, own account workers make up 84.8 per cent of the total employed population. The large majority of that share are those running farms, but it also includes those running small non-farm enterprises, almost exclusively without employing others as less than 1 per cent of the employed population is an employer. Contributing family workers, which do not receive remuneration but contribute to the own account work of another household member, make up 7.6 per cent of the employed population according to ILO statistics (International Labour Organization, 2018). The available data does not allow further disaggregation of the kinds of non-farm activities that individuals and household units engage in in the context of rural Burundi. Overall, the understanding of household non-farm activities in rural African contexts remains limited (Nagler \& Naudé, 2017), and does so especially in the context of countries that have been affected by conflict like Burundi.

Burundi has seen many violent civil conflicts since gaining independence from Belgium in 1962. These have impacted the country in many ways and led to significant, diverse forced migration movements both internally and internationally (Fransen \& Otieno Ongáyo, 2010). Conflicts in Burundi, and consequential displacement, have largely been caused by ethnic tensions between the two main ethnic groups, the Tutsi minority (about 14 per cent of the total population) and the Hutu majority (about 85 per cent of the total population) (Central Intelligence Agency, 2017).

The first large movement of mainly Hutu Burundians recorded in 1972, was the result of the first genocide, with movements mainly to neighbouring countries, especially Tanzania, Rwanda, and the DRC (Lemarchand, 1996; Ngaruko \& Nkurunziza, 2000, 2005). After a series of smaller conflicts in 1965, 1969, 1988, and 1991, the second mass displacement happened in 1993 after the first democratically elected president Melchoir Ndadaye, a Hutu - was assassinated only one hundred days after taking office. This event led to the beginning of a long civil war lasting for close to thirteen years. The impacts of this conflict were disastrous and significant considering the small total population of the country: "around 300,000 people were killed, over 500,000 fled 
abroad and another 800,000 were displaced internally, often for many years" (Uvin, 2007, p. 39).

Large numbers of refugees started to return to the country in 1994, but the tensions continued and escalated again in 1996, with the consequence of another wave of displacement, in this case especially to Tanzania. As a consequence of the large outward movements, the stabilization of the situation in Burundi, and the closure of refugee camps in Tanzania, more than half a million refugees returned to Burundi between 2001 and 2013 alone (Fransen, 2015). In addition, around 700,000 IDPs returned to their origins between 1999 and 2005 (United Nations Office for the Coordination of Humanitarian Affairs, 2005).

Many of these returnees faced difficulties reintegrating due to a variety of factors, such as the duration of displacement, the widespread poverty, the labour market conditions and the overall economic situation, as well as land scarcity and disputes. As such the reintegration of returned refugees is often challenging, a fact that has been the topic of prior research in different contexts (Black \& Gent, 2006; Huggins, 2007; Özerdem \& Sofizada, 2006), including that of Burundi (Fransen, 2017; Fransen \& Kuschminder, 2012).

Recent research on the economic implications of international displacement in the Burundian context has found that there is a significant economic gap between households that previously experiences displacement (returnee households) and those that did not (stayee households). Specifically, the analysis by Fransen et al. (2017) shows that return migrants on average have less livestock and, therefore, engage in different economic activities than stayees, particularly those activities that require less livestock. However, as seen in the previous Section 6.2, occupational choices are often made jointly with other household members and businesses may be used as an income diversification method at the household level. This chapter therefore analyses the patterns and determinants of non-farm businesses at the household level to see if differences observed among individuals collate up to the household unit.

Due to the historic as well as recent events ${ }^{32}$, there are currently still an estimated 59,000 IDPs in the country (Internal Displacement Monitoring Centre, 2017a) and more than

\footnotetext{
32 Since April 2015 more than 400,000 Burundians have left the country, mainly to Tanzania, and more than 50,000 have been internally displaced (United Nations High Commissioner for Refugees, 2017b). This is the result of tensions and violent outbreaks that arose in the light of the announcement of the President Pierre Nkurunziza to run for a third term (United Nations Department of Political Affairs, 2018). These events occurred after the collection of the data used in this chapter, but the implications are still important to consider in the context of the present analysis.
} 
400,000 refugees from Burundi living in surrounding countries (United Nations High Commissioner for Refugees, 2017a), many of which are likely to return to Burundi eventually. Considering these numbers, it is important to gain a deeper understanding of the economic activities of returning refugees and IDPs as well as stayees. The role of non-farm enterprises may gain importance, particularly considering the concerns regarding land scarcity. Due to the described conditions in terms of the shortage of resources, limited labour market opportunities, and displacement, rural Burundi presents an interesting and valid case study to analyse the determinants of engagement of households in non-farm enterprises and the potential linkages between displacement experiences and such endeavours.

\subsection{Data and Methodology}

\subsubsection{Data and Sample}

The data used in this chapter was collected within the framework of the project "The Labour Market Impacts of Forced Migration (LAMFOR)", which was funded by the UK Department for International Development (DFID) and the Institute for the Study of Labour (IZA). The data was collected in the first quarter of 2015 across all provinces of Burundi. Information was obtained through a household survey for a total of 8,177 individuals within 1,500 households. A detailed description of the sampling and data collection procedure is provided in Appendix A.3 of this dissertation.

While the focus of the data collection was not specific on non-farm enterprises due to the focus on labour market and economic outcomes more generally, the household survey does contain a module on business activities of all household members. This information is the basis for the analysis in this chapter. Specifically, the focus is on the engagement of households in a non-farm business or self-employment.

Considering all the economic activities of individuals of working age (18-65) in the surveyed households in rural Burundi, any engagement of a household member in business activities classifies the respective household as one with a non-farm business for the purpose of this study. This activity does not have to be the individual's primary activity or be the main income source for the household. After excluding the 
households situated in urban Bujumbura ${ }^{33}$ and screening for missing information, the remaining sample used in this chapter consists of 1,390 households in 94 rural communities spread throughout the country.

In order to investigate the linkages between displacement and non-farm business establishment, both internal and international displacement experiences are considered in the following analysis. Considering that the displacement experiences of households are self-reported, there is a risk of under-reporting, especially in the case of IDPs. Some people that moved during the conflicts due to security concerns within Burundi may not self-identify as having been displaced as such (Fransen et al., 2017).

While the measurement of displacement may therefore not be perfect, three main types of households can be identified in the data: Returnee households are defined as those that have at least one member that was displaced for more than three months across international borders due to security or political reasons. IDP households are those households where at least one member was displaced internally for a minimum period of at least three months, while stayee households do not have an international or internal displacement experience. ${ }^{34}$ Of the total 1,390 households, 237 are returnee households (17.1 per cent), 358 IDP households (25.8 per cent), and the remaining 795 households are classified as being stayees (57.2 per cent).

\subsubsection{Empirical Approach}

The aim of this chapter is to analyse the patterns and determinants of households' nonfarm business operations, with a focus on the role of displacement experiences. In order to do so, descriptive and multivariate analysis are employed, the latter in form of probit regressions given the binary expression of the dependent variable. A series of probit models are estimated to identify different factors at the individual, household, and community levels that, based on the literature review in Section 6.2,

\footnotetext{
${ }_{33}$ Prior research has found that the economic structures and poverty profiles of urban and rural parts of Burundi differ with worse outcomes in the rural areas of the country (Bundervoet, 2006). In addition, the dynamics and impacts of the conflicts in the capital city were significantly different than in the rest of the country (Fransen, 2015). As such, to avoid skewed results, the six communities located in the urban province of Bujumbura Mairie are excluded from the analysis in this chapter.

34 Where a household has both an IDP and a refugee, the more recent episode was considered for this classification. This only applies to 41 of the 1,390 households included in the analysis. In the empirical analysis, however, both experiences will be considered using dummy variables as further explained in Section 6.4 .2 below.
} 
are correlated with such activities. In addition, a specific focus in the analysis is on the potential role of displacement experiences.

The probit model can formally be expressed as

$$
\operatorname{Pr}\left(B_{i} \mid d_{i}, x_{i} y_{i} z_{i}\right)=\Phi\left(d_{i}^{\prime} \alpha+x_{i}^{\prime} \beta+y_{i}^{\prime} \gamma+z_{i}^{\prime} \delta\right)
$$

where $B_{i}$ is a binary dependent variable indicating whether household $i$ operates a non-farm business (value one) or does not do so (value zero) and $\Phi$ is the standard normal cumulative distribution function. $d_{i}^{\prime}$ represents a number of different displacement experiences of household $i$ used in various models in the analysis.

Displacement is explored stepwise by using binary variables for both internal and external displacement (where a household could have members with either or both of these experiences indicated by the respective dummy variables), the relative share of displaced household members, the timing as well as the duration of displacement, and prior business experiences before or during displacement.

$x_{i}^{\prime}$ is a vector of individual characteristics for the head of the household, including age, gender, marital status, as well as education.

$y_{i}^{\prime}$ represents a vector of household characteristics, including the household composition, home ownership, food security, self-sufficiency based on agricultural activities, informal networks, and access to micro-finance institutions.

Finally, $z_{i}^{\prime}$ denotes a vector of community level variables, including the accessibility of the respective community, the distance to the nearest market, as well as binary variables indicating whether the community has experienced any economic or environmental shocks.

Concrete operationalisations of each of the included possible determinants of nonfarm business operation can be found in Appendix E of this dissertation. Standard errors reported for each of the models are robust and clustered at the community level.

The following Table 6.1 presents the summary statistics of the independent variables, differentiating the households by displacement status. The data does not show many differences between the three groups in terms of their characteristics. In fact, they look surprisingly similar, with the exception of experiences of food shortages, selfsufficiency, and the distance to markets. Both returnee and IDP households are more likely to experience food shortages and less likely to be self-sufficient than stayee households, while it on average takes stayee households the longest to reach the nearest market. 
Table 6.1: Summary Statistics

\begin{tabular}{lccc}
\hline \hline & $\begin{array}{c}\text { Returnee } \\
\text { Household }\end{array}$ & $\begin{array}{c}\text { IDP } \\
\text { Household }\end{array}$ & $\begin{array}{c}\text { Stayee } \\
\text { Household }\end{array}$ \\
\hline Household head level & & & \\
Female & 0.18 & 0.21 & 0.17 \\
Age & 46.63 & 46.65 & 46.41 \\
Married & 0.81 & 0.79 & 0.81 \\
Primary & 0.17 & 0.19 & 0.19 \\
Secondary & 0.01 & 0.03 & 0.02 \\
Household level & & & \\
Child to adult ratio & 0.97 & 0.93 & 0.87 \\
Own house & 0.96 & 0.96 & 0.96 \\
Food shortage *** & 0.70 & 0.71 & 0.61 \\
Self-sufficient *** & 0.64 & 0.64 & 0.73 \\
Informal network & 0.55 & 0.55 & 0.61 \\
Micro-finance & 0.09 & 0.14 & 0.12 \\
Community level & & & \\
Accessibility of community & 0.40 & 0.33 & 0.40 \\
Market*** & 57.38 & 59.41 & 63.06 \\
Economic shock & 0.89 & 0.92 & 0.90 \\
Environmental shock & 0.84 & 0.86 & 0.81 \\
\hline \hline
\end{tabular}

Note: ${ }^{* * *}$ indicates statistically significant differences between the groups at the 1 per cent level.

Prior to estimating the models, it is important to consider the possibility of presence of endogeneity in the analysis of this chapter. Even in conflict contexts, there is the likelihood that those households with household members that were forcibly displaced differ in observable and unobservable characteristics from households in which all household members stayed. In the context of labour migration, the assumption is that migrants are inherently more likely to take risks and spot opportunities (see Chapter 2), but in how far this can be transferred to the context of forced migration is not clear.

In this case it could be argued that those who stay throughout the conflict are the less risk averse. Independent of which is in fact the case, there is reason to believe that these households differ from each other with regards to risk and opportunity perceptions and that these may, in turn, be correlated with engagement in non-farm businesses. While there are methods to control for selection, such as instrumental variable or matching approaches ${ }^{35}$, the present data did not allow them to be used. There was not

\footnotetext{
${ }^{35} \mathrm{~A}$ discussion of how such methodologies might have benefitted the analysis and the challenges faced in attempting to do so, is provided in the concluding chapter of this dissertation in Section 7.2.
} 
enough data on the situation of households prior to displacement to conduct a proper matching technique, and the instrument of distance to the border previously employed by Fransen et al. (2017) did not turn out to be a valid instrument in the present analysis.

As such the results reported in this chapter do not establish causal relationships. Instead the analysis aims to provide insights of the patterns and determinants of household non-farm business operation in rural Burundi, where one factor correlated with such activities may be prior international or internal displacement experiences.

\subsection{Descriptive Statistics}

Before analysing the determinants of households' engagement in non-farm businesses, this section presents the patterns of these activities in rural Burundi. Table 6.2 presents an overview of the share of households that run at least one non-farm business. Herein, it does not matter whether this business is the main income-generating activity within the household or one complimenting other sources of income.

The data shows that close to one quarter of households captured in the survey data operates a non-farm business in rural Burundi. ${ }^{36}$ Looking at differences between household types, the share of returnee households with a business is slightly smaller (24.1 per cent) than that of stayee households (25.0 per cent) and that of IDP households slightly larger (25.7 per cent). This difference is, however, not statistically significant. Only a few households operate more than one non-farm business. The average number of businesses in households that operate at least one business is 1.2 overall and is slightly higher in returnee households with an average of 1.3 businesses.

Looking at the kinds of business activities that households in rural Burundi engage in, Table 6.3 shows the sectors across which such activities are spread. While there is a total of 409 businesses captured in the sample, not all households provided details on their enterprise so that the information on the sector of operation is only available for 95 per cent, or 387 , of the businesses.

\footnotetext{
${ }^{36}$ Nagler \& Naudé (2017) report rates of household non-farm enterprises in six other Sub-Saharan African countries (Ethiopia, Malawi, Niger, Nigeria, Tanzania, and Uganda). The average rate reported across these countries is 41.6 per cent, with the lowest incidence identified in Malawi at only 16.9 per cent. In comparison, the rate in the present data from Burundi is on the lower side, but does fall within the spectrum found in other countries in the region.
} 
Table 6.2: Prevalence of Non-Farm Businesses

\begin{tabular}{|c|c|c|c|c|}
\hline & $\begin{array}{c}\text { Returnee } \\
\text { Household }\end{array}$ & $\begin{array}{c}\text { IDP } \\
\text { Household }\end{array}$ & $\begin{array}{c}\text { Stayee } \\
\text { Household }\end{array}$ & Total \\
\hline No Business & 180 & 266 & 597 & 1,043 \\
\hline$\%$ & 75.95 & 74.30 & 75.09 & 75.04 \\
\hline At Least One Business & 57 & 92 & 198 & 347 \\
\hline$\%$ & 24.05 & 25.70 & 24.91 & 24.96 \\
\hline Total & 237 & 358 & 795 & 1,390 \\
\hline$\%$ & 100.00 & 100.00 & 100.00 & 100.00 \\
\hline
\end{tabular}

This still provides interesting insights, showing that the majority of businesses are in either trade or sales, which includes activities such as small shops as well as crossborder trading. Other occupations that are often carried out as self-employment activities are construction, transport, and skilled trades (such as hair dressers, carpenters, etc.). Professional services in the education, health, or other sectors are less common across all three groups. Small numbers of individuals across the three groups also indicated operating a business in another sector such as hospitality or art. Differences between the different household types are small and not significant.

Table 6.3: Sector of Non-Farm Business

\begin{tabular}{lrrrr}
\hline \hline & $\begin{array}{c}\text { Returnee } \\
\text { Household }\end{array}$ & $\begin{array}{c}\text { IDP } \\
\text { Household }\end{array}$ & $\begin{array}{c}\text { Stayee } \\
\text { Household }\end{array}$ & Total \\
\hline Trade and Sales & 37 & 48 & 114 & 199 \\
$\%$ & 56.06 & 50.00 & 50.67 & 51.42 \\
Skilled Trades & 14 & 17 & 37 & 68 \\
$\%$ & 21.21 & 17.71 & 16.44 & 17.57 \\
Construction & 4 & 10 & 22 & 36 \\
$\%$ & 6.06 & 10.42 & 9.78 & 9.30 \\
Transport & 4 & 8 & 21 & 33 \\
$\%$ & 6.06 & 8.33 & 9.33 & 8.53 \\
Agribusiness & 2 & 5 & 10 & 17 \\
$\%$ & 3.03 & 5.21 & 4.44 & 4.39 \\
Professional Services & 1 & 3 & 5 & 9 \\
$\%$ & 1.52 & 3.13 & 2.22 & 2.33 \\
Other & 4 & 5 & 16 & 25 \\
$\%$ & 6.06 & 5.21 & 7.11 & 6.46 \\
\hline Total & 66 & 96 & 225 & 387 \\
$\%$ & 100.00 & 100.00 & 100.00 & 100.00 \\
\hline \hline
\end{tabular}


Respondents were also asked to indicate for how long they have been operating their non-farm enterprises. While this information was not obtained for all of the businesses (but for 357), the business age was varying from 0 to 49 years with an average of 9.9 years. There are no significant differences depending on displacement status of the household, with all three types ranging around the 10-year mark on average. In terms of the size of the business, or rather the number of employees, the data shows that the majority of businesses captured in the data, are operated by the owner alone. This is the case for 64.0 per cent of the businesses for which this information could be collected. A further 18.1 per cent employ one other person. In contrast, only 10 businesses employ more than 10 other individuals reflecting the low rate of job creation by businesses found in the ILO statistics. Differences across displacement experience groups are also not observed in this case.

Data on the amount of income made from these businesses was unfortunately not collected as part of the survey. Households were, on the other hand, asked to indicate the different sources from which they derive their income. Figure 6.1 presents a graphical illustration of the top three income sources of returnee, IDP, and stayee households, differentiating between income from non-farm businesses, wage labour, casual labour, farming and livestock, as well as other income (this includes social transfers, rental income, as well as remittances).

Some interesting differences can be observed. Across the top three income sources, casual labour is more important for returnee households than for the other two. Furthermore, and most relevant in this chapter, the non-farm businesses operated by returnee households are the most important income source for 5.5 per cent of returnee households, compared to 3.6 per cent of stayee and IDP households respectively. In contrast stayee households indicate income from wage labour as the main source in 5.0 per cent of cases and IDPs even in 8.1 per cent, compared to only 2.1 per cent of returnee households.

As such, while farming and livestock activities are the main income source for the absolute majority of all types of households, those households not relying on agriculture differ significantly in terms of their main income sources. The differences between groups for the second and third income sources are not significant, but it shows that in many cases non-farm businesses are more common as complementary income sources for households than as the main source, indicating a potential need for income diversification at the household level. This holds for all three household types. 


\section{Figure 6.1: Importance of Different Income Sources}

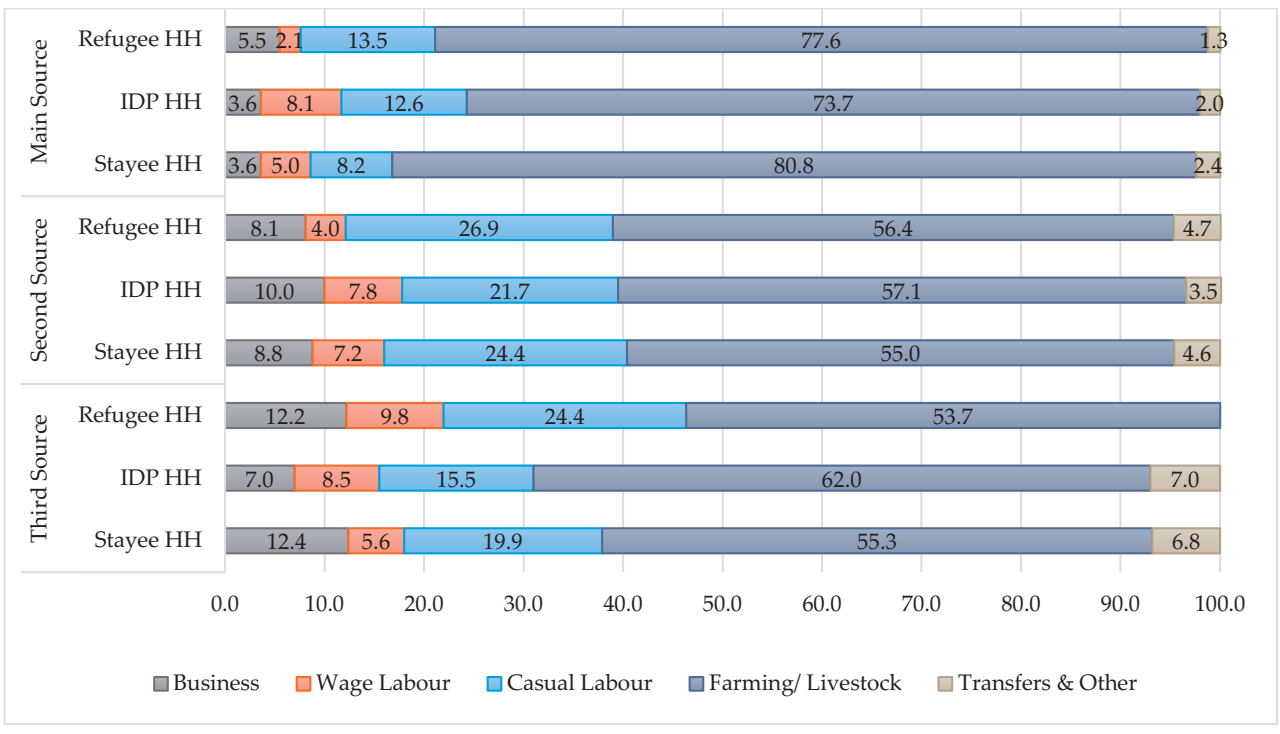

Note: Households mentioned a variety of different activities relating to farming and livestock, so that for many households this sector provides more than one income source.

Overall, the descriptive results do not provide any indication that the operation of nonfarm businesses is different for households in rural Burundi that have experienced displacement, whether internally or across international borders, and those that have not. The following empirical analysis will investigate this further and identify potential determinants of non-farm business operation in rural Burundi more generally.

\subsection{Estimation Results}

As described in Section 6.4.2, the analysis in the present chapter is based on the estimation of a series of discrete choice models, in the form of probit regressions, of the determinants of operation of a non-farm business. The variables included as explanatory variables, for which summary statistics were presented above, are based on the review of the literature conducted in Section 6.2.

The baseline results of the analysis of determinants of household businesses for refugee, IDP, and stayee households are presented in Table 6.4 below, which reports the average marginal effects of three probit models and the corresponding robust standard errors, clustered at the community level, in parenthesis. The models in column 1 and 2 include only the binary variables for being a refugee or IDP household respectively, while both of these are included in column 3 . These results overall show 
that displacement experiences of at least one household member do not seem to impact the households' likelihood of operating a household non-farm business. Both the effects of having a refugee and of having an IDP in the household are not significant, though interestingly their signs are opposites.

In order to control for the fact that some households were relatively more affected by displacement, the same analysis was also conducted using the relative share of the number of displaced household members to the overall number of adult household members. This is done for the share of refugees, the share of IDPs, as well as the share of both combined. The results also do not indicate any relationship between displacement experiences and non-farm business operation, while the other determinants further discussed below show consistent findings. The results table is provided in Appendix E (Table E. 2).

The analysis does, on the other hand, present some other interesting determinants of non-farm businesses in rural Burundi besides displacement. While the gender and marital status of the household head are not significant, age is negatively related to household business ownership at the 10 per cent level. Moreover, the model does show that there is correlation with the education of the household head. There is no significant effect for primary education, but secondary education of the household head reduces the likelihood of having a non-farm enterprise in the household. This is in line with the existing literature indicating a negative relationship between higher level of education and self-employment. This may be an indication that those with higher education levels have a different set of opportunities and therefore may not need to rely on additional income made from businesses.

The composition of the household, measured through the child to adult ratio, is positive and significant, showing that those households with a higher ratio are more likely to run a business. This may be the result of increased responsibility to generate enough income to provide for relatively more people and as a consequence may push household members into non-farm entrepreneurship. As assumed, those households that are more or less self-sufficient and able to mainly sustain their livelihoods based on subsistence farming, are significantly less likely to run a non-farm enterprise, an indication of the significant role of agriculture and land in the context of rural Burundi.

Social networks on the other hand, increase the likelihood of having a business in the household, underlining the role of social capital highlighted in the previous chapters of this dissertation and in the entrepreneurship literature more generally. Equally, having access to a micro-finance institute has a significant and positive effect on the likelihood of having a non-farm enterprise within the household. The importance of 
access to credit is highlighted extensively in the literature (Beck \& Demirguc-Kunt, 2006; Evans \& Jovanovic, 1989; Hurst \& Lusardi, 2004). As such, this finding is consistent with those studies and highlights the importance of access to credit for nonfarm entrepreneurship in rural Burundi.

Table 6.4: Determinants of Non-Farm Business Activities (Probit estimates)

\begin{tabular}{|c|c|c|c|}
\hline & (1) & $(2)$ & (3) \\
\hline & Refugee $\mathrm{HH}$ & IDP HH & Displaced HH \\
\hline \multirow[t]{2}{*}{ Returnee } & -0.016 & & -0.015 \\
\hline & $(0.028)$ & & $(0.028)$ \\
\hline \multirow[t]{2}{*}{ IDP } & & 0.008 & 0.007 \\
\hline & & $(0.026)$ & $(0.026)$ \\
\hline \multirow{2}{*}{ Female } & -0.018 & -0.019 & -0.019 \\
\hline & $(0.059)$ & $(0.059)$ & $(0.058)$ \\
\hline \multirow[t]{2}{*}{ Age } & $-0.002 *$ & $-0.002 *$ & $-0.002 *$ \\
\hline & $(0.001)$ & $(0.001)$ & $(0.001)$ \\
\hline \multirow[t]{2}{*}{ Married } & 0.087 & 0.086 & 0.086 \\
\hline & $(0.061)$ & $(0.061)$ & $(0.061)$ \\
\hline \multirow[t]{2}{*}{ Primary } & -0.006 & -0.006 & -0.006 \\
\hline & $(0.027)$ & $(0.027)$ & $(0.027)$ \\
\hline \multirow[t]{2}{*}{ Secondary } & $-0.336 * * *$ & $-0.336 * * *$ & $-0.336 * * *$ \\
\hline & $(0.106)$ & $(0.106)$ & $(0.106)$ \\
\hline \multirow[t]{2}{*}{ Child to adult ratio } & $0.032 * *$ & $0.031 * *$ & $0.031 * *$ \\
\hline & $(0.014)$ & $(0.014)$ & $(0.014)$ \\
\hline \multirow[t]{2}{*}{ Own house } & -0.080 & -0.080 & -0.080 \\
\hline & $(0.051)$ & $(0.051)$ & $(0.051)$ \\
\hline \multirow[t]{2}{*}{ Self-sufficient } & $-0.086 * * *$ & $-0.085 * * *$ & $-0.086 * * *$ \\
\hline & $(0.023)$ & $(0.023)$ & $(0.023)$ \\
\hline \multirow[t]{2}{*}{ Food shortage } & -0.021 & -0.022 & -0.021 \\
\hline & $(0.024)$ & $(0.024)$ & $(0.024)$ \\
\hline \multirow[t]{2}{*}{ Informal network } & $0.135 * * *$ & $0.135 * * *$ & $0.135 * * *$ \\
\hline & $(0.024)$ & $(0.024)$ & $(0.024)$ \\
\hline \multirow{2}{*}{$\begin{array}{l}\text { Access to micro-finance } \\
\text { institution }\end{array}$} & $0.165^{* * *}$ & $0.165^{* * *}$ & $0.165^{* * *}$ \\
\hline & $(0.035)$ & $(0.035)$ & $(0.035)$ \\
\hline \multirow[t]{2}{*}{ Accessibility of community } & $-0.052 *$ & $-0.052 *$ & $-0.052 *$ \\
\hline & $(0.027)$ & $(0.027)$ & $(0.027)$ \\
\hline \multirow[t]{2}{*}{ Market in community } & -0.000 & -0.000 & -0.000 \\
\hline & $(0.000)$ & $(0.000)$ & $(0.000)$ \\
\hline \multirow[t]{2}{*}{ Economic Shock } & -0.059 & -0.058 & -0.059 \\
\hline & $(0.052)$ & $(0.053)$ & $(0.052)$ \\
\hline \multirow[t]{2}{*}{ Environmental Shock } & -0.007 & -0.008 & -0.008 \\
\hline & $(0.050)$ & $(0.050)$ & $(0.050)$ \\
\hline Observations & 1,390 & 1,390 & 1,390 \\
\hline
\end{tabular}

Notes: ${ }^{* *} \mathrm{p}<0.01,{ }^{* *} \mathrm{p}<.05,{ }^{*} \mathrm{p}<0.10$. Average marginal effects are reported. Standard errors in parentheses are robust and clustered at the community level.

Factors at the community level seem to be less important, with both economic and environmental shocks not showing a significant effect. This is surprising in so far that the literature highlights the role of non-farm business as both insurance against and coping strategy in the aftermath of experiencing shocks. However, the lack of a 
significant effect in this case, may be due to the indicators used at the community level rather than the household level, at which this information is unfortunately not available. Interestingly and counter-intuitive, the presence of a market in or close to the community is negatively associated with the existence of non-farm enterprises in households as is the accessibility of the community. Both may be an indication that where the infrastructure is better and other opportunities therefore may exist, nonfarm enterprises may not be as needed by households as in more distant and less developed communities, where necessity entrepreneurship is more prevalent.

A factor that is also often described as increasing the likelihood of a household to engage in a non-farm business, are prior experiences of working in self-employment. While this is not captured as such in the present data, a sub-sample of refugees and IDPs were asked to indicate their economic activities both just before experiencing displacement as well as during displacement. This information was only collected from one randomly selected refugee returnee and/ or IDP per respective relevant household, where the main respondent indicated that one of the household members qualified as such.

The results of probit regressions including these variables are included in the first two rows of Table 6.5. Only the main variables of interest are presented here, but the same control variables as in the models above were included. They show consistent results, when it comes to the main determinants identified. For reference, the full tables (Table E. 3 and Table E. 4) are provided in Appendix E of this dissertation.

Interestingly, the regressions show that prior experience in a non-farm business activity at either of the times increases the likelihood of returnee households to be operating such a business now. In the case of IDPs, on the other hand, the variables do not show a significant effect. Evidence exists that IDPs often faced much more difficult situations than refugees in camps for example in Tanzania (Fransen, 2015). It may therefore be the case that deterioration of skills is a more significant problem for IDPs than it is for refugees in this specific case, which may be leading to this finding.

Furthermore, prior studies have found that differences in socio-economic outcomes of displaced populations are driven by their respective displacement experience. This relates to the duration of displacement as well as the time passed since return (Fransen et al., 2017); more specifically, whether the displaced had an early return or not, where an early return is defined as being displaced for a maximum of one year (Verwimp \& Muñoz-Mora, 2017). Further probit regressions were therefore run to check if these time aspects of displacement also impact the likelihood of engaging in a non-farm business activity. 
As the bottom part of Table 6.5 shows, the factors that were checked did not have a significant relationship with non-farm business operation, with the exception of the years since return for refugees (the same information is not available for IDP households in the dataset). In this case, having returned ten years or more ago has a positive effect on non-farm businesses, showing a potential positive development in terms of reintegration upon return, a process which often takes time (Kuschminder, 2017).

Table 6.5: Displacement and Current Non-Farm Business Operations (Probit estimates)

\begin{tabular}{lcc}
\hline \hline & Refugee Household & IDP Household \\
\hline Prior Business Experiences & & \\
Before displacement & $\mathbf{0 . 2 6 3 * * *}$ & 0.034 \\
& $(0.066)$ & $(0.085)$ \\
& $\mathbf{0 . 3 0 5 * * *}$ & -0.004 \\
During displacement & $(0.063)$ & $(0.094)$ \\
& & \\
Displacement Experience & & \\
Short-term displacement (less than & -0.068 & -0.029 \\
one year) & $(0.050)$ & $(0.058)$ \\
Return ten or more years ago & $\mathbf{0 . 1 1 8 *}$ & \\
& $(0.064)$ & $\mathrm{X}$ \\
Controls & $\mathrm{X}$ & 185 \\
Observations & 226 & \\
\hline \hline
\end{tabular}

Notes: Results reported are from separate regressions. Average marginal effects reported. ${ }^{* * *} \mathrm{p}<0.01,{ }^{* *} \mathrm{p}<.05$, ${ }^{*} \mathrm{p}<0.10$. Standard errors in parentheses are robust and clustered at the community level.

\subsection{Concluding Remarks}

This chapter investigated the patterns and determinants of non-farm business operation in rural Burundi. Due to the country context, characterized by a series of violent conflicts over the past decades and consequential internal and international displacement of relatively large shares of the population, a specific focus herein lies on analysing the role of such displacement experiences as a factor potentially influencing the uptake of business activities. Specifically, the chapter answered the research question: What is the relationship between forced migration experiences and engagement in non-farm household business activities in a rural (post-) conflict developing country context?

The literature on household non-farm businesses and potential linkages with displacement experiences in developing country contexts is still in its early stages and 
as such this chapter contributes to the existing evidence by looking specifically at a (post-) conflict situation. Ultimately, such investigations and an enrichment of the evidence base is needed in order to understand rural non-farm businesses in a way that policies and programmes can be developed that efficiently and effectively support potential entrepreneurs to start businesses when they see an opportunity but prevents them from having to do so out of necessity.

The analysis of a unique dataset covering 1,390 households in rural Burundi showed that, as expected in such a context, activities in the agricultural sector are the main income source for the majority of these households. However, the data also showed that a quarter of the households do engage in non-farm businesses and that their importance should therefore not be underestimated; even if this rate is lower than those reported for other countries in Sub-Saharan Africa (Niger, Nigeria, Tanzania, and Uganda) by Nagler and Naudé (2017). The importance of these activities is confirmed when looking at the main income source of rural Burundian households, where it appears that such businesses are used by households to complement agricultural income, next to casual wage labour.

With regards to the displacement experiences of households, and therefore answering the posed research question, the analysis in the present chapter did not find any evidence that the operation of businesses is correlated with either internal displacement or displacement across international borders as such. While there is reason to believe that those that experienced displacement may be more likely to engage in such activities, solely based on the fact that they may experience problems accessing sufficient amounts of land for subsistence farming, the analysis does not confirm this expectation. Instead a series of other determinants of non-farm business operation in rural Burundi have been identified.

Looking at these determinants, beyond displacement of non-farm business operation by household in rural Burundi, several factors stand out. Existing studies on the topic of non-farm entrepreneurship largely focus on the individual level, however, evidence exists that in many cases the choices of labour market activities of individual household members, are actually taken jointly at the household level as part of its livelihood strategy (Alsos et al., 2014).

The analysis therefore controls not only for individual characteristics of the household head, but also for a range of household level characteristics as well as community level factors. The results indicate that these determinants are indeed much more significant for business operation in this context. Specifically, the self-sufficiency of the household based on agricultural production is negatively related to non-farm business operation, 
indicating that much of the businesses are indeed born out of necessity, in situations when the household cannot meet their food needs based simply on such activities. This does apply to all three different types of households and is therefore not directly related to displacement experiences, though the descriptive statistics show that former refugees and IDPs are more likely to face the challenges of insufficient land.

Furthermore, with regard to the theoretical assumption about the role of the different types of capital, and their relationship to labour market activities and business engagement specifically, the results also provide further evidence on the importance of financial and social capital specifically. Existing informal networks of household members as well as the access of household members to micro-finance institution are indeed associated with a higher likelihood of running a business.

This highlights the importance of both social and financial capital, which can be pooled at the household level and the importance of micro-finance institutions in such contexts, which is already the basis of many policies and programmes aiming at developing the business sector in developing countries. Higher levels of human capital, proxied through the education level of the household head, on the other hand show a negative relationship with non-farm business operation, indicating that there are other options available for those that have higher qualifications.

Overall, the findings of this chapter feed into the ongoing debate in the literature on the limited ability of rural non-farm entrepreneurship to contribute to economic growth of a country and more importantly to contribute to poverty reduction. Turning back to the classification of entrepreneurs into necessity and opportunity, it indeed seems that large shares of the non-farm businesses observed in the present study may have been started out of necessity when households did not have sufficient other options (indicated by the inability to sustain their livelihood based on their own farm land and the lower education level of the household head). However, the actual motivations of households behind starting businesses, and specific types of businesses for that matter, cannot be identified in the present data.

In conclusion, the non-farm business activities identified in this chapter in the context of rural Burundi are not likely to contribute significantly to the economic growth of the country as a whole and to employment creation more generally due to their nature and size. Such activities may not even be sufficient to better the conditions of households living in extreme poverty. However, they do contribute to households' abilities to diversify income sources and sustain livelihoods. Considering the role of displacement in such a context is important in so far that households that have been affected by conflict in, may overall be worse off in economic terms, but do not seem to rely 
specifically on necessity non-farm businesses to cope with their situation upon return. Instead this appears to be a strategy of households in rural Burundi more generally to diversify income sources, when they are able to do so based on their access to different forms of capital. 


CHAPTER 7: CONCLUSION 



\subsection{Introduction}

This dissertation analysed several aspects related to the labour market participation of forced migrants and their household members in developing countries. While there is a growing literature on the economic activities of migrants and refugees, much of the current evidence is based on studies set in contexts in the global North. The present work contributes to this literature by focusing on the less explored linkages between forced migration and labour market engagement in developing countries, where both migration patterns and labour market characteristics differ significantly from their counterparts in the generally more advanced economies of the global North.

Case studies based on unique datasets containing information on both (forced) migration experiences and labour market activities, allowed the investigation of four research questions to which answers are largely lacking for developing country contexts at this stage. Considering the growing importance of evidence-based policymaking, research such as this is important in the light of the current migration and displacement dynamics taking place around the world.

Only when understanding the linkages between forced migration and labour market outcomes, such as the ones discussed in this dissertation, will stakeholders be able to make informed choices about interventions and policies that will be beneficial to all involved and further the self-reliance of forced migrants during displacement as well as their sustainable reintegration upon return.

This concluding chapter of the dissertation proceeds as follows: Section 7.2 presents the main findings of each of the chapters by answering the four research question posted at the beginning of this dissertation. Section 7.3 critically reflects on the findings and discusses the limitations of the present dissertation. Section 7.4 presents suggestions for future research, before discussing the implications of this dissertation for policy-making in Section 7.5.

\subsection{Main Findings}

Following the introductory chapter, which presented the motivations, research questions, and main concepts, as well as the outline and the contribution of this dissertation, Chapter 2 explored the existing evidence on the linkages between migration, entrepreneurship, and development. This literature review highlighted a specific lack of research on the linkages between forced migration and entrepreneurship. Considering that the largest share of those displaced across 
international borders is hosted by developing countries, it is therefore especially important to generate more evidence on the role of entrepreneurship and the participation of forced migrants in the labour market more generally in developing country contexts.

This dissertation contributes to the literature by analysing research topics, which have been addressed in the context of economic migration, using case studies that are characterized by migration movements that are largely caused by conflicts and general insecurities. In Chapter 1 four research questions, which are then further embedded in the literature in Chapter 2, were posed addressing this overall theme. Each of these questions was addressed in one of the four empirical chapters (Chapters 3 to 6) that make up the core of this dissertation. Here, an answer to each of these questions will be provided, highlighting the main findings and contributions of this dissertation.

1) What are the patterns and determinants of refugees' labour market participation and in what ways do their economic activities differ from those of locals?

Chapter 3 of this dissertation, the first of the four empirical chapters, analysed the labour market activities of refugees from the Democratic Republic of Congo (DRC) living in Rwanda in response to this first research question. Specifically, the analysis focused on refugees in three distinct camps located in different regions of the country: Gihembe in the Northern Province, Kigeme in the Southern Province, and Kiziba in the Western Province. In doing so, the chapter first took a comparative approach to study the activities of refugees and native Rwandans that live in communities around each respective camp, and then analysed the activities of refugees more specifically across the different camp locations.

These camp locations are spread across the country and are characterized by different infrastructural and geographical factors, such as the access to close-by cities and markets which are likely to shape the economic opportunity structures of refugees. The analysis across the three camps therefore allowed, to some extent, to understand the influence of the conditions of the respective environment on the ability of refugees to access and engage in different types of labour market opportunities, including selfemployment activities.

The analysis found that unemployment is a significant issue among Congolese refugees living in refugee camps in Rwanda and that specifically land scarcity is a main driver of this unemployment. While activities in agriculture are the primary daily 
activity for the vast majority of locals, refugees seldom have access to such activities; and when they do it is in the form of casual wage labour.

Wage labour opportunities overall are limited, but where they are available the type of employers differs between locals and refugees. Refugees more often work for international and non-governmental organizations; as such, they carry out jobs directly related to the existence of the camps in which they live. Opportunities to access labour market opportunities with locals, on the other hand, are rare and where they exist it is largely through informal arrangements. Specifically, this is the case in the camps that are located further away from the closest urban centres. In such cases, focus groups discussions with refugees highlighted the fact that the benefits of taking up employment do not outweigh the costs of doing so, particularly in terms of getting to and from the work place from the camp when it is quite a far distance to travel.

The analysis also highlighted the role of gender in the labour market outcomes of both refugees and locals in and around refugee camps in Rwanda. In general, women are more likely to be engaged in self-employment than are men, possibly indicating that there may be fewer wage employment opportunities for them as much of the work that is available is manual labour. Consequently, when women are active in the labour market, it is more often in own account self-employed work and the odds of refugee women to engage in self-employment activities are specifically high. This is likely because local females often have the alternative of supporting the agricultural activities of their households when they are economically active.

One of the specific points that the analysis in Chapter 3 focused on was the relevance of the respective context for the labour market outcomes of refugees based on the differences due to the location of the three camps. The findings did indeed highlight some such differences. Specifically, labour market opportunities in Kiziba, a camp that is located in a remote area on top of a mountain, are specifically limited for refugees. This is the case for both wage- and self-employment, a fact that can be explained by the limited access to markets to trade, buy, and sell products and services in the latter case. Still the main activity of refugees in Kiziba is self-employment, in contrast to the other two camps where it is wage employment.

This may well be an indication of necessity entrepreneurship in a situation where refugees are left with little other options for income-generating activities. However, overall the analysis highlighted that in many cases accessing the local labour market is not only difficult for refugees but is equally challenging for the local population due to an overall limited number of wage employment opportunities in an economy that is largely still shaped by the agricultural sector, especially in rural areas of the country. 
The main difference between the groups therefore relates to the access to land and the consequential reliance on work in agriculture by most of the local population, an option not available to refugees living in camps.

2) How are self-employment activities of non-migrants shaped by the forced or voluntary migration experiences of household members?

Chapter 4 of this dissertation took a comparative approach to the linkages between migration of a household member and self-employment activities of non-migrants. As such, the analysis shifted the focus from the (forced) migrants themselves to their household members in the countries of origin.

Considering current and return migration, the chapter investigated whether there is a relationship between the migration experiences of household members and the selfemployment activities of non-migrants in the same household. Using four unique datasets from Afghanistan, Burundi, Ethiopia, and Morocco made it possible to investigate this question in diverse labour market and migration contexts, including two characterized by mainly forced migration movements. The chance to compare them, while recognizing such differences in context, provided an opportunity to learn more about the linkages between migration and self-employment of household members in the country of origin.

While the results should be interpreted with caution due to the possibility of present bias, some interesting results did come out of the estimations. Looking at the results across the four countries, it becomes clear that indeed the respective country context matters. As may be expected, in cases were migration is dominated by movements that are for reasons such as escaping from violent conflict or general insecurity - in this case Afghanistan and Burundi - no relationship between a current migrant in the household and self-employment activities could be identified.

In the case of Ethiopia, there is evidence that the presence of a current migrant in the household is negatively associated with self-employment and with working at all. Considering that most of the migration captured from this country is migration to the Middle East with the main purpose of sending remittances and contributing to consumption smoothing of the household left behind, such a finding may not be surprising.

Migration from Morocco, on the other hand, is much more likely to be for reasons such as overcoming credit constraints and gathering of savings. In this case, there is a 
negative relationship of a current migrant and the likelihood of non-migrants to be working, but the estimates suggest that there is indeed a positive relationship between the migration experiences and self-employment activities of non-migrant household members. This may show that in such an environment, there is potential of migration to contribute to development through positive spill overs of migration on small business development through non-migrant household members.

Besides the analysis of the potential relationship between a current migrant in the household and self-employment of non-migrants, the analysis also considered the relationship between the latter and a return migrant in the household. In this case, a potential relationship could only be found in the case of Morocco, indicating that in the most advanced economy of the four countries migration may be used by households as a strategy to overcome liquidity constraints. However, overall there is little evidence for spill overs of return migration on non-migrants in the same household and their self-employment activities, particularly in the context of forced migration.

3) To what extent do forced migration experiences shape the labour market reintegration of returned refugees in a (post-) conflict developing country context?

Chapter 5 focused on the labour market activities of returned refugees in the context of Afghanistan. Employment and income-generation more generally are essential in the process of reintegration and the building of sustainable livelihoods of returnees. Despite this importance, there is a lack of evidence on such activities and especially the role of self-employment of returnees in such a (post-) conflict context. In the light of discussions around sustainable return and reintegration, the chapter analysed the labour market activities of refugees that returned from neighbouring Iran and Pakistan.

Afghanistan has been affected by conflict and general insecurity for decades and, at the same time, return movements of displaced populations have been significant. As such, it presents an interesting and relevant case study to investigate the posed question using a unique dataset gathered through the use of a household survey in 2011 across five provinces of the country. The chapter approached the question by first analysing the labour market outcomes of returned refugees in contrast to those of nonmigrants, before moving on to investigate the role of the migration and return experiences specifically for the group of returnees. 
The results highlighted the role of socio-economic status and capital for the successful labour market reintegration of returned refugees. Specifically, returned refugees are less likely to be wage employed in comparison to non-migrants. Considering the overall limited wage employment opportunities in the labour market of Afghanistan, the results highlight that non-migrants with a higher socio-economic status are more likely to access such opportunities.

For returned refugees the results underlined the importance of social capital for accessing wage employment as well as self-employment in both agriculture and business. Looking specifically at the latter, the descriptive statistics showed that on average more returned refugees engage in self-employment in business activities than do non-migrants. However, the further analysis indicated that this is not due to the migration experience as such but can be explained through the socio-economic factors as well as social capital.

Looking specifically at the migration and return experience of the group of returned refugees, a few key factors were found to be of particular importance for the current employment status. These include the time spent abroad, return assistance and intentions to re-migrate, as well as employment prior to migration, an indicator of human capital, and the amount of savings brought back upon return, an indicator of financial capital. Specifically, those returned refugees that were wage employed prior to leaving the country, have a higher likelihood of being wage employed upon return. Returnees' savings, on the other hand, appear to allow them to invest in agricultural activities more so than businesses.

Overall, these findings help to shed light on the reintegration process of returned refugees in Afghanistan, an issue of growing concern for policy-makers (see Section 7.5) taking into consideration the recent increase in return flows around the world. In addition, the contribution lies in the analysis of the topic of labour market outcomes of returnees, which has so far only been analysed quantitatively in relation to labour migration, in a (post-) conflict context.

4) What is the relationship between forced migration experiences and engagement in non-farm household business activities in a rural (post-) conflict developing country context?

Chapter 6 moved from the individual to the household level by investigating the patterns and determinants of non-farm business operation by households in rural Burundi and potential linkages with displacement experiences of household members. 
Non-farm businesses have been found to be of increasing importance in rural areas of developing countries where households engage in such activities in order to diversify their income sources. This chapter contributed to the literature by focusing on the context of post-conflict rural Burundi, which is particularly interesting due to the relatively large share of the population that was affected by the repeated waves of violent conflict by being displaced either within Burundi or across the border to neighbouring countries.

This context allowed the investigation of the relationship between experiences of forced migration and the likelihood of engaging in non-farm business activities. The fact that land scarcity has been identified as one of the main concerns when large numbers of returnees arrived in many areas of Burundi, presents the theoretical argument that returnees may be more likely to engage in small businesses as they are more likely to depend on other income sources than agriculture, which overall is the main economic activity used by households to satisfy their daily needs.

The results did, however, not confirm this hypothesis. While one quarter of the surveyed households do engage in such businesses, no relationship is found between displacement and non-farm business operation as such. Instead the engagement of households in rural Burundi in such activities is relatively similar across the households with displacement experience and those without. The argument of a lack of land being a driver of necessity entrepreneurship, on the other hand, is confirmed in the analysis. Specifically, those households that are not able to satisfy their daily food needs with products from their own agricultural operations, are significantly more likely to be engaged in non-farm businesses.

Furthermore, the results provided further evidence regarding the importance of different types of capital when it comes to the engagement in self-employment activities. Both the role of social capital and of financial capital were highlighted in the context of household non-farm business operation in rural Burundi. A household's access to financial capital, measured through the membership in a micro-credit institution, is strongly correlated with such activities. In addition, existing social networks are a further factor explaining the engagement in business. Also consistent with the existing literature, the results showed that human capital is negatively related to non-farm business operation in the context of rural Burundi, where most of these activities are driven by necessity. While not the topic of this chapter, it is likely that higher levels of human capital instead lead to better opportunities regarding wage employment and as such households with such capital are less likely to need to diversify income sources into non-farm entrepreneurship. 


\subsection{Limitations}

As discussed in the previous section, this dissertation provides new evidence on forced migration and labour market participation in developing countries. However, the analysis conducted in Chapters 3 through 6 of this dissertation uses data and methodologies that come with inherent limitations. The discussed limitations are largely related to the nature of the used data and the challenges associated with the issue of endogeneity in migration research.

It is important that the respective challenges and limitations that are common across the chapters are discussed further in the conclusion of this work as the findings and policy recommendations (see Section 7.5) should be seen in the light of these limitations. In addition, reflecting on the limitations, along with the main findings presented in the previous section, allows to develop suggestions for further research on the labour market engagement of forced migrants and their households (see Section 7.4).

One of the main limitations of the present research lies in the fact that the main purpose of the data collection efforts that produced the datasets used in the four empirical chapters was to understand different aspects related to migration, but not specifically labour market participation. Specifically, these were the linkages between migration and development in the IS Academy datasets (Chapters 4 and 5), the impacts of hosting refugees on the local communities in the UNHCR Rwanda dataset (Chapter 3), and the labour market impacts of forced migration in the LAMFOR Burundi dataset (Chapter 6). While the focus of the latter was placed on labour market activities and the economic situation of households in Burundi more generally, household businesses were just one of several activities that were assessed in the survey. As such, the specific activity at the centre of the analysis in Chapter 6 was not the main interest of the collected data.

Generally, the surveys conducted to collect the data aimed to gather information on a variety of characteristics, experiences, and future perspectives of the sampled households and their members with a focus on migration experiences. They were, on the other hand, not focused specifically on the collection of data on labour market activities and/ or entrepreneurial activities and, for example, the possible determinants of the occupational choices of forced migrants and non-migrants, the role of different economic activities for the overall livelihood of the households, or the possible motivations for operating a non-farm business. 
As a consequence, it was not possible to investigate the questions posed in each of the four empirical chapters of this dissertation in as much detail as may have been desirable. For example, it would have been beneficial to not only account for the primary activity of individuals, but to be able to record the use of time more accurately and to see changes over time in the occupational status.

In addition, the development potentials of the labour market participation of forced migration and their households could not be assessed with the present data. In this regard, there is also still a knowledge gap on the implications of entrepreneurship of migrants and specifically refugees, some examples of which will be elaborated in the following section on suggestions for future research.

Another limitation of the data used in this dissertation is its cross-sectional nature. Self-reliance of refugees is not something that is expected to work immediately after displacement in the emergency context, but a process that takes time. Therefore, looking at a snapshot in time may mask the dynamics of the abilities of refugees to adapt to the situation over time.

The same is true in relation to reintegration, which is also a process that takes time. While in Chapter 5 returnees that returned at different points in time are included and the differences are analysed, it would be much more important to follow the same individuals over time to better understand the importance of their labour market activities for the overall reintegration and where specific critical points lay in when it comes to decision-making about potential re-migration. More generally, with regard to self-employment and entrepreneurship panel data would allow the study of survival and growth as well as failures and moves away from current undertakings when other opportunities arise.

A final limitation that relates to the cross-sectional nature of the data is the potential risk of endogeneity that is inherent to migration research. Specifically, three concerns in this regard are common in the study of migration and related topics and also are relevant to the research in this dissertation. These are reverse causality, selection bias, and omitted variable bias (McKenzie \& Sasin, 2007). This stems from the fact that those that migrate, and their households, may be different than those that do not due to the fact that migrants are self-selected, even in the case of forced displacement. Therefore, there is reason to believe that those that move when affected by violent conflict and general insecurity are different from those that stay based on observable characteristics, such as wealth, and on unobservable characteristics, such as their risk perception and attitude. As discussed, for example in Chapter 4, the relationship between self-employment of non-migrants and current and return migration 
experiences in the household may work in both ways. This may mean that a household where somebody is active in self-employment is more likely to have a migrant abroad or returned from a period abroad.

Methodologies do exist to deal with such risks, for example instrumental variable approaches and propensity score matching. Neither of these econometric techniques was, however, possible or appropriate to implement in the empirical chapters of this dissertation. Instrumental variable approaches can be used to estimate regression results in the presence of endogeneity through the use of an instrumental variable.

This variable should, on the one hand, be correlated to the endogenous independent variable, in this case migration and/ or return migration, but, on the other hand, not directly correlated with the dependent variable, in this case labour market activities, except through the former independent variable. A strong instrument needs to satisfy both of these conditions, otherwise the bias in the estimation is not controlled for but further bias is introduced.

Tests to check the strength of instruments exist to ensure that no weak instruments are used. Throughout the different chapters, different kinds of instrumental variables were explored and tested, such as the intensity of conflict, the distance to the border prior to the onset of conflict, or differences in economic development between countries of origin and destination, but none were found that satisfied the necessary conditions to be considered a strong instrument for the respective question of interest.

A second approach that was considered to control for potential selection into forced migration was propensity score matching. This methodology is used to compare individuals or households that share the same characteristics more generally, but differ in one specific aspect, the treatment, which in this case would be the migration. The aim is to see if this treatment variable has a treatment effect regarding an outcome variable of interest, in this case labour market activities. The probability of receiving the treatment is estimated based on observable characteristics. Therefore, the treated and untreated individuals or households should differ in no characteristics that relate in some way to labour market activities but the migration experience. As a consequence, when using this method, the assumption always has to be that all characteristics can be controlled for before receiving this treatment. In the case of migration this means that data needs to contain detailed information on the characteristics of individuals or households prior to migration. Even where such information is collected, the sample sizes generally need to be quite large in order to ensure the similarity of groups of treated and untreated. 
These conditions were not met in the present datasets and as such propensity score matching was also not considered be an appropriate tool for analysis. There is therefore the possibility that endogeneity is present in this research. As a consequence, no causal relationships or impacts can be established, and instead all results reported are based on identified associations and correlations.

\subsection{Suggestions for Future Research}

Based on the findings as well as the limitations summarized in the previous two sections, several suggestions for future research on the labour market participation of forced migrants in developing country contexts can be developed. The topics for further studies suggested here are some of the most relevant ones as follow-up to the work conducted for this dissertation. They do not present an exhaustive list as there are many other research areas that are closely related to those mentioned in this work, which would equally add to the existing knowledge base in the field of the labour market participation of forced migrants both during migration and upon return in different contexts.

As elaborated in the previous section, the data used throughout this dissertation was not collected with the purpose of analysing the posed research questions as such. As a consequence, there is an inherent need for improved data collection efforts, which would allow more rigorous analysis and therefore move the understanding of the labour market participation of forced migrants and their households, both during migration and upon return, forward.

In line with the limitations pointed out, further research needs to be developed with the specific question in mind that needs to be answered; it can then be ensured that the information necessary to answer it is collected comprehensively. In addition, the specific context should be considered. When it comes to labour market participation in general and entrepreneurial activities specifically, this would ideally be done using in a longitudinal approach. Data collection efforts that take such an approach would allow the analysis of the dynamics of the labour market participation of forced migrants and their households, an issue that is important both in the light of selfreliance as well as sustainable return and ultimately the development implications of forced migration.

The topic of the dynamics of non-farm self-employment, especially in rural areas, and labour market activities more generally in developing countries is one that is increasingly attracting attention, but limited research has been conducted on it in 
relation to migration and specifically forced migration. In this case, a lack of data sources can be identified as the main reason for this, though some first efforts to improve data collection efforts have been made.

An example of this are the LSMS-ISA surveys that have been conducted in eight SubSaharan countries. ${ }^{37}$ They are a unique tool that collects nationally representative household panel data with a specific module on non-farm enterprises. While the resulting datasets are not without challenges (see Nagler (2015) for a detailed discussion), they did allow the development of new and comparative insights into rural non-farm entrepreneurship in rural Africa. However, inconsistencies of the surveys across countries led to the inclusion of a migration module in only some of the included countries. And even where such a module was included, few current and return migrants were captured. Therefore, while data collection efforts are increasing, more specific data is needed if the understanding of the labour market activities of forced migrants and their households is to be moved forward.

One example where the lack of data is specifically apparent, and more research is therefore needed, is the classification of entrepreneurs into being driven by necessity or motivated by opportunity. Proxies and the general context allow, to some extent, to investigate the specific drivers of business start-ups of forced migrants. This leads to the conclusion that it indeed seems that large shares of the self-employment across the case studies have been started out of necessity where households did not have sufficient other options (indicated, for example by the inability to sustain their livelihood based on their own farm land and the overall limited availability of wage employment opportunities). The actual motivations of individuals and households behind starting businesses, and specific types of businesses for that matter, can, however, not be identified in the present data.

More generally, the decision-making that leads to different labour market activities of forced migrants is a significant research gap. In how far these decisions are taken by individuals and in what situations they are made jointly as part of a household strategy is at this stage unclear. Equally, while assumptions can be made about the relevance of the respective opportunity structure as well as the challenges present in the forced migrants' environment based on information on policies, the local context, and infrastructure, the role that these different factors play deserves attention.

\footnotetext{
37 These countries are Burkina Faso, Ethiopia, Malawi, Mali, Nigeria, Niger, Tanzania, and Uganda.
} 
Therefore, in terms of further research, much remains to be done. In particular, the motivations of households to engage in non-farm businesses in contexts like that of rural Burundi or when returning to Afghanistan remain unclear. Along the same lines, in Chapter 4, the data does not allow to really investigate the channels of potential linkages between (return) migration and labour market activities of non-migrant household members. In how far these are in fact decisions made at the household level or individual is not clear. Equally, the importance of such businesses for the people that engage in them cannot be identified based on the present data and understanding this would provide further evidence for well-suited support mechanisms for forced migrants and others beyond agricultural activities.

Further suggestions for research relate to the fact that it can be expected that it matters where forced migrants come from and where they settle. As elaborated, the vast majority of those that are forcibly displaced beyond the borders of their country of origin remain in countries neighbouring their countries origin. The case studies analysed in this dissertation all focus on such movements and the implications for the labour market participation of the forced migrants and their households. The exception are Ethiopia and Morocco in Chapter 4, where these movements are not considered to be forced due to conflict or general insecurity but are motivated by economic reasons.

The analysis in Chapter 4 as well as prior comparative research on labour markets and self-employment (De Vreyer et al., 2010; Jean et al., 2010; Nagler \& Naudé, 2017; OECD, 2010) have highlighted the large heterogeneity of patterns and determinants of economic activities of the population and migrants across different countries, especially developing countries. In addition, the conclusion of the literature review in Chapter 2 stresses the importance of context for the accumulation of skills and knowledge as well as for their usage in terms of labour market activities.

When it comes to return migration, it matters in how far the destination country provides opportunities to gather financial and human capital and in how far these can then be used upon return in the country prior. And in terms of immigration, there are also differences in regard to policies, opportunity structures, and challenges experienced by migrants. As such, it can be expected that different conflicts and situations of general insecurity as well as potential displacement also have different impacts on both the labour markets in countries of origin and destination as well as on the displaced and those staying throughout the conflict. As such, in order to widen the knowledge base on the labour market participation of forced migrants and their 
households, research on the topic needs to be extended to other countries and situations.

Finally, forced migration takes place across international borders but also within the borders of one country. Internal displacement is often cited as receiving far less attention than international displacement and, as a consequence, IDPs are often the most vulnerable in conflict contexts (Internal Displacement Monitoring Centre, 2017b). At the same time, even less is known about their labour market participation than about that of refugees in developing country contexts. It is crucial to develop an understanding of the types of income-generating activities accessible and desired among IDP communities. More research in this area would therefore be particularly opportune considering that the number of IDPs around the world, just like the number of forced migrants overall, has been increasing.

\subsection{Policy Implications}

Based on the main findings of this dissertation, this section presents several implications for policy-making in the area of the labour market participation of forced migrants during migration as well as upon return. These implications aim to improve the opportunities and eliminate some of the challenges of forced migrants that want to work in order to be self-reliant or to successfully reintegrate into the labour market in their home country. At the same time, the labour market participation of non-migrant and local populations needs to also be considered as the results showed that in many cases it is in fact not the specific migration experience that leads to challenges, but the opportunity structures more generally. Therefore, focusing policies and programmes on forced migrants only is likely to lead to tensions between refugees and locals, or returnees and non-migrants, which should be avoided in order not to risk social tensions. In order to do so, several avenues for policy-making can be identified, including, the facilitation of a deeper understanding of the labour market participation of forced migrants and the societies in which they live, the improvement of their access to the labour markets of the respective country of residence and the respective working conditions, and the provision of well-targeted support for those that aim to become self-employed in business.

Firstly, as highlighted in the previous section there is a need for improved data collection efforts. The importance of more evidence for policy-making on the labour market activities of forced migration requires more specific data on the linkages. It is not sufficient to base policy on experiences or anecdotal evidence, but instead is important to rigorously collect and analyse high quality data in order to generate the 
knowledge on the economic lives of refugees, IDPs, and returnees that is lacking so far. Recognizing the development potential that lies in displacement situations is one thing, but understanding what can facilitate the productive use of this potential is much more urgent in the light of the current displacement dynamics in the world.

Within such research, it is important that, as also highlighted in Chapter 2, the nuances of migration and displacement are considered and that no general conclusions are made. Taking into account that the situation of refugees changes over time as their situation switches from an emergency to a protracted one, and considering the differences in return depending on the initial cause of displacement and the respective experiences, the differences in policies, etc., it is likely to make each study specific to the respective situation and in order to effectively and efficiently implement policies, this specific context needs to be well understood. While it is not realistic that the labour market dynamics of forced migration and return are researched separately for each displacement situation, studies across multiple countries may be a way to generate evidence that allows to understand these dynamics in a more comprehensive manner. By collecting comparable data across different contexts, and ideally also over time, more robust conclusions and recommendations could be developed.

In addition to data collection as such, it is specifically important that more evaluations of policies and programmes are conducted to understand if and how such interventions support refugees in terms of labour market participation, what could be learned from individual cases, and what needs to be improved. In the case of return, many voluntary return programmes contain elements related to the economic life of returnees once back in the home country. One example of this is entrepreneurship training. Some initiatives simply provide in-kind or financial support, while others also offer training. The fact that this support is often given to people with no prior experience in running a business and maybe even no interest in doing so, can in this context be seen as a form of positive discrimination. It is, however, the case that evaluations of such programmes are largely lacking. In order to increase the efficiency and effectiveness of such programmes, more evidence is therefore needed.

Secondly, the access of forced migrants to the labour market is crucial to achieve selfreliance and sustainable return. It is clear that forced migrants have potential in the form of human, social, and sometimes financial capital. If allowed to do so and given the opportunity, they can contribute to the economy of the country of residence. This requires that there are no legal or administrative hurdles for refugees to take on employment or start a business. 
Here it is important that policies within a country are coherent and discrepancies between, for example, refugee and labour market policies do not lead to unintended barriers. The case of Congolese refugees in Rwanda discussed in Chapter 3 shows that though they officially have the right to move freely and work, few do so. This is due to administrative hurdles in getting the required paperwork as well as the location of the camps in relation to places in the country where jobs may be available.

Existing evidence from Uganda shows that in this case refugees are much more able and likely to take advantage of encountered economic opportunities. As is the case in Rwanda, they have the right to free movement and to work and large numbers of refugees utilize these rights (Betts et al., 2017). While the case of Uganda is not representative of displacement dynamics in other countries, it can provide important insights. Comparative approaches to research this case and one like Rwanda may provide insights into factors that facilitate and hinder the labour market participation of forced migrants.

It is also important to understand that the environment as such needs to enable refugees and returnees to engage economically when they can do so. While those in vulnerable situations should not be 'forced' to work, those that want to and are ready, should not be seen as dependent on humanitarian assistance, but instead recognized as economic actors. Support and policies should therefore focus on actions that can facilitate this. This includes opportunities for (further) education and training for the refreshment and development of skills, but also infrastructure such as transportation and internet and cell phone access.

Thirdly, in light of the present findings, there seem to be a number of opportunities to assist small business creation by forced migrants both during displacement as well as upon return to the country of origin with the ultimate goal of supporting self-reliance and sustainable return and reintegration respectively. When considering potential interventions, however, it is necessary to emphasize a logical selection of the specific areas where support is implemented as well as proper targeting.

When developing support of any kind it is important that this assistance be meaningful to the localized context of the recipient. Unsurprisingly, individuals in rural areas are more likely to become self-employed in agriculture than in business. As such, in-kind assistance like tools, seeds, or livestock are likely to enable and support these agricultural activities, whereas assistance like business training may be more appropriate in an urban context or in cases where individual or households indicate a specific business idea that they need support implementing. 
This is also specifically relevant to refugees that arrive in a new location in which they are less familiar with the ways of doing business, even if they were previously engaged in a similar activity. The specificities of the local context are unfamiliar and it may only take minimal support to get them engaged in self-employment. Such support has also been found to not only be beneficial to the development of businesses and therefore self-reliance of refugees, but to contribute to the building of self-confidence and the empowerment of refugees (Jabbar \& Zaza, 2016; Marchand \& Dijkhuizen, 2018).

Furthermore, when targeting individuals or households for interventions, such as entrepreneurship training, the selection of beneficiaries is an important step for efficient and effective implementation. Not all (forced) migrants are entrepreneurs and different kinds of migrants in different situations are much more likely to end up in entrepreneurship, with different success rates. Screening of potential beneficiaries is therefore an important pre-condition to ensure that they are both motivated and have useful skills and experiences.

At the same time, it is important that interventions targeting forced migrants to do not exclude other potential vulnerable groups that could benefit from the same kind of support. In such situations it is often advisable to make interventions more inclusive in order to avoid social tensions that could be created by letting one group benefit and leaving another one aside. In the case of Afghanistan, for example, programmes such as shelter assistance specifically target areas with high return rates. But in those areas support is given to both returnees as well as the local population that never left but is in need for similar support as those that more recently returned. As such once the intervention areas are identified, beneficiaries are not selected based on their status as a former forced migrant but based on more general vulnerability factors (Maastricht Graduate School of Governance \& Samuel Hall, 2013).

Given the role of social networks highlighted throughout the chapters, assistance focused on helping forced migrants and returnees build strategic linkages in their respective communities may be particularly beneficial. The capacity of refugees as well as returnees could be improved by bringing them in touch with other actors like business associations or a network of experts. Indeed a now-outdated programme run by the Dutch IntEnt Foundation providing support to return migrants from the Netherlands to several countries had an extensive network at origin willing to help newcomers by sharing knowledge, contacts, and in some cases even investments (de Haas, 2006).

The German Development Cooperation GIZ runs a similar and currently ongoing programme called Business Ideas for Development. This support programme 
operated by the Centre for International Migration and Development (CIM) has proven to be beneficial to return migrants wanting to open a business in several developing countries and emerging market economies, for example Morocco, Cameroon, Ghana, Senegal, and Nigeria in Africa or Ecuador, Colombia, and Peru in Latin America. It provides potential return migrant entrepreneurs support with developing and implementing their business plan, provides opportunities for networking, and is even able to offer some start-up funding (Centrum für internationale Migration und Entwicklung, 2018). ${ }^{38}$

Additionally, the findings concerning the importance of savings and access to financial capital suggest a possible credit constraint which earnings from abroad help to ease. Forced migration movements in most cases are not undertaken with the intention of accumulating savings, while this may be the case in other migration movements with this specific purpose. As a consequence, returnees and refugees often face the same challenges concerning start-up capital as do locals. With this in mind, small grants and/ or loans for the purpose of investing in a business venture may be a viable strategy if provided to a suitable recipient with practical ideas and the capacity to carry them out. Careful selection is therefore important in order to increase the likelihood of effective implementation, but certain conditions could be put in place to help improve the odds of success, including mandatory attendance to training session or membership in a business group, where this exists.

Overall, and in conclusion, it is important that forced migrants are more often seen as people with experiences, knowledge, and skills. They may have been adversely affected by conflict, insecurity, or persecution, but this does not make them passive actors. While many refugees, asylum seekers, IDPs, and returnees are in vulnerable situations, in which they require humanitarian assistance, this does not mean that they do not also aspire and want to ultimately be able to create a sustainable livelihood for themselves and their households. As such it is important that policies, programmes, and any support mechanisms aiming at helping forced migrants, as well as other vulnerable groups, recognize such aspirations and ultimately provide the help needed for these populations to help themselves. This does require careful analysis of the local context but is the most efficient way that support can enable the self-reliance of forced migrants and the sustainable reintegration of returnees through labour market participation.

\footnotetext{
${ }^{38}$ For more information on this programme please refer to the following website provided by CIM: https://www.cimonline.de/en/html/business-ideas.html
} 




\section{REFERENCES}



Acosta, P. (2006). Labor Supply, School Attendance, and Remittances from International Migration: The Case of El Salvador (World Bank Policy Research Working Paper No. 3903). Washington, D.C.: World Bank.

Acosta, P. (2007). Entrepreneurship, Labour Market and International Remittances: Evidence from El Salvador. In Çaglar Özden \& M. Schiff (Eds.), International Migration, Economic Development and Policy (pp. 141-159). Washington, D.C.: The World Bank and Palgrave Macmillan.

Acosta, P., Fajnzylber, P., \& Lopez, J. H. (2007). The Impact of Remittances on Poverty and Human Capital: Evidence from Latin American Household Surveys. In Çağlar Özden \& M. Schiff (Eds.), International Migration, Economic Development and Policy (pp. 59-98). Washington, D.C.: The World Bank and Palgrave Macmillan.

Ács, Z. (2006). How Is Entrepreneurship Good for Economic Growth? Innovations: Technology, Governance, Globalization, 1(1), 97-107.

Adams, R. H. (1991). The effects of international remittances on poverty, inequality, and development in rural Egypt (IFPRI Research Report No. 86). Washington, D.C.: International Food Policy Research Institute.

Adams, R. H. (2004). Remittances and Poverty in Guatemala (World Bank Policy Research Working Paper No. 3418). Washington, D.C.: The World Bank.

Adams, R. H. (2006). Remittances and Poverty In Ghana (World Bank Policy Research Working Paper No. 3838). Washington, D.C.: The World Bank.

Adams, R. H. (2009). The Determinants of International Remittances in Developing Countries. World Development, 37(1), 93-103.

Adams, R. H., \& Page, J. (2003). International Migration, Remittances, and Poverty in Developing Countries (World Bank Policy Research Working Paper No. 3179). Washington, D.C.: The World Bank.

Adams, R. H., \& Page, J. (2005). Do international migration and remittances reduce poverty in developing countries? World Development, 33(10), 1645-1669. 
Agunias, D. R. (2006). Remittances and Development: Trends, Impacts, and Policy Options - A Review of the Literature. Washington, D.C.: Migration Policy Institute. Retrieved from https://www.migrationpolicy.org/research/remittances-anddevelopment-trends-impacts-and-policy-options-review-literature

Airola, J. (2008). Labor Supply in Response to Remittance Income: The Case of Mexico. The Journal of Developing Areas, 41(2), 69-78.

Aleinikoff, T. A. (2015). From Dependence to Self-Reliance - Changing the Paradigm in Protracted Refugee Situations (MPI Policy Brief). Washington, D.C.: Migration Policy Institute.

Alsos, G., Carter, S., \& Ljunggren, E. (2014). Entrepreneurial families and households. In T. Baker \& F. Welter (Eds.), The Routledge Companion to Entrepreneurship (pp. 165-177). Oxford: Routledge.

Amisi, B. (2006). An exploration of the livelihood strategies of Durban Congolese refugees (New Issues in Refugee Research Working Paper No. 123). Geneva: UNHCR.

Amorós, J. E., \& Cristi, O. (2011). Poverty and Entrepreneurship in Developing Countries. In M. Minniti (Ed.), The Dynamics of Entrepreneurship: Evidence from Global Entrepreneurship Monitor Data (pp. 209-230). Oxford: Oxford University Press.

Amuedo-Dorantes, C., \& Pozo, S. (2004). Workers' remittances and the real exchange rate: a paradox of gifts. World Development, 32(8), 1407-1417.

Amuedo-Dorantes, C., \& Pozo, S. (2006). Migration, Remittances, and Male and Female Employment Patterns. The American Economic Review, 96(2), 222-226.

Anderson, S., \& Platzer, M. (2006). American made: the impact of immigrant entrepreneurs and professionals on U.S. competitiveness. Arlington: National Venture Capital Association.

Andersson, L. (2014). Migration, remittances and household welfare in Ethiopia (UNUMERIT Working Paper Series No. 2014-004). Maastricht: UNU-MERIT. 
Ang, A., Jha, S., \& Sugiyarto, G. (2009). Remittances and Household Behavior in the Philippines (ADB Economics Working Paper Series No. 188). Manila: Asian Development Bank.

Ardagna, S., \& Lusardi, A. (2010). Explaining international differences in entrepreneurship: The role of individual characteristics and regulatory constraints. In J. Lerner \& A. Schoar (Eds.), International Differences in Entrepreneurship (pp. 17-62). University of Chicago Press.

Arif, G. M., \& Irfan, M. (1997). Return Migration and Occupational Change: The Case of Pakistani Migrants Returned from the Middle East. The Pakistan Development Review, 36(1), 1-37.

Audretsch, D. B., Heger, D., \& Veith, T. (2015). Infrastructure and entrepreneurship. Small Business Economics, 44(2), 219-230.

Azam, J.-P., \& Gubert, F. (2006). Migrants' Remittances and the Household in Africa: A Review of Evidence. Journal of African Economies, 15(suppl_2), 426-462.

Bakewell, O. (2014). Encampment and Self-Settlement. In E. Fiddian-Qasmiyeh, G. Loescher, K. Long, \& N. Sigona (Eds.), The Oxford Handbook of Refugee and Forced Migration Studies (pp. 127-138). Oxford: Oxford University Press.

Bakker, L., Dagevos, J., \& Engbersen, G. (2017). Explaining the refugee gap: a longitudinal study on labour market participation of refugees in the Netherlands. Journal of Ethnic and Migration Studies, 43(11), 1775-1791.

Bao, S., Bodvarsson, Ö. B., Hou, J. W., \& Zhao, Y. (2011). The regulation of migration in a transition economy: China's hukou system. Contemporary Economic Policy, 29(4), 564-579.

Barrett, C. B., Reardon, T., \& Webb, P. (2001). Nonfarm income diversification and household livelihood strategies in rural Africa: concepts, dynamics, and policy implications. Food Policy, 26(4), 315-331.

Bascom, J. (2005). The Long,'Last Step'? Reintegration of Repatriates in Eritrea. Journal of Refugee Studies, 18(2), 165-180. 
Batista, C., McIndoe-Calder, T., \& Vicente, P. C. (2017). Return Migration, Self-selection and Entrepreneurship. Oxford Bulletin of Economics and Statistics, 79(5), 797-821.

Batista, C., \& Vicente, P. C. (2011). Do Migrants Improve Governance at Home? Evidence from a Voting Experiment. The World Bank Economic Review, 25(1), 77104.

Beck, T., \& Demirguc-Kunt, A. (2006). Small and medium-size enterprises: Access to finance as a growth constraint. Journal of Banking E Finance, 30(11), 2931-2943.

Beine, M., Docquier, F., \& Rapoport, H. (2008). Brain Drain and Human Capital Formation in Developing Countries: Winners and Losers. The Economic Journal, 118(528), 631-652.

Benzing, C., Chu, H. M., \& Kara, O. (2009). Entrepreneurs in Turkey: A Factor Analysis of Motivations, Success Factors, and Problems. Journal of Small Business Management, 47(1), 58-91.

Berriane, M., \& Aderghal, M. (2009). The state of research into international migration from, to and through Morocco. Agdal, Morocco: Université Mohamed V.

Betts, A., Bloom, L., Kaplan, J., \& Omata, N. (2017). Refugee Economies: Forced Displacement and Development. Oxford: Oxford University Press.

Betts, A., Bloom, L., \& Weaver, N. (2015). Refugee Innovation: Humanitarian Innovation that Starts with Communities (Humanitarian Innovation Project). Oxford: Refugee Studies Centre.

Binzel, C., \& Assaad, R. (2011). Egyptian men working abroad: Labour supply responses by the women left behind. Labour Economics, 18, S98-S114.

Bjelica, J., \& Ruttig, T. (2017). Voluntary and Forced Returns to Afghanistan in 2016/17: Trends, statistics and experiences. Retrieved 11 September 2017, from https://www.afghanistan-analysts.org/voluntary-and-forced-returns-toafghanistan-in-201617-trends-statistics-and-experiences/ 
Black, R., \& Castaldo, A. (2009). Return Migration and Entrepreneurship in Ghana and Cote d'Ivoire: The Role of Capital Transfers. Tijdschrift Voor Economische En Sociale Geografie, 100(1), 44-58.

Black, R., \& Gent, S. (2006). Sustainable Return in Post-conflict Contexts. International Migration, 44(3), 15-38.

Black, R., King, R., \& Tiemoko, R. (2003). Migration, return and small enterprise development in Ghana: A route out of poverty? (Sussex Migration Working Paper No. 9). Brighton: Sussex Centre for Migration Research.

Blau, P. M., Gustad, J. W., Jessor, R., Parnes, H. S., \& Wilcock, R. C. (1956). Occupational Choice: A Conceptual Framework. Industrial and Labor Relations Review, 9(4), $531-543$.

Bloch, A. (2002). Refugees' opportunities and barriers in employment and training (DWP Research Report No. 179). London: Department of Work and Pensions.

Bloom, L., \& Betts, A. (2013). The two worlds of humanitarian innovation (Refugee Studies Centre Working Paper Series No. 94). Oxford: University of Oxford.

Borjas, G. J. (1987). Self-Selection and the Earnings of Immigrants. American Economic Review, 77(4), 531-553.

Borjas, G. J. (1995). Ethnicity, Neighborhoods, and Human-Capital Externalities. American Economic Review, 85(3), 365-390.

Borodak, D., \& Piracha, M. (2011). Occupational choice of return migrants in Moldova. Eastern European Economics, 49(4), 24-46.

Bosma, N., Van Praag, M., Thurik, R., \& De Wit, G. (2004). The value of human and social capital investments for the business performance of startups. Small Business Economics, 23(3), 227-236.

Bourdet, Y., \& Falck, H. (2006). Emigrants' remittances and Dutch disease in Cape Verde. International Economic Journal, 20(3), 267-284. 
Brixy, U., Sternberg, R., \& Vorderwülbecke, A. (2013). Business start-ups by migrants (IAB Brief Report No. 25). Nürnberg: Institute for Employment Research.

Bruder, J., \& Räthke-Döppner, S. (2008). Ethnic Minority Self-Employment in Germany: Geographical Distribution and Determinants of Regional Variation (Thünen-Series of Applied Economic Theory Working Paper No. 100). Rostock: Universität Rostock.

Bundervoet, T. (2006). Estimating Poverty in Burundi (HiCN Working Papers No. 20). Brighton: Households in Conflict Network.

Buscher, D. (2013). New approaches to urban refugee livelihoods. Refuge: Canada's Journal on Refugees, 28(2), 17-29.

Cabegin, E. (2006). The effect of Filipino overseas migration on the non-migrant spouse's market participation and labor supply behavior. (IZA Discussion Paper Series No. 2240). Bonn: Institute for the Study of Labor.

Calderón, C., \& Servén, L. (2010). Infrastructure and economic development in SubSaharan Africa. Journal of African Economies, 19(suppl_1), i13-i87.

Cassarino, J. P. (2004). Theorising return migration: The conceptual approach to return migrants revisited. International Journal on Multicultural Societies, 6(2), 253-279.

Castles, S. (2009). Development and Migration-Migration and Development: What Comes First? Global Perspective and African Experiences. Theoria: A Journal of Social and Political Theory, 56(121), 1-31.

Castles, S., de Haas, H., \& Miller, M. J. (2014). The Age of Migration - (5th edition). Basingstoke: Palgrave Macmillan.

Central Intelligence Agency. (2017). The World Factbook. Retrieved 13 September 2017, from https://www.cia.gov/library/publications/the-world-factbook

Central Statistics Office. (2014). National Risk and Vulnerability Assessment 2011/2012. Afghanistan Living Conditions Survey. Kabul: Central Statistics Office. 
Centrum für internationale Migration und Entwicklung. (2018). Business Ideas for Development. $\quad$ Retrieved 6 July 2018, from https://www.cimonline.de/en/html/business-ideas.html

Ceritoglu, E., Yunculer, H. B. G., Torun, H., \& Tumen, S. (2017). The impact of Syrian refugees on natives' labor market outcomes in Turkey: evidence from a quasiexperimental design. IZA Journal of Labor Policy, 6(5), 1-28.

Chami, R., Fullenkamp, C., \& Jahjah, S. (2005). Are immigrant remittance flows a source of capital for development? IMF Staff Papers, 52(1), 55-81.

Chamie, J. (2013). The Choice: More Immigrants or Fewer Citizens? | YaleGlobal Online. $\quad 23$ Retrieved February 2018, from https://yaleglobal.yale.edu/content/choice-more-immigrants-or-fewer-citizens

Chang, H., Dong, X., \& MacPhail, F. (2011). Labor Migration and Time Use Patterns of the Left-behind Children and Elderly in Rural China. World Development, 39(12), 2199-2210.

Charmes, J. (2012). The Informal Economy Worldwide: Trends and Characteristics. Margin: The Journal of Applied Economic Research, 6(2), 103-132.

Cheung, S. Y., \& Phillimore, J. (2014). Refugees, Social Capital, and Labour Market Integration in the UK. Sociology, 48(3), 518-536.

Chimni, B. S. (2002). Refugees, Return and Reconstruction of 'Post-Conflict' Societies: A Critical Perspective. International Peacekeeping, 9(2), 163-180.

Ciarli, T., Parto, S., \& Savona, M. (2010). Conflict and Entrepreneurial Activity in Afghanistan: Findings from the National Risk Vulnerability Assessment Data (Working Paper No. No. 2010/08). Helsinki: World Institute for Development Economic Research (UNU-WIDER).

Cieslik, K., \& D’Aoust, O. (2017). Risky Business? Rural Entrepreneurship in Subsistence Markets: Evidence from Burundi. The European Journal of Development Research, 30(4), 693-717. 
Colic-Peisker, V., \& Tilbury, F. (2006). Employment Niches for Recent Refugees: Segmented Labour Market in Twenty-first Century Australia. Journal of Refugee Studies, 19(2), 203-229.

Collier, P. (2009). Post-conflict recovery: how should strategies be distinctive? Journal of African Economies, 18(suppl_1), i99-i131.

Collins, J. (2003). Cultural diversity and entrepreneurship: Policy responses to immigrant entrepreneurs in Australia. Entrepreneurship \& Regional Development, 15(2), 137-149.

Connor, P. (2010). Explaining the refugee gap: Economic outcomes of refugees versus other immigrants. Journal of Refugee Studies, 23(3), 377-397.

Constant, A., Shachmurove, Y., \& Zimmermann, K. F. (2007). What makes an entrepreneur and does it pay? Native men, Turks, and other migrants in Germany. International Migration, 45(4), 71-100.

Constant, A., \& Zimmermann, K. F. (2006). The making of entrepreneurs in Germany: Are native men and immigrants alike? Small Business Economics, 26(3), 279-300.

Cox Edwards, A., \& Ureta, M. (2003). International migration, remittances, and schooling: evidence from El Salvador. Journal of Development Economics, 72(2), 429-461.

Cramer, C. (2015). Peace Work: Labour Markets, Work and Violence (UNDP Human Development Report Office Think Piece). New York: UNDP.

Crisp, J. (2003). No Solutions in Sight: the Problem of Protracted Refugee Situations in Africa. Refugee Survey Quarterly, 22(4), 114-150.

Dai, O., \& Liu, X. (2009). Returnee entrepreneurs and firm performance in Chinese high-technology industries. International Business Review, 18(4), 373-386.

Davis, B., Di Giuseppe, S., \& Zezza, A. (2017). Are African households (not) leaving agriculture? Patterns of households' income sources in rural Sub-Saharan Africa. Food Policy, 67, 153-174. 
Davis, B., Winters, P., Carletto, G., Covarrubias, K., Quiñones, E. J., Zezza, A., ... DiGiuseppe, S. (2010). A Cross-Country Comparison of Rural Income Generating Activities. World Development, 38(1), 48-63.

de Haas, H. (2005). International Migration, Remittances and Development: Myths and Facts. Third World Quarterly, 26(8), 1269-1284.

de Haas, H. (2006). Engaging Diasporas - How governments and development agencies can support diaspora involvement in the development of their origin countries (A Study for Oxfam Novib). Oxford: International Migration Institute (IMI), University of Oxford.

de Haas, H. (2008). The Myth of Invasion: the inconvenient realities of African migration to Europe. Third World Quarterly, 29(7), 1305-1322.

de Haas, H. (2010). Migration and Development: A Theoretical Perspective. International Migration Review, 44(1), 227-264.

de Montclos, M.-A. P., \& Kagwanja, P. M. (2000). Refugee camps or cities? The socioeconomic dynamics of the Dadaab and Kakuma camps in Northern Kenya. Journal of Refugee Studies, 13(2), 205-222.

De Vreyer, P., Gubert, F., \& Robilliard, A.-S. (2010). Are there returns to migration experience? An empirical analysis using data on return migrants and nonmigrants in West Africa. Annals of Economics and Statistics/Annales d'Économie et de Statistique, 307-328.

De Vriese, M. (2006). Refugee Livelihoods: a review of the evidence (Evaluation and Policy Analysis Unit No. 2006/04). Geneva: UNHCR.

Del Carpio, X. V., \& Wagner, M. (2015). The Impact of Syrians Refugees on the Turkish Labor Market (World Bank Policy Research Working Paper No. 7402). Washington, D.C.: World Bank.

Démurger, S., \& Xu, H. (2011). Return Migrants: The Rise of New Entrepreneurs in Rural China. World Development, 39(10), 1847-1861. 
Department of Economic and Social Affairs, United Nations Population Division. (2017a). International Migrant Stock: The 2017 Revision. Retrieved from http://www.un.org/en/development/desa/population/migration/data/estimate s2/estimates17.shtml

Department of Economic and Social Affairs, United Nations Population Division. (2017b). World Population Prospects: The 2017 Revision. Retrieved 11 March 2018, from https://esa.un.org/unpd/wpp/DataQuery/

Desai, S. (2011). Measuring Entrepreneurship in Developing Countries. In W. Naudé (Ed.), Entrepreneurship and Economic Development (pp. 94-107). Basingstoke: Palgrave Macmillan.

di Giovanni, J., Levchenko, A. A., \& Ortega, F. (2015). A Global View of Cross-Border Migration. Journal of the European Economic Association, 13(1), 168-202.

Di Maria, C., \& Stryszowski, P. (2009). Migration, human capital accumulation and economic development. Journal of Development Economics, 90(2), 306-313.

Dick, S. (2002). Responding to Protracted Refugee Situations: A Case Study of Liberian Refugees in Ghana (EPAU No. 06). Geneva: Evaluation and Policy Analysis Unit, United Nations High Commissioner for Refugees.

Docquier, F., Lodigiani, E., Rapoport, H., \& Schiff, M. (2016). Emigration and democracy. Journal of Development Economics, 120, 209-223.

Docquier, F., \& Rapoport, H. (2012). Globalization, Brain Drain, and Development. Journal of Economic Literature, 50(3), 681-730.

Dustmann, C., \& Kirchkamp, O. (2002). The optimal migration duration and activity choice after remigration. Journal of Development Economics, 67(2), 351-372.

Easton-Calabria, E., \& Lindsay, A. (2013). Towards Durable Solutions for Protracted Congolese Refugees in Rwanda. Oxford Monitor of Forced Migration, 3(2), 58-66.

Egger, P. H., von Ehrlich, M., \& Nelson, D. R. (2012). Migration and Trade. The World Economy, 35(2), 216-241. 
Elfring, T., \& Hulsink, W. (2003). Networks in entrepreneurship: The case of hightechnology firms. Small Business Economics, 21(4), 409-422.

European Commission. (2016). EU Conference on Migrant Entrepreneurship Background paper. Brussels: European Commission, Directorate Enterprise and Industry, Unit F2 Innovation and Advanced Manufacturing, Clusters, Social Economy and Entrepreneurship. Retrieved from http://news.ucamere.net/20160217183433_Background\%20policy\%20paper.pdf

Evans, D. S., \& Jovanovic, B. (1989). An Estimated Model of Entrepreneurial Choice under Liquidity Constraints. Journal of Political Economy, 97(4), 808-827.

Fafchamps, M., \& Shilpi, F. (2003). The spatial division of labour in Nepal. The Journal of Development Studies, 39(6), 23-66.

Fairlie, R. W., \& Lofstrom, M. (2013). Immigration and Entrepreneurship (IZA Discussion Paper Series No. 7669). Bonn: Institute for the Study of Labor.

Fakih, A., \& Ibrahim, M. (2016). The impact of Syrian refugees on the labor market in neighboring countries: empirical evidence from Jordan. Defence and Peace Economics, 27(1), 64-86.

Falco, P., \& Haywood, L. (2016). Entrepreneurship versus joblessness: Explaining the rise in self-employment. Journal of Development Economics, 118, 245-265.

Feeley, F., Foster, S., Galer, K., Gioli, G., Harris, J. R., Hinojosa-Ojeda, R., ... Natter, R. (2013). Remittance flows to post-conflict states: Perspectives on human security and development. Boston: Boston University Frederick S. Pardee Center for the Study of the Longer-Range Future.

Fields, G. S. (2009). Segmented Labor Market Models in Developing Countries. In D. Ross \& H. Kincaid (Eds.), The Oxford Handbook of Philosophy of Economics (pp. 476-510). Oxford: Oxford University Press.

Fields, G. S. (2011). Labor market analysis for developing countries. Labour Economics, 18(Supplement 1), S16-S22. 
Fleischmann, F., \& Dronkers, J. (2010). Unemployment among immigrants in European labour markets: an analysis of origin and destination effects. Work, Employment and Society, 24(2), 337-354.

Fong, R., Busch, N. B., Armour, M., Heffron, L. C., \& Chanmugam, A. (2007). Pathways to Self-Sufficiency: Successful Entrepreneurship for Refugees. Journal of Ethnic $\mathcal{E}$ Cultural Diversity in Social Work, 16(1-2), 127-159.

Fransen, S. (2015). The Economic and Social Effects of Remittances and Return Migration in Conflict-Affected Areas: The Case of Burundi. Maastricht: Boekenplan.

Fransen, S. (2017). The Socio-Economic Sustainability of Refugee Return: Insights from Burundi. Population, Space and Place, 23(e1976), 1-16.

Fransen, S., \& Kuschminder, K. (2009). Migration in Ethiopia: History, current trends and future prospects (Paper Series: Migration and Development Country Profiles, Maastricht Graduate School of Governance). Maastricht: MGSoG.

Fransen, S., \& Kuschminder, K. (2012). Back to the land: The long-term challenges of refugee return and reintegration in Burundi (New Issues in Refugee Research Research Paper No. 242). Geneva: UNHCR, Policy Development and Evaluation Service.

Fransen, S., \& Otieno Ongáyo, A. (2010). Migration in Burundi: History, Current Trends and Future Prospects (Migration and Development Country Profiles). Maastricht: Maastricht Graduate School of Governance.

Fransen, S., Ruiz, I., \& Vargas-Silva, C. (2017). Return Migration and Economic Outcomes in the Conflict Context. World Development, 95, 196-210.

Frese, M., \& de Kruif, M. (2000). Psychological success factors of entrepreneurship in Africa: a selective literature review. In M. Frese (Ed.), Success and failure of microbusiness owners in Africa (pp. 31-53). Westport, CT: Quorum Books.

Frijters, P., Kong, T. S., \& Meng, X. (2011). Migrant Entrepreneurs and Credit Constraints under Labour Market Discrimination (IZA Discussion Paper Series No. 5967). Bonn: Institute for the Study of Labor (IZA). 
Frölich, M., \& Haile, G. (2011). Labour markets in developing countries. Labour Economics, 18(Supplement 1), S2-S6.

Funkhouser, E. (1992). Migration from Nicaragua: some recent evidence. World Development, 20(8), 1209-1218.

Gibson, J., \& McKenzie, D. (2012). The economic consequences of 'Brain Drain' of the best and brightest: Microeconomic evidence from five countries. The Economic Journal, 122(560), 339-375.

Gibson, J., McKenzie, D., \& Stillman, S. (2011). The impacts of international migration on remaining household members: omnibus results from a migration lottery program. Review of Economics and Statistics, 93(4), 1297-1318.

Gimeno, J., Folta, T. B., Cooper, A. C., \& Woo, C. Y. (1997). Survival of the fittest? Entrepreneurial human capital and the persistence of underperforming firms. Administrative Science Quarterly, 42(4), 750-783.

Gindling, T. H., \& Newhouse, D. (2014). Self-Employment in the Developing World. World Development, 56, 313-331.

Giuliano, P., \& Ruiz-Arranz, M. (2009). Remittances, financial development, and growth. Journal of Development Economics, 90(1), 144-152.

Giulietti, C., Ning, G., \& Zimmermann, K. F. (2012). Self-employment of rural-to-urban migrants in China. International Journal of Manpower, 33(1), 96-117.

Giulietti, C., Wahba, J., \& Zimmermann, K. F. (2013). Entrepreneurship of the LeftBehind. In C. Giulietti, K. Tatsiramos, \& K. F. Zimmermann (Eds.), Labor Market Issues in China (pp. 65-92). Emerald Group Publishing Limited.

Grabska, K. (2005). Living on the Margins: The Analysis of the Livelihood Strategies of Sudanese Refugees with Closed Files in Egypt (Forced Migration and Refugee Studies Working Paper No. 6). Cairo: The American University.

Grabska, K. (2006). Marginalization in Urban Spaces of the Global South: Urban Refugees in Cairo. Journal of Refugee Studies, 19(3), 287-307. 
Gries, T., \& Naudé, W. (2010). Entrepreneurship and structural economic transformation. Small Business Economics, 34(1), 13-29.

Gubert, F., \& Nordman, C. J. (2011). Return Migration and Small Enterprise Development in the Maghreb. In S. Plaza \& D. Ratha (Eds.), Diaspora for Development in Africa (pp. 103-126). Washington, D.C.: World Bank.

Gurgand, M., Lambert, S., Rapoport, H., \& Zenou, Y. (2012). Migration and development: Insights from the 3rd AFD-World Bank Migration and Development Conference. Regional Science and Urban Economics, 42(5), 761-764.

Haggblade, S., Hazell, P., \& Reardon, T. (2010). The Rural Non-farm Economy: Prospects for Growth and Poverty Reduction. World Development, 38(10), 1429 1441.

Hainmueller, J., Hangartner, D., \& Lawrence, D. (2016). When lives are put on hold: Lengthy asylum processes decrease employment among refugees. Science Advances, 2(8), 1-7.

Hamdouch, B., \& Wahba, J. (2015). Return migration and entrepreneurship in Morocco. Middle East Development Journal, 7(2), 129-148.

Harris, J. R., \& Todaro, M. P. (1970). Migration, Unemployment and Development: A Two-Sector Analysis. The American Economic Review, 60(1), 126-142.

Hart, D. M., \& Ács, Z. (2011). High-Tech Immigrant Entrepreneurship in the United States. Economic Development Quarterly, 25(2), 116-129.

Hautaniemi, P., Juntunen, M., \& Satō, M. (2013). Return migration and vulnerability: case studies from Somaliland and Iraqi Kurdistan. Helsinki: Interkont Books.

Hedley, D., Dunn, S., \& Izabiriza, B. (2016). Rwanda PRRO 200744: Food and Nutrition Assistance to Refugees and Returnees - A mid-term evaluation of WFP's Operation. Rome: World Food Programme - Office of Evaluation. Retrieved from http://documents.wfp.org/stellent/groups/public/documents/reports/wfp28481 5.pdf?_ga=1.103181568.1864223717.1462562999 
Herrington, M., \& Kelley, D. J. (2013). African Entrepreneurship: Sub-Saharan African Regional Report 2012 (Global Entrepreneurship Monitor). Cape Town: University of Cape Town.

Hildebrandt, N., \& McKenzie, D. (2005). The Effects of Migration on Child Health in Mexico (World Bank Policy Research Working Paper No. 3573). Washington, D.C.: The World Bank.

Hovil, L. (2011). Shadows of Return: The Dilemmas of Congolese Refugees in Rwanda (Citizenship and Displacement in the Great Lakes Region Working Paper No. 6). New York, Kampala, Chippenham: International Refugee Rights Initiative (IRRI).

Huggins, C. (2007). Land in return, reintegration and recovery processes: Some lessons from the Great Lakes region of Africa. In S. Pantuliano (Ed.), Uncharted territory: Land, conflict and humanitarian action (pp. 67-93). Rugby, UK: Practical Action Publishing.

Human Rights Watch. (2017). Pakistan: Mass Forced Returns of Afghan Refugees. Retrieved 11 September 2017, from https://www.hrw.org/news/2017/02/13/ pakistan-mass-forced-returns-afghan-refugees

Hunt, J., \& Gauthier-Loiselle, M. (2010). How much does immigration boost innovation? American Economic Journal: Macroeconomics, 2(2), 31-56.

Hurst, E., \& Lusardi, A. (2004). Liquidity Constraints, Household Wealth, and Entrepreneurship. Journal of Political Economy, 112(2), 319-347.

Ilahi, N. (1999). Return migration and occupational change. Review of Development Economics, 3(2), 170-186.

Internal Displacement Monitoring Centre. (2017a). Burundi. Retrieved 5 February 2018, from http://www.internal-displacement.org/countries/burundi/

Internal Displacement Monitoring Centre. (2017b). Global Report on Internal Displacement 2017. Geneva: Internal Displacement Monitoring Centre. 
International Labour Organization. (2012). Afghanistan: Time to move to Sustainable Jobs - A Study on the State of Employment in Afghanistan (Report). Retrieved from http://www.ilo.org/asia/whatwedo/publications/WCMS_182253/lang-en/index.htm

International Labour Organization. (2013). Assessment of Livelihood Opportunities for the Returnees/IDPs and the Host Communities in Afghanistan. Kabul: International Labour Organization.

International Labour Organization. (2018). ILOSTAT Key Indicators of the Labour Market. Retrieved 24 January 2018, from http://www.ilo.org/ilostat

International Organization for Migration. (2011). Glossary on Migration - 2nd Edition (International Migration Law No. 25). Geneva: International Organization for Migration.

International Organization for Migration. (2015). Key Migration Terms. Retrieved 16 February 2018, from https://www.iom.int/key-migration-terms

International Organization for Migration. (2017). Return of Undocumented Afghans from Pakistan and Iran - 2016 Overview. Geneva: IOM.

Itzigsohn, J. (1995). Migrant Remittances, Labor Markets, and Household Strategies: A Comparative Analysis of Low-Income Household Strategies in the Caribbean Basin. Social Forces, 74(2), 633-655.

Jabbar, S. A., \& Zaza, H. I. (2016). Evaluating a vocational training programme for women refugees at the Zaatari camp in Jordan: women empowerment: a journey and not an output. International Journal of Adolescence and Youth, 21(3), 304-319.

Jacobsen, K. (2002). Livelihoods in conflict: the pursuit of livelihoods by refugees and the impact on the human security of host communities. International Migration, 40(5), 95-123.

Jacobsen, K. (2005). The economic life of refugees. Bloomfield, CT: Kumarian Press. 
Jansen, M., de Kok, J., van Spronsen, J., \& Willemsen, S. (2003). Immigrant entrepreneurship in the Netherlands - Demographic determinants of entrepreneurship from non-western countries (Research Report No. H200304). Zoetermeer: SCALES (SCientific AnaLysis of Entrepreneurship and SMEs).

Jean, S., Causa, O., Jiménez, M., \& Wanner, I. (2010). Migration and labour market outcomes in OECD countries. OECD Journal. Economic Studies, 2010(1), 1-34.

Karymshakov, K., \& Sulaimanova, B. (2017). Migration impact on left-behind women's labour participation and time-use: Evidence from Kyrgyzstan (WIDER Working Paper No. 119/2017). Helsinki: World Institute for Development Economic Research (UNU-WIDER).

Kattaa, M. (2016). Syrian Refugee's Status in the Jordanian Labor Market. Turkish Policy Quarterly, 15(3), 71-78.

Kenney, M., Breznitz, D., \& Murphree, M. (2013). Coming back home after the sun rises: Returnee entrepreneurs and growth of high tech industries. Research Policy, 42(2), 391-407.

Khan, M. I., \& Valatheeswaran, C. (2016). International Migration, Remittances and Labour Force Participation of Left-behind Family Members: A Study of Kerala. Margin: The Journal of Applied Economic Research, 10(1), 86-118.

Kilic, T., Carletto, C., Davis, B., \& Zezza, A. (2009). Investing back home - Return migration and business ownership in Albania. Economics of Transition, 17(3), 587-623.

Klagge, B., Klein-Hitpaß, K., Fihel, A., Kindler, M., Matejko, E., \& Okólski, M. (2007). High-skilled Return Migration and Knowledge-based Economic Development in Regional Perspective: Conceptual Considerations and the Example of Poland. Centre of Migration Research.

Koser, K. (2007). International Migration: A Very Short Introduction. Oxford: Oxford University Press. 
Koser, K., \& Black, R. (1999). The End of the Refugee Cycle? - Refugee Repatriation and Reconstruction. In K. Koser \& R. Black (Eds.), The End of the Refugee Cycle? (pp. 2-17). New York \& Oxford: Berghahn Books.

Kotabe, M., Riddle, L., Sonderegger, P., \& Täube, F. A. (2013). Diaspora Investment and Entrepreneurship: The Role of People, Their Movements, and Capital in the International Economy. Journal of International Management, 19(1), 3-5.

Kugler, M., \& Rapoport, H. (2011). Migration, FDI and the Margins of Trade (CID Working Paper No. 222). Cambridge, MA: Center for International Development at Harvard University.

Kuschminder, K. (2013). Female Return Migration and Reintegration Strategies in Ethiopia (MGSoG Dissertation Series No 42). Maastricht University, Maastricht.

Kuschminder, K. (2017). Reintegration Strategies - Conceptualizing How Return Migrants Reintegrate. London: Palgrave Macmillan.

Lemarchand, R. (1996). Burundi: Ethnic Conflict and Genocide. Cambridge: Cambridge University Press.

Levitt, P. (1998). Social Remittances: Migration Driven Local-Level Forms of Cultural Diffusion. The International Migration Review, 32(4), 926-948.

Lewis, W. A. (1954). Economic Development with Unlimited Supplies of Labour. The Manchester School, 22(2), 139-191.

Lianos, T., \& Pseiridis, A. (2009). On the occupational choices of return migrants. Entrepreneurship \& Regional Development, 21(2), 155-181.

Lokshin, M., \& Glinskaya, E. (2009). The effect of male migration on employment patterns of women in Nepal. The World Bank Economic Review, 23(3), 481-507.

López-Córdova, E., \& Olmedo, A. (2006). International remittances and development: existing evidence, policies and recommendations (INATL -ITD Occasional Paper No. 41). Buenos Aires: Inter-American Development Bank. 
Lucas, R. E. B., \& Stark, O. (1985). Motivations to Remit: Evidence from Botswana. Journal of Political Economy, 93(5), 901-918.

Lundborg, P. (2013). Refugees' Employment Integration in Sweden: Cultural Distance and Labor Market Performance. Review of International Economics, 21(2), 219232.

Lyon, F., Sepulveda, L., \& Syrett, S. (2007). Enterprising Refugees: Contributions and Challenges in Deprived Urban Areas. Local Economy, 22(4), 362-375.

Maastricht Graduate School of Governance, \& Samuel Hall. (2013). Evaluation of the UNHCR Shelter Assistance Programme: Full Report. Maastricht: Maastricht Graduate School of Governance.

Mansuri, G. (2007). Does Work Migration Spur Investment in Origin Communities? Entrepreneurship, Schooling, and Child Health in Rural Pakistan. In Çağlar Özden \& M. Schiff (Eds.), International Migration, Economic Development and Policy (pp. 99-140). Washington, D.C.: The World Bank and Palgrave Macmillan.

Marchand, K., \& Dijkhuizen, J. (2018). Entrepreneurship as a Tool for a New Beginning - Entrepreneurship Training for Refugees in a New Homeland. In $\mathrm{N}$. Apostolopoulos, H. Al-Dajani, D. Holt, P. Jones, \& R. Newbery (Eds.), Entrepreneurship and the Sustainable Development Goals (pp. 135-149). Bingley: Emerald Group Publishing Limited.

Marchand, K., Reinold, J., \& Dias e Silva, R. (2017). Study on Migration Routes in the East and Horn of Africa. Maastricht: UNU-MERIT I Maastricht Graduate School of Governance.

Marchand, K., \& Siegel, M. (2014). Immigrant entrepreneurship in cities. Background paper for world migration report migrants and cities: new urban partnerships to manage mobility (World Migration Report 2015 Background Paper). Geneva: International Migration for Migration. 
Marchand, K., Siegel, M., Kuschminder, K., Majidi, N., Vanore, M., \& Buil, C. (2014). Afghanistan Migration Profile. Kabul: IOM Afghanistan.

Marchetta, F. (2012). Return migration and the survival of entrepreneurial activities in Egypt. World Development, 40(10), 1999-2013.

Margolis, D. N. (2014). By choice and by necessity: entrepreneurship and selfemployment in the developing world. The European Journal of Development Research, 26(4), 419-436.

Martin, S. F. (2016). Rethinking Protection of Those Displaced by Humanitarian Crises. The American Economic Review, 106(5), 446-450.

Massey, D. S., \& Parrado, E. A. (1998). International migration and business formation in Mexico. Social Science Quarterly, 79(1), 1-20.

Mata Greenwood, A. (1999). International definitions and prospects of Underemployment Statistics. ILO. Retrieved from http://www.ilo.org/wcmsp5/groups/public/--dgreports/---stat/documents/publication/wcms_091440.pdf

Maystadt, J.-F., \& Duranton, G. (2014). The Development Push of Refugees - Evidence from Tanzania (IFPRI Discussion Paper No. 01377). Washington, D.C.: IFPRI.

Maystadt, J.-F., \& Verwimp, P. (2014). Winners and Losers among a Refugee-Hosting Population. Economic Development and Cultural Change, 62(4), 769-809.

McCormick, B., \& Wahba, J. (2001). Overseas Work Experience, Savings and Entrepreneurship Amongst Return Migrants to LDCs. Scottish Journal of Political Economy, 48(2), 164-178.

McElwee, G. (2008). Editorial: Special Issue on the Rural Entrepreneur: Problems of Definition. International Journal of Entrepreneurship and Small Business, 6(3), 319320.

McKenzie, D. (2006). Beyond remittances: the effects of migration on Mexican households. In Çaglar Özden \& M. Schiff (Eds.), International Migration, Remittances, and the Brain Drain (pp. 123-147). 
McKenzie, D., \& Sasin, M. J. (2007). Migration, remittances, poverty, and human capital: conceptual and empirical challenges (Policy Research Working Paper Series No. 4272). The World Bank. Retrieved from https://ideas.repec.org/p/wbk/wbrwps/4272.html

Mendola, M., \& Carletto, C. (2009). International Migration and Gender Differentials in the Home Labor Market: Evidence from Albania (SSRN Scholarly Paper No. ID 1401206). Rochester, NY: Social Science Research Network. Retrieved from https://papers.ssrn.com/abstract=1401206

Mesić, M., \& Bagić, D. (2011). Minority return to Croatia - Study of an open process. Zagreb: UNHCR.

Mesnard, A. (2004). Temporary migration and capital market imperfections. Oxford Economic Papers, 56(2), 242-262.

Milner, J., \& Loescher, G. (2011). Responding to protracted refugee situations (Lessons from a decade of Discussion. Forced Migration Policy Briefing Series No. 6). Oxford: Refugee Studies Centre.

Monsutti, A. (2005). War and migration: social networks and economic strategies of the Hazaras of Afghanistan. New York \& London: Routledge.

Mora, M. T., \& Dávila, A. (2005). Ethnic group size, linguistic isolation, and immigrant entrepreneurship in the USA. Entrepreneurship $\mathcal{E}$ Regional Development, 17(5), 389-404.

Mountford, A. (1997). Can a brain drain be good for growth in the source economy? Journal of Development Economics, 53(2), 287-303.

Mu, R., \& van de Walle, D. (2011). Left behind to farm? Women's labor re-allocation in rural China. Labour Economics, 18, S83-S97.

Münz, R. (2014). The Global Race for Talent: Europe's Migration Challenge (Bruegel Policy Brief No. 2014/02). Brussels: Bruegel.

Nagler, P. (2015). Occupational Choice in the Developing World. Maastricht: Boekenplan. 
Nagler, P., \& Naudé, W. (2014). Non-Farm Entrepreneurship in Rural Africa: Patterns and Determinants (IZA Discussion Papers No. 8008). Bonn: Institute for the Study of Labor (IZA).

Nagler, P., \& Naudé, W. (2017). Non-farm entrepreneurship in rural sub-Saharan Africa: New empirical evidence. Food Policy, 67, 175-191.

National Institute of Statistics of Rwanda. (2016). Integrated Household Living Conditions Survey [EICV] 2013/2014 Thematic Report: Economic Activity. Kigali: National Institute of Statistics of Rwanda.

Naudé, W. (2008). Entrepreneurship in Economic Development (Working Paper Series No. RP2008/20). Helsinki: World Institute for Development Economic Research (UNU-WIDER).

Naudé, W. (2009). Out with the sleaze, in with the ease: Insufficient for entrepreneurial development? (Research Paper No. 2009/01). Helsinki: World Institute for Development Economic Research (UNU-WIDER).

Naudé, W. (2010a). Entrepreneurship, developing countries, and development economics: new approaches and insights. Small Business Economics, 34(1), 1-12.

Naudé, W. (2010b). Promoting Entrepreneurship in Developing Countries - Policy Challenges (United Nations University Policy Brief No. 4). Helsinki: United Nations University World Institute for Development Economics Research.

Naudé, W. (2011). Entrepreneurship is Not a Binding Constraint on Growth and Development in the Poorest Countries. World Development, 39(1), 33-44.

Naudé, W., Siegel, M., \& Marchand, K. (2017). Migration, entrepreneurship and development: critical questions. IZA Journal of Migration, 6(5).

Navarra, M. Q., Niehof, A., \& van der Vaart, W. (2013). Social capital in involuntary displacement and resettlement. International Journal of Social Sciences and Humanity Studies, 5(2), 139-154. 
Neville, F., Orser, B., Riding, A., \& Jung, O. (2014). Do young firms owned by recent immigrants outperform other young firms? Journal of Business Venturing, 29(1), 55-71.

Ngaruko, F., \& Nkurunziza, J. D. (2000). An economic interpretation of conflict in Burundi. Journal of African Economies, 9(3), 370-409.

Ngaruko, F., \& Nkurunziza, J. D. (2005). Civil War and Its Duration in Burundi. In P. Collier \& N. Sambanis (Eds.), Understanding Civil War: Africa (Vol. 1). Washington, D.C.: World Bank Publications.

Niragira, S., D’Haese, M., D’Haese, L., Ndimubandi, J., Desiere, S., \& Buysse, J. (2015). Food for Survival: Diagnosing Crop Patterns to Secure Lower Threshold Food Security Levels in Farm Households of Burundi. Food and Nutrition Bulletin, 36(2), 196-210.

Novak, P. (2007). Place and Afghan refugees: A contribution to Turton. Journal of Refugee Studies, 20(4), 551-578.

Nyberg-Sørensen, N., Van Hear, N., \& Engberg-Pedersen, P. (2002). The MigrationDevelopment Nexus Evidence and Policy Options State-of-the-Art Overview. International Migration, 40(5), 3-47.

Omata, N. (2013). 'Community resilience or shared destitution?'Refugees' internal assistance in a deteriorating economic environment. Community Development Journal, 48(2), 264-279.

Omata, N., \& Kaplan, J. (2013). Refugee livelihoods in Kampala, Nakivale and Kyangwali refugee settlements: patterns of engagement with the private sector (RSC Working Paper Series). Oxford: Refugee Studies Centre. Retrieved from https://www.rsc.ox.ac.uk/publications/refugee-livelihoods-in-kampalanakivale-and-kyangwali-refugee-settlements-patterns-of-engagement-withthe-private-sector 
Organisation for Economic Co-operation and Development. (2008). International Migration Outlook 2008. Paris: Organisation for Economic Co-operation and Development.

Organisation for Economic Co-operation and Development. (2010). Entrepreneurship and Migrants. Report by the OECD Working Party on SMEs and Entrepreneurship. Paris: Organisation for Economic Co-operation and Development.

Organisation for Economic Co-operation and Development. (2011). International Migration Outlook 2011. Paris: Organisation for Economic Co-operation and Development.

Özerdem, A., \& Sofizada, A. H. (2006). Sustainable reintegration to returning refugees in post-Taliban Afghanistan: land-related challenges: Analysis. Conflict, Security $\mathcal{E}$ Development, 6(1), 75-100.

Page, J., \& Plaza, S. (2006). Migration Remittances and Development: A Review of Global Evidence. Journal of African Economies, 15(suppl_2), 245-336.

Parker, S. C. (2004). The Economics of Self-Employment and Entrepreneurship. Cambridge: Cambridge University Press.

Pavanello, S., Elhawary, S., \& Pantuliano, S. (2010). Hidden and Exposed: Urban Refugees in Nairobi, Kenya (Humanitarian Policy Group Working Paper). London: Overseas Development Institute.

Phillips, M. (2003). Refworld I The role and impact of humanitarian assets in refugee-hosting countries (New Issues in Refugee Research Working Paper No. 84). Geneva: UNHCR. Retrieved from http://www.refworld.org/docid/4ff2b6f52.html

Piracha, M., \& Vadean, F. (2010). Return migration and occupational choice: evidence from Albania. World Development, 38(8), 1141-1155.

Plaza, S., \& Ratha, D. (2011). Diaspora for Development in Africa. World Bank Publications. 
Porter, G., Hampshire, K., Kyei, P., Adjaloo, M., Rapoo, G., \& Kilpatrick, K. (2008). Linkages between livelihood opportunities and refugee-host relations: learning from the experiences of Liberian camp-based refugees in Ghana. Journal of Refugee Studies, 21(2), 230-252.

Pratap, S., \& Quintin, E. (2006). Are labor markets segmented in developing countries? A semiparametric approach. European Economic Review, 50(7), 1817-1841.

Price, M., \& Chacko, E. (2009). The mixed embeddedness of ethnic entrepreneurs in a new immigrant gateway. Journal of Immigrant $\mathcal{E}$ Refugee Studies, 7(3), 328-346.

Quatraro, F., \& Vivarelli, M. (2014). Drivers of entrepreneurship and post-entry performance of newborn firms in developing countries. The World Bank Research Observer, 30(2), 277-305.

Ranalli, B. (2014). Local Currencies: A Potential Solution for Liquidity Problems in Refugee Camp Economies. Journal of Refugee Studies, 27(3), 422-433.

Rapoport, H. (2002). Migration, credit constraints and self-employment: a simple model of occupational choice, inequality and growth. Economics Bulletin, 15(7), $1-5$.

Ratha, D. (2007). Leveraging remittances for development (MPI Policy Brief). Washington, D.C.: Migration Policy Institute.

Ratha, D., Mohapatra, S., Özden, Ç., Plaza, S., Shaw, W., \& Shimeles, A. (2011). Leveraging migration for Africa: remittances, skills and investments. Washington, D.C.: World Bank.

Rauch, J. E., \& Trindade, V. (2002). Ethnic Chinese Networks in International Trade. The Review of Economics and Statistics, 84(1), 116-130.

Reardon, T., Berdegué, J., Barrett, C. B., \& Stamoulis, K. (2007). Household income diversification into rural nonfarm activities. In S. Haggblade, P. B. R. Hazell, \& T. Reardon (Eds.), Transforming the rural nonfarm economy: opportunities and threats in the developing world (pp. 115-140). Baltimore: The Johns Hopkins Press. 
Renkow, M. (2007). Cities, Towns, and the Rural Nonfarm Economy. In S. Haggblade, P. B. R. Hazell, \& T. Reardon (Eds.), Transforming the Rural Nonfarm Economy: Opportunities and Threats in the Developing World (pp. 183-198). Baltimore: The Johns Hopkins Press.

Republic of Rwanda. (2012). Rwanda Vision 2020 - Revised 2012. Kigali: Republic of Rwanda. Retrieved from http://www.minecofin.gov.rw/fileadmin/templates/ documents/NDPR/Vision_2020_.pdf

Reynolds, P. D., Bosma, N., Autio, E., Hunt, S., De Bono, N., Servais, I., ... Chin, N. (2005). Global Entrepreneurship Monitor: Data Collection Design and Implementation 1998-2003. Small Business Economics, 24(3), 205-231.

Reynolds, P. D., Camp, S. M., Bygrave, W. D., Autio, E., \& Hay, M. (2001). Global Entrepreneurship Monitor - 2001 Executive Report. London: Babson College/London Business School.

Rijkers, B., \& Costa, R. (2012). Gender and Rural Non-Farm Entrepreneurship. World Development, 40(12), 2411-2426.

Rodriguez, E. R., \& Tiongson, E. R. (2001). Temporary Migration Overseas and Household Labor Supply: Evidence from Urban Philippines. The International Migration Review, 35(3), 709-725.

Ruiz, I., \& Vargas-Silva, C. (2013). The Economics of Forced Migration. The Journal of Development Studies, 49(6), 772-784.

Saxenian, A. (2002). Brain Circulation. How high-skill immigration makes everyone better off. Brookings Review, 20(1), 28-31.

Saxenian, A. (2007). The New Argonauts - Regional Advantage in a Global Economy. Cambridge, MA: Harvard University Press.

Skeldon, R. (2014). Migration and Development: A Global Perspective. Routledge.

Spilimbergo, A. (2009). Democracy and Foreign Education. The American Economic Review, 99(1), 528-543. 
Stark, O., \& Wang, Y. (2002). Inducing human capital formation: migration as a substitute for subsidies. Journal of Public Economics, 86(1), 29-46.

Stel, N. (2013). Diaspora versus Refugee - The Political Economy of Lebanese Entrepreneurship Regimes (Maastricht School of Management Working Paper No. 16/2013). Maastricht: Maastricht School of Management.

Stephan, P. E., \& Levin, S. G. (2001). Exceptional contributions to US science by the foreign-born and foreign-educated. Population Research and Policy Review, 20(1), 59-79.

Stewart, F. (2015). Employment in Conflict and Post-conflict Situations (UNDP Human Development Report Office Think Piece). New York: UNDP.

Tani, M., \& Mahuteau, S. (2008). Return Migration and Working Choices. MIREM Project Analytical Report, 2008/01.

Taylor, J. E., Mora, J., Adams, R. H., \& Lopez-Feldman, A. (2005). Remittances, Inequality and Poverty: Evidence from Rural Mexico (Working Paper No. 05-003). Davis, CA: Department of Agricultural and Resource Economics, University of California, Davis.

Turner, L. (2015). Explaining the (Non-)Encampment of Syrian Refugees: Security, Class and the Labour Market in Lebanon and Jordan. Mediterranean Politics, 20(3), 386-404.

Ulandssekretariatet. (2015). Labour Market Profile Burundi 2015. Copenhagen: LO/FTF Council's Analytical Unit. Retrieved from http://www.ulandssekretariatet.dk/ sites/default/files/uploads/public/PDF/LMP/LMP2015/lmp_burundi_2015_fina 1_version.pdf

Ulandssekretariatet. (2016). Labour Market Profile Rwanda 2016. Copenhagen: Ulandssekretariatet LO/TFT Council's Analytical Unit. Retrieved from http://www.ulandssekretariatet.dk/sites/default/files/uploads/public/PDF/LM P/lmp_rwanda_2016_final.pdf 
United Nations Department of Political Affairs. (2018). Burundi. Retrieved 31 January 2018, from http://www.un.org/undpa/en/africa/burundi

United Nations Development Programme. (2016). Human Development Report 2016 Human Development for Everyone. New York: United Nations Development Programme.

United Nations High Commissioner for Refugees. (2004). Executive Committee of the High Commissioner's Programme - Standing Committee 30th Meeting: Protracted Refugee Situations. Geneva: UNHCR. Retrieved from http://www.unhcr.org/ excom/standcom/40c982172/protracted-refugee-situations.html

United Nations High Commissioner for Refugees. (2016). UNHCR's Presence in Rwanda. Retrieved 28 August 2017, from http://www.unhcr.org/rw/66overview-2.html

United Nations High Commissioner for Refugees. (2017a). Burundi Situation. Retrieved 15 January 2018, from https://data2.unhcr.org/en/situations/burundi

United Nations High Commissioner for Refugees. (2017b). Burundi Situation 2017 Supplementary Appeal January-December 2017. Geneva: UNHCR. Retrieved from http://www.unhcr.org/59244aa77.pdf

United Nations High Commissioner for Refugees. (2017c). Executive Committee of the High Commissioner's Programme - Standing Committee 68th Meeting: Resilience and self-reliance from a protection and solutions perspective. Geneva: UNHCR. Retrieved from http://www.unhcr.org/58ca4f827.pdf

United Nations High Commissioner for Refugees. (2017d). Global Trends: Forced Displacement in 2016. Geneva: UNHCR. Retrieved from http://www.unhcr.org/5943e8a34.pdf

United Nations High Commissioner for Refugees. (2017e). Joint Strategy by MIDIMAR \& UNHCR. Retrieved 28 August 2017, from http://www.unhcr.org/rw/10543joint-strategy-by-midimar-unhcr.html 
United Nations High Commissioner for Refugees. (2017f). Rwanda: Population of Concern to UNHCR, Statistics as of 31st July 2017. Retrieved 28 August 2017, from http://www.refworld.org/docid/598988eb4.html

United Nations High Commissioner for Refugees. (2018a). Global Trends: Forced Displacement in 2017. Geneva: UNHCR. Retrieved from http://www.unhcr.org/statistics/unhcrstats/5b27be547/unhcr-global-trends2017.html

United Nations High Commissioner for Refugees. (2018b). Refugee Statistics: Global Trends at a Glance. Retrieved 25 June 2018, from https://www.unrefugees.org/refugee-facts/statistics/

United Nations High Commissioner for Refugees. (2018c). Rwanda Operational Update - February 2018. Retrieved from http://www.unhcr.org/rw/wpcontent/uploads/sites/4/2018/03/Operational-Update-Feb-2018.pdf

United Nations High Commissioner for Refugees. (2018d). UNHCR Statistical Online Population Database. Retrieved 4 April 2018, from http://popstats.unhcr.org/en/overview

United Nations Office for the Coordination of Humanitarian Affairs. (2005). Enquête sur les populations déplacées au Burundi (Situation Report). Bujumbura, Burundi: United Nations Office for the Coordination of Humanitarian Affairs.

Uvin, P. (2007). Human security in Burundi: The view from below (by youth). African Security Studies, 16(2), 38-52.

Vaaler, P. M. (2011). Immigrant remittances and the venture investment environment of developing countries. Journal of International Business Studies, 42(9), 11211149.

Van de Ven, W. P. M. M., \& Van Praag, B. M. S. (1981). The demand for deductibles in private health insurance: A probit model with sample selection. Journal of Econometrics, 17(2), 229-252. 
Van Hear, N. (2006). 'I Went as Far as My Money Would Take Me': Conflict, Forced Migration and Class. In F. Crépeau, D. Nakache, M. Collyer, N. H. Goetz, A. Hansen, R. Modi, ... L. H. M. Van Willigen (Eds.), Forced Migration and Global Processes: A View from Forced Migration Studies (pp. 125-157). Oxford: Lexington Books.

Vasco, C. (2013). Migration, remittances and entrepreneurship: the case of rural Ecuador. Migraciones Internacionales, 7(1), 37-64.

Verwimp, P., \& Muñoz-Mora, J. C. (2017). Returning Home after Civil War: Food Security and Nutrition among Burundian Households. The Journal of Development Studies, 1-22.

Vinck, P., Bizuneh, M., Rubavu, M., \& Tahirou, L. (2008). Burundi-Comprehensive Food Security and Vulnerability Analysis. Rome: World Food Programme.

Vorderwülbecke, A. (2013). Entrepreneurship and migration. In S. R. Xavier, P. Kelley, L. Kew, M. Herrington, \& A. Vorderwülbecke (Eds.), Global Entrepreneurship Monitor-2012 Global Report (pp. 42-50). London: Global Entrepreneurship Research Association.

Wadhwa, V., Rissing, B. A., Saxenian, A., \& Gereffi, G. (2007). Education, entrepreneurship and immigration: America's new immigrant entrepreneurs, Part II. Duke School of Engineering, UC Berkley School of Information and Ewing Kauffman Foundation.

Wahba, J., \& Zenou, Y. (2012). Out of sight, out of mind: Migration, entrepreneurship and social capital. Regional Science and Urban Economics, 42(5), 890-903.

Wauters, B., \& Lambrecht, J. (2006). Refugee entrepreneurship in Belgium: Potential and practice. The International Entrepreneurship and Management Journal, 2(4), $509-525$.

Wauters, B., \& Lambrecht, J. (2008). Barriers to Refugee Entrepreneurship in Belgium: Towards an Explanatory Model. Journal of Ethnic and Migration Studies, 34(6), 895-915. 
Werker, E. (2007). Refugee Camp Economies. Journal of Refugee Studies, 20(3), 461-480.

Westlund, H., \& Bolton, R. (2003). Local social capital and entrepreneurship. Small Business Economics, 21(2), 77-113.

Wong, P. K., Ho, Y. P., \& Autio, E. (2005). Entrepreneurship, innovation and economic growth: Evidence from GEM data. Small Business Economics, 24(3), 335-350.

Woodruff, C., \& Zenteno, R. (2007). Migration networks and microenterprises in Mexico. Journal of Development Economics, 82(2), 509-528.

World Bank. (2007). World Development Report 2008: Agriculture for Development. Washington, D.C.: World Bank.

World Bank. (2016). Migration and Remittances Factbook 2016 (Third Edition). Washington, D.C.: World Bank Group.

World Bank. (2017a). Migration and Remittances Data. Retrieved 10 January 2018, from http://www.worldbank.org/en/topic/migrationremittancesdiasporaissues /brief/migration-remittances-data

World Bank. (2017b). Migration and Remittances: Recent Developments and Outlook Special Topic: Global Compact on Migration (Migration and Development Brief No. 27). Washington, D.C.: World Bank Group and KNOMAD.

World Bank. (2017c). Rwanda Overview. Retrieved 28 August 2017, from http://www.worldbank.org/en/country/rwanda/overview

World Bank. (2018). World Development Indicators. Retrieved 7 March 2018, from https://data.worldbank.org/

Yakushko, O., Backhaus, A., Watson, M., Ngaruiya, K., \& Gonzalez, J. (2008). Career development concerns of recent immigrants and refugees. Journal of Career Development, 34(4), 362-396.

Yang, D. (2008). International Migration, Remittances and Household Investment: Evidence from Philippine Migrants' Exchange Rate Shocks. The Economic Journal, 118(528), 591-630. 
Yang, D. (2011). Migrant Remittances. The Journal of Economic Perspectives, 25(3), 129 151.

Zenou, Y. (2008). Job search and mobility in developing countries. Theory and policy implications. Journal of Development Economics, 86(2), 336-355.

Zetter, R., \& Ruaudel, H. (2016). Refugees' Right to Work and Access to Labor Markets An Assessment. Part I: Synthesis (KNOMAD Working Paper and Study Series). Washington, D.C.: KNOMAD.

Zezza, A., Carletto, G., Davis, B., Stamoulis, K., \& Winters, P. (2009). Rural income generating activities: whatever happened to the institutional vacuum? Evidence from Ghana, Guatemala, Nicaragua and Vietnam. World Development, 37(7), 1297-1306.

Zhang, G. (2008). The choice of formal or informal finance: Evidence from Chengdu, China. China Economic Review, 19(4), 659-678.

Zhou, M. (2004). Revisiting Ethnic Entrepreneurship: Convergencies, Controversies, and Conceptual Advancements. International Migration Review, 38(3), 10401074. 


Appendix A: Data Sources 



\section{A.1. UNHCR Rwanda Dataset}

The data used in Chapter 3 of this dissertation was collected within the framework of the project The Economic Impacts of Congolese Refugees in Rwanda: Labour Markets, Social Infrastructure and Aid Effectiveness. This project was implemented between 2015 and 2016 by UNU-MERIT and its Maastricht Graduate School of Governance and was funded by the United Nations High Commissioner for Refugees (UNHCR). As indicated by the project title, the main aim of the project was to understand the economic impacts of hosting refugees from the Democratic Republic of Congo (DRC) on local communities in Rwanda. Within this bigger question several themes were of specific interest to the researchers, with one of the main ones being the effects on the local labour markets.

A large component of the project was the implementation of a household survey that covered both refugee and local households in Rwanda. The sampling strategy that led to the selection of the surveyed households took three and four stages for refugees (camp location, household, and individual) and locals (camp location, community, household, and individual) respectively. Communities, also called villages, are the lowest administrative unit in Rwanda.

In the first stage, the general locations of the fieldwork had to be determined by looking at the sites and characteristics of refugee camps in the country. UNHCR currently operates five refugee camps in Rwanda which are dedicated to hosting refugees from the DRC. These are Nyabiheke in the Eastern Province, Kigeme and Mugombwa in the Southern Province, Kiziba in the Western Province, and Gihembe in the Northern Province (UNHCR, 2016c). Three of these were selected to be included in the present study: Gihembe, Kigeme, and Kiziba.

These three camps were selected primarily for two reasons (see Table A. 1 for characteristics): their locations are spread across the country and the camps were opened at different points in time. The latter allows the comparison between protracted refugee situations (Gihembe and Kiziba) and more recent arrivals $\left(\right.$ Kigeme $\left.^{39}\right)$. A third reason, relevant in the overall design of the study, was the difference in the type of assistance provided in the three camps.

\footnotetext{
${ }^{39}$ While Kigeme as such was established earlier, it only started hosting refugees from the DRC in 2012.
} 
Table A. 1: Camp Characteristics

\begin{tabular}{lcccc}
\hline \hline & Province & $\begin{array}{c}\text { Year } \\
\text { Established }\end{array}$ & $\begin{array}{c}\text { Total } \\
\text { Population }\end{array}$ & Key Assistance \\
\hline Gihembe & Northern & 1997 & 12,485 & Cash-based \\
Kigeme & Southern & 2012 & 20,232 & Cash-based \\
Kiziba & Western & 1996 & 17,093 & In kind \\
\hline \hline
\end{tabular}

Source: Hedley et al. (2016); United Nations High Commissioner for Refugees (2016, 2018c).

Note: The total population column presents the number of Congolese refugees living in each camp respectively as of February 2018.

In the second stage of selecting the refugee respondents, the households to be surveyed within each camp needed to be determined. The target in each camp was to survey 140 households. In Gihembe and Kigeme, the research team largely based the selection of these households on an existing list of participants from prior research conducted in both camps. This research was carried out by researchers from UC Davis in June 2015. The aim of including the same households was to generate a panel data sub-sample and therefore the goal was to re-interview as many of the previously interviewed households as possible. In Kigeme, UC David had interviewed more than the target number of households and therefore all 140 households could be drawn from this list. In Gihembe, the existing list needed to be complemented with 13 additional households to reach the target. These were randomly selected from a list of all households in the camp, which was provided by UNHCR.

In Kiziba, on the other hand, no prior comparable research was identified and therefore participant households had to be identified from the total camp population. For this purpose, UNHCR provided a comprehensive list of households residing in the camp. The surveyed households were then randomly selected from this list, ensuring representativeness of the camp population. In the case of the other two camps, UC Davis had randomly selected the households they surveyed following the same procedure, so that the samples there can also be considered to have been randomly selected. A total of 427 refugee households were surveyed across the three camps: 148 in Gihembe, 139 in Kigeme, and 140 in Kiziba.

In the case of the local households, the project design required the research team to consider the distance of communities to the respective camp. In order to investigate potential impacts of camps on the local communities, the interest was to look at communities within a $10 \mathrm{~km}$ radius from the camps and communities that were at least 
$20 \mathrm{~km}$ from the camps. The target number of surveys for each camp area was 320 households, split equally between the two distance.

As the research team from UC Davis used the same approach, the local households were also largely selected based on the participants in their study in the communities within $10 \mathrm{~km}$ of Gihembe and Kigeme respectively. In the case of Kiziba, on the other hand, a list of all possible cells in the relevant area within $10 \mathrm{~km}$ of the camp was first compiled based on available administrative data. This list was then cross-checked with information from the latest census on the presence of markets. Any cells in which no market was registered were then deleted. This criterion was important for the selection of communities, as the research team was specifically interested in interactions between locals and refugees for which one important location are markets. Within each area four cells were then randomly selected from those left on the list and in each cell the community with the largest population was the one where the survey was implemented.

Finally, in the case of the communities that are more than $20 \mathrm{~km}$ away from each camp, an equal number of cells was selected as was the case for those within $10 \mathrm{~km}$. In the case of Gihembe, for example, there were 51 cells within the $10 \mathrm{~km}$ radius around the camp. Therefore the 51 cells closest to the camps above the $20 \mathrm{~km}$ radius were identified to then randomly choose from. As was the case within $10 \mathrm{~km}$, all cells without a market were dropped before four cells were randomly selected among the remaining ones. In each cell the community with the largest population was then identified for enumeration.

In the next stage, the households to be surveyed within the selected communities needed to be identified. In the case of the communities within $10 \mathrm{~km}$ of Gihembe and Kigeme, the research team again re-interviewed households previously included in the UC Davis study. In the other locations (within $10 \mathrm{~km}$ of Kiziba and all outside 20 $\mathrm{km}$ communities), households were randomly selected based on a list compiled during a preparatory visit by the research team. During these visits to each location, the team compiled lists of households within each respective community with the support of community representatives. From these lists 40 households were then randomly selected to be surveyed in each of the locations. Only one household approached by the research team refused participation and another household was therefore randomly selected from the list to reach the target number. Overall, data was collected for 953 households in the host communities.

In the final stage for both refugees and locals, the individual to be surveyed within the selected households needed to be identified. For this purpose, the enumerators were 
given clear instructions in order to ensure that the most suitable main respondent would be chosen. In general, the main respondent was the household head or spouse of the household head and at least 21 years old. Furthermore, anyone that normally lived in and shared meals with the household was considered to be a household member, while anyone that had been away for six months or longer was excluded. The module focused on employment, specifically relevant for the present chapter, was answered by all household members that were 16 or older at the time of the survey. 


\section{A.2. IS Academy Datasets}

The data used in Chapters 4 and 5 of this dissertation was collected within the framework of the IS Academy Migration and Development: A World in Motion project. This project was implemented between 2009 and 2014 by the Maastricht Graduate School of Governance and partners and financed by the Dutch Ministry of Foreign Affairs. It aimed to understand the linkages between migration and development from sending and receiving country perspectives for the purpose of expanding the knowledge base, which informs policy in the area of migration and development.

Within this context, the Netherlands were considered as an example of a migrant receiving country and, at the same time, four migrant origin countries were studied: Afghanistan, Burundi, Ethiopia, and Morocco. These four countries of origin for the project were chosen based on their existing relationship in terms of migration with the Netherlands as well as other parts of the world. As such, the selection of these countries aimed at covering a variety of origin countries with different characteristics such as a diversity of predominant countries/ regions of destination, the timing of migration flows - some older, others more recent - and different types of migration, including forced movements.

In each of the four origin countries household surveys were conducted in order to collect rich data on both the individual and household levels on current and return migrants and their families/ households. Chapter 4 of this dissertation relies on the datasets from all four of the origin countries, while Chapter 5 focuses on the case of Afghanistan specifically. The surveys used in the four countries were largely identical, with the exception of a few country specific questions that were adjusted to each respective context, such as questions about ethnicity or religion. The surveys were, however, translated into the official country language(s) therefore the precise meaning and range of possible interpretations for a question may be different across countries.

The surveys aimed to collect information on different themes related to migration and development such as remittances, brain drain, and return migration, along with a variety of other themes related to socio-economic characteristics, living conditions, and everyday life. Table A. 2 provides an overview of the data collection in each of the four countries in terms of the respective local partner institution as well as the period of data collection in each country. 
Table A. 2: IS Academy Data Collection Partners and Timing

\begin{tabular}{|c|c|c|}
\hline Country & Local Partner & Data Collection Period \\
\hline Afghanistan & Samuel Hall Consulting & Mid-March-mid-May 2011 \\
\hline \multirow[t]{2}{*}{ Burundi } & Development Through & January - March 2011 \\
\hline & Consultancy (DeVec) & \\
\hline Ethiopia & Ethiopian Development Research Institute & February - April 2011 \\
\hline Morocco & Mohammed V University & November 2011 - February 2012 \\
\hline
\end{tabular}

Sampling of households to be surveyed came with challenges in each of the four countries. Random sampling, ideally applied in order achieve representativeness of results, was not possible and desired in all cases, but was used wherever possible. In order to understand migration movements, the survey aimed at the collection of data on both households with migration experience(s) as well as those without. In a case where a representative sampling scheme is applied to the whole country, it is likely that the number of migrants and return migrants captured is rather low considering their overall relatively small share in the population (see Section 4.3). In order to achieve the coverage of various migration experiences in each country, various levels of purposive sampling were therefore implemented to reach a sufficient number of households with such experiences. As a result, the national representativeness of any conclusions drawn from this data is compromised to achieve having enough information to compare migrant and non-migrant households. The following paragraphs briefly describe the sampling strategy in each of the countries respectively, which generally followed a four-stage procedure. Selection was first done at the province (Afghanistan and Burundi), region (Ethiopia) or area (Morocco) level, where districts were selected, before identifying the primary sampling units (PSU) within each district from where household were chosen to take part in the surveys. Within the household one respondent was selected to answer the main body of the questionnaire. The respondent was chosen on the basis of being the most knowledgeable individual on household affairs over the age of 18; preferably the household head or another senior member such as a parent or grandparent.

In the case of Afghanistan random sampling was not possible due to a lack of recent census data as well as safety concerns. Therefore, five provinces were purposively selected: Balkh in the north of the country, Herat in the west, Kandahar in the south, and Kabul and Kandahar in the east. As such, this selection allowed to capture different geographic areas of the country, where different migration patterns are present. In addition, the five provinces all feature densely populated urban centres. Within each of the provinces, districts were purposively selected based on information 
obtained from the Central Statistics Organization (CSO) of Afghanistan with the aim of ensuring the coverage of urban and rural areas in a nationally representative manner. Accessibility and safety further influenced the selection of the chosen districts. Within the districts the PSUs were then randomly selected based on the CSO data. At the community level, the research team compiled a list of all households in cooperation with respective leaders or elders of the community. Based on the classification of the households into current, return, as well as non-migrant households, households were then chosen in a way that reflected the overall migration profile of the specific area.

In Burundi, two rounds of the survey were conducted. The first round was a nationally representative household survey and the second round was an urban household survey of households randomly selected in the capital of Bujumbura. The sampling strategy for the national survey followed a representative sampling scheme, where the share of questionnaires conducted per province was based on the respective share of that province's population of the total population. This was done based on the population figures provided from the latest Population Census of 2008. Within each province collines, the second smallest administrative unit in Burundi, were then identified also based on the population shares identified in the Census. A total of 100 collines were selected across the whole country. Within each of these collines the PSUs were sous-collines, for which no comprehensive list could be obtained. Therefore, the PSUs per colline were randomly selected at the fieldwork site, once a list of all souscollines could be put together locally. Within each of the selected sous-collines, a list of all households was compiled with the assistance of a community leader. From this list households were then randomly selected for participation in the survey. Once the national household survey was completed, the data collection in Burundi continued with the collection of the urban household survey, where data collection took place only in urban Bujumbura, Burundi's capital city. Within the city, quartiers were sampled as PSUs, relative to the respective population size. Within each of the quartiers, one block, comprised of two to four streets, was randomly selected and for each of these blocks 15 interviews with randomly selected households were conducted. Overall, the case of Burundi is the only of the four countries were purposive sampling was not used and as a consequence the number of migrants captured in the survey is much lower.

In Ethiopia sampling of regions was also conducted with a purposive approach. In this case this decision was largely made due to the sheer size of the country and the size and distribution of the population. As such the five regions where the vast 
majority of the total population lives were selected. These are Addis Ababa, Amhara, Oromia, SNNP, and Tigray. In the Ethiopian context, administratively each region is divided into woredas and further into kebeles. For the sampling for the survey, three woredas were selected within each of the five regions. Except for in Addis Ababa, these were chosen to represent an urban woreda and two rural ones in each region respectively, where one of the rural ones was located close to an international border and one was further away. In a region where multiple woredas fit the criteria, the selection was done randomly. In Addis Ababa, which is divided into 11 urban woredas, the selection was based on the average income level within the woreda. One poor woreda, one with middle, and one with higher income levels were selected respectively. In the next stage of the sampling process, the PSUs were identified at the level of kebeles, where each kebele eligible for selection had to contain of a minimum of 80 households with a migration experience. In order to determine the eligible kebeles, lists of households were obtained for each kebele and with the help of a local official, elder, or health worker all households were classified as migrant, return migrant, or non-migrant households. If more than one kebele within each woreda qualified for the migration experience criteria, other criteria used for the selection of the kebeles in which the survey would be conducted included the attitude of the local administration towards participation in the survey as well as the accessibility of the respective community. Finally, within the selected kebeles, 115 households were randomly chosen for enumeration, where half had members with some sort of migration experience and half had no such experience. The field teams were then required to survey at least 84 of those households, or where that was not possible, further households were randomly selected for enumeration until this goal was met.

Finally, in the case of Morocco, four areas of the country were purposively selected based on the fact that migration is particularly common in those areas and as such trends captured there would ensure that important characteristics of Moroccan migration were represented in the data. In this case, areas were selected not on the basis of administrative records, but on the basis of socio-economic characteristics. These areas are the Tingitane Peninsula in the north-west, the Tadla in in central Morocco, the Central Rif in the north-east, as well as the Atlantic Axis with Casablanca, Rabat, and Kénitra. Within these areas, administrative units where then selected at the level of prefectures in urban areas and provinces in rural areas. Due to differences in the administrative registration between urban and rural areas the selection of the survey sites had to take a different approach in both types of areas, but in both cases places were chosen where migration is known to have impacted investments and infrastructure or return migrants have clustered. In the urban context, prefectures 
were purposively selected as places where investment and infrastructure due to migration are known to cluster. In rural areas, provinces were selected for the same reason. The next smallest unit, the annex was purposively selected for the same reason, except in the case of Rabat, where a list of annexes was available, and selection was made using a random number generator. In rural areas a further unit - the commune - was selected. In the next stage for urban areas, the number of questionnaires for each annex was determined in proportion to its number of inhabitants. The PSU in urban areas was the quartier. In each quartier the number of surveys was determined by the relative weight of it population. In rural areas the PSU was the douar but no standard lists of inhabitants could be obtained. The numbers of surveys per douar was decided through consultation with chikh (local public official). Finally, a random walk was used, beginning at a point of interest decided upon through discussion with a local administrative official. Depending on the density of the population every third or fifth household was interviewed along a pre-determined route. 


\section{A.3. LAMFOR Dataset}

The data used in Chapter 6 of this dissertation was collected in the framework of the project The Labour Market Impacts of Forced Migration. The project was funded by the UK Department for International Development (DIFD) and the Institute for the Study of Labour (IZA) and implemented in a partnership between researchers at the University of Oxford and UNU-MERIT I Maastricht Graduate School of Governance. It ran between June 2013 and December 2015. The overall aim of the project was to provide unique data on the effects of forced migration on labour markets, with a focus on such situations in the Great Lakes region in East Africa. The present data specifically focuses on forced migration in the context of Burundi.

The data collection for this project in Burundi was a follow-up of the data that was collected as part of the IS Academy: Migration and Development and as such a similar strategy for data collection was used. Details on that are provided in Appendix A.2 above. As was the case in 2011, data was collected across all provinces of Burundi in 2015. Specifically, a household survey of 1,500 households in 100 communities across the country was conducted between January and March 2015. It is important to note that the collection of the data was completed before the renewed outbreak of violent conflict which has led to the displacement of more than 400,000 Burundians (United Nations High Commissioner for Refugees, 2017b).

Sampling of these households was conducted using a two-stage sampling design considering the demographic weight of the different provinces that was developed based on the most recent census conducted in Burundi in 2008. The first stage consisted of random sampling at the sous-colline (village) level. Figure A.1 shows the location of the 100 sampled communities across the country. Within each of these communities 15 households were randomly selected in the second stage and these were then interviewed.

In addition to the household survey, the respective community representative completed a community survey to collect information on the community-level, complementing the micro-level data. The data from the household survey contains a variety of information on both the individual and household level, such as personal characteristics, education, household assets, migration, and displacement and return experiences, exposure to shocks, as well as labour market activities. In addition, to place these households in the respective context, the community survey includes information about, among others, the population, infrastructure, and different types of shocks experienced. 
Figure A.1: Location of the Sampled Communities

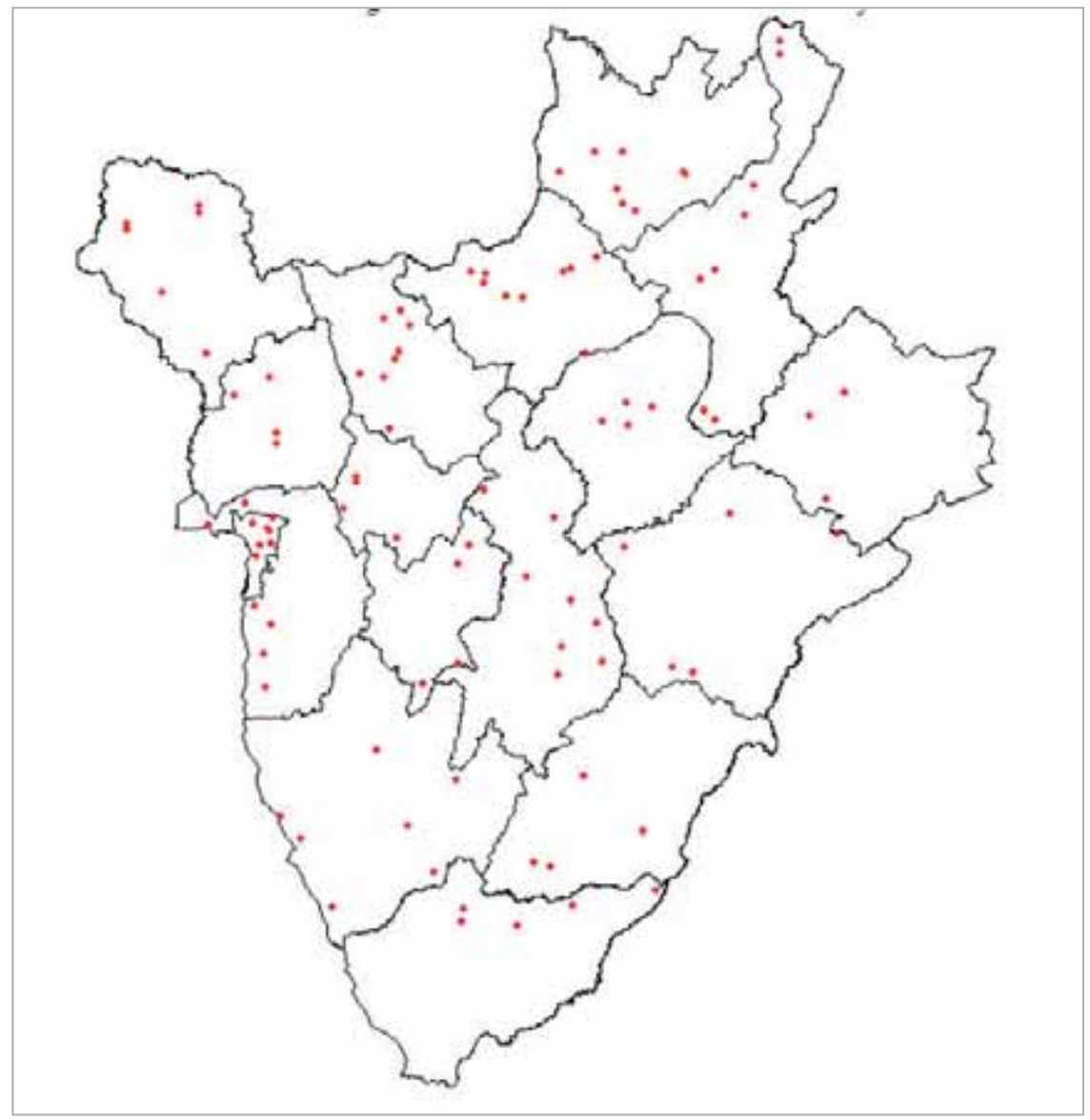

Source: Fransen et al. (2017). 

APPENDIX B: LABOUR MARKET ACTIVITIES OF CONGOLESE REFUGEES IN RWANDA 



\section{Table B.1: Operationalization of Variables}

\begin{tabular}{|c|c|}
\hline Variable & Description \\
\hline Female & 1 if female \\
\hline Age & In years (16-65) \\
\hline Married & 1 if married \\
\hline Household head & 1 if individual is the household head \\
\hline Years of education & In years; only formal education \\
\hline Size of household & Number of household members \\
\hline Share of children & $\begin{array}{l}\text { Number of children relative to number of adults in the } \\
\text { household }\end{array}$ \\
\hline Market distance & In minutes \\
\hline Time in community & In years \\
\hline Remittances & 1 if household receives remittances \\
\hline Social network & $\begin{array}{l}1 \text { if individual can count on people beyond immediate } \\
\text { household for financial support in time of need }\end{array}$ \\
\hline \multicolumn{2}{|l|}{ Refugees only } \\
\hline Food assistance & 1 if household receives food assistance \\
\hline Cash assistance & 1 if household receives cash assistance \\
\hline \multicolumn{2}{|l|}{ Work prior to migration } \\
\hline Wage employment & 1 if refugee was wage employed prior to displacement \\
\hline Self-employment & $\begin{array}{l}1 \text { if refugee was self-employed in business prior to } \\
\text { displacement }\end{array}$ \\
\hline Agriculture & $\begin{array}{l}1 \text { if refugee was working in (subsistence) agriculture prior to } \\
\text { displacement }\end{array}$ \\
\hline
\end{tabular}


Table B. 2: Labour Market Activities of Refugees and Locals, Limited Sample (Logit estimates)

\begin{tabular}{|c|c|c|c|c|c|c|}
\hline \multirow[b]{2}{*}{ Model: Logit (odds ratio/ se) } & \multicolumn{2}{|c|}{$\begin{array}{l}\text { Employment versus } \\
\text { Unemployment }\end{array}$} & \multicolumn{2}{|c|}{$\begin{array}{c}\text { Wage or self- } \\
\text { employment versus } \\
\text { Unemployment }\end{array}$} & \multicolumn{2}{|c|}{$\begin{array}{c}\text { Self-employment } \\
\text { versus Wage } \\
\text { employment }\end{array}$} \\
\hline & (1) & $(2)$ & (3) & $(4)$ & (5) & (6) \\
\hline Refugee & $\begin{array}{l}0.08^{* * *} \\
(0.04)\end{array}$ & $\begin{array}{l}0.07^{* * *} \\
(0.03)\end{array}$ & $\begin{array}{l}0.23^{* * *} \\
(0.08)\end{array}$ & $\begin{array}{l}0.28^{* *} \\
(0.14)\end{array}$ & $\begin{array}{l}2.81^{* * *} \\
(0.65)\end{array}$ & $\begin{array}{l}3.42^{* * *} \\
(1.53)\end{array}$ \\
\hline Gihembe & $\begin{array}{l}1.40^{* *} \\
(0.23)\end{array}$ & $\begin{array}{c}1.11 \\
(0.52)\end{array}$ & $\begin{array}{l}1.60^{* * *} \\
(0.23)\end{array}$ & $\begin{array}{l}2.06^{*} \\
(0.87)\end{array}$ & $\begin{array}{l}0.67^{* *} \\
(0.14)\end{array}$ & $\begin{array}{c}0.79 \\
(0.32)\end{array}$ \\
\hline Kigeme & $\begin{array}{c}1.74 \\
(0.83)\end{array}$ & $\begin{array}{c}1.67 \\
(0.83)\end{array}$ & $\begin{array}{l}1.58 \\
(0.56)\end{array}$ & $\begin{array}{c}1.57 \\
(0.56)\end{array}$ & $\begin{array}{l}1.67^{*} \\
(0.44)\end{array}$ & $\begin{array}{c}1.78 \\
(0.73)\end{array}$ \\
\hline Female & $\begin{array}{c}1.12 \\
(0.36)\end{array}$ & $\begin{array}{l}1.13 \\
(0.37)\end{array}$ & $\begin{array}{c}0.87 \\
(0.24)\end{array}$ & $\begin{array}{c}0.87 \\
(0.24)\end{array}$ & $\begin{array}{l}3.34^{* * *} \\
(1.38)\end{array}$ & $\begin{array}{l}3.36^{* * *} \\
(1.39)\end{array}$ \\
\hline Age & $\begin{array}{c}1.01 \\
(0.02)\end{array}$ & $\begin{array}{c}1.01 \\
(0.02)\end{array}$ & $\begin{array}{c}1.01 \\
(0.02)\end{array}$ & $\begin{array}{c}1.01 \\
(0.02)\end{array}$ & $\begin{array}{l}0.98^{* *} \\
(0.01)\end{array}$ & $\begin{array}{l}0.98^{* *} \\
(0.01)\end{array}$ \\
\hline Married & $\begin{array}{l}2.41^{* * *} \\
(0.58)\end{array}$ & $\begin{array}{l}2.40^{* * *} \\
(0.57)\end{array}$ & $\begin{array}{l}2.24^{* * *} \\
(0.49)\end{array}$ & $\begin{array}{l}2.23^{* * *} \\
(0.48)\end{array}$ & $\begin{array}{l}1.51^{* *} \\
(0.31)\end{array}$ & $\begin{array}{l}1.52^{* *} \\
(0.31)\end{array}$ \\
\hline HH head & $\begin{array}{l}1.06 \\
(0.14)\end{array}$ & $\begin{array}{c}1.06 \\
(0.14)\end{array}$ & $\begin{array}{c}1.05 \\
(0.12)\end{array}$ & $\begin{array}{c}1.05 \\
(0.12)\end{array}$ & $\begin{array}{c}1.12 \\
(0.27)\end{array}$ & $\begin{array}{c}1.13 \\
(0.27)\end{array}$ \\
\hline Education (years) & $\begin{array}{c}0.91^{* * *} \\
(0.03)\end{array}$ & $\begin{array}{c}0.91^{* * *} \\
(0.03)\end{array}$ & $\begin{array}{c}0.91^{* * *} \\
(0.02)\end{array}$ & $\begin{array}{c}0.92^{* * *} \\
(0.02)\end{array}$ & $\begin{array}{c}0.98 \\
(0.03)\end{array}$ & $\begin{array}{c}0.98 \\
(0.03)\end{array}$ \\
\hline Size of household & $\begin{array}{c}0.87^{* * *} \\
(0.03)\end{array}$ & $\begin{array}{c}0.87^{* * *} \\
(0.03)\end{array}$ & $\begin{array}{c}0.86^{* * *} \\
(0.04)\end{array}$ & $\begin{array}{c}0.86^{* * *} \\
(0.04)\end{array}$ & $\begin{array}{l}0.94^{*} \\
(0.03)\end{array}$ & $\begin{array}{l}0.94^{*} \\
(0.03)\end{array}$ \\
\hline Share of children & $\begin{array}{l}1.27^{* *} \\
(0.13)\end{array}$ & $\begin{array}{l}1.27^{* *} \\
(0.14)\end{array}$ & $\begin{array}{l}1.25^{* *} \\
(0.13)\end{array}$ & $\begin{array}{l}1.24^{* *} \\
(0.13)\end{array}$ & $\begin{array}{c}0.96 \\
(0.09)\end{array}$ & $\begin{array}{c}0.95 \\
(0.10)\end{array}$ \\
\hline Market distance & $\begin{array}{c}1.00 \\
(0.00)\end{array}$ & $\begin{array}{c}1.00 \\
(0.00)\end{array}$ & $\begin{array}{c}1.00 \\
(0.00)\end{array}$ & $\begin{array}{c}1.00 \\
(0.00)\end{array}$ & $\begin{array}{c}0.99^{* * *} \\
(0.00)\end{array}$ & $\begin{array}{l}0.99^{* *} \\
(0.00)\end{array}$ \\
\hline Time in community & $\begin{array}{l}1.05^{* *} \\
(0.02)\end{array}$ & $\begin{array}{l}1.05^{*} \\
(0.03)\end{array}$ & $\begin{array}{l}1.04^{*} \\
(0.02)\end{array}$ & $\begin{array}{l}1.05^{*} \\
(0.03)\end{array}$ & $\begin{array}{l}1.02^{*} \\
(0.01)\end{array}$ & $\begin{array}{l}1.02^{*} \\
(0.01)\end{array}$ \\
\hline Remittances & $\begin{array}{c}0.97 \\
(0.30)\end{array}$ & $\begin{array}{c}0.95 \\
(0.30)\end{array}$ & $\begin{array}{l}1.07 \\
(0.39)\end{array}$ & $\begin{array}{c}1.10 \\
(0.40)\end{array}$ & $\begin{array}{l}2.31^{*} \\
(1.03)\end{array}$ & $\begin{array}{l}2.36^{*} \\
(1.07)\end{array}$ \\
\hline Informal network & $\begin{array}{c}0.88 \\
(0.20)\end{array}$ & $\begin{array}{c}0.88 \\
(0.20)\end{array}$ & $\begin{array}{c}0.90 \\
(0.20)\end{array}$ & $\begin{array}{c}0.90 \\
(0.20)\end{array}$ & $\begin{array}{c}1.16 \\
(0.23)\end{array}$ & $\begin{array}{c}1.17 \\
(0.23)\end{array}$ \\
\hline Gihembe X Refugee & & $\begin{array}{c}1.43 \\
(0.86)\end{array}$ & & $\begin{array}{c}0.69 \\
(0.37)\end{array}$ & & $\begin{array}{c}0.73 \\
(0.34)\end{array}$ \\
\hline Kigeme X Refugee & & $\begin{array}{c}1.17 \\
(0.68)\end{array}$ & & $\begin{array}{c}1.03 \\
(0.66) \\
\end{array}$ & & $\begin{array}{c}0.86 \\
(0.58) \\
\end{array}$ \\
\hline Adjusted R-squared & 0.45 & 0.45 & 0.29 & 0.29 & 0.11 & 0.11 \\
\hline Observations & 1802 & 1802 & 848 & 848 & 561 & 561 \\
\hline
\end{tabular}

Note: $* * * \mathrm{p}<0.01, * * \mathrm{p}<.05, * \mathrm{p}<0.10$. Kiziba is the reference refugee camp. Standard errors in parentheses are robust and clustered at the community level. 


APPENDix C: INTERNATIONAL Migration OF HOUSEHOLD MEMBERS AND SELF-EMPLOYMENT OF NON-MigRANTS 



\section{Table C. 1: Operationalisation of Variables}

\begin{tabular}{|c|c|}
\hline Variable & Definition \\
\hline Self-employed & 1 if individual is economically active and self-employed \\
\hline Working & 1 if an individual is economically active \\
\hline Household migrant & 1 if there is at least one current international migrant in the household \\
\hline Return migrant & 1 if there is at least one international return migrant in the household \\
\hline Age & In years (15-65) \\
\hline Male & 1 if male \\
\hline Household head & 1 if respondent is the household head \\
\hline Education & In years \\
\hline Married & 1 if married \\
\hline Number of children & Number of children 14 or younger in the household \\
\hline Household size & Number of household members \\
\hline Household owns house & 1 if the household owns the house in which it lives \\
\hline Household owns land & 1 if the household owns land \\
\hline $\begin{array}{l}\text { Household } \quad \text { receives } \\
\text { remittances }\end{array}$ & 1 if the household receives remittances from abroad \\
\hline Urban & 1 if household is located in an urban area \\
\hline Economic situation & $\begin{array}{l}1 \text { if most households in the community are coping or living } \\
\text { comfortably }\end{array}$ \\
\hline Employment opportunities & 1 if medium to high availability of employment in the community \\
\hline Migration prevalence & $\begin{array}{l}1 \text { if more than } 25 \text { (Afghanistan and Burundi), } 75 \text { (Morocco), or } 100 \\
\text { (Ethiopia) households in the community have a migrant abroad } \\
\text { respectively }\end{array}$ \\
\hline
\end{tabular}


Table C. 2: Primary Daily Activity in the Past 12 Months by Gender

\begin{tabular}{lrrrrrrrr}
\hline \hline & \multicolumn{2}{c}{ Afghanistan } & \multicolumn{2}{c}{ Burundi } & \multicolumn{2}{c}{ Ethiopia } & \multicolumn{2}{c}{ Morocco } \\
\cline { 2 - 9 } & Female & Male & Female & Male & Female & Male & Female & Male \\
\hline Working & 43 & 741 & 1,802 & 1,592 & 503 & 1,023 & 233 & 1,365 \\
$\%$ & 2.56 & 53.15 & 58.15 & 58.77 & 24.95 & 58.05 & 11.40 & 66.13 \\
Unemployed & 3 & 98 & 58 & 17 & 123 & 164 & 609 & 264 \\
$\%$ & 0.18 & 7.03 & 1.87 & 0.63 & 6.21 & 9.31 & 29.79 & 12.79 \\
Inactive & 1,637 & 555 & 1,239 & 1,100 & 1,354 & 575 & 1,202 & 435 \\
$\%$ & 97.27 & 39.81 & 39.98 & 40.61 & 68.38 & 32.63 & 58.81 & 21.08 \\
\hline \hline
\end{tabular}

Table C. 3: Type of Primary Daily Activity of Working Population by Gender

\begin{tabular}{lrrrrrrrr}
\hline \hline & \multicolumn{2}{c}{ Afghanistan } & \multicolumn{2}{c}{ Burundi } & \multicolumn{2}{c}{ Ethiopia } & \multicolumn{2}{c}{ Morocco } \\
\cline { 2 - 9 } & \multicolumn{1}{c}{ Female } & Male & Female & Male & Female & Male & Female & Male \\
\hline Self-empl. & 20 & 342 & 155 & 253 & 163 & 196 & 54 & 495 \\
$\%$ & 46.51 & 46.15 & 8.60 & 15.89 & 32.41 & 19.16 & 23.18 & 36.26 \\
Wage empl. & 22 & 283 & 198 & 385 & 242 & 397 & 175 & 778 \\
$\%$ & 51.16 & 28.19 & 10.99 & 24.18 & 48.11 & 38.81 & 75.11 & 57.00 \\
Agriculture & 1 & 116 & 1,449 & 954 & 98 & 430 & 4 & 92 \\
$\%$ & 2.33 & 15.65 & 80.41 & 59.92 & 19.48 & 42.03 & 1.72 & 6.74 \\
\hline \hline
\end{tabular}


Table C. 4: Binomial Probit with Sample Selection Model Estimations - Females

\begin{tabular}{|c|c|c|c|c|}
\hline & $(1)$ & (2) & (3) & (4) \\
\hline & AFG & BUR & ETH & MOR \\
\hline \multicolumn{5}{|l|}{ Self-Employment } \\
\hline \multirow[t]{2}{*}{ Current migrant } & & 0.012 & -0.009 & 0.044 \\
\hline & & $(0.071)$ & $(0.024)$ & $(0.073)$ \\
\hline \multirow[t]{2}{*}{ Return migrant } & & -0.045 & 0.040 & 0.203 \\
\hline & & $(0.036)$ & $(0.035)$ & $(0.137)$ \\
\hline \multicolumn{5}{|l|}{ Individual level } \\
\hline \multirow[t]{2}{*}{ Age } & & -0.005 & $-0.038^{* * *}$ & $0.025 *$ \\
\hline & & $(0.008)$ & $(0.005)$ & $(0.015)$ \\
\hline \multirow[t]{2}{*}{ Age squared } & & 0.000 & $0.047^{* * *}$ & $-0.035 *$ \\
\hline & & $(0.000)$ & $(0.006)$ & $(0.020)$ \\
\hline \multirow{2}{*}{$\begin{array}{l}\text { Household head } \\
\text { * }\end{array}$} & & 0.004 & $-0.090^{* * *}$ & 0.050 \\
\hline & & $(0.028)$ & $(0.027)$ & $(0.065)$ \\
\hline \multirow[t]{2}{*}{ Years of education } & & 0.003 & $-0.023^{* * *}$ & -0.010 \\
\hline & & $(0.003)$ & $(0.005)$ & $(0.014)$ \\
\hline \multicolumn{5}{|l|}{ Household level } \\
\hline \multirow[t]{2}{*}{ Size of household } & & $0.017^{* * *}$ & 0.009 * & -0.002 \\
\hline & & $(0.005)$ & $(0.005)$ & $(0.014)$ \\
\hline \multirow[t]{2}{*}{ Land ownership } & & $-0.093^{* * *}$ & $-0.077^{*}$ & -1.127 \\
\hline & & $(0.023)$ & $(0.040)$ & (322.041) \\
\hline \multirow[t]{2}{*}{ House ownership } & & $-0.112^{* * *}$ & 0.013 & -0.006 \\
\hline & & $(0.023)$ & $(0.026)$ & $(0.051)$ \\
\hline \multirow[t]{2}{*}{ Bank account } & & -0.024 & $0.085^{* *}$ & -0.078 \\
\hline & & $(0.028)$ & $(0.033)$ & $(0.085)$ \\
\hline \multicolumn{5}{|l|}{ Community level } \\
\hline \multirow[t]{2}{*}{ Urban } & & $0.228^{* * *}$ & 0.052 & 0.018 \\
\hline & & $(0.032)$ & $(0.035)$ & $(0.070)$ \\
\hline \multirow[t]{2}{*}{ Employment availability } & & $-0.038 *$ & $-0.185^{* * *}$ & 0.037 \\
\hline & & $(0.023)$ & $(0.056)$ & $(0.073)$ \\
\hline \multirow[t]{2}{*}{ Economic situation } & & -0.024 & -0.075 * & -0.001 \\
\hline & & $(0.027)$ & $(0.039)$ & $(0.049)$ \\
\hline \multirow[t]{2}{*}{ Migration incidence } & & -0.034 & 0.093 * & -0.077 \\
\hline & & $(0.030)$ & $(0.054)$ & $(0.076)$ \\
\hline \multicolumn{5}{|l|}{ Working } \\
\hline \multirow[t]{2}{*}{ Current migrant } & & 0.036 & -0.033 & -0.027 \\
\hline & & $(0.048)$ & $(0.020)$ & $(0.017)$ \\
\hline \multirow[t]{2}{*}{ Return migrant } & & 0.029 & -0.033 & 0.029 \\
\hline & & $(0.022)$ & $(0.030)$ & $(0.028)$ \\
\hline \multicolumn{5}{|l|}{ Individual level } \\
\hline \multirow[t]{2}{*}{ Age } & & $0.053^{* * *}$ & $0.052^{* * *}$ & $0.035^{* * *}$ \\
\hline & & $(0.003)$ & $(0.004)$ & $(0.004)$ \\
\hline \multirow[t]{2}{*}{ Age squared } & & $-0.001^{* * *}$ & $-0.065^{* * *}$ & $-0.042^{* * *}$ \\
\hline & & $(0.000)$ & $(0.005)$ & $(0.005)$ \\
\hline
\end{tabular}




\begin{tabular}{|c|c|c|c|}
\hline Household head & $\begin{array}{c}0.120^{* * *} \\
(0.028)\end{array}$ & $\begin{array}{l}0.184^{* * *} \\
(0.027)\end{array}$ & $\begin{array}{c}0.124^{* * *} \\
(0.023)\end{array}$ \\
\hline Years of education & $\begin{array}{c}-0.015^{* * *} \\
(0.002)\end{array}$ & $\begin{array}{c}0.016^{* * *} \\
(0.002)\end{array}$ & $\begin{array}{l}0.014^{* * *} \\
(0.001)\end{array}$ \\
\hline Married & $\begin{array}{c}0.164^{* * *} \\
(0.018)\end{array}$ & $\begin{array}{l}-0.011 \\
(0.018)\end{array}$ & $\begin{array}{c}-0.100^{* * *} \\
(0.016)\end{array}$ \\
\hline Number of children & $\begin{array}{c}0.008 \\
(0.005)\end{array}$ & $\begin{array}{l}-0.014 * \\
(0.007)\end{array}$ & $\begin{array}{l}-0.002 \\
(0.010)\end{array}$ \\
\hline \multicolumn{4}{|l|}{ Household level } \\
\hline Size of household & $\begin{array}{c}-0.020^{* * *} \\
(0.004)\end{array}$ & $\begin{array}{l}-0.009 * \\
(0.005)\end{array}$ & $\begin{array}{l}-0.003 \\
(0.005)\end{array}$ \\
\hline Land ownership & $\begin{array}{c}0.087^{* * *} \\
(0.015)\end{array}$ & $\begin{array}{c}0.014 \\
(0.025)\end{array}$ & $\begin{array}{l}-0.019 \\
(0.026)\end{array}$ \\
\hline House ownership & $\begin{array}{l}0.098^{* * *} \\
(0.016)\end{array}$ & $\begin{array}{c}-0.063^{* * *} \\
(0.022)\end{array}$ & $\begin{array}{l}-0.021 \\
(0.017)\end{array}$ \\
\hline Bank account & $\begin{array}{l}0.037^{* *} \\
(0.017)\end{array}$ & $\begin{array}{l}-0.021 \\
(0.020)\end{array}$ & $\begin{array}{l}0.034^{* *} \\
(0.016)\end{array}$ \\
\hline \multicolumn{4}{|l|}{ Community level } \\
\hline Urban & $\begin{array}{c}-0.183^{* * *} \\
(0.016)\end{array}$ & $\begin{array}{l}-0.002 \\
(0.026)\end{array}$ & $\begin{array}{l}-0.004 \\
(0.020)\end{array}$ \\
\hline Employment availability & $\begin{array}{c}0.023 \\
(0.014)\end{array}$ & $\begin{array}{c}0.182^{* * *} \\
(0.044)\end{array}$ & $\begin{array}{l}-0.017 \\
(0.018)\end{array}$ \\
\hline Economic situation & $\begin{array}{c}0.004 \\
(0.017)\end{array}$ & $\begin{array}{l}-0.013 \\
(0.021)\end{array}$ & $\begin{array}{c}0.004 \\
(0.015)\end{array}$ \\
\hline Migration incidence & $\begin{array}{l}-0.002 \\
(0.019)\end{array}$ & $\begin{array}{c}-0.146^{* * *} \\
(0.041)\end{array}$ & $\begin{array}{l}-0.008 \\
(0.016)\end{array}$ \\
\hline $\mathrm{N}$ & 3,099 & 1,980 & 2,044 \\
\hline Uncensored N & 1,802 & 503 & 1,811 \\
\hline rho & -0.26 & -0.96 & 0.26 \\
\hline $\begin{array}{l}\text { LR test of indep. eqns } \\
(\mathrm{rho}=0) \text { : chi2(1) }\end{array}$ & 2.19 & 2.76 & 0.36 \\
\hline
\end{tabular}

Note: Average marginal effects are reported with standard errors in parentheses. ${ }^{* * *} \mathrm{p}<0.01,{ }^{* *} \mathrm{p}<0.05,{ }^{*} \mathrm{p}<0.1$. 
Table C. 5: Binomial Probit with Sample Selection Model Estimations - Males

\begin{tabular}{|c|c|c|c|c|}
\hline & $(1)$ & $(2)$ & (3) & $(4)$ \\
\hline & AFG & BUR & ETH & MOR \\
\hline \multicolumn{5}{|l|}{ Self-Employment } \\
\hline \multirow[t]{2}{*}{ Current migrant } & 0.057 & 0.065 & -0.039 & $0.116^{* *}$ \\
\hline & $(0.059)$ & $(0.100)$ & $(0.033)$ & $(0.047)$ \\
\hline \multirow[t]{2}{*}{ Return migrant } & -0.010 & 0.017 & -0.010 & 0.079 \\
\hline & $(0.052)$ & $(0.048)$ & $(0.054)$ & $(0.073)$ \\
\hline \multicolumn{5}{|l|}{ Individual level } \\
\hline \multirow[t]{2}{*}{ Age } & 0.021 & 0.003 & -0.024 & $0.023^{* *}$ \\
\hline & $(0.013)$ & $(0.009)$ & $(0.020)$ & $(0.012)$ \\
\hline \multirow[t]{2}{*}{ Age squared } & -0.000 & -0.000 & 0.020 & $-0.031^{* *}$ \\
\hline & $(0.000)$ & $(0.000)$ & $(0.023)$ & $(0.015)$ \\
\hline \multirow[t]{2}{*}{ Household head } & 0.030 & -0.082 & $0.082 *$ & $0.094^{* *}$ \\
\hline & $(0.056)$ & $(0.072)$ & $(0.045)$ & $(0.041)$ \\
\hline \multirow[t]{2}{*}{ Years of education } & $-0.008 *$ & $-0.007^{* *}$ & -0.002 & $-0.017^{* * *}$ \\
\hline & $(0.005)$ & $(0.003)$ & $(0.004)$ & $(0.003)$ \\
\hline \multicolumn{5}{|l|}{ Household level } \\
\hline \multirow[t]{2}{*}{ Size of household } & 0.005 & 0.001 & 0.005 & -0.003 \\
\hline & $(0.007)$ & $(0.005)$ & $(0.007)$ & $(0.007)$ \\
\hline \multirow[t]{2}{*}{ Land ownership } & $-0.148^{* * *}$ & -0.027 & $-0.215^{* * *}$ & $-0.096^{*}$ \\
\hline & $(0.051)$ & $(0.028)$ & $(0.040)$ & $(0.049)$ \\
\hline \multirow[t]{2}{*}{ House ownership } & 0.042 & -0.031 & $0.090^{* *}$ & $0.078^{* *}$ \\
\hline & $(0.038)$ & $(0.027)$ & $(0.036)$ & $(0.034)$ \\
\hline \multirow{2}{*}{ Bank account } & -0.092 & 0.049 & $0.107^{* * *}$ & $0.066^{* *}$ \\
\hline & $(0.093)$ & $(0.031)$ & $(0.031)$ & $(0.030)$ \\
\hline \multicolumn{5}{|l|}{ Community level } \\
\hline \multirow[t]{2}{*}{ Urban } & $0.098^{* *}$ & $0.287^{* * *}$ & 0.000 & 0.061 * \\
\hline & $(0.044)$ & $(0.045)$ & $(0.043)$ & $(0.031)$ \\
\hline \multirow[t]{2}{*}{ Employment availability } & 0.022 & -0.028 & 0.057 & -0.028 \\
\hline & $(0.044)$ & $(0.025)$ & $(0.079)$ & $(0.033)$ \\
\hline \multirow[t]{2}{*}{ Economic situation } & 0.049 & -0.023 & $-0.075 *$ & $0.085^{* * *}$ \\
\hline & $(0.040)$ & $(0.030)$ & $(0.039)$ & $(0.030)$ \\
\hline \multirow[t]{2}{*}{ Migration incidence } & $-0.107^{* *}$ & -0.037 & $-0.216^{* * *}$ & 0.033 \\
\hline & $(0.042)$ & $(0.035)$ & $(0.069)$ & $(0.033)$ \\
\hline \multicolumn{5}{|l|}{ Working } \\
\hline \multirow[t]{2}{*}{ Current migrant } & -0.004 & 0.007 & -0.020 & $-0.072^{* * *}$ \\
\hline & $(0.039)$ & $(0.045)$ & $(0.020)$ & $(0.024)$ \\
\hline \multirow[t]{2}{*}{ Return migrant } & -0.027 & 0.011 & 0.003 & 0.030 \\
\hline & $(0.031)$ & $(0.023)$ & $(0.032)$ & $(0.054)$ \\
\hline \multicolumn{5}{|l|}{ Individual level } \\
\hline \multirow[t]{2}{*}{ Age } & $0.054^{* * *}$ & $0.042^{* * *}$ & $0.075^{* * *}$ & $0.070^{* * *}$ \\
\hline & $(0.005)$ & $(0.003)$ & $(0.003)$ & $(0.003)$ \\
\hline \multirow[t]{2}{*}{ Age squared } & $-0.001^{* * *}$ & $-0.001^{* * *}$ & $-0.090^{* * *}$ & $-0.096^{* * *}$ \\
\hline & $(0.000)$ & $(0.000)$ & $(0.004)$ & $(0.004)$ \\
\hline
\end{tabular}




\begin{tabular}{|c|c|c|c|c|}
\hline Household head & $\begin{array}{c}0.170 * * * \\
(0.038)\end{array}$ & $\begin{array}{c}0.240^{* * *} \\
(0.027)\end{array}$ & $\begin{array}{c}0.087^{* *} \\
(0.043)\end{array}$ & $\begin{array}{c}0.262^{* * *} \\
(0.031)\end{array}$ \\
\hline Years of education & $\begin{array}{c}-0.019^{* * *} \\
(0.002)\end{array}$ & $\begin{array}{c}-0.015^{* * *} \\
(0.002)\end{array}$ & $\begin{array}{c}-0.007^{* * *} \\
(0.002)\end{array}$ & $\begin{array}{c}-0.009^{* * *} \\
(0.002)\end{array}$ \\
\hline Married & $\begin{array}{c}0.117^{* * *} \\
(0.036)\end{array}$ & $\begin{array}{c}0.075^{* * *} \\
(0.027)\end{array}$ & $\begin{array}{c}0.109^{* * *} \\
(0.038)\end{array}$ & $\begin{array}{l}0.058 * \\
(0.030)\end{array}$ \\
\hline Number of children & $\begin{array}{c}0.013 \\
(0.008)\end{array}$ & $\begin{array}{c}0.002 \\
(0.006)\end{array}$ & $\begin{array}{c}0.002 \\
(0.009)\end{array}$ & $\begin{array}{l}-0.029 * \\
(0.015)\end{array}$ \\
\hline \multicolumn{5}{|l|}{ Household level } \\
\hline Size of household & $\begin{array}{l}-0.010 * \\
(0.006)\end{array}$ & $\begin{array}{c}-0.005 \\
(0.004)\end{array}$ & $\begin{array}{l}-0.007 \\
(0.006)\end{array}$ & $\begin{array}{c}0.008 \\
(0.007)\end{array}$ \\
\hline Land ownership & $\begin{array}{c}0.036 \\
(0.026)\end{array}$ & $\begin{array}{c}0.072^{* * *} \\
(0.016)\end{array}$ & $\begin{array}{c}0.044 \\
(0.027)\end{array}$ & $\begin{array}{c}0.095^{* * *} \\
(0.030)\end{array}$ \\
\hline House ownership & $\begin{array}{c}0.039 \\
(0.027)\end{array}$ & $\begin{array}{c}0.027 \\
(0.018)\end{array}$ & $\begin{array}{l}-0.013 \\
(0.025)\end{array}$ & $\begin{array}{c}0.007 \\
(0.027)\end{array}$ \\
\hline Bank account & $\begin{array}{c}0.007 \\
(0.062)\end{array}$ & $\begin{array}{c}0.000 \\
(0.017)\end{array}$ & $\begin{array}{c}0.022 \\
(0.021)\end{array}$ & $\begin{array}{c}-0.038 \text { * } \\
(0.022)\end{array}$ \\
\hline \multicolumn{5}{|l|}{ Community level } \\
\hline Urban & $\begin{array}{c}-0.037 \\
(0.024)\end{array}$ & $\begin{array}{c}-0.066^{* * *} \\
(0.018)\end{array}$ & $\begin{array}{c}-0.063^{* *} \\
(0.029)\end{array}$ & $\begin{array}{l}-0.019 \\
(0.024)\end{array}$ \\
\hline Employment availability & $\begin{array}{l}-0.040 \\
(0.029)\end{array}$ & $\begin{array}{c}0.003 \\
(0.015)\end{array}$ & $\begin{array}{c}0.091^{* *} \\
(0.041)\end{array}$ & $\begin{array}{c}-0.061^{* *} \\
(0.026)\end{array}$ \\
\hline Economic situation & $\begin{array}{c}0.065^{* *} \\
(0.028)\end{array}$ & $\begin{array}{c}-0.008 \\
(0.018)\end{array}$ & $\begin{array}{c}0.105^{* * *} \\
(0.022)\end{array}$ & $\begin{array}{l}-0.019 \\
(0.021)\end{array}$ \\
\hline Migration incidence & $\begin{array}{c}-0.010 \\
(0.026)\end{array}$ & $\begin{array}{c}-0.018 \\
(0.019)\end{array}$ & $\begin{array}{c}-0.070 * \\
(0.036)\end{array}$ & $\begin{array}{l}-0.030 \\
(0.024)\end{array}$ \\
\hline $\mathrm{N}$ & 1,394 & 2,709 & 1,762 & 2,064 \\
\hline Uncensored $\mathrm{N}$ & 741 & 1,592 & 1,023 & 1,365 \\
\hline rho & 0.46 & -0.20 & -0.36 & 0.45 \\
\hline $\begin{array}{l}\text { LR test of indep. eqns } \\
(\mathrm{rho}=0) \text { : chi2(1) }\end{array}$ & 1.15 & 0.41 & 1.23 & 1.02 \\
\hline
\end{tabular}

Note: Average marginal effects are reported with standard errors in parentheses. ${ }^{* * *} \mathrm{p}<0.01,{ }^{* *} \mathrm{p}<0.05,{ }^{*} \mathrm{p}<0.1$. 
Table C. 6: Binomial Probit with Sample Selection Model Estimations - Urban

\begin{tabular}{|c|c|c|c|c|}
\hline & (1) & (2) & (3) & (4) \\
\hline & AFG & BUR & ETH & MOR \\
\hline \multicolumn{5}{|l|}{ Self-Employment } \\
\hline \multirow[t]{2}{*}{ Current migrant } & 0.058 & 0.103 & -0.013 & $0.149^{* * *}$ \\
\hline & $(0.084)$ & $(0.126)$ & $(0.041)$ & $(0.057)$ \\
\hline \multirow[t]{2}{*}{ Return migrant } & 0.003 & -0.018 & 0.030 & $0.187^{* *}$ \\
\hline & $(0.045)$ & $(0.058)$ & $(0.055)$ & $(0.077)$ \\
\hline \multicolumn{5}{|l|}{ Individual level } \\
\hline \multirow[t]{2}{*}{ Female } & $-0.259^{* * *}$ & $-0.083^{* *}$ & $0.159^{* * *}$ & $-0.140^{* *}$ \\
\hline & $(0.044)$ & $(0.039)$ & $(0.044)$ & $(0.071)$ \\
\hline \multirow[t]{2}{*}{ Age } & 0.008 & $0.029 * * *$ & -0.019 & 0.007 \\
\hline & $(0.013)$ & $(0.011)$ & $(0.033)$ & $(0.014)$ \\
\hline \multirow[t]{2}{*}{ Age squared } & -0.000 & $-0.000^{* * *}$ & 0.022 & -0.011 \\
\hline & $(0.000)$ & $(0.000)$ & $(0.040)$ & $(0.018)$ \\
\hline \multirow[t]{2}{*}{ Household head } & $0.082^{* *}$ & -0.019 & 0.060 & 0.051 \\
\hline & $(0.041)$ & $(0.055)$ & $(0.107)$ & $(0.056)$ \\
\hline \multirow[t]{2}{*}{ Years of education } & -0.006 & $-0.013^{* * *}$ & $-0.031^{* * *}$ & $-0.020 * * *$ \\
\hline & $(0.005)$ & $(0.004)$ & $(0.005)$ & $(0.006)$ \\
\hline \multicolumn{5}{|l|}{ Household level } \\
\hline \multirow[t]{2}{*}{ Size of household } & 0.002 & 0.007 & -0.011 & -0.007 \\
\hline & $(0.007)$ & $(0.007)$ & $(0.010)$ & $(0.009)$ \\
\hline \multirow[t]{2}{*}{ Land ownership } & -0.074 & -0.025 & -0.162 & $-0.112 *$ \\
\hline & $(0.066)$ & $(0.037)$ & $(0.107)$ & $(0.060)$ \\
\hline \multirow[t]{2}{*}{ House ownership } & 0.021 & -0.018 & $0.162^{* * *}$ & $0.066^{*}$ \\
\hline & $(0.031)$ & $(0.031)$ & $(0.062)$ & $(0.037)$ \\
\hline \multirow[t]{2}{*}{ Bank account } & 0.049 & -0.043 & $0.071^{*}$ & 0.031 \\
\hline & $(0.095)$ & $(0.038)$ & $(0.042)$ & $(0.031)$ \\
\hline \multicolumn{5}{|l|}{ Community level } \\
\hline \multirow[t]{2}{*}{ Employment availability } & -0.002 & 0.012 & $-0.208^{* * *}$ & -0.021 \\
\hline & $(0.054)$ & $(0.033)$ & $(0.062)$ & $(0.039)$ \\
\hline \multirow[t]{2}{*}{ Economic situation } & 0.077 & $-0.097^{*}$ & -0.044 & $0.096^{* * *}$ \\
\hline & $(0.049)$ & $(0.051)$ & $(0.039)$ & $(0.036)$ \\
\hline \multirow[t]{2}{*}{ Migration incidence } & -0.015 & -0.020 & 0.000 & 0.032 \\
\hline & $(0.032)$ & $(0.046)$ & $(0.000)$ & $(0.038)$ \\
\hline \multicolumn{5}{|l|}{ Working } \\
\hline \multirow[t]{2}{*}{ Current migrant } & -0.007 & -0.041 & -0.021 & $-0.056^{* * *}$ \\
\hline & $(0.036)$ & $(0.059)$ & $(0.025)$ & $(0.019)$ \\
\hline \multirow[t]{2}{*}{ Return migrant } & 0.002 & 0.050 * & 0.001 & 0.037 \\
\hline & $(0.024)$ & $(0.029)$ & $(0.035)$ & $(0.034)$ \\
\hline \multicolumn{5}{|l|}{ Individual level } \\
\hline \multirow[t]{2}{*}{ Female } & $-0.260 * * *$ & 0.015 & $-0.140^{* * *}$ & $-0.276^{* * *}$ \\
\hline & $(0.032)$ & $(0.023)$ & $(0.029)$ & $(0.014)$ \\
\hline \multirow[t]{2}{*}{ Age } & $0.032 * * *$ & $0.058^{* * *}$ & $0.071^{* * *}$ & $0.057^{* * *}$ \\
\hline & $(0.004)$ & $(0.004)$ & $(0.004)$ & $(0.003)$ \\
\hline
\end{tabular}




\begin{tabular}{|c|c|c|c|c|}
\hline Age squared & $\begin{array}{c}-0.000^{* * *} \\
(0.000)\end{array}$ & $\begin{array}{c}-0.001^{* * *} \\
(0.000)\end{array}$ & $\begin{array}{c}-0.088^{* * *} \\
(0.006)\end{array}$ & $\begin{array}{c}-0.074^{* * *} \\
(0.004)\end{array}$ \\
\hline Household head & $\begin{array}{c}0.149^{* * *} \\
(0.028)\end{array}$ & $\begin{array}{c}0.209^{* * *} \\
(0.023)\end{array}$ & $\begin{array}{c}0.177^{* * *} \\
(0.036)\end{array}$ & $\begin{array}{c}0.272^{* * *} \\
(0.019)\end{array}$ \\
\hline Years of education & $\begin{array}{c}0.000 \\
(0.002)\end{array}$ & $\begin{array}{c}-0.004 * \\
(0.002)\end{array}$ & $\begin{array}{c}0.014^{* * *} \\
(0.003)\end{array}$ & $\begin{array}{c}0.007^{* * *} \\
(0.001)\end{array}$ \\
\hline Married & $\begin{array}{c}0.023 \\
(0.024)\end{array}$ & $\begin{array}{c}0.179 * * * \\
(0.019)\end{array}$ & $\begin{array}{c}0.061 * * \\
(0.031)\end{array}$ & $\begin{array}{c}-0.047^{* * *} \\
(0.017)\end{array}$ \\
\hline Number of children & $\begin{array}{c}0.007 \\
(0.007)\end{array}$ & $\begin{array}{c}0.004 \\
(0.009)\end{array}$ & $\begin{array}{c}0.000 \\
(0.017)\end{array}$ & $\begin{array}{l}-0.011 \\
(0.015)\end{array}$ \\
\hline Female * children & $\begin{array}{c}-0.036^{* * *} \\
(0.011)\end{array}$ & $\begin{array}{c}-0.020^{* *} \\
(0.010)\end{array}$ & $\begin{array}{c}-0.037^{*} \\
(0.022)\end{array}$ & $\begin{array}{l}-0.029 \\
(0.020)\end{array}$ \\
\hline \multicolumn{5}{|l|}{ Household level } \\
\hline Size of household & $\begin{array}{c}-0.007^{*} \\
(0.004)\end{array}$ & $\begin{array}{l}-0.005 \\
(0.005)\end{array}$ & $\begin{array}{c}0.003 \\
(0.007)\end{array}$ & $\begin{array}{c}0.007 \\
(0.005)\end{array}$ \\
\hline Land ownership & $\begin{array}{c}0.003 \\
(0.022)\end{array}$ & $\begin{array}{c}0.107^{* * *} \\
(0.019)\end{array}$ & $\begin{array}{c}-0.012 \\
(0.046)\end{array}$ & $\begin{array}{c}0.028 \\
(0.026)\end{array}$ \\
\hline House ownership & $\begin{array}{c}0.019 \\
(0.018)\end{array}$ & $\begin{array}{c}0.047^{* * *} \\
(0.018)\end{array}$ & $\begin{array}{c}-0.032 \\
(0.026)\end{array}$ & $\begin{array}{l}-0.002 \\
(0.019)\end{array}$ \\
\hline Bank account & $\begin{array}{l}-0.009 \\
(0.046)\end{array}$ & $\begin{array}{l}-0.025 \\
(0.020)\end{array}$ & $\begin{array}{l}-0.008 \\
(0.024)\end{array}$ & $\begin{array}{l}-0.007 \\
(0.016)\end{array}$ \\
\hline \multicolumn{5}{|l|}{ Community level } \\
\hline Employment availability & $\begin{array}{c}-0.069^{* * *} \\
(0.025)\end{array}$ & $\begin{array}{c}-0.004 \\
(0.019)\end{array}$ & $\begin{array}{c}0.055^{* *} \\
(0.024)\end{array}$ & $\begin{array}{c}-0.039 * * \\
(0.019)\end{array}$ \\
\hline Economic situation & $\begin{array}{c}0.067^{* * *} \\
(0.025)\end{array}$ & $\begin{array}{c}0.003 \\
(0.026)\end{array}$ & $\begin{array}{l}0.044 \text { * } \\
(0.025)\end{array}$ & $\begin{array}{l}-0.019 \\
(0.015)\end{array}$ \\
\hline Migration incidence & $\begin{array}{c}-0.027 \\
(0.019)\end{array}$ & $\begin{array}{l}-0.013 \\
(0.025) \\
\end{array}$ & $\begin{array}{c}0.000 \\
(0.000) \\
\end{array}$ & $\begin{array}{l}-0.028 \\
(0.018) \\
\end{array}$ \\
\hline $\mathrm{N}$ & 1,591 & 2,237 & 1,420 & 3,169 \\
\hline Uncensored N & 395 & 880 & 607 & 1,938 \\
\hline rho & 0.64 & 0.20 & -0.67 & 0.03 \\
\hline $\begin{array}{l}\text { LR test of indep. eqns } \\
(\mathrm{rho}=0) \text { : chi2(1) }\end{array}$ & 0.78 & 0.68 & 0.99 & 0.01 \\
\hline
\end{tabular}

Note: Average marginal effects are reported with standard errors in parentheses. ${ }^{* * *} \mathrm{p}<0.01,{ }^{* *} \mathrm{p}<0.05,{ }^{*} \mathrm{p}<0.1$. 
Table C. 7: Binomial Probit with Sample Selection Model Estimations - Rural

\begin{tabular}{|c|c|c|c|c|}
\hline & (1) & (2) & (3) & (4) \\
\hline & AFG & BUR & ETH & MOR \\
\hline \multicolumn{5}{|l|}{ Self-Employment } \\
\hline \multirow[t]{2}{*}{ Current migrant } & 0.038 & -0.014 & -0.051 & 0.080 \\
\hline & $(0.076)$ & $(0.039)$ & $(0.032)$ & $(0.087)$ \\
\hline \multirow[t]{2}{*}{ Return migrant } & 0.013 & -0.005 & 0.012 & 0.043 \\
\hline & $(0.078)$ & $(0.018)$ & $(0.058)$ & $(0.121)$ \\
\hline \multicolumn{5}{|l|}{ Individual level } \\
\hline \multirow[t]{2}{*}{ Female } & 0.233 & $-0.050^{* * *}$ & 0.044 & -0.118 \\
\hline & $(0.291)$ & $(0.015)$ & $(0.063)$ & $(0.180)$ \\
\hline \multirow[t]{2}{*}{ Age } & 0.018 & 0.001 & -0.000 & $0.020 *$ \\
\hline & $(0.022)$ & $(0.002)$ & $(0.010)$ & $(0.010)$ \\
\hline \multirow[t]{2}{*}{ Age squared } & -0.000 & -0.000 & -0.005 & -0.021 \\
\hline & $(0.000)$ & $(0.000)$ & $(0.012)$ & $(0.014)$ \\
\hline \multirow[t]{2}{*}{ Household head } & -0.090 & -0.000 & 0.002 & 0.056 \\
\hline & $(0.088)$ & $(0.013)$ & $(0.048)$ & $(0.073)$ \\
\hline \multirow[t]{2}{*}{ Years of education } & -0.003 & 0.000 & $-0.008^{* *}$ & -0.003 \\
\hline & $(0.010)$ & $(0.001)$ & $(0.004)$ & $(0.005)$ \\
\hline \multicolumn{5}{|l|}{ Household level } \\
\hline \multirow[t]{2}{*}{ Size of household } & 0.003 & 0.002 & -0.000 & -0.001 \\
\hline & $(0.010)$ & $(0.002)$ & $(0.006)$ & $(0.011)$ \\
\hline \multirow[t]{2}{*}{ Land ownership } & $-0.194^{* * *}$ & -0.013 & $-0.106^{* * *}$ & -0.164 \\
\hline & $(0.061)$ & $(0.010)$ & $(0.040)$ & $(0.133)$ \\
\hline \multirow[t]{2}{*}{ House ownership } & 0.012 & $-0.059^{* * *}$ & -0.040 & 0.064 \\
\hline & $(0.065)$ & $(0.016)$ & $(0.036)$ & $(0.083)$ \\
\hline \multirow[t]{2}{*}{ Bank account } & $-0.249 *$ & $0.042^{* * *}$ & $0.167^{* * *}$ & 0.095 \\
\hline & $(0.146)$ & $(0.013)$ & $(0.044)$ & $(0.067)$ \\
\hline \multicolumn{5}{|l|}{ Community level } \\
\hline \multirow[t]{2}{*}{ Employment availability } & 0.006 & $-0.022 *$ & 0.090 & -0.004 \\
\hline & $(0.056)$ & $(0.013)$ & $(0.065)$ & $(0.060)$ \\
\hline \multirow[t]{2}{*}{ Economic situation } & 0.017 & -0.002 & $-0.179^{* * *}$ & 0.061 \\
\hline & $(0.055)$ & $(0.011)$ & $(0.066)$ & $(0.066)$ \\
\hline \multirow[t]{2}{*}{ Migration incidence } & $-0.181^{* *}$ & $-0.040^{* *}$ & -0.040 & 0.000 \\
\hline & $(0.071)$ & $(0.018)$ & $(0.063)$ & $(0.000)$ \\
\hline \multicolumn{5}{|l|}{ Working } \\
\hline \multirow[t]{2}{*}{ Current migrant } & $0.039 *$ & $0.074^{*}$ & $-0.044^{* *}$ & -0.045 \\
\hline & $(0.022)$ & $(0.040)$ & $(0.018)$ & $(0.028)$ \\
\hline \multirow[t]{2}{*}{ Return migrant } & $-0.046^{* *}$ & 0.004 & -0.039 & $0.112^{*}$ \\
\hline & $(0.019)$ & $(0.018)$ & $(0.031)$ & $(0.062)$ \\
\hline \multicolumn{5}{|l|}{ Individual level } \\
\hline \multirow[t]{2}{*}{ Female } & $-0.287^{* * *}$ & 0.023 & $-0.238^{* * *}$ & $-0.356^{* * *}$ \\
\hline & $(0.030)$ & $(0.017)$ & $(0.022)$ & $(0.024)$ \\
\hline \multirow[t]{2}{*}{ Age } & $0.026^{* * *}$ & $0.041^{* * *}$ & $0.051^{* * *}$ & $0.038^{* * *}$ \\
\hline & $(0.004)$ & $(0.003)$ & $(0.004)$ & $(0.005)$ \\
\hline
\end{tabular}




\begin{tabular}{|c|c|c|c|c|}
\hline Age squared & $\begin{array}{c}-0.000 * * * \\
(0.000)\end{array}$ & $\begin{array}{c}-0.000^{* * *} \\
(0.000)\end{array}$ & $\begin{array}{c}-0.063^{* * *} \\
(0.005)\end{array}$ & $\begin{array}{c}-0.052^{* * *} \\
(0.006)\end{array}$ \\
\hline Household head & $\begin{array}{c}0.165^{* * *} \\
(0.026)\end{array}$ & $\begin{array}{c}0.063^{* * *} \\
(0.019)\end{array}$ & $\begin{array}{c}0.276^{* * *} \\
(0.024)\end{array}$ & $\begin{array}{c}0.257^{* * *} \\
(0.038)\end{array}$ \\
\hline Years of education & $\begin{array}{c}-0.012^{* * *} \\
(0.002)\end{array}$ & $\begin{array}{c}-0.025^{* * *} \\
(0.001)\end{array}$ & $\begin{array}{c}0.005^{* *} \\
(0.002)\end{array}$ & $\begin{array}{c}-0.005 * \\
(0.003)\end{array}$ \\
\hline Married & $\begin{array}{l}-0.011 \\
(0.022)\end{array}$ & $\begin{array}{c}0.145^{* * *} \\
(0.015)\end{array}$ & $\begin{array}{c}0.033 \\
(0.022)\end{array}$ & $\begin{array}{c}-0.090^{* * *} \\
(0.033)\end{array}$ \\
\hline Number of children & $\begin{array}{c}0.015^{* *} \\
(0.007)\end{array}$ & $\begin{array}{c}0.013^{* *} \\
(0.006)\end{array}$ & $\begin{array}{c}0.004 \\
(0.008)\end{array}$ & $\begin{array}{l}-0.009 \\
(0.017)\end{array}$ \\
\hline Female ${ }^{*}$ children & $\begin{array}{c}-0.027^{* * *} \\
(0.010)\end{array}$ & $\begin{array}{l}-0.000 \\
(0.006)\end{array}$ & $\begin{array}{c}-0.032^{* * *} \\
(0.010)\end{array}$ & $\begin{array}{l}-0.035 \\
(0.027)\end{array}$ \\
\hline \multicolumn{5}{|l|}{ Household level } \\
\hline Size of household & $\begin{array}{c}-0.003 \\
(0.004)\end{array}$ & $\begin{array}{c}-0.015^{* * *} \\
(0.004)\end{array}$ & $\begin{array}{l}-0.004 \\
(0.005)\end{array}$ & $\begin{array}{c}0.008 \\
(0.007)\end{array}$ \\
\hline Land ownership & $\begin{array}{l}0.029 * \\
(0.017)\end{array}$ & $\begin{array}{c}0.047^{* * *} \\
(0.014)\end{array}$ & $\begin{array}{c}0.045^{* *} \\
(0.022)\end{array}$ & $\begin{array}{c}0.070^{* *} \\
(0.029)\end{array}$ \\
\hline House ownership & $\begin{array}{c}0.007 \\
(0.021)\end{array}$ & $\begin{array}{c}0.060 * * * \\
(0.019)\end{array}$ & $\begin{array}{c}-0.106^{* * *} \\
(0.027)\end{array}$ & $\begin{array}{c}0.010 \\
(0.042)\end{array}$ \\
\hline Bank account & $\begin{array}{c}0.004 \\
(0.044)\end{array}$ & $\begin{array}{c}0.026 \\
(0.017)\end{array}$ & $\begin{array}{l}-0.012 \\
(0.021)\end{array}$ & $\begin{array}{c}0.009 \\
(0.026)\end{array}$ \\
\hline Community level & & & & \\
\hline Employment availability & $\begin{array}{c}0.014 \\
(0.019)\end{array}$ & $\begin{array}{l}-0.006 \\
(0.014)\end{array}$ & $\begin{array}{c}0.085 * * \\
(0.034)\end{array}$ & $\begin{array}{l}-0.046 \\
(0.033)\end{array}$ \\
\hline Economic situation & $\begin{array}{l}-0.005 \\
(0.019)\end{array}$ & $\begin{array}{l}-0.003 \\
(0.015)\end{array}$ & $\begin{array}{c}0.058^{* *} \\
(0.026)\end{array}$ & $\begin{array}{c}0.000 \\
(0.031)\end{array}$ \\
\hline Migration incidence & $\begin{array}{c}0.007 \\
(0.018)\end{array}$ & $\begin{array}{l}-0.008 \\
(0.018)\end{array}$ & $\begin{array}{c}-0.111^{* * *} \\
(0.030)\end{array}$ & $\begin{array}{c}0.000 \\
(0.000)\end{array}$ \\
\hline $\mathrm{N}$ & 1,486 & 3,571 & 2,322 & 939 \\
\hline Uncensored N & $\begin{array}{l}389 \\
0.02\end{array}$ & 2,514 & 919 & $\begin{array}{l}367 \\
019\end{array}$ \\
\hline $\begin{array}{l}\text { LR test of indep. eqns } \\
(\mathrm{rho}=0) \text { : chi2 }(1)\end{array}$ & 0.00 & 0.66 & 0.12 & 0.07 \\
\hline
\end{tabular}

Note: Average marginal effects are reported with standard errors in parentheses. ${ }^{* * *} \mathrm{p}<0.01,{ }^{* *} \mathrm{p}<0.05,{ }^{*} \mathrm{p}<0.1$. 




\section{APPENDIX D: LABOUR MARKET REINTEGRATION OF RETURNED REFUGEES IN AFGHANISTAN}





\section{Table D. 1: Operationalization of Variables}

\begin{tabular}{|c|c|}
\hline Variable & Description \\
\hline Returned Refugee & 1 if the individual is a returned refugee \\
\hline Head of $\mathrm{HH}$ & 1 if the individual is the household head \\
\hline Age & In years $(15-65)$ \\
\hline Married & 1 if the individual is married \\
\hline Number of Children & Number of children in the household of the individual \\
\hline $\begin{array}{l}\text { Educational Attainment: } \\
\text { Secondary or higher }\end{array}$ & 1 if the individual has at least secondary education \\
\hline HH Owns Land & 1 if the individual's household owns land \\
\hline Social Network & 1 if the individual is active in a community organization \\
\hline Ethnicity & $\begin{array}{l}1 \text { if individual is Pashtun; } 2 \text { if individual is Tajik; } 3 \text { if } \\
\text { individual has an "Other" ethnicity }\end{array}$ \\
\hline District Type & $\begin{array}{l}1 \text { if district type is urban; } 2 \text { if district type is semi-rural; } 3 \text { if } \\
\text { district type is rural }\end{array}$ \\
\hline Province & $\begin{array}{l}1 \text { if province is Kabul; } 2 \text { if province is Herat; } 3 \text { if province is } \\
\text { Balkh; } 4 \text { if province is Nangarhar; } 5 \text { if province is Kandahar }\end{array}$ \\
\hline \multicolumn{2}{|l|}{ Returned Refugees only } \\
\hline Employed pre-migration & $\begin{array}{l}1 \text { if the returned refugee was employed before moving } \\
\text { abroad }\end{array}$ \\
\hline Migration duration & In years \\
\hline Migration destination: Iran & $\begin{array}{l}1 \text { if the migration destination was Iran; } 0 \text { if the migration } \\
\text { destination was Pakistan }\end{array}$ \\
\hline Remittances sent & 1 if the returned refugee sent remittances while abroad \\
\hline Return period: $2002-2011$ & $\begin{array}{l}1 \text { if the refugee returned between } 2002 \text { and 2011; } 0 \text { if the } \\
\text { refugee returned between } 1992 \text { and } 2001\end{array}$ \\
\hline Time since returned & In years \\
\hline Return reason: political/security & $\begin{array}{l}1 \text { if the refugee returned for reasons related to the political } \\
\text { and security situation; } 0 \text { if the refugee returned for personal } \\
\text { or family reasons }\end{array}$ \\
\hline Return savings & $\begin{array}{l}\text { Amount of savings returnee brought with him upon return } \\
\text { expressed as log of USD }\end{array}$ \\
\hline Return assistance & 1 if the returned refugee received return assistance \\
\hline Re-migration intentions & $\begin{array}{l}1 \text { if the returned refugee expressed the intention to migrate } \\
\text { again in the future }\end{array}$ \\
\hline
\end{tabular}


Table D. 2: Labour Market Activity - Full Model (Multinomial logit estimates)

\begin{tabular}{|c|c|c|c|}
\hline & Self-employment & Agriculture & Wage Employment \\
\hline \multirow[t]{2}{*}{ Returned Refugee } & $0.7093 *$ & $0.5800 * *$ & $0.4169^{* * *}$ \\
\hline & $(-0.1417)$ & -0.1515 & -0.0913 \\
\hline \multirow[t]{2}{*}{ Head of HH } & $4.6679^{* * *}$ & $5.1664^{* * *}$ & $4.8012^{* * *}$ \\
\hline & -1.1397 & -1.6244 & -1.2508 \\
\hline \multirow[t]{2}{*}{ Age } & $0.9438^{* * *}$ & $0.9634^{* * *}$ & $0.9484^{* * *}$ \\
\hline & -0.0073 & -0.0092 & -0.0079 \\
\hline \multirow[t]{2}{*}{ Married } & $3.1273^{* * *}$ & $3.0185^{* * *}$ & $2.3338^{* * *}$ \\
\hline & -0.7458 & -0.9691 & -0.5853 \\
\hline \multirow[t]{2}{*}{ Number of Children } & 0.9571 & 0.9949 & 0.9839 \\
\hline & -0.0385 & -0.051 & -0.0421 \\
\hline \multirow[t]{2}{*}{$\begin{array}{l}\text { Educational Attainment: } \\
\text { Secondary or higher }\end{array}$} & $0.6412 * *$ & $0.2429 * * *$ & $2.4956^{* * *}$ \\
\hline & -0.1449 & -0.1071 & -0.5743 \\
\hline \multirow[t]{2}{*}{ HH Owns Land } & 1.053 & $5.0329 * * *$ & 0.9316 \\
\hline & -0.2051 & -1.1382 & -0.1926 \\
\hline \multirow[t]{2}{*}{ Social Network } & $2.2726^{* * *}$ & $2.6145^{* * *}$ & $2.1635^{* * *}$ \\
\hline & -0.3962 & -0.6345 & -0.3945 \\
\hline \multicolumn{4}{|l|}{ Ethnicity (Reference: Other) } \\
\hline \multirow[t]{2}{*}{ Pashtun } & 1.1576 & 0.9399 & 1.3958 \\
\hline & -0.3437 & -0.3963 & -0.5054 \\
\hline \multirow[t]{2}{*}{ Tajik } & 1.1966 & 0.5675 & 1.0294 \\
\hline & -0.2975 & -0.1999 & -0.3349 \\
\hline \multicolumn{4}{|c|}{ District Type (Reference: Rural) } \\
\hline \multirow[t]{2}{*}{ Urban } & $1.8858^{* * *}$ & $0.1150^{* * *}$ & 1.0449 \\
\hline & -0.3457 & -0.0326 & -0.2076 \\
\hline \multirow[t]{2}{*}{ Semi-rural } & $1.9234^{* * *}$ & 1.1073 & $1.7753^{* *}$ \\
\hline & -0.4348 & -0.2786 & -0.4305 \\
\hline \multicolumn{4}{|c|}{ Province (Reference: Kandahar) } \\
\hline \multirow[t]{2}{*}{ Kabul } & 1.1795 & $0.3638^{* * *}$ & $0.3799^{* * *}$ \\
\hline & -0.3033 & -0.128 & -0.0973 \\
\hline \multirow[t]{2}{*}{ Herat } & $15.5413^{* * *}$ & $11.6802^{* * *}$ & 1.1271 \\
\hline & -5.7422 & -4.9929 & -0.4476 \\
\hline \multirow[t]{2}{*}{ Balkh } & $2.4969 * * *$ & 0.8964 & $0.1685^{* * *}$ \\
\hline & -0.736 & -0.3675 & -0.0566 \\
\hline \multirow[t]{2}{*}{ Nangarhar } & $2.5496^{* * *}$ & 0.7166 & $0.3901^{* * *}$ \\
\hline & -0.623 & -0.2353 & -0.0991 \\
\hline Pseudo-R2 & 0.2080 & & \\
\hline $\mathrm{N}$ & 1,841 & & \\
\hline
\end{tabular}

Note: Significance Levels: ${ }^{*} \mathrm{p}<0.10,{ }^{* *} \mathrm{p}<0.05,{ }^{* * *} \mathrm{p}<0.01$. Relative risk ratios are reported, with robust standard errors in parentheses. The base category for the labour market activity is 'Not Working'. The reference group for Educational Attainment is 'Lower than secondary'. 
Table D. 3: Labour Market Activity, Comparing Non-migrants to Returned Refugees - Full Models (Multinomial logit estimates)

\begin{tabular}{|c|c|c|c|c|c|c|}
\hline \multirow[b]{2}{*}{ Base: Not working } & \multicolumn{3}{|c|}{ Non-migrant } & \multicolumn{3}{|c|}{ Returned refugee } \\
\hline & $\begin{array}{c}\text { Self- } \\
\text { employ. }\end{array}$ & Agric. & $\begin{array}{c}\text { Wage } \\
\text { employ. }\end{array}$ & $\begin{array}{c}\text { Self- } \\
\text { employ. }\end{array}$ & Agric. & $\begin{array}{c}\text { Wage } \\
\text { employ. }\end{array}$ \\
\hline \multirow[t]{2}{*}{ Head of $\mathrm{HH}$} & $4.4075^{* * *}$ & $5.3701^{* * *}$ & $4.7482 * * *$ & $4.8621 * *$ & 3.6079 & $5.7055^{* *}$ \\
\hline & -1.0821 & -1.7967 & -1.2748 & -3.0015 & -2.8974 & -4.8777 \\
\hline \multirow[t]{2}{*}{ Age } & $0.9464^{* * *}$ & $0.9617^{* * *}$ & $0.9478^{* * *}$ & $0.9381^{* * *}$ & $0.9634^{*}$ & $0.9501 * * *$ \\
\hline & -0.0087 & -0.0111 & -0.0094 & -0.015 & -0.0188 & -0.0167 \\
\hline \multirow[t]{2}{*}{ Married } & $3.3443^{* * *}$ & $3.1959^{* * *}$ & $2.5051^{* * *}$ & 2.7105 & 2.7101 & 1.9905 \\
\hline & -0.8405 & -1.1225 & -0.657 & -1.9118 & -2.535 & -1.7207 \\
\hline \multirow[t]{2}{*}{ Number of children } & $0.9130 * *$ & 0.9906 & 0.9446 & 1.0858 & 1.0204 & 1.1387 \\
\hline & -0.0418 & -0.0604 & -0.0471 & -0.0908 & -0.1072 & -0.1041 \\
\hline \multirow[t]{2}{*}{ Education: secondary or higher } & $0.6148 *$ & $0.2753 * *$ & $2.8348^{* * *}$ & 0.8992 & $0.1652^{* *}$ & 2.2920 \\
\hline & -0.1721 & -0.1707 & -0.8252 & -0.3872 & -0.1254 & -1.0599 \\
\hline \multirow[t]{2}{*}{ HH owns land } & 0.9018 & $3.9817^{* * *}$ & 0.9534 & 1.7468 & $11.3484^{* * *}$ & 0.855 \\
\hline & -0.2044 & -1.03 & -0.2276 & -0.7893 & -5.8669 & -0.4509 \\
\hline \multirow[t]{2}{*}{ Social network } & $2.3039 * * *$ & $2.6049^{* * *}$ & $2.0563^{* * *}$ & $2.9124^{* * *}$ & $3.3171^{* *}$ & $2.8980 * * *$ \\
\hline & -0.4655 & -0.7477 & -0.433 & -1.112 & -1.9121 & -1.1689 \\
\hline \multicolumn{7}{|l|}{ Ethnicity (Reference: Other) } \\
\hline \multirow[t]{2}{*}{ Pashtun } & 1.1995 & 0.852 & 1.5266 & 1.4496 & 1.1891 & 1.4345 \\
\hline & -0.4044 & -0.3902 & -0.6166 & -1.0884 & -1.1752 & -1.1748 \\
\hline \multirow[t]{2}{*}{ Tajik } & 1.2505 & 0.5743 & 1.043 & 1.4373 & 0.5452 & 1.3503 \\
\hline & -0.3364 & -0.2131 & -0.3658 & -1.0142 & -0.5042 & -1.0597 \\
\hline \multicolumn{7}{|l|}{ District Type (Reference: Rural) } \\
\hline \multirow[t]{2}{*}{ Urban } & $1.6875^{* *}$ & $0.0909^{* * *}$ & 0.8424 & $2.4384^{* *}$ & $0.2782 * *$ & 1.7666 \\
\hline & -0.3661 & -0.029 & -0.2029 & -1.0331 & -0.1727 & -0.8238 \\
\hline \multirow[t]{2}{*}{ Semi-rural } & $2.0955^{* * *}$ & 1.0747 & $1.6282 *$ & 1.241 & 1.3191 & 1.8967 \\
\hline & -0.5738 & -0.3165 & -0.4802 & -0.5649 & -0.6721 & -0.9214 \\
\hline \multicolumn{7}{|l|}{ Province (Reference: Kandahar) } \\
\hline \multirow[t]{2}{*}{ Kabul } & 1.2779 & $0.3268^{* * *}$ & $0.3532 * * *$ & 1.0736 & 0.3791 & 0.5153 \\
\hline & -0.3912 & -0.1344 & -0.1056 & -0.5336 & -0.2537 & -0.2662 \\
\hline \multirow[t]{2}{*}{ Herat } & $16.9165^{* * *}$ & $9.9857^{* * *}$ & 1.0899 & $15.5168^{* * *}$ & $11.3550 * *$ & 1.3483 \\
\hline & -6.8433 & -4.6457 & -0.4694 & -14.1821 & -12.4871 & -1.3575 \\
\hline \multirow[t]{2}{*}{ Balkh } & $2.3139 * *$ & 0.6416 & $0.1461^{* * *}$ & $7.0915^{* *}$ & 2.9061 & 0.5485 \\
\hline & -0.7775 & -0.2857 & -0.0554 & -6.2639 & -3.2103 & -0.5383 \\
\hline \multirow[t]{2}{*}{ Nangarhar } & $3.5205^{* * *}$ & 0.5086 & $0.3873^{* * *}$ & 1.5034 & 1.0015 & 0.5107 \\
\hline & -1.0473 & -0.235 & -0.1257 & -0.6407 & -0.5338 & -0.2378 \\
\hline Pseudo-R ${ }^{2}$ & 0.2177 & & & 0.2118 & & \\
\hline $\mathrm{N}$ & 1,380 & & & 461 & & \\
\hline
\end{tabular}

Note: Significance levels: ${ }^{*} \mathrm{p}<0.10,{ }^{* *} \mathrm{p}<0.05,{ }^{* * *} \mathrm{p}<0.01$. Relative risk ratios are reported, with robust standard errors in parentheses. 
Table D. 4: Labour Market Activity of Returnees - Full Model (Multinomial logit estimates)

\begin{tabular}{|c|c|c|c|}
\hline Base: Not working & Self-employment & Agriculture & Wage employment \\
\hline \multirow[t]{2}{*}{ Head of $\mathrm{HH}$} & $4.6167^{* *}$ & 5.9601 & $6.8055^{* *}$ \\
\hline & -2.9092 & -7.2036 & -6.2497 \\
\hline \multirow[t]{2}{*}{ Age } & $0.9377^{* * *}$ & 0.9687 & $0.9401 * * *$ \\
\hline & -0.0162 & -0.0228 & -0.0177 \\
\hline \multirow[t]{2}{*}{ Married } & 3.3634 & 1.8144 & 2.4886 \\
\hline & -2.497 & -2.2175 & -2.3804 \\
\hline \multirow[t]{2}{*}{ Number of children } & 1.071 & 1.0477 & 1.137 \\
\hline & -0.0952 & -0.1246 & -0.1072 \\
\hline \multirow[t]{2}{*}{ Education: secondary or higher } & 0.7923 & $0.1267^{* *}$ & $2.3410 *$ \\
\hline & -0.3493 & -0.1061 & -1.1374 \\
\hline \multirow[t]{2}{*}{ HH owns land } & 1.7603 & $8.5190^{* * *}$ & 0.8625 \\
\hline & -0.7934 & -4.6091 & -0.4608 \\
\hline \multirow[t]{2}{*}{ Social Network } & $3.0249^{* * *}$ & $3.2202 *$ & $3.0439 * * *$ \\
\hline & -1.2048 & -2.0635 & -1.2922 \\
\hline \multicolumn{4}{|l|}{ Ethnicity (Reference: Other) } \\
\hline \multirow[t]{2}{*}{ Pashtun } & 1.3075 & 1.0682 & 1.1954 \\
\hline & -0.9867 & -1.0707 & -0.9898 \\
\hline \multirow[t]{2}{*}{ Tajik } & 1.4853 & 0.286 & 1.1194 \\
\hline & -1.0779 & -0.2911 & -0.8983 \\
\hline \multicolumn{4}{|l|}{ District Type (Reference: Rural) } \\
\hline \multirow[t]{2}{*}{ Urban } & $2.2879 *$ & $0.2049^{* *}$ & 1.6359 \\
\hline & -1.0514 & -0.1366 & -0.7853 \\
\hline \multirow[t]{2}{*}{ Semi-rural } & 1.2292 & 1.9605 & 1.8088 \\
\hline & -0.6165 & -1.2173 & -0.9437 \\
\hline \multicolumn{4}{|l|}{ Province (Reference: Kandahar) } \\
\hline \multirow[t]{2}{*}{ Kabul } & 1.2613 & 0.1964 * & 0.6422 \\
\hline & -0.7147 & -0.1683 & -0.3766 \\
\hline \multirow[t]{2}{*}{ Herat } & $18.1041^{* * *}$ & 1.7519 & 0.9062 \\
\hline & -18.9889 & -2.5213 & -1.0152 \\
\hline \multirow[t]{2}{*}{ Balkh } & $7.1350 * *$ & 0.6711 & 0.6189 \\
\hline & -6.6494 & -0.9044 & -0.6388 \\
\hline \multirow[t]{2}{*}{ Nangarhar } & 1.4175 & 1.7896 & 0.4803 \\
\hline & -0.6428 & -1.0463 & -0.2375 \\
\hline \multirow[t]{2}{*}{ Employed pre-migration } & 1.0656 & 0.3563 & $2.1744^{* *}$ \\
\hline & -0.4277 & -0.2324 & -0.9228 \\
\hline \multirow[t]{2}{*}{ Migration duration (years) } & 1.0342 & 1.0031 & 1.0479 * \\
\hline & -0.0264 & -0.0389 & -0.0298 \\
\hline \multicolumn{4}{|c|}{ Migration destination (Reference: Pakistan) } \\
\hline \multirow[t]{2}{*}{ Iran } & 0.831 & $10.2048^{* *}$ & 1.7203 \\
\hline & -0.4893 & -10.4416 & -1.019 \\
\hline \multirow[t]{2}{*}{ Remittances sent } & 0.9843 & 1.3304 & 0.1693 \\
\hline & -0.851 & -1.4124 & -0.2071 \\
\hline \multicolumn{4}{|l|}{ Return period (Reference: 1992-2001) } \\
\hline $2002-2011$ & 0.5023 & 1.0911 & 0.9115 \\
\hline & -0.275 & -0.7591 & -0.5451 \\
\hline
\end{tabular}




\begin{tabular}{lccc}
\hline & & & \\
Time since returned (years) & 1.0092 & $1.1223^{*}$ & 1.0449 \\
& -0.056 & -0.0822 & -0.0646 \\
Return reason: political/security & 0.6685 & 0.979 & 0.9114 \\
& -0.2608 & -0.4874 & -0.3816 \\
Return savings (log of USD) & 1.1102 & $1.1884^{*}$ & 0.9854 \\
& -0.0789 & -0.1143 & -0.0778 \\
Return assistance & 0.6446 & $0.3509 * *$ & $0.5031^{*}$ \\
& -0.2323 & -0.18 & -0.2069 \\
Re-migration intentions & 1.803 & $0.2808^{* *}$ & 1.2658 \\
& -0.9119 & -0.2015 & -0.6818 \\
\hline Pseudo-R & 0.2680 & & \\
$\mathrm{~N}$ & 461 & & \\
\hline \hline
\end{tabular}

Note: Significance levels: ${ }^{*} \mathrm{p}<0.10,{ }^{* *} \mathrm{p}<0.05,{ }^{* * *} \mathrm{p}<0.01$. Relative risk ratios are reported, with robust standard errors in parentheses. 



\section{APPENDIX E: DisPlacement AND NON-FARM BUSINESSES - EVIDENCE FROM RURAL BURUNDI}





\section{Table E. 1: Operationalization of Variables}

\begin{tabular}{|c|c|}
\hline Variable & Description \\
\hline Refugee & 1 if there is at least one former refugee in the household \\
\hline IDP & 1 if there is at least one former IDP in the household \\
\hline Female & 1 if household head is female \\
\hline Age & Age of household head in years (16-65) \\
\hline Married & 1 if household head married \\
\hline Primary & 1 if household head has completed primary education \\
\hline Secondary & 1 if household head has completed secondary education \\
\hline Child to adult ratio & $\begin{array}{l}\text { Number of children (younger than } 14 \text { ) divided by number of } \\
\text { adults (14 and older) }\end{array}$ \\
\hline Own house & 1 if household owns the house in which it lives \\
\hline Food shortage & $\begin{array}{l}1 \text { if the household regularly experiences problems satisfying } \\
\text { their food needs }\end{array}$ \\
\hline Self-sufficient & $\begin{array}{l}1 \text { if the household relies on own land for at least half of } \\
\text { consumed food }\end{array}$ \\
\hline Informal network & $\begin{array}{l}1 \text { if household can rely on social network beyond the } \\
\text { household unit in case of a sudden need }\end{array}$ \\
\hline Micro-finance & 1 if the household has access to a micro-finance institution \\
\hline Accessibility of community & 1 if the community is easily accessible via a road \\
\hline Market & Distance to the nearest market in minutes \\
\hline Economic shock & 1 if the community has experienced an economic shock \\
\hline Environmental shock & 1 if the community has experienced an environmental shock \\
\hline
\end{tabular}


Table E. 2: Determinants of Non-Farm Business Activities - Shares of Displaced (Probit estimates)

\begin{tabular}{|c|c|c|c|}
\hline & (1) & $(2)$ & (3) \\
\hline & Refugee $\mathrm{HH}$ & IDP HH & Displaced HH \\
\hline Returnee & $\begin{array}{l}-0.051 \\
(0.042)\end{array}$ & & \\
\hline \multirow[t]{2}{*}{ IDP } & & $\begin{array}{c}0.004 \\
(0.034)\end{array}$ & \\
\hline & & & $\begin{array}{l}-0.007 \\
(0.026)\end{array}$ \\
\hline Female & $\begin{array}{l}-0.018 \\
(0.058)\end{array}$ & $\begin{array}{l}-0.018 \\
(0.059)\end{array}$ & $\begin{array}{l}-0.017 \\
(0.058)\end{array}$ \\
\hline Age & $\begin{array}{l}-0.002 * \\
(0.001)\end{array}$ & $\begin{array}{c}-0.002 * \\
(0.001)\end{array}$ & $\begin{array}{l}-0.002 * \\
(0.001)\end{array}$ \\
\hline Married & $\begin{array}{c}0.087 \\
(0.061)\end{array}$ & $\begin{array}{c}0.087 \\
(0.061)\end{array}$ & $\begin{array}{c}0.087 \\
(0.061)\end{array}$ \\
\hline Primary & $\begin{array}{l}-0.007 \\
(0.027)\end{array}$ & $\begin{array}{l}-0.006 \\
(0.027)\end{array}$ & $\begin{array}{l}-0.006 \\
(0.027)\end{array}$ \\
\hline Secondary & $\begin{array}{c}-0.336 * * * \\
(0.106)\end{array}$ & $\begin{array}{c}-0.335 * * * \\
(0.106)\end{array}$ & $\begin{array}{c}-0.335 * * * \\
(0.107)\end{array}$ \\
\hline Child to adult ratio & $\begin{array}{c}0.032 * * \\
(0.014)\end{array}$ & $\begin{array}{l}0.031 * * \\
(0.014)\end{array}$ & $\begin{array}{l}0.031 * * \\
(0.014)\end{array}$ \\
\hline Own house & $\begin{array}{l}-0.081 \\
(0.051)\end{array}$ & $\begin{array}{l}-0.080 \\
(0.051)\end{array}$ & $\begin{array}{l}-0.080 \\
(0.051)\end{array}$ \\
\hline Self-sufficient & $\begin{array}{c}-0.087 * * * \\
(0.023)\end{array}$ & $\begin{array}{c}-0.086 * * * \\
(0.023)\end{array}$ & $\begin{array}{c}-0.086 * * * \\
(0.024)\end{array}$ \\
\hline Food shortage & $\begin{array}{l}-0.020 \\
(0.024)\end{array}$ & $\begin{array}{l}-0.021 \\
(0.024)\end{array}$ & $\begin{array}{l}-0.021 \\
(0.024)\end{array}$ \\
\hline Informal network & $\begin{array}{l}0.135 * * * \\
(0.024)\end{array}$ & $\begin{array}{c}0.135 * * * \\
(0.024)\end{array}$ & $\begin{array}{c}0.135 * * * \\
(0.024)\end{array}$ \\
\hline \multirow[t]{2}{*}{$\begin{array}{l}\text { Access to micro-finance } \\
\text { institution }\end{array}$} & $0.164 * * *$ & $0.166 * * *$ & $0.166 * * *$ \\
\hline & $(0.035)$ & $(0.035)$ & $(0.035)$ \\
\hline Accessibility of community & $\begin{array}{l}-0.052 * \\
(0.027)\end{array}$ & $\begin{array}{l}-0.053 * \\
(0.027)\end{array}$ & $\begin{array}{c}-0.053 * * \\
(0.027)\end{array}$ \\
\hline Market in community & $\begin{array}{l}-0.000 \\
(0.000)\end{array}$ & $\begin{array}{l}-0.000 \\
(0.000)\end{array}$ & $\begin{array}{l}-0.000 \\
(0.000)\end{array}$ \\
\hline Economic Shock & $\begin{array}{l}-0.060 \\
(0.051)\end{array}$ & $\begin{array}{l}-0.058 \\
(0.053)\end{array}$ & $\begin{array}{l}-0.058 \\
(0.052)\end{array}$ \\
\hline Environmental Shock & $\begin{array}{l}-0.007 \\
(0.050)\end{array}$ & $\begin{array}{l}-0.008 \\
(0.050)\end{array}$ & $\begin{array}{l}-0.008 \\
(0.050)\end{array}$ \\
\hline Observations & 1,390 & 1,390 & 1,390 \\
\hline
\end{tabular}

Notes: ${ }^{* * *} \mathrm{p}<0.01,{ }^{* *} \mathrm{p}<.05,{ }^{*} \mathrm{p}<0.10$. Average marginal effects are reported. Standard errors in parentheses are robust and clustered at the community level. 
Table E. 3: Results - Prior Business Experiences (Probit estimates)

\begin{tabular}{|c|c|c|c|c|}
\hline & $(1)$ & $(2)$ & (3) & $(4)$ \\
\hline & Refugee $\mathrm{HH}$ & IDP HH & Refugee $\mathrm{HH}$ & IDP HH \\
\hline \multicolumn{5}{|l|}{ Prior Business Experiences } \\
\hline Before displacement & $\begin{array}{l}0.263 * * * \\
(0.066)\end{array}$ & $\begin{array}{c}0.034 \\
(0.085)\end{array}$ & & \\
\hline During displacement & & & $\begin{array}{c}0.305 * * * \\
(0.063)\end{array}$ & $\begin{array}{c}-0.004 \\
(0.094)\end{array}$ \\
\hline Female & $\begin{array}{l}-0.049 \\
(0.089)\end{array}$ & $\begin{array}{c}0.144 \\
(0.203)\end{array}$ & $\begin{array}{l}-0.039 \\
(0.090)\end{array}$ & $\begin{array}{c}0.137 \\
(0.190)\end{array}$ \\
\hline Age & $\begin{array}{c}0.001 \\
(0.002)\end{array}$ & $\begin{array}{c}-0.008 * * * \\
(0.003)\end{array}$ & $\begin{array}{c}0.000 \\
(0.002)\end{array}$ & $\begin{array}{c}-0.008 * * * \\
(0.003)\end{array}$ \\
\hline Married & $\begin{array}{c}0.028 \\
(0.109)\end{array}$ & $\begin{array}{c}0.221 \\
(0.227)\end{array}$ & $\begin{array}{c}0.042 \\
(0.112)\end{array}$ & $\begin{array}{c}0.216 \\
(0.216)\end{array}$ \\
\hline Primary & $\begin{array}{c}0.014 \\
(0.073)\end{array}$ & $\begin{array}{c}0.058 \\
(0.061)\end{array}$ & $\begin{array}{c}0.030 \\
(0.075)\end{array}$ & $\begin{array}{c}0.062 \\
(0.060)\end{array}$ \\
\hline Secondary & $\begin{array}{c}0.000 \\
(0.000)\end{array}$ & $\begin{array}{c}0.000 \\
(0.000)\end{array}$ & $\begin{array}{c}0.000 \\
(0.000)\end{array}$ & $\begin{array}{c}0.000 \\
(0.000)\end{array}$ \\
\hline Child to adult ratio & $\begin{array}{c}0.075 * * \\
(0.037)\end{array}$ & $\begin{array}{c}-0.100 * * \\
(0.048)\end{array}$ & $\begin{array}{l}0.057 * \\
(0.035)\end{array}$ & $\begin{array}{c}-0.099 * * \\
(0.048)\end{array}$ \\
\hline Own house & $\begin{array}{c}-0.144 \\
(0.103)\end{array}$ & $\begin{array}{c}0.000 \\
(0.000)\end{array}$ & $\begin{array}{l}-0.180 \\
(0.122)\end{array}$ & $\begin{array}{c}0.000 \\
(0.000)\end{array}$ \\
\hline Self-sufficient & $\begin{array}{l}-0.012 \\
(0.049)\end{array}$ & $\begin{array}{l}-0.053 \\
(0.067)\end{array}$ & $\begin{array}{l}-0.005 \\
(0.048)\end{array}$ & $\begin{array}{l}-0.052 \\
(0.068)\end{array}$ \\
\hline Food shortage & $\begin{array}{l}-0.088 \\
(0.065)\end{array}$ & $\begin{array}{c}-0.122 * * \\
(0.054)\end{array}$ & $\begin{array}{l}-0.093 \\
(0.063)\end{array}$ & $\begin{array}{c}-0.120 * * \\
(0.053)\end{array}$ \\
\hline Informal network & $\begin{array}{c}0.151 * * * \\
(0.046)\end{array}$ & $\begin{array}{c}0.108 * * \\
(0.050)\end{array}$ & $\begin{array}{c}0.172 \text { *** } \\
(0.044)\end{array}$ & $\begin{array}{c}0.110 * * \\
(0.050)\end{array}$ \\
\hline $\begin{array}{l}\text { Access to micro-finance } \\
\text { institution }\end{array}$ & $0.255 * * *$ & $0.148 *$ & $0.265 * * *$ & $0.155 *$ \\
\hline & $(0.087)$ & $(0.077)$ & $(0.088)$ & $(0.079)$ \\
\hline Accessibility of community & $\begin{array}{c}0.000 \\
(0.001)\end{array}$ & $\begin{array}{c}0.001 \\
(0.001)\end{array}$ & $\begin{array}{c}0.000 \\
(0.001)\end{array}$ & $\begin{array}{c}0.001 \\
(0.001)\end{array}$ \\
\hline Market in community & $\begin{array}{c}0.043 \\
(0.103)\end{array}$ & $\begin{array}{c}0.099 \\
(0.132)\end{array}$ & $\begin{array}{l}-0.072 \\
(0.094)\end{array}$ & $\begin{array}{c}0.097 \\
(0.131)\end{array}$ \\
\hline Economic Shock & $\begin{array}{l}-0.036 \\
(0.089)\end{array}$ & $\begin{array}{c}-0.214 * * \\
(0.091)\end{array}$ & $\begin{array}{c}0.037 \\
(0.078)\end{array}$ & $\begin{array}{c}-0.209 * * \\
(0.090)\end{array}$ \\
\hline Environmental Shock & $\begin{array}{l}-0.053 \\
(0.065)\end{array}$ & $\begin{array}{l}-0.033 \\
(0.061)\end{array}$ & $\begin{array}{l}-0.029 \\
(0.062)\end{array}$ & $\begin{array}{l}-0.034 \\
(0.061)\end{array}$ \\
\hline Observations & 226 & 185 & 226 & 185 \\
\hline
\end{tabular}

Notes: ${ }^{* *} \mathrm{p}<0.01,{ }^{* *} \mathrm{p}<.05,{ }^{*} \mathrm{p}<0.10$. Average marginal effects are reported. Standard errors in parentheses are robust and clustered at the community level. 
Table E. 4: Results - Displacement Experiences (Probit estimates)

\begin{tabular}{|c|c|c|c|}
\hline & $(1)$ & $(2)$ & (3) \\
\hline & Refugee $\mathrm{HH}$ & IDP HH & Refugee $\mathrm{HH}$ \\
\hline $\begin{array}{l}\text { Short-term displacement } \\
\text { (less than one year) }\end{array}$ & $\begin{array}{l}-0.068 \\
(0.050)\end{array}$ & $\begin{array}{l}-0.029 \\
(0.058)\end{array}$ & \\
\hline Return ten or more years ago & & & $\begin{array}{l}0.118 * \\
(0.064)\end{array}$ \\
\hline Female & $\begin{array}{l}-0.077 \\
(0.099)\end{array}$ & $\begin{array}{c}0.145 \\
(0.191)\end{array}$ & $\begin{array}{l}-0.097 \\
(0.105)\end{array}$ \\
\hline Age & $\begin{array}{l}-0.002 \\
(0.002)\end{array}$ & $\begin{array}{c}-0.008 * * * \\
(0.003)\end{array}$ & $\begin{array}{l}-0.002 \\
(0.002)\end{array}$ \\
\hline Married & $\begin{array}{c}0.005 \\
(0.111)\end{array}$ & $\begin{array}{c}0.224 \\
(0.216)\end{array}$ & $\begin{array}{l}-0.006 \\
(0.121)\end{array}$ \\
\hline Primary & $\begin{array}{l}-0.042 \\
(0.073)\end{array}$ & $\begin{array}{c}0.084 \\
(0.056)\end{array}$ & $\begin{array}{l}-0.050 \\
(0.079)\end{array}$ \\
\hline Secondary & $\begin{array}{c}0.000 \\
(0.000)\end{array}$ & $\begin{array}{c}0.000 \\
(0.000)\end{array}$ & $\begin{array}{c}0.000 \\
(0.000)\end{array}$ \\
\hline Child to adult ratio & $\begin{array}{c}0.059 \\
(0.041)\end{array}$ & $\begin{array}{c}-0.095 * * \\
(0.048)\end{array}$ & $\begin{array}{c}0.062 \\
(0.040)\end{array}$ \\
\hline Own house & $\begin{array}{l}-0.186 \\
(0.116)\end{array}$ & $\begin{array}{c}0.000 \\
(0.000)\end{array}$ & $\begin{array}{l}-0.201 * \\
(0.112)\end{array}$ \\
\hline Self-sufficient & $\begin{array}{l}-0.006 \\
(0.056)\end{array}$ & $\begin{array}{l}-0.055 \\
(0.070)\end{array}$ & $\begin{array}{l}-0.009 \\
(0.055)\end{array}$ \\
\hline Food shortage & $\begin{array}{l}-0.070 \\
(0.052)\end{array}$ & $\begin{array}{c}-0.130 * * \\
(0.058)\end{array}$ & $\begin{array}{l}-0.059 \\
(0.053)\end{array}$ \\
\hline Informal network & $\begin{array}{l}0.221 * * * \\
(0.051)\end{array}$ & $\begin{array}{c}0.110 * * \\
(0.050)\end{array}$ & $\begin{array}{l}0.224 * * * \\
(0.051)\end{array}$ \\
\hline $\begin{array}{l}\text { Access to micro-finance } \\
\text { institution }\end{array}$ & $0.213 * *$ & $0.149 * *$ & $0.223 * *$ \\
\hline & $(0.094)$ & $(0.075)$ & $(0.087)$ \\
\hline Accessibility of community & $\begin{array}{l}-0.000 \\
(0.001)\end{array}$ & $\begin{array}{c}0.001 \\
(0.001)\end{array}$ & $\begin{array}{l}-0.000 \\
(0.001)\end{array}$ \\
\hline Market in community & $\begin{array}{l}-0.126 \\
(0.141)\end{array}$ & $\begin{array}{c}0.097 \\
(0.131)\end{array}$ & $\begin{array}{l}-0.143 \\
(0.142)\end{array}$ \\
\hline Economic Shock & $\begin{array}{c}0.084 \\
(0.140)\end{array}$ & $\begin{array}{c}-0.211 * * \\
(0.089)\end{array}$ & $\begin{array}{c}0.102 \\
(0.141)\end{array}$ \\
\hline Environmental Shock & $\begin{array}{l}-0.092 \\
(0.063)\end{array}$ & $\begin{array}{c}-0.034 \\
(0.061)\end{array}$ & $\begin{array}{c}-0.088 \\
(0.061)\end{array}$ \\
\hline Observations & 213 & 184 & 213 \\
\hline
\end{tabular}

Notes: ${ }^{* * *} \mathrm{p}<0.01,{ }^{* *} \mathrm{p}<.05,{ }^{*} \mathrm{p}<0.10$. Average marginal effects are reported. Standard errors in parentheses are robust and clustered at the community level. 




\section{VALORIZATION}



This dissertation addresses the topic of the labour market participation of forced migrants and their households in developing country contexts. This addendum presents the valorization opportunities of this work. The valorization addendum has been added in accordance with article 23.5 of the "Regulation governing the attainment of doctoral degrees at Maastricht University" decreed by resolution of the Board of Deans.

The main focus of these Essays on Forced Migration and Labour Market Participation in Developing Countries has been to explore the labour market activities of forced migrants and their households using different case studies. Herein, a specific focus is placed on people displaced by conflict and general insecurity and their experiences both during displacement as well as upon return. The core of this work consists of four selfcontained papers covering different angels of analysis on the overall theme using unique datasets from (post-) conflict countries. Access to labour markets for all, including displaced populations, is a crucial component of achieving Sustainable Development Goal (SDG) 8. SDG 8 defines the 'promotion of inclusive and sustainable economic growth, employment and decent work for all' as one of the priorities for development across the world until 2030.

Considering their relevance for SDG 8, the current challenges posed by forced migration around the world, and the ambition of the Global Compact on Refugees, the findings of the present dissertation may be of interest to different stakeholders such as policy-makers, practitioners, and other researchers. Besides the academic contribution of looking at questions that have so far largely been addressed in the context of more advanced economies, the findings and derived implications for policy also have economic and societal relevance more generally.

Chapter 2 poses and answers a number of critical questions about the relationship between migration and entrepreneurship in the process of economic development. Much of the existing literature on entrepreneurial activities, as well as labour market activities more generally, and their link to migration focuses on developed country contexts and voluntary migration movements. Little research, on the other hand, exists on the same issues in the context of developing countries, especially when looking at experiences of those affected by conflict-induced migration movements. The findings of the literature review and the following chapters are therefore relevant for policymaking. Specifically, Chapter 2 shows that the standard policy response to migrants and migrant entrepreneurs are often based on an inadequate understanding of migrant entrepreneurs. The chapter concludes that it must be avoided that migrants are seen as 'super-entrepreneurs' and that the (positive) developmental impact of 
migration is more significant through other channels. Removal of discriminatory barriers against migrants and against migrant entrepreneurs in labour, consumer, and financial markets will, on the other hand, promote development in both sending and receiving countries, not least through reducing the shares of migrants that are reluctant entrepreneurs.

Chapter 3 looks at the labour market activities of Congolese refugees in Rwanda and analyses the different factors that may contribute to their engagement in the labour market. It is based on the premise that forced migrants are not passive actors but agents with human, social, and sometimes also financial capital. The findings show that, as one may expect, unemployment is a significant issue for Congolese refugees in Rwanda and that the biggest difference between natives and refugees lies in the access to land in a context where a reliance on agricultural activities is still common. Furthermore, self-employment is an important form of activity for females and especially female refugees, as alternative economic activities for them largely do not exist in the absence of the possibility of engagement in agricultural activities. The study also highlights that the local context of refugee camps does matter and that refugees benefit from being closer to urban centres, where they can engage in trade and casual labour arrangements with the local population. Overall, these findings are relevant for policy-makers because, if legally allowed and enabled to do so, refugees are in a position to engage in the labour market and contribute to the economy of the hosting country. This does, however, require that there are no legal or administrative hurdles in this regard. It is, therefore, important that policies within a country are coherent and that discrepancies between, for example, refugee and labour market policies are avoided.

Chapter 4 focuses on individuals that do not have a migration experience themselves, but on the impact of migration of household members on the labour market activities of those non-migrants, with a focus on self-employment. Data for four countries characterized by significantly different labour market and migration contexts is used to analyse this relationship. These countries are Afghanistan and Burundi, as countries with mainly forced migration flows, as well as Ethiopia and Morocco where migration is mainly for economic purposes. The analysis shows that in countries where the vast majority of migration is motivated for the most part by the escape from violent conflict and general insecurity no relationship between migration and self-employment of non-migrant household members does exist. In countries, where the main reasons for migration are economic ones, such a relationship is more likely. Here it seems that the specific strategy of the respective household may make a difference. Therefore, the 
findings highlight that the context in which migration and labour market engagement take place indeed matters significantly. As such, it is important that policies, programmes, and any support mechanisms aiming at helping forced migrants, their households, as well as other vulnerable groups, recognize the specific local context in order to ensure that proper approaches are used.

Chapter 5 explores the economic activities of refugees upon return to the country of origin, in this case Afghanistan. Specifically, the case study analyses the labour market reintegration of refugees returning from Iran and Pakistan. Employment is a key component in the overall process of sustainable reintegration and as such it is important to understand the determinants of different potential labour market activities in order to improve policy-making in this regard. The findings provide evidence that returned refugees are less likely to be wage employed in comparison to non-migrants, and that those factors related to socio-economic status, including educational attainment, and the strength of social networks play an influential role in labour market outcomes in Afghanistan. In addition, there is evidence that even in contexts of forced migration, the migration experience may be influential for the economic reintegration, particularly in contexts where the forcibly displaced do have opportunities to be economically activity during displacement. Overall, the main contribution of this chapter is the analysis of the potential role of migration experiences in labour market outcomes of migrants upon return; an issue that has previously been analysed in the context of voluntary movements for employment purposes, but not those caused by factor such as violent conflict and general insecurity. Given the role of social networks highlighted in this chapter, as well as throughout the dissertation more generally, assistance focused on helping forced migrants and returnees build strategic linkages in their respective communities may be particularly beneficial. The capacity of refugees as well as returnees could be improved by bringing them in touch with other actors like business associations or a network of experts. Additionally, the findings concerning the importance of savings and access to financial capital suggest a possible credit constraint at home which earnings from abroad help to ease. Therefore, small grants and/ or loans for the purpose of investing in a business venture may be a viable strategy if targeted at recipients with practical ideas and the capacity to carry them out. Careful selection is therefore important in order to increase the likelihood of effective implementation, but conditions can be put in place to help improve the odds of success.

In Chapter 6 the focus is on the operation of non-farm businesses by households in rural Burundi. The change in level of analysis from the individual to the household 
level is due to evidence that highlights that decisions to engage in small businesses are often not made by individuals themselves, but rather at the household level; often as a strategy of diversifying income sources. The patterns and determinants of such activities are explored and analysed in the context of the rural parts of post-conflict Burundi. Within the analysis, specific attention is paid to the potential impact of forced migration experiences of household members on such activities. The chapter therefore contributes to the existing literature by considering that displacement experiences and the consequences upon return in terms of loss of land rights, assets, and deterioration of skills may be an additional reason to engage in entrepreneurial activities in rural contexts that are characterized by land scarcity and limited wage employment opportunities. The analysis does, however, not confirm such an expectation. Instead, it highlights that households with international, internal, or no displacement experiences are more or less likely to operate a non-farm business based on a variety of other factors, including, first and foremost, the necessity to engage in another activity due to the inability to satisfy daily needs based on household agricultural activities. Understanding the motivations of households and individuals to engage in business activities is important in so far that policies shape the conditions in which the economy operates. Understanding the driving factors can then enable policy-makers to develop policies and support programmes that have the potential to facilitate startup processes. At the same time, there is a need to find alternative ways of supporting poor households who enter into low-productivity entrepreneurship out of necessity.

These findings and resulting policy lessons have been shared with different stakeholders on a variety of different occasions, including international conferences, workshops, and meetings attended by policy-makers and researchers from a diverse range of organizations. The chapters of this dissertation have, for example, been presented at the IS Academy Migration and Development final conference in Maastricht in 2014; MACIMIDE Conferences and Workshops in 2014, 2016, 2017, and 2018; workshops with representatives of the Dutch government in 2014 and 2016; the annual conferences of the Human Capital and Development Association in Washington, D.C. in 2015 and Tokyo in 2016; the 2nd International Conference on Migration \& Diaspora Entrepreneurship in Bremen in 2016; the RSC Conference 2017 (Beyond Crisis: Rethinking Refugee Studies) in Oxford; the IMISCOE Annual Conference 2017 in Rotterdam; the UNU-MERIT Annual Internal Conferences 2017 and 2018; the Migrating out of Poverty: From Evidence to Policy Conference in London in 2017; the International Forum on Migration Statistics in Paris in 2018; and the 2018 World Congress of the International Political Science Association in Brisbane. In terms of further diffusion of the results, the chapters of this dissertation have either been 
published or are in the process of being published as peer-reviewed journal articles or working papers. Chapter 2 has been published open access in the IZA Journal of Migration (since renamed to IZA Journal of Migration and Development). Results from Chapter 3 were used in a final project report for UNHCR. Chapter 5 has been accepted for publication in a Special Issue on "Forced Migration, Enterprise and Development" of Small Business Economics.

In conclusion, the findings of this dissertation show that it is important to understand that, ideally, policies and infrastructure should enable forced migrants to engage economically at the different stages of their migration journey when they want to do so. While those in vulnerable situations should not be 'forced' to work, those that show motivation should be recognized as economic actors. Support and policies should therefore focus on actions that can facilitate this. This includes opportunities for (further) education and training for the refreshment and development of skills, but also infrastructure as such, for example transportation or internet and cell phone access. Well-designed policies and programmes have the potential to contribute to the well-being of forced migrants and their household members as well as to development of countries of origin and destination respectively so that ideally all involved parties can benefit. 



\section{About the Author}

Katrin Marchand was born in Nürnberg, Germany in 1983. After finishing secondary school in Aachen, she studied Economics at the University of Trier in Germany and obtained her Diplom (German equivalent of a Master's degree) in 2008. Katrin then pursued a Master of Science in Public Policy and Human Development at the Maastricht Graduate School of Governance, Maastricht University, the Netherlands. During her prior education in Maastricht, she specialized in Migration Studies and has subsequently been working as a researcher in this field since 2010. In November 2011, Katrin joined the joint Ph.D. programme at UNU-MERIT and its Maastricht Graduate School of Governance. During her time as a Ph.D. fellow she further developed her research skills in the area of migration using both quantitative and qualitative methods. Katrin was able to apply these skills when conducting evaluations of programmes and policies, drafting migration profiles and mappings, as well as preparing extensive literature reviews for a variety of stakeholders, including GIZ, ICMPD, ILO, IOM, UNHCR, and the Swiss government. She also developed and taught a series of migration online courses. Katrin's main research interests are in (forced) migration and development, specifically labour migration, migrants' occupational choices, and the interlinkages of migration and private sector development. Currently she is working as a post-doctoral researcher at UNU-MERIT I Maastricht Graduate School of Governance on, among others, the Horizon 2020 REMINDER (Role of European Mobility and its Impacts in Narratives, Debates and EU Reforms) project. 



\section{UNU-MERIT/MGSOG DISSERTATION SERIES}

2018

\section{Ortrun Merkle}

The Myth of Gender Neutral Power:

Corruption and Gender Norms

UNU-MERIT/MGSoG Dissertation

Series № 215

\section{Biljana Meshkovska}

Life after Trafficking: (re)integration processes of women that have been trafficked for the purpose of sexual exploitation in Europe

UNU-MERIT/MGSoG Dissertation

Series № 214

\section{Vincenzo Vinci}

The Relevance of Institutions and People's

Preferences for Social Protection

UNU-MERIT/MGSoG Dissertation

Series № 213

\section{Silke Heuser}

The Effectiveness of Environmental Policies on Reducing Deforestation in the Brazilian Amazon

UNU-MERIT/MGSoG Dissertation

Series № 212

\section{Jennifer Waidler}

Social Assistance and Remittances and Their

Role in the Fight Against Poverty

UNU-MERIT/MGSoG Dissertation

Series № 211

\section{Choolwe Muzyamba}

The role of community mobilization in the promotion of maternal health of women living with HIV in Zambia UNU-MERIT/MGSoG Dissertation Series № 210
Juan Carlos A. Castillo Sánchez

Assessing the Role of the Export Sector in

Mexican Economic Development,1965-2014

UNU-MERIT/MGSoG Dissertation

Series № 209

\section{Tareq Abuelhaj}

Food Security Policy Impact Analysis: The

Econometrics of Cash and Food Assistance

Cost Effectiveness

UNU-MERIT/MGSoG Dissertation

Series № 208

Marta Férnandez de Arroyabe

Arranz

Essays on MEAS and Innovation

UNU-MERIT/MGSoG Dissertation

Series № 207

Clotilde Mahé

Essays on Migration and Occupational

Choice

UNU-MERIT/MGSoG Dissertation

Series № 206

\section{Simone Sasso}

Talent on the move. Essays on Human

Capital, Graduate Mobility and Economic

Development

UNU-MERIT/MGSoG Dissertation

Series № 205

\section{Khaled Walid Rajab}

Strategic Planning under Fragility

UNU-MERIT/MGSoG Dissertation

Series № 204

Mutinta Hambayi Nseluke

A Tall Order: Improving Child Linear

Growth

UNU-MERIT/MGSoG Dissertation

Series № 203 


\section{Elvis Korku Avenyo}

Innovations and Firm Performance in sub-

Saharan Africa: Empirical Analyses

UNU-MERIT/MGSoG Dissertation

Series № 202

\section{Ni Zhen}

Employment Dynamics, Firm Performance and Innovation Persistence in the Context of

Differentiated Innovation Types: Evidence from Luxembourg

UNU-MERIT/MGSoG Dissertation

Series № 201

\section{Caroline Wehner}

Too Scared to Achieve: The Relation

Between Neuroticism, Conscientiousness

and Socioeconomic Outcomes

UNU-MERIT/MGSoG Dissertation

Series № 200

\section{Stefania Innocenti}

On Institutional Persistence

UNU-MERIT/MGSoG Dissertation

Series № 199

\section{Hassen Abda Wako}

Economic Globalization, Institutions and Development: Essays on Aid, Foreign Direct Investment and Trade

UNU-MERIT/MGSoG Dissertation

Series № 198

2017

\section{Hans-Erik Edsand}

Winds of Change

UNU-MERIT/MGSoG Dissertation

Series № 197

\section{Ana Patricia Silva Vara}

Redressing the Gender Gap

UNU-MERIT/MGSoG Dissertation

Series № 196
Andrés Iván Mideros Mora

Essays on the Economic Effects of

Noncontributory Social Protection

UNU-MERIT/MGSoG Dissertation

Series № 195

\section{Tobias Broich}

New Actors in the Global Economy

UNU-MERIT/MGSoG Dissertation

Series № 194

\section{Bernard Nikaj}

From No-government to E-government UNU-MERIT/MGSoG Dissertation

Series № 193

\section{Ali Safarnejad}

Prioritizing the HIV Response

UNU-MERIT/MGSoG Dissertation

Series № 192

\section{Clovis Freire}

Diversification and Structural Economic

Dynamics

UNU-MERIT/MGSoG Dissertation

Series № 191

\section{Michael Verba}

Innovation and Knowledge Dynamics:

Essays on the Knowledge Economy

UNU-MERIT/MGSoG Dissertation

Series № 190

\section{Pui Hang Wong}

The Hearts and Minds in Conflict and Peace: The Economics of Counterinsurgency and the Psychology of Reconstruction UNU-MERIT/MGSoG Dissertation Series № 189

\section{Brenda Yamba}

Schooling Despite All Odds: Evidence from Lesotho on Female Child Carers who Stayed in School UNU-MERIT/MGSoG Dissertation Series № 188 


\section{Sheng Zhong}

Moving towards An Energy Efficient

Future: Essays on Energy Efficiency,

Technology and Development

UNU-MERIT/MGSoG Dissertation

Series № 187

\section{Julieta Marotta}

Access to Justice and Legal Empowerment of Victims of Domestic Violence through Legal Organizations in the City of Buenos Aires:

A Qualitative Empirical Legal Study

UNU-MERIT/MGSoG Dissertation

Series, № 186

\section{Andrea Franco-Correa}

On the Measurement of Multidimensional

Poverty as a Policy Tool: Empirical

Applications to Chile, Colombia, Ecuador

and Peru

UNU-MERIT/MGSoG Dissertation

Series, № 185

2016

\section{Yesuf Awel}

Insurance for Growth: Empirical Essays on

Insurance Demand and Impacts in Africa

UNU-MERIT Dissertation Series, № 108

\section{Tigist Mekonnen Melesse}

Grow More Food using Fewer Resources:

Agricultural Technology Adoption and

Innovation Practices for Inclusive and

Sustainable Development

UNU-MERIT Dissertation Series, № 107

\section{Eleni Yitbarek}

Getting Ahead or left Behind? Essays on

Poverty Dynamics and Social Mobility in

Africa

UNU-MERIT Dissertation Series, № 106

\section{Thuy Dieu Nguyen}

Firm-Level Theory and Evidence of

Corruption

UNU-MERIT Dissertation Series, № 105

\section{Raquel Tsukada Lehman}

Essays on Household Production with

Labor-Saving Technology

UNU-MERIT Dissertation Series, № 104

\section{Eva Barteková}

Multi-Problem Challenges for a Renewable

Future: Empirical Studies on Competitive

Disadvantages from Electricity Price

Differentials and Mineral Supply Risk in an

Open Economy

UNU-MERIT Dissertation Series, № 103

\section{Jocelyn Olivari}

Entrepreneurial Traits and Innovation:

Evidence from Chile

UNU-MERIT Dissertation Series, № 102

\section{Muhammad Shafique}

Essays on the role of knowledge, $R \mathcal{E} D$, and

Technology-based Firms in the Evolution of

Socio-techno-economic System

UNU-MERIT Dissertation Series, № 101

\section{Serdar Türkeli}

Governance of Innovation Policy: Empirical Studies on Applied Political Economy by Multi-Methods Analysis

UNU-MERIT Dissertation Series, № 100

\section{Ayokunu Adedokun}

Pathways to Sustainable Peace building in Divided Societies: Lessons and Experiences from Mozambique

MGSoG Dissertation Series, № 75

\section{Luiz Rothier Bautzer}

Organizing Concurrent Engineering through ICT Platforms Blueprinting Product Lifecycle Management Platforms across Disciplinary Agencies

MGSoG Dissertation Series, № 74 


\section{Natalia Popova}

Migration in the Periphery of the European Union: Determinants of Successful and Sustainable Labour Market Integration of Return Migrants in Albania, Egypt,

Moldova and Tunisia

MGSoG Dissertations Series, № 73

\section{Richard A. Martina}

Uncertainty and Resource Constraint in the Small Island Developing States: Essays in Entrepreneurial Cognition

MGSoG Dissertations Series, № 72

\section{Cécile Cherrier}

The Expansion of Basic Social Protection in Low-income Countries: An Analysis of Foreign Aid Actors' Role in the Emergence of Social Transfers in Sub-Saharan Africa MGSoG Dissertations Series, № 71

\section{Paul Caldron}

The Tacit Bargain in Short-Term Medical Missions: Why U.S. physicians go and what it costs

MGSoG Dissertation Series, № 70

\section{Mahmut Kobal}

Customs \& Excellence: A Comparative Approach on Administrative and Regulatory Compliance Perspectives of the EU-Turkey Customs Union

MGSoG Dissertation Series, № 69

\section{Craig Loschmann}

Essays on Conflict-related Migration and Development in the Case of Afghanistan MGSoG Dissertations Series, № 68

\section{Andrea Milan}

Rural Livelihoods, Location and Vulnerable Environments: Approaches to Migration in Mountain areas of Latin America MGSoG Dissertation Series, № 67

\section{Farida Lada}

On Guarding the Welfare of Clinical Trial Subjects While Promoting Novel Drug Innovation A Game Theoretical Approach MGSoG Dissertation Series, № 66

\section{5}

\section{Hibret Belete Maemir}

Dissecting Aggregate Productivity:

International Integration and Growth with Heterogeneous Firms

UNU-MERIT Dissertation Series, № 96

\section{Giorgio Triulzi}

Looking for the Right Path: Technology

Dynamics, Inventive Strategies and

Catching-up in the Semiconductor Industry

UNU-MERIT Dissertation Series, № 95

\section{Abdul Baseer Qazi}

Knowledge flows and networks in the ICT sector: The case of Pakistan

UNU-MERIT Dissertation Series, № 94

\section{Ajay Thutupalli}

Technology Paradigm Shifts in Agriculture: Drivers of Sustainability and Catch up UNU-MERIT Dissertation Series, № 93

\section{Eduardo Urias}

Improving access to HIVIAIDS treatment in Brazil: When are Compulsory Licenses effective in Price Negotiations?

UNU-MERIT Dissertation Series, № 92

\section{Francesca Guadagno}

Why have so few Countries Industrialised? UNU-MERIT Dissertation Series, № 91

\section{Daniel Opolot}

The Evolution of Beliefs and Strategic Behaviour UNU-MERIT Dissertation Series, № 90 
Alejandro Lavopa

Structural Transformation and Economic

Development: Can Development Traps be

Avoided

UNU-MERIT Dissertation Series, № 89

\section{Jinjin Zhao}

Urban water management reform: The Case of China

UNU-MERIT Dissertation Series, № 88

\section{Simona Vezzoli}

Borders, Independence and Postcolonial

Ties: the Role of the State in Caribbean

Migration

MGSoG Dissertation Series, № 65

\section{Silvia Consuelo Gómez Soler}

Civil Conflict and Education: How Does

Exposure to Civil Conflict Affect Human

Capital Accumulation? Evidence from

Standardized Exit Exams in Colombia

MGSoG Dissertation Series, № 64

\section{Paula Nagler}

Occupational Choice in the Developing

World

MGSoG Dissertation Series, № 63

\section{Jasmin Kientzel}

Determinants of Professional Commitment

to Environmental Sustainability

MGSoG Dissertation Series, № 62

\section{Mehmet Güney Celbiş}

Regional Policies: Convergence, Trade, and the Allocation of Public Capital

MGSoG Dissertation Series, № 61

\section{Florian Henning}

Living Up to Standard: Interoperability Governance and Standards Adoption in Government Information Networks MGSoG Dissertation Series, № 60

\section{Niels P. Groen}

The Never-Ending Project Understanding

E-Government Project Escalation

MGSoG Dissertation Series, № 59

\section{Derek Copp}

Teacher-Based Reactivity to Provincial

Large-scale Assessment in Canada

MGSoG Dissertation Series, № 58

\section{Michaella Vanore}

Family-Member Migration and the Psychosocial Health Outcomes of Children in Moldova and Georgia

MGSoG Dissertation Series, № 57

\section{Sonja Fransen}

The Economic and Social Effects of

Remittances and Return Migration in

Conflict-Affected Areas: The Case of

Burundi

MGSoG Dissertation Series, № 56

\section{Ibrahim Khalil Conteh}

The Impact of Floods on Primary School

Education in Zambia

MGSoG Dissertation Series, № 55

\section{Richard Bluhm}

Growth Dynamics and Development Essays in Applied Econometrics and Political

Economy

MGSoG Dissertation Series, № 54

\section{Nevena P. Zhelyazkova}

Work-Family Reconciliation and Use of Parental Leave in Luxembourg: Empirical Analysis of Administrative Records MGSoG Dissertation Series, № 53

\section{4}

\section{Dirk Crass}

The Impact of Brands on Innovation and Firm Performance: Empirical Evidence from Germany

UNU-MERIT Dissertation Series, № 87 


\section{Samyukta Bhupatiraju}

The Geographic Dimensions of Growth and Development

UNU-MERIT Dissertation Series, № 86

\section{François Lafond}

TheEvolution of Knowledge Systems

UNU-MERIT Dissertation Series, № 85

\section{Annalisa Primi}

Promoting Innovation in Latin America:

What Countries Have Learned (and What

They Have Not) in Designing and

Implementing Innovation and Intellectual

Property Policies

UNU-MERIT Dissertation Series, № 84

\section{Fatoumata Lamarana Diallo}

Evaluation of Meal and Deworming

Programs for Primary Schools in Rural

Senegal

UNU-MERIT Dissertation Series, № 83

\section{Sachin Kumar Badkas}

Metachoice and Metadata: Innovating with Environmental Policy Analysis in Europe MGSoG Dissertation Series, № 52

\section{Irina S. Burlacu}

An Evaluation of Tax-Benefit Systems Impact on the Welfare of Frontier Worker: The Case of Luxembourg and Belgium MGSoG Dissertation Series, № 51

\section{Özge Bilgili}

Simultaneity in Transnational Migration Research: Links Between Migrants' Host and Home Country Orientation

MGSoG Dissertation Series, № 50

\section{Yulia Privalova Krieger}

Reshaping the Big Agenda: Transnational Politics and Domestic Resistance; Financial crisis and social protection reform in Bosnia and Herzegovina

MGSoG Dissertation Series, № 49
Marieke van Houte

Moving Back or Moving Forward? Return migration after Conflict

MGSoG Dissertation Series, № 48

\section{Oxana Slobozhan}

Global Governance in the Management of Natural Resources: The Case of the

Extractive Industries Transparency Initiative (EITI)

MGSoG Dissertation Series, № 47

\section{Luis Bernardo Mejia Guinand}

The Changing Role of the Central Planning Offices in Latin America: A Comparative Historical Analysis Perspective (1950-2013)

MGSoG Dissertation Series, № 46

\section{Cheng Boon Ong}

Ethnic Segregation in Housing, Schools and Neighbourhoods in the Netherlands

MGSoG Dissertation Series, № 45

\section{Luciana V. Cingolani}

Bureaucracies for Development: Oxymoron or Reality? Studies on State Capacity in

Challenging Governance Contexts

MGSoG Dissertation Series, № 44

\section{Carlos Cadena Gaitán}

Green Politics in Latin American Cities -

Sustainable Transport Agendas

MGSoG Dissertation Series, № 43

\section{Katie Kuschminder}

Female Return Migration and Reintegration Strategies in Ethiopia

MGSoG Dissertation Series, № 42

\section{Metka Hercog}

Highly-Skilled Migration and New

Destination Countries

MGSoG Dissertation Series, № 41 


\section{Margaret Agaba Rugadya}

Can Remittances Influence the Tenure and

Quality of Housing in Uganda?

MGSoG Dissertation Series, № 40

\section{Ilire Agimi}

New Governance Under Limited Statehood:

The Case of Local Government Reform in

Kosovo

MGSoG Dissertation Series, № 39

2013

\section{Anant Kamath}

Information Sharing through Informal

Interaction in Low-Tech Clusters

UNU-MERIT Dissertation Series, № 82

\section{Flavia Pereira de Carvalho}

What we talk about when we talk about Brazilian Multinationals: An Investigation on Brazilian FDI, Economic Structure, Innovation and the Relationship between them

UNU-MERIT Dissertation Series, № 81

\section{Jun Hou}

Complementarity in Innovation and

Development: A Cross-country Comparison

UNU-MERIT Dissertation Series, № 80

\section{Rufin Baghana}

Impacts of Government Incentives to RED, Innovation and Productivity: A Microeconometric Analysis of the Québec Case UNU-MERIT Dissertation Series, № 79

\section{Lilia I. Stubrin}

High-Tech Activities in Emerging

Countries: A Network perspective on the Argentinean Biotech Activity

UNU-MERIT Dissertation Series, № 78

\section{Kristine Farla}

Empirical Studies on Institutions, Policies and Economic Development

MGSoG Dissertation Series, № 38

\section{Marina Petrovic}

Social Assistance and Activation in the Pursuit of Happiness: Shedding New Light on Old Policy Solutions to Social Exclusion MGSoG Dissertation Series, № 37

\section{Laura Torvinen}

Assessing Governance Assessments: The Case of Mozambique: Governance Assessments in the Context of Aid Effectiveness Discourse

MGSoG Dissertation Series, № 36

\section{Biniam Egu Bedasso}

Institutional Change in the LongShadow of Elite: Essays on Institutions, Human

Capital and Ethnicity in Developing Countries

MGSoG Dissertation Series, № 35

\section{Sepideh Yousefzadeh Faal Deghati}

Childhoods Embargoed: Constructing and Reconstructing Multidimensional Child Poverty in Iran 1984-2009

MGSoG Dissertation Series, № 34

\section{Robert Bauchmüller}

Investing in Early Childhood Care and Education: The Impact of Quality on Inequality

MGSoG Dissertation Series, № 33

\section{Martin Rehm}

Unified Yet Separated: Empirical Study on the Impact of Hierarchical Positions within Communities of Learning

MGSoG Dissertation Series, № 32

\section{2}

\author{
Abdul Waheed \\ Innovation Determinants and Innovation as \\ a Determinant: Evidence from Developing \\ Countries \\ UNU-MERIT Dissertation Series, № 77
}




\section{Bilal Mirza}

Energy Poverty and Rural Energy Markets in Pakistan

UNU-MERIT Dissertation Series, № 76

\section{Benjamin Engelstätter}

Enterprise Software and Video Games: An Empirical Analysis

UNU-MERIT Dissertation Series, № 75

\section{Fulvia Farinelli}

Natural Resources, Innovation and Export Growth: The Wine Industry in Chile and Argentina

UNU-MERIT Dissertation Series

\section{Rodolfo Lauterbach}

Innovation in Manufacturing: From

Product Variety and Labor Productivity

Growth to Economic Development in Chile

UNU-MERIT Dissertation Series

\section{Kirsten Wiebe}

Quantitative Assessment of Sustainable

Development and Growth in Sub-Saharan Africa

UNU-MERIT Dissertation Series, № 74

\section{Julio Miguel Rosa}

Organizational Strategies, Firms'

Performance and Spatial Spillovers: The

Canadian Case in Research and

Development.

UNU-MERIT Dissertation Series, № 73

\section{Johannes Wilhelmus Marie Boels}

Joseph Schumpeter, Honderd Jaar

Economische Ontwikkeling: Een Historischtheoretische Beschouwing.

UNU-MERIT Dissertation Series

\section{Dorcas Mbuvi}

Utility Reforms and Performance of the

Urban Water Sector in Africa

MGSoG Dissertation Series, № 31

\section{Lina Salanauskaite}

Distributional Impacts of Public Policies:

Essays in Ex-Ante and Ex-Post Evaluation

MGSoG Dissertation Series, № 30

\section{Esther Schüring}

To Condition or not - is that the Question? An Analysis of the Effectiveness of Ex-Ante and Ex-Post Conditionality in Social Cash Transfer Programs

MGSoG Dissertation Series, № 29

Joe Abah

Strong Organisations in Weak States:

Atypical Public Sector Performance in

Dysfunctional Environments

MGSoG Dissertation Series, № 28

\section{Zina Samih Nimeh}

Social Citizenship Rights: Inequality and

Exclusion

MGSoG Dissertation Series, № 27

\section{1}

\section{Daniel Vertesy}

Interrupted Innovation: Emerging

Economies in the Structure of the Global

Aerospace Industry

UNU-MERIT Dissertation Series, № 72

\section{Tina Saebi}

Successfully Managing Alliance Portfolios: AnAlliance Capability View

UNU-MERIT Dissertation Series, № 71

\section{Nora Engel}

Tuberculosis in India: A Case of Innovation and Control

UNU-MERIT Dissertation Series, № 70

\section{Evans Mupela}

Connectivity and growth in Sub-Saharan

Africa: The Role of Communication

Satellites

UNU-MERIT Dissertation Series, № 69 


\section{Nantawan Kwanjai}

Cross Cultural Intelligence amid Intricate

Cultural Webs: A Tale of the UnDutchables in the Land of 1002 Smiles

UNU-MERIT Dissertation Series, № 68

\section{Lina Sonne}

Innovation in Finance to Finance

Innovation: Supporting Pro-poor

Entrepreneur-based Innovation

UNU-MERIT Dissertation Series, № 67

\section{Lenka Eisenhamerová}

Legitimacy of 'Humanitarian Military

Intervention'

MGSoG Dissertation Series, № 26

\section{Sonila Tomini}

Informal Payments for Health Care Services in Albania

MGSoG Dissertation Series, № 25

\section{Jinjing Li}

Dynamic Microsimulation in Public Policy

Evaluation

MGSoG Dissertation Series, № 24

\section{Aziz Atamanov}

Rural Nonfarm Employment and International Migration as Alternatives to Agricultural Employment: The Case of Kyrgyzstan

MGSoG Dissertation Series, № 23

\section{Frieda Vandeninden}

Poverty Alleviation: Aid and Social

Pensions

MGSoG Dissertation Series, № 22

\section{Juliana Nyasha Tirivayi}

The Welfare Effects of Integrating AIDS

Treatment with Food Transfers: Evidence from Zambia

MGSoG Dissertation Series, № 21

\section{Agnieska Ewa Sowa}

Who's Left Behind? Social Dimensions of Health Transition and Utilization of

Medical Care in Poland

MGSoG Dissertation Series, № 20

\section{Emmanaouil Sfakianakis}

The Role of Private Actors in the Provision of Public Goods with Applications to Infrastructure and Financial Stability MGSoG Dissertation Series, № 19

\section{Siu Hing Lo}

White Collars Green Sleeves: An Interorganizational Comparison of Determinants of Energy-Related Behaviors among Office Workers

MGSoG Dissertation Series, № 18

\section{Treena $\mathbf{W u}$}

Constraints to Human Capital Investment in Developing Countries: Using the Asian Financial Crisis in Indonesia as a Natural Experiment

MGSoG Dissertation Series, № 17

\section{Henry Espinoza Peña}

Impact Evaluation of a Job-Training

Programme for Disadvantaged Youths: The Case of Projoven

MGSoG Dissertation Series, № 16

\section{0}

\section{Fernando Santiago}

Human Resources Management Practices and Learning for Innovation in Developing Countries: Pharmaceutical Firms in Mexico UNU-MERIT Dissertation Series, № 66

\section{Zakaria Babutsidze}

Essays on Economies with Heterogeneous Interacting Consumers

UNU-MERIT Dissertation Series, № 65 


\section{Bertha Vallejo}

Learning and Innovation Under Changing Market Conditions: The Auto Parts

Industry in Mexico

UNU-MERIT Dissertation Series, № 64

\section{Donatus Ayitey}

Technical Change, Competitiveness and

Poverty Reduction: A Study of the

Ghanaian Apparel Industry

UNU-MERIT Dissertation Series, № 63

\section{Sergey Filippov}

Multinational Subsidiary Evolution:

Corporate Change in New EU Member

States

UNU-MERIT Dissertation Series, № 62

\section{Asel Doranova}

Technology Transfer and Learning under the Kyoto Regime: Exploring the

Technological Impact of CDM Projects in Developing Countries

UNU-MERIT Dissertation Series, № 61

\section{Florian Tomini}

Between Family and Friend: Understanding the Interdependency of Private Transfers

MGSoG Dissertation Series, № 15

\section{Michał Polalowski}

The Institutional Transformation of Social Policy in East Central Europe: Poland and Hungary in Comparative and Historical Perspective

MGSoG Dissertation Series, № 14

\section{Maha Ahmed}

Defining, Measuring and Addressing Vulnerability: The Case of Post Conflict Environments

MGSoG Dissertation Series, № 13

\section{Pascal Beckers}

Local Space and Economic Success: The Role of Spatial Segregation of Migrants in the Netherlands

MGSoG Dissertation Series, № 12

\section{Victor Cebotari}

Conflicting Demands in Ethnically Diverse Societies: Ethno political Contention and Identity Values in Europe MGSoG Dissertation Series, № 11

\section{Dennis Gyllensporre}

Competing and Complementary Perspectives on the EU as a Crisis Management Actor: An Examination of the Common Security and Defence Policy through the Lenses of Idealism and Realism MGSoG Dissertation Series, № 10

\section{Judit Vall Castello}

Business Cycle and Policy Effects on Labour Market Transitions of Older and Disabled Workers in Spain

MGSoG Dissertation Series, № 9

\section{Keetie Roelen}

False Positives or Hidden Dimensions: The Definition and Measurement of Child Poverty

MGSoG Dissertation Series, № 8

Denisa Maria Sologon

Earning Dynamics in Europe

MGSoG Dissertation Series, № 7

\section{Melissa Siegel}

Money and Mobility: Migration and

Remittances

MGSoG Dissertation Series, № 6

\section{Jessica S. Hagen-Zanker}

Modest Expectations: Causes and Effects of Migration on Migrant Households in Source Countries MGSoG Dissertation Series, № 5 


\section{Alexis Habiyaremye}

From Primary Commodity Dependence to

Diversification and Growth: Absorptive

Capacity and Technological Catch Up in

Botswana and Mauritius.

UNU-MERIT Dissertation Series, № 60

\section{Yoseph Getachew}

The Role of Public Capital in Economic

Development

UNU-MERIT Dissertation Series, № 59

\section{Sandra Leitner}

Embodied Technological Change and

Patterns of Investment in Austrian

Manufacturing

UNU-MERIT Dissertation Series, № 58

\section{Semih Akçomak}

The Impact of Social Capital on Economic and Social Outcomes

UNU-MERIT Dissertation Series, № 57

\section{Abraham Garcia}

The Role of Demand in Technical Change UNU-MERIT Dissertation Series, № 56

\section{Saurabh Arora}

Coherence in Socio-technical Systems: A

Network Perspective on the Innovation

Process

UNU-MERIT Dissertation Series, № 55

\section{Mirtha R. Muniz Castillo}

Human Development and Autonomy in Project Aid: Experiences from four bilateral projects in Nicaragua and El Salvador MGSoG Dissertation Series, № 4

\section{Christiane Arndt}

Governance Indicators

MGSoG Dissertation Series, № 3
Microfinance: Greater Good or LesserEvil?

MGSoG Dissertation Series, № 2

2008

\section{Rutger Daems}

Medicines for the Developing World

UNU-MERIT Dissertation Series, № 54

\section{Johannes Hanel}

Assessing Induced Technology: Sombart's Understanding of Technical Change in the History of Economics

UNU-MERIT Dissertation Series, № 53

\section{Rifka Weehuizen}

Mental Capital: the Economic Significance of Mental Health

UNU-MERIT Dissertation Series, № 52

\section{Danielle Cloodt}

The Relationship between RED Partnership Formation, Social Embeddedness and Innovative Performance

UNU-MERIT Dissertation Series, № 51

\section{Sabine Fuss}

Sustainable Energy Development under

Uncertainty

UNU-MERIT Dissertation Series, № 50

\section{Geranda Notten}

Measuring and Managing Poverty Risks

MGSoG Dissertation Series, № 1

\section{7}

\section{Tobias Kronenberg}

Reconciling Environmental Conservation with Economic Prosperity: The Feasibility of Double Dividends in the Short and Long Run

UNU-MERIT Dissertation Series, № 49 


\section{Viktoria Kravtsova}

Assessing the Impact of Foreign Direct

Investment in Transition Economies

UNU-MERIT Dissertation Series, № 48

\section{Suhail Sultan}

The Competitive Advantage of Small and

Medium Sized Enterprises: The Case of

Jordan's Natural Stone Industry

UNU-MERIT Dissertation Series, № 47

2006

\section{Bulat Sanditov}

Essays on Social Learning and Imitation

UNU-MERIT Dissertation Series, № 46

\section{Mamata Parhi}

Dynamics of New Technology Diffusion: A Study of the Indian Automotive Industry UNU-MERIT Dissertation Series, № 45

\section{Andreas Reinstaller}

Social Structures and the Innovation

Process: Their Role in the Demand of Firms and Consumers

UNU-MERIT Dissertation Series, № 44

\section{Rose Kiggundu}

Innovation systems and Development: The Journey of a Beleaguered Nile Perch Fishery in Uganda

UNU-MERIT Dissertation Series, № 43

\section{Thomas Pogue}

The Evolution of Research Collaboration in South African Gold Mining: 1886-1933

UNU-MERIT Dissertation Series, № 42

\section{Geoffrey Gachino}

Foreign Direct Investment, Spillovers and Innovation: The Case of Kenyan

Manufacturing Industry

UNU-MERIT Dissertation Series, № 41
Önder Nomaler

Technological Change, International Trade and Growth: An Evolutionary, Multi-

Agents-Based Modeling Approach

UNU-MERIT Dissertation Series, № 40

2005

\section{Samia Satti Osman Mohamed-Nour}

Change and Skill Development in the Arab Gulf Countries

UNU-MERIT Dissertation Series, № 39

\section{Elad Harison}

Intellectual Property Rights: Economics and Policy Analysis

UNU-MERIT Dissertation Series, № 38

\section{Daniel Dalohoun}

The Relationship between RED Partnership Formation, Social Embeddedness and Innovative Performance: a Multi-level Approach of Social Embeddedness UNU-MERIT Dissertation Series, № 37

\section{Müge Ozman}

Networks, Organizations and Knowledge UNU-MERIT Dissertation Series, № 36

\section{Bas Straathof}

Product Variety and Economic Growth: The Counteracting Effects of Scale and

Idiosyncrasy

UNU-MERIT Dissertation Series, № 35

\section{Wilfred Schoenmakers}

Knowledge Flows between Multinational Companies: A Patent Data Analysis

UNU-MERIT Dissertation Series, № 34

\section{Myriam Cloodt}

Mergers and Acquisitions ( $M$ and As) in High-Tech Industries: Measuring the Post$M$ and $A$ Innovative Performance of Companies

UNU-MERIT Dissertation Series, № 33 


\section{Paola Criscuolo}

RED Internationalisation and Knowledge

Transfer: Impact on MNEs and their Home Countries

UNU-MERIT Dissertation Series, № 32

\section{Maarten Verkerk}

Trust and Power on the Shop Floor

UNU-MERIT Dissertation Series, № 31

\section{Gottfried Leibbrandt}

Adoption, Harmonization and Succession of Network Technologies across Countries

UNU-MERIT Dissertation Series, № 30

\section{Mark Sanders}

Skill Biased Technical change: Its Origins, the Interaction with the Labour Market and Policy Implications

UNU-MERIT Dissertation Series, № 29

2003

\section{Nadine Roijakkers}

Inter-firm Cooperation in High-tech Industries: a Study of RED Partnerships in Pharmaceutical Biotechnology

UNU-MERIT Dissertation Series, № 28

\section{Viki Sonntag}

Speed, Scale and Sustainability

UNU-MERIT Dissertation Series, № 27

\section{Masaru Yarime}

From End-of-Pipe Technology to Clean

Technology

UNU-MERIT Dissertation Series, № 26

\section{Stéphane Malo}

The Combinatorial Chemistry Revolution: Sustaining a Superior Performance Position through Technological Learning UNU-MERIT Dissertation Series, № 25

\section{Annelies Hogenbirk}

Determinants of Inward Foreign Direct Investment: the Case of the Netherlands UNU-MERIT Dissertation Series, № 24

\section{Bastiaan Johan terWeel}

The Computerization of the Labour Market UNU-MERIT Dissertation Series

2001

\section{John Adeoti}

Technology Investment in Pollution Control in Sub-Saharan Africa: The Case of the Nigerian Manufacturing Industry UNU-MERIT Dissertation Series, № 23

\section{Edward Huizenga}

Innovation Management: How

Frontrunners Stay Ahead: An Empirical Study on Key Success Factors in the ICT sector

UNU-MERIT Dissertation Series, № 22

\section{0}

\section{Machiel van Dijk}

Technological Change and the Dynamics of Industries: Theoretical Issues and Empirical evidence from Dutch Manufacturing

UNU-MERIT Dissertation Series, № 21

\section{9}

\section{Jan Cobbenhagen}

Managing Innovation at the Company Level: A Study on Non-Sector-Specific Success Factors

UNU-MERIT Dissertation Series, № 20

\section{Marjolein Caniëls}

Regional Growth Differentials: The Impact of Locally Bounded Knowledge Spillovers UNU-MERIT Dissertation Series, № 19 
1998

\section{Aldo Geuna}

Resource Allocation and Knowledge production: Studies in the Economics of University Research

UNU-MERIT Dissertation Series, № 18

1996

\section{Reinoud Joosten}

Dynamics, Equilibria, and Values

UNU-MERIT Dissertation Series, № 17

\section{Hugo Kruiniger}

Investment, RED, and the Financing

Decisions of the Firm

UNU-MERIT Dissertation Series, № 16

1995

\section{Hans van Meij1}

Endogenous Technological Change: The

Case of Information Technology, Theoretical

Considerations and Empirical Results

UNU-MERIT Dissertation Series, № 15

\section{René Kemp}

Environmental Policy and Technical

Change: A Comparison of the Technological Impact of Policy Instruments

UNU-MERIT Dissertation Series, № 14

\section{Rohini Acharya}

The Impact of New Technologies on

Economic Growth and Trade: A Case Study of Biotechnology

UNU-MERIT Dissertation Series, № 13

\section{Geert Duysters}

The Evolution of Complex Industrial Systems: The Dynamics of Major IT Sectors UNU-MERIT Dissertation Series, № 12

\section{Marjan Groen}

Technology, Work and Organisation: A

Study of the Nursing Process in Intensive

Care Units

UNU-MERIT Dissertation Series, № 11

\section{4}

\section{Huub Meijers}

On the Diffusion of Technologies in a

Vintage Framework: Theoretical

Considerations and Empirical Results

UNU-MERIT Dissertation Series, № 10

\section{Theon van Dijk}

The Limits of Patent Protection: Essays on the Economics of Intellectual Property

Rights

UNU-MERIT Dissertation Series, № 9

\section{Hans Voordijk}

Naar Integrale Logistiek in Bedrijfsketens:

Ontwikkelingen in de Bouw

UNU-MERIT Dissertation Series, № 8

1993

\section{Paul Diederen}

Technological Progress in Enterprises and Diffusion of Innovation: Theoretical Reflections and Empirical Evidence UNU-MERIT Dissertation Series, № 7

\section{Ben Dankbaar}

Economic Crisis and Institutional Change: The Crisis of Fordism from the Perspective of the Automobile Industry

UNU-MERIT Dissertation Series, № 6

\section{Hanno Roberts}

Accountability and Responsibility: The Influence of Organisation Design on Management Accounting UNU-MERIT Dissertation Series, № 5 


\section{Bart Verspagen}

Uneven Growth between Interdependent

Economies: An Evolutionary View on

Technology Gaps, Trade and Growth

UNU-MERIT Dissertation Series, № 4

\section{Sjoerd Romme}

A Self-organization Perspective on Strategy

Formation

UNU-MERIT Dissertation Series, № 3

1989

\section{John Spangenberg}

Economies of Scale, and Atmosphere in

Research Organisations

UNU-MERIT Dissertation Series, № 2

1988

John Hagedoorn

Evolutionary and Heterodox Innovation

Analysis: A Study of Industrial and

Technological Development in Process

Control and Information Technology

UNU-MERIT Dissertation Series, № 1 
